\title{
Bienestar \\ y políticas \\ públicas
}

Armando Sánchez Vargas Isalia Nava Bolaños José Nabor Cruz Marcelo (Coordinadores)
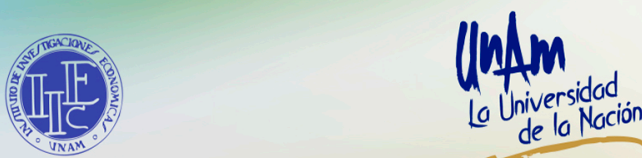


BIENESTAR Y POLÍTICAS PÚBLICAS 


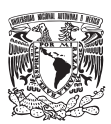

UNIVERSIDAD NACIONAL AUTÓNOMA DE MÉXICO

Dr. Enrique Graue Wiechers

Rector

Dr. Leonardo Lomelí Vanegas

Secretario General

Dr. Luis Agustín Álvarez Icaza Longoria

Secretario Administrativo

Dra. Guadalupe Valencia García

Coordinadora de Humanidades

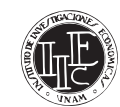

INSTITUTO DE INVESTIGACIONES ECONÓMICAS

Dr. Armando Sánchez Vargas

Director

Dra. Isalia Nava Bolaños

Secretaria Académica

Ing. Patricia Llanas Oliva

Secretaria Técnica

Mtra. Graciela Reynoso Rivas

Jefa del Departamento de Ediciones 


\title{
BIENESTAR Y POLÍTICAS PÚBLICAS
}

\author{
Armando Sánchez Vargas \\ Isalia Nava Bolaños \\ José Nabor Cruz Marcelo \\ (coordinadores)
}

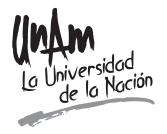


Primera edición impresa, 2020.

Primera edición en formato pdf, junio 2021.

D.R. (C) Universidad Nacional Autónoma de México

Ciudad Universitaria, Coyoacán, 04510, Ciudad de México.

Instituto De InVEstigaciones Económicas

Circuito Mario de la Cueva s/n,

Ciudad de la Investigación en Humanidades, 04510, Ciudad de México.

ISBN IIEC-UNAM: 978-607-30-4689-3

Diseño de portada: Laura Elena Mier Hughes.

Cuidado de la edición: Hélida De Sales Y.

Las opiniones expresadas en cada uno de los trabajos son de exclusiva responsabilidad de las personas que colaboran en esta obra.

Prohibida la reproducción total o parcial por cualquier medio sin la autorización escrita del titular de los derechos patrimoniales.

Hecho en México 


\section{ÍNDICE}

Presentación

INTRODUCCIÓN AL ESTUDIO DEL BIENESTAR

Y LAS POLÍTICAS PÚBLICAS

Armando Sánchez Vargas e Isalia Nava Bolaños

\section{Hacia Una CONSTRUCCión DEL BIENESTAR}

EL BIENESTAR EN LA FILOSOFÍA POLÍTICA, LOS DERECHOS Y LA JUSTICIA SOCIOESPACIAL

Adolfo Sánchez Almanza

BIENESTAR EN EL SIGLO XXI

Alberto Castro Jaimes, José Nabor Cruz Marcelo, Verónica Villarespe Reyes y Bernardo Ramírez Pablo

PolítICA PÚBLICA Y BIENESTAR SOCIAL:

UN ENFOQUE DE DERECHOS SOCIALES

Humberto Ríos Bolivar e Isidro Cerón Palma

¿QUÉ REQUIERE EL CRECIMIENTO ECONÓMICO

PARA AUMENTAR EL BIENESTAR?

Moritz Cruz

\section{Finanzas PÚblicas PARA EL BIENESTAR}

EL BIENESTAR EN LA POLÍTICA SOCIAL: ALCANCES Y LÍMITES 
FinANCIAMIENTO DEL GASTO PÚBLICO:

¿RETO PARA ALCANZAR EL BIENESTAR SOCIAL?

Marcela Astudillo Moya

¿SON LOS IMPUESTOS INSTRUMENTO

PARA PROMOVER EL BIENESTAR?

José Manuel Márquez y Mildred Espíndola

\section{MERCAdo de TRABAJo, Migración Y BIENESTAR}

ABANDONO DE LA POLÍTICA NEOLIBERAL

Y MARCO NORMATIVO DEL TRABAJO

José Alfonso Bouzas Ortiz

EMPLEO DECENTE DIGNO Y SALARIO JUSTO

EN EL CRECIMIENTO DE LA PRODUCTIVIDAD

LABORAL EN MÉXICO

Andrés Blancas y Rodrigo Aliphat

¿EL Estado DE BIENESTAR PUEDE FRENAR LA MIGRACIÓN?

309

Ana María Aragonés y Uberto Salgado

\section{ECOSISTEMAS Y BIENESTAR}

Medio AMBIENTE: BIENESTAR INDIVIDUAL Y COLECTIVO

Alonso Aguilar Ibarra

LA RESILIENCIA COMO UNA MEDIDA

DE BIENESTAR DE LOS HOGARES

Véronique Sophie Ávila Foucat

AlimentaCión, BIENESTAR Y SISTEMAS

AGROALIMENTARIOS LOCALIZADOS (SIAL)

Jessica M. Tolentino Martínez

Un CONTRAPUNTO ENTRE EL "DESARROLLO"-"BIENESTAR"

Y LOS "BUENOS VIVIRES"-"BUENA VIDA" DESCOLONIALES

EN AMÉRICA LATINA

Hilda Caballero y Boris Marañón 


\section{PRESENTACIÓN}

Este libro es un esfuerzo impulsado por el grupo de investigación sobre "Crecimiento económico y distribución del ingreso" del Instituto de Investigaciones Económicas. Se parte de considerar que el nuevo contexto económico, social y político invita a repensar la función de la política pública frente a los retos que demanda una nueva política de bienestar que asegure el goce pleno de derechos sin exclusión ni discriminación.

Para ello, en noviembre de 2019 y marzo de 2020 se organizaron dos seminarios-talleres en los que académicas y académicos especialistas reflexionaron acerca de la definición de un marco de referencia para analizar el bienestar. El diálogo se centró en la definición, las dimensiones y las metodologías más apropiadas para el análisis del bienestar. Particular atención se dedicó a revisar los mecanismos más adecuados para garantizar una adecuada interrelación entre el bienestar y las políticas públicas. A partir de la reflexión colectiva al interior del grupo de investigación, esta publicación tiene como objetivo central reflexionar sobre la función que desempeñan las políticas públicas en el bienestar.

La obra es el resultado de un intenso trabajo de crítica y reflexión conjunta de la comunidad académica participante, de continuas reuniones de trabajo entre quienes coordinamos la publicación en las que fue visible el intercambio de conocimiento de las generaciones consolidadas con las nuevas generaciones. Deseamos agradecer a todas las personas que apoyaron la propuesta, pero en especial va nuestro 
reconocimiento a Mildred Espíndola y José Manuel Márquez por su comprometida colaboración en la planeación académica del proyecto.

Esperamos que esta publicación contribuya a enriquecer el conocimiento sobre bienestar y que coadyuve a repensar la participación de la política pública frente a los retos que demanda una política de bienestar que garantice el goce pleno de derechos sin exclusión ni discriminación, bajo el principio de territorialidad, en nuestro país.

Coordinadores Mayo, 2020 


\title{
INTRODUCCIÓN AL ESTUDIO DEL BIENESTAR Y LAS POLÍTICAS PÚBLICAS ${ }^{1}$
}

\author{
Armando Sánchez Vargas * \\ Isalia Nava Bolaños **
}

En las últimas décadas, se ha generado un mayor interés por analizar el bienestar de la población y las formas de intervención del bienestar con las políticas públicas. Sin embargo, a pesar de que existe una extensa bibliografía del tema [Bache y Scott, 2018], los trabajos carecen de una definición clara del concepto y no se puede encontrar un marco teórico totalmente acabado que sea el fundamento conceptual y analítico para su estudio; más bien el énfasis se pone sobre las dimensiones que le dan forma. En algunas de las investigaciones del tema, el concepto de bienestar se ha equiparado con el de calidad de vida o la dimensión subjetiva de la felicidad. Por ejemplo, Stiglitz, Sen y Fitoussi [2010] se refieren a la medición de la calidad de vida como la sensación de bienestar. Así, la interrogante acerca de qué es el bienestar no ha sido contestada, solo se ha desplazado.

Por tanto, se requiere trabajar en criterios sobre el bienestar que sean científicamente sólidos, pero que a la vez sean adaptables a la realidad nacional y lo suficientemente amplios para incluir las diferentes formas de concebirlo. De hecho, el enfoque del bienestar no puede desligarse del contexto social, cultural y territorial donde se trabaja. La conceptualización clara de un criterio de bienestar es importante dado

\footnotetext{
${ }^{1}$ Agradecemos la colaboración del ingeniero Lester Erick Arancibia Balderrama.

* Investigador del Instituto de Investigaciones Económicas, UNAM. Correo electrónico: <armando_sanchez123@hotmail.com>.

** Investigadora del Instituto de Investigaciones Económicas, UnAM. Correo electrónico: <isalia@unam.mx>.
} 
que tendría incidencia en tres aspectos adicionales: a) la cuestión metodológica respecto de cómo construir los indicadores cuantitativos y/o cualitativos que sirvan para medir el bienestar; b) la manera de entender las dimensiones del mismo; y c) las formas de intervención, es decir, el diseño, la implementación, el seguimiento y la evaluación de las políticas públicas.

El objetivo de este capítulo es doble. Primero, se revisan los principales antecedentes del bienestar y su vínculo con la política pública a fin de identificar los avances y desafíos aún pendientes. Segundo, se presentan las principales contribuciones de las y los autores que en los distintos capítulos se han dado a la tarea de profundizar en torno a los retos que demanda una política de bienestar que asegure y garantice el goce pleno de derechos.

\section{BIENESTAR Y POLÍTICA PÚBLICA}

Existen diversas formas en que se incorpora el bienestar en las políticas públicas y cómo se articulan los conceptos. Enseguida se retoma la propuesta de White [2016] para contextualizar los debates que estructuran los enfoques sobre el bienestar en la política pública. La autora identifica cuatro de ellos: bienestar integral, bienestar personal, enfoque económico de utilidad y desarrollo alternativo.

\section{El enfoque de bienestar integral}

Mucha de la bibliografía relacionada con el bienestar gira en torno al criterio integral que es el más influyente en el debate conceptual y metodológico de las últimas décadas. Incluso varios de los capítulos de este libro se enmarcan en esta aproximación.

El enfoque de bienestar integral, también identificado como "más allá del PIB", se caracteriza por presentar un amplio 
abordaje teórico y empírico para medir algo más que el crecimiento económico e identificar lo que realmente le importa a la población. Incluye una gran amplitud de indicadores objetivos ${ }^{2}$ y subjetivos ${ }^{3}$ para su medición, se utiliza de manera evaluativa y sustantiva ${ }^{4}$ y tiene un interés particular por incorporar estadísticas que reflejen lo que le importa a la gente en diferentes contextos sociales y culturales [White, 2016; Oman, 2016].

La medición del bienestar bajo este criterio ha pasado por un largo proceso desde las décadas de 1920 y 1930, cuando Colin Clark (en el Reino Unido) y Simon Kuznets (en Estados Unidos) comenzaron a recopilar estadísticas y a definir un indicador del ingreso nacional para evaluar la eficacia de las medidas de política económica en el contexto de la Gran Depresión de la década de 1930 y después de la Segunda Guerra Mundial (1939 a 1945) [Coyle, 2014]. A pesar de las advertencias de Kuznets [1962] cuando señaló las dificultades de identificar el bienestar de un país a partir de su renta y advirtió acerca de la necesidad de que las metas de mayor crecimiento especificaran de qué y para qué, con el tiempo el producto interno bruto (РIB) y el PIB per cápita pasaron a ser indicadores muy utilizados para dar cuenta del desarrollo y el bienestar de un país o región.

Las limitaciones de solo considerar los ingresos y bienes como indicadores del bienestar se reconocieron desde hace tiempo y han incentivado el diseño de indicadores "más allá del PIB". Uno de los fundamentos teóricos más influyentes para el enfoque del bienestar integral es el de Amartya Sen [White, 2016]. El autor identifica diversas fuentes diferenciadoras

${ }^{2}$ Cuando puede verificarlos un observador externo.

${ }^{3} \mathrm{El}$ individuo es la máxima autoridad.

${ }^{4}$ En política pública, el interés en el bienestar toma dos formas: sustantiva, cuando el bienestar es una preocupación sustancial: ¿qué significa el bienestar para cada persona?, ¿qué promueve o inhibe el bienestar?; y evaluativa, cuando el bienestar es un medio para evaluar otra cosa, por ejemplo, el éxito de una política [White, 2016]. 
entre el ingreso real y las ventajas que se extraen en términos de bienestar y libertad, como la heterogeneidad personal, la diversidad relacionada con el medio ambiente, las diferencias de clima social, las diferencias entre las perspectivas relacionales y la distribución dentro de la familia. Sen propone modificar el espacio de la evaluación centrado en las utilidades o los bienes primarios al de las libertades fundamentales (las capacidades) para elegir la vida deseada. Por tanto, deben tenerse en cuenta las características que determinan la conversión de los bienes primarios en la capacidad de las personas para alcanzar sus fines; es decir, en la libertad fundamental para conseguir distintas combinaciones de funciones ${ }^{5}$ (o estilos de vida) [Sen, 2000].

En la década de 1990, se desarrollaron cuatro iniciativas internacionales relevantes que tenían como objetivo central mejorar la medición del desarrollo y del bienestar: la Comisión Sur, la Comisión Brandt, el Informe Brundtland y el primer Informe de Desarrollo Humano publicado por el Programa de las Naciones Unidas para el Desarrollo (PNUD) [Phélan, 2018]. El índice de desarrollo humano (IDH), que formó parte de ese primer informe, presentaba el desarrollo como un criterio centrado en las personas, en la mejora de su bienestar, en el incremento de sus capacidades y en el aumento de sus libertades. El IDH 2019 propone ir más allá del ingreso, de los promedios y del presente, al mismo tiempo que reconoce la persistencia de las desigualdades y la injusticia, así como el auge de nuevas desigualdades que afectan las capacidades aumentadas [UNDP, 2019]. ${ }^{6}$ Estos antecedentes fungieron como fundamento analí-

\footnotetext{
${ }^{5}$ El concepto de funciones da cuenta de las diversas cosas que una persona valora (pueden ser elementales o muy complejas).

${ }^{6}$ Con el objetivo de mejorar el diseño de las políticas públicas, en 2010 el PNUD y la Iniciativa sobre Pobreza y Desarrollo Humano de Oxford (OPHI, por sus siglas en inglés) presentaron el índice de pobreza multidimensional (IPM) global, que a partir del método Alkire Foster identifica a la población pobre con base en sus privaciones [OPHI, 2014].
} 
tico en los Objetivos de desarrollo del milenio de las Naciones Unidas y como base para la Agenda 2030 y los Objetivos de desarrollo sostenible.

En la primera década del siglo xxI, la idea de contar con un concepto más amplio del bienestar se afianzó. Dos iniciativas fueron relevantes. La primera fue la Comission on the Measurement of Economic Performance and Social Progress (CMEPSP) (Comisión de Medición del Desempeño Económico y el Progreso Social), establecida en 2008 por el entonces presidente de Francia, Nicolás Sarkozy, y conformada por los economistas Joseph Stiglitz, Amartya Sen y Jean Paul Fitoussi para analizar las limitaciones del PIB como indicador del progreso económico y social. Los resultados quedaron plasmados en el informe Mismeasuring Our Lives: Why GDP Doesn't Add Up. El informe plantea la necesidad de cambiar el enfoque de la producción económica al del bienestar de las personas y los hogares, tomar en cuenta la evaluación del bienestar presente y su sustentabilidad, y considerar una definición pluridimensional tanto en su dimensión objetiva como subjetiva [Stiglitz, Sen y Fitoussi, 2009].

La segunda, ampliamente influida por la Comisión Stiglitz, Sen y Fitoussi, fue el grupo de expertos de alto nivel sobre la medición del desempeño económico y el progreso social que en 2011 conformó la Organización para la Cooperación y el Desarrollo Económicos (OCDE). Su propósito era desarrollar mejores métricas de desempeño económico y progreso social que condujeran a mejores políticas. Los resultados fueron reconocidos en el informe Beyond GDP: Measuring What Counts for Economic and Social Performance, de Joseph Stiglitz, Jean Paul Fitoussi y Martine Durand. El documento señalaba la necesidad de contar con un tablero de indicadores más completo pero parsimonioso, basado en el diálogo nacional, que reflejara lo que la sociedad valora y diera cuenta de un crecimiento equitativo y sostenible [Stiglitz, Fitoussi y Durand, 2018].

En 2011, la ocDE presentó un marco conceptual para la medición del bienestar basado en las recomendaciones de la Comisión 
Stiglitz, Sen y Fitoussi y otras iniciativas nacionales e internacionales. La propuesta conceptualiza el bienestar como una construcción multidimensional que distingue entre el bienestar actual y su sostenibilidad en el tiempo, y dentro del primero, entre las condiciones materiales y la calidad de vida. Como parte del programa de "The Better Life Initiative" dos herramientas son relevantes: el informe How's Life?, en el cual se revisa el bienestar de los países de la OCDE, cuya versión más reciente corresponde a 2020 e incluye 11 dimensiones y más de 80 indicadores (cuadro 1), y el Better Life Index, que permite comparar el desempeño de los países tomando en cuenta la propia evaluación de la importancia relativa de las diferentes dimensiones de la vida.

Cuadro 1. Marco de bienestar de la OCDE

\begin{tabular}{lll}
\hline & \multicolumn{2}{c}{ Bienestar actual } \\
\hline \multicolumn{2}{c}{ Dimensiones } & \multicolumn{1}{c}{ ¿Cómo medirlas? } \\
\hline - Ingreso y patrimonio & - Bienestar subjetivo & - Promedios \\
- Empleo y calidad del & - Seguridad & - Desigualdades entre \\
empleo & - Balance vida-trabajo & los mejores y peores \\
- Vivienda & - Conexiones sociales & - Desigualdades entre \\
- Salud & - Compromiso cívico & grupos \\
- Conocimiento y & & - Privaciones \\
competencias & & \\
- Calidad ambiental & & \\
\hline
\end{tabular}

Recursos para el bienestar futuro

\begin{tabular}{ll}
\hline \multicolumn{1}{c}{ Dimensiones } & \multicolumn{1}{c}{ ¿Cómo medirlas? } \\
\hline - Capital natural & - Stocks \\
- Capital económico & - Factores de riesgo \\
- Capital humano & - Flujos \\
- Capital social & - Resiliencia \\
\hline
\end{tabular}

Fuente: 0ECD [2020: 21] (traducción de los autores). 
Algunos otros índices que incorporan medidas objetivas y subjetivas del bienestar son:

- El Happy Planet Index (índice de felicidad) de la New Economics Foundation (NEF), publicado desde 2006. Este índice revela que las personas (de 178 naciones de las cuales se disponen datos) pueden vivir vidas largas y felices utilizando de manera justa los recursos de la tierra [NEF, 2020].

- El Prosperity Index (índice de prosperidad) del Legatum Institute, que a partir de 2007 evalúa el desempeño de 167 países en 12 pilares, respaldados por 65 elementos centrados en políticas, para proporcionar una imagen integral y holística de la prosperidad [Legatum Institute, 2020].

- El Social Progress Index (índice de progreso social), que en 2013 comenzó a publicar la organización Social Progress Imperative. Este índice es una herramienta de política útil para rastrear los cambios en la sociedad a lo largo del tiempo e incluye tres grandes dimensiones del progreso social: necesidades humanas básicas, fundamentos del bienestar y oportunidades [SPI, 2020].

- El Global AgeWatch Index (índice global de envejecimiento), que desde 2013 levanta la red global HelpAge en 96 naciones del mundo. Este índice permite clasificar a los países según el bienestar social y económico de las personas mayores [HelpAge, 2020].

Enfoques de bienestar personal, económico de utilidad $y$ desarrollo alternativo

El enfoque de bienestar personal se centra en el comportamiento de las personas. Incorpora sobre todo indicadores subjetivos y se utiliza de manera sustantiva. Las políticas apuntan a promover el bienestar individual, asumiendo que el individuo es responsable de sí mismo. Por ejemplo, las políticas de salud que alientan por medio de campañas a comer 
saludablemente, realizar ejercicio, no beber alcohol y no fumar [White, 2016].

Una iniciativa relevante es la lista de acciones para mejorar el bienestar basadas en la evidencia de los Foresight Challenge Reports y la bibliografía emergente en psicología positiva; los resultados quedaron plasmados en los cinco caminos para mejorar el bienestar personal: conectar, mantenerse activo, prestar atención, seguir aprendiendo y dar [Aked, Marks, Cordon y Thompson, 2008].

En el análisis del bienestar personal es fundamental la felicidad. La medición y la promoción de la felicidad son el núcleo de la psicología positiva. Layard [2006] analiza la felicidad con base en la World Values Survey y utiliza siete factores: relaciones familiares, situación financiera, trabajo, comunidad y amigos, salud, libertad personal y valores personales. Encuentra que las sociedades occidentales se han vuelto más ricas, pero no más felices. En ese mismo año, Adrian White de la Universidad de Leicester (Reino Unido) elaboró el primer mapa mundial de la felicidad [University of Leicester, 2020].

Seligman [2011] señala que la felicidad auténtica, eje de la psicología positiva, tiene tres aspectos que se miden de forma subjetiva y aumentan la satisfacción con la vida: emoción positiva, compromiso y sentido. Por su parte, el bienestar, tema de estudio de la psicología positiva, se compone de cinco elementos: emoción positiva (la felicidad y la satisfacción con la vida forman parte de esta), compromiso, sentido, relaciones positivas y logros. Estos elementos se miden de manera subjetiva y objetiva. Así, la meta de la psicología positiva en la teoría de la felicidad es aumentar la felicidad en la vida de las personas y el planeta, mientras que en la teoría del bienestar es medir y generar el florecimiento humano.

En esta línea Bután, en Asia del Sur, mide la Gross National Happiness (felicidad nacional bruta). El paradigma se basa en dos premisas fundamentales. La primera es la búsqueda del bienestar y la felicidad; esta última se refiere a un 
sentido profundo de armonía con el mundo natural y con nuestros semejantes que se caracteriza por la compasión, la satisfacción y la alegría. La segunda es la existencia de límites planetarios y la gravedad de las realidades ecológicas actuales. Así, se propone un índice que adopta un enfoque holístico del bienestar general de la población butanesa en lugar de una clasificación psicológica subjetiva de la felicidad. Se compone de 33 indicadores en nueve dominios, que incluyen áreas tradicionales de interés socioeconómico, como el nivel de vida, la salud y la educación, y aspectos menos tradicionales de la cultura y el bienestar psicológico [NDP, 2013].

El enfoque económico de utilidad se refiere al concepto economicista de utilidad e implica el uso de medidas subjetivas de felicidad o satisfacción para evaluar la efectividad de las políticas y los programas. Incluye indicadores subjetivos para su medición y se utiliza de manera evaluativa en la política pública [White, 2016].

En 2013, por recomendación de la Comisión Stiglitz, Sen y Fitoussi y con el objetivo de mirar más allá de las formas tradicionales de medir el desempeño económico, la ocDE publicó las primeras directrices para la medición del bienestar subjetivo, en el marco del programa The Better Life Initiative (Iniciativa para una Vida Mejor). En esta nueva propuesta, la definición de bienestar subjetivo abarca tres elementos: evaluación de la vida, afecto y eudaimonia (florecimiento) [OCDE, 2013].

Se trata de una iniciativa relevante en la que la ocDE reconoce la riqueza de las medidas de bienestar subjetivo para las y los responsables de la formulación de políticas públicas en la medida en que pueden alertar sobre cuestiones que otros indicadores sociales y económicos podrían no identificar. Por ejemplo, en la "primavera árabe", la reducción de los indicadores promedio de bienestar subjetivo en Egipto y Túnez en los años previos a 2011 contrastaba con los datos del PIB, el cual registraba aumentos [Gallup, 2011, citado por OCDE, 2013]. 
El enfoque de desarrollo alternativo plantea preguntas fundamentales sobre los asentamientos políticos, económicos y sociales actuales; se concibe como la realización humana en un ambiente sostenible e incorpora un conjunto alternativo de valores. Parte de cuestionar qué es un "buen crecimiento" y sugiere que la economía se desarrolle solo de manera que sirva para la realización humana y sea ambientalmente sostenible. Enfatiza la justicia social y considera algunas formas de economía solidaria, que involucran unidades de producción más pequeñas y autogestionadas con formas igualitarias de gestión, y una orientación hacia el comercio justo y la sostenibilidad ambiental. Considera el bienestar en términos sustantivos y tiende a disolver la distinción entre subjetivo y objetivo [White, 2016].

Un reconocido ejemplo que aparece en la región de América Latina, donde los puntos de vista de la población indígena sobre el bienestar han logrado permear, es el debate acerca del buen vivir.

El buen vivir es un constructo complejo y abstracto en el que convergen diferentes puntos de vista sobre su significado, que responden a marcos teóricos y valores diferentes. León [2015] identifica tres posiciones del buen vivir en Ecuador: indigenista, posdesarrollista y posmarxista. Para la corriente indigenista-culturalista (sumak kawsay) el buen vivir se define como "vida plena que incluye la dimensión espiritual". Para la corriente ecologista-posdesarrollista se trata de "una utopía en (re)construcción, que va más allá del desarrollo, centrada en la vida de todos los seres vivos (biocentrismo), en armonía con la naturaleza, el respeto a la dignidad humana, y mejora de la calidad de vida de las personas y comunidades". Para la corriente socialista-ecomarxista se define "como expansión y florecimiento, en paz y armonía con la naturaleza de las libertades, oportunidades, capacidades y potencialidades reales de los individuos de modo que les permitan logran aquello que valoran como 
objetivo de vida deseable y construir un porvenir compartido" [León, 2015: 41].7

\section{CONSIDERACIONES SOBRE EL BIENESTAR}

A partir de la revisión previa del contenido de los enfoques de bienestar en la política pública y de los dos seminarios-talleres en los que participaron las y los autores de los distintos capítulos, se plantean las siguientes consideraciones.

\section{Sobre el concepto y las dimensiones del bienestar}

Si bien es cierto que en los últimos años se ha registrado un avance significativo en términos de la incorporación de dimensiones prioritarias del bienestar, específicamente de elementos subjetivos, la interrogante sobre qué es el bienestar aún sigue pendiente. Se llegó a un consenso de que el concepto de bienestar se refiere a la condición en la cual las personas gozan de manera efectiva de los derechos humanos (civiles, económicos, sociales, culturales y ambientales) que les garantiza la ley (la Constitución Política de los Estados Unidos Mexicanos y los tratados internacionales firmados por México) en un espacio y un tiempo determinados.

Una condición necesaria para generar bienestar es el reconocimiento legal de los derechos de los individuos en la Constitución, pero la condición suficiente es que existan instrumentos que permitan que estos derechos sean efectivos. El Estado dispone de la política pública como el mecanismo

${ }^{7}$ El capítulo "Un contrapunto entre el 'desarrollo'-bienestar' y los 'buenos vivires'-'buena vida' descoloniales en América Latina” de Hilda Caballero y Boris Marañón, de esta obra, presenta un detallado análisis de los buenos vivires como alternativas al desarrollo. 
a partir del cual es posible generar desarrollo sostenible, crecimiento económico y bienestar efectivos.

Se reconoce que el bienestar abarca mediciones de carácter objetivo y subjetivo, y que existe una diversidad de variables en función del enfoque. El grupo académico que conforma la presente obra identifica las siguientes variables como componentes inobjetables del bienestar: ingreso, alimentación, educación, medio ambiente, salud, trabajo, seguridad social y vivienda. Además, se plantea el derecho al trabajo decente ${ }^{8} \mathrm{y}$ a empleos dignos como los componentes del bienestar que requieren mayor atención para el caso de México, dado que permiten que las personas desarrollen sus capacidades y puedan satisfacer sus necesidades, por lo que la creación de empleo es un elemento crucial para generar bienestar y promover el desarrollo. Además, se identifica la necesidad de incorporar elementos objetivos y subjetivos tanto de aspectos individuales como colectivos.

\section{Sobre la medición del bienestar y su vinculación con la política pública}

La medición del bienestar requiere partir de un concepto claro y bien definido y de un marco teórico y conceptual que coadyuve en el diseño de los indicadores. Se reconoce la relevancia de basarse en un criterio garantista de derechos, donde se resalte nuevamente la función del gobierno como garante de la efectividad de los mismos, pero con la corresponsabilidad de los otros actores sociales. Se expresa la necesidad de un Estado

\footnotetext{
${ }^{8}$ Se refiere a "la oportunidad de acceder a un empleo productivo que genere un ingreso justo, la seguridad en el lugar de trabajo y la protección social para las familias, mejores perspectivas de desarrollo personal e integración social, libertad para que los individuos expresen sus opiniones, se organicen y participen en las decisiones que afectan sus vidas, y la igualdad de oportunidades y trato para todos, mujeres y hombres" [огт, 2020].
} 
que coadyuve al bienestar con una política construida desde los actores sociales, económicos y políticos a nivel local y que sea un reflejo de las necesidades de la colectividad, con una visión histórica, territorial y temporal.

Se requiere una política de bienestar inclusiva y vinculatoria con otras políticas (social, industrial, laboral y económica) que, indudablemente, permita la sana convivencia entre los distintos actores. Asimismo, la política de bienestar debe encaminarse al alcance de beneficios, más allá de lo meramente económico, además de buscar de modo constante un cambio positivo, ser sostenible y sustentable en el tiempo (como eje dinámico fundamental), y resolver las fallas institucionales actuales.

Al tratarse de un enfoque garantista, se reconocen los principios fundamentales como universalidad, interdependencia, indivisibilidad y progresividad. Se considera que si bien es cierto que debe asegurarse el goce pleno y acceso efectivo de todos los ciudadanos a los derechos humanos, la política pública que se diseñe debe focalizarse en los grupos prioritarios para así garantizar que los recursos del Estado (que son limitados) se destinen estratégicamente a las personas en situación de mayor vulnerabilidad de manera que puedan superar los rezagos a lo largo de sus vidas.

También es necesaria una política que asegure la justicia social y garantice las reglas de acceso efectivo a los servicios para alcanzar el bienestar, las cuales deben ser justas y equitativas. Se recomienda que el diseño de la política pública tenga como punto de partida la satisfacción de las necesidades específicas de la población en las distintas etapas del ciclo de vida, por ejemplo: infantes, jóvenes, personas en edades laborables y personas mayores. Particular atención tiene que dedicarse a la población indígena, con alguna discapacidad y la de las localidades rurales. Además, es necesaria la incorporación de indicadores que recojan, como eje transversal, las diferencias y desigualdades entre mujeres y hombres. 
La política deberá ir más allá del alcance de los umbrales mínimos y erradicar la corrupción y el individualismo. Algunas otras características que deberá tener son que sea viable, transparente, ejecutable y robusta. No deberán olvidarse los elementos culturales que influyen en los usos y costumbres de la población, así como en el cumplimiento de los derechos.

Con base en estos elementos resulta relevante diagnosticar lo que se ha hecho, identificar los avances en materia de bienestar y replantear nuevas propuestas basadas en lo que ha funcionado para reestructurar el paradigma de bienestar. Ese es el propósito y contenido de los capítulos que conforman la presente obra y para ello se han organizado cuatro grandes apartados: Hacia una construcción del bienestar, Finanzas públicas para el bienestar, Mercado de trabajo, migración y bienestar, y Ecosistemas y bienestar.

\section{ConTENIDO DE LOS CAPÍTULOS}

\section{Hacia una construcción del bienestar}

En el capítulo "El bienestar en la filosofía política, los derechos y la justicia socioespacial", Adolfo Sánchez desarrolla un marco de referencia sobre el bienestar a partir de la revisión de las principales corrientes filosóficas que abordan el fenómeno. Para completar la revisión, Alberto Castro, Verónica Villarespe, José Nabor Cruz y Bernardo Ramírez se centran en el estudio del debate conceptual para ofrecer una respuesta acerca del tipo de bienestar al que se debería aspirar y los principales mecanismos que intervienen en él. Su aportación lleva por título "Bienestar en el siglo xxl". En la misma dirección, "Política pública y bienestar social: un enfoque de derechos sociales", de Humberto Ríos e Isidro Cerón, ofrece una articulación entre los elementos conceptuales del bienestar y ciertas condiciones de la sociedad como la educación, la salud y la alimentación. El capítulo "¿Qué requiere el crecimiento 
económico para aumentar el bienestar?", de Moritz Cruz, cierra esta sección con una revisión de los mecanismos que deben acompañar al crecimiento económico para generar bienestar.

\section{Finanzas públicas para el bienestar}

El capítulo "El bienestar en la política social: alcances y límites", de Berenice Ramírez, consiste en una revisión del bienestar y los paradigmas que explican la política social, así como la trayectoria del gasto social, con especial atención a las pensiones. De manera específica, Marcela Astudillo analiza el bienestar social y su relación con la política social para el combate a la pobreza a partir de la revisión del presupuesto de egresos de la Federación durante los últimos años, en el trabajo "Financiamiento del gasto público: ¿reto para alcanzar el bienestar social?". En la misma materia, pero con una mirada diferente, José Manuel Márquez y Mildred Espíndola estudian la función de los impuestos y sus efectos en la mejora del bienestar, con base en la Matriz de Contabilidad Social, en "¿Son los impuestos instrumento para promover el bienestar?”.

\section{Mercado de trabajo, migración y bienestar}

El capítulo "Abandono de la política neoliberal y marco normativo del trabajo", de Alfonso Bouzas, incorpora una detallada revisión de los procesos político-sociales que han permitido reformar la ley laboral, con especial atención en el ejercicio de los derechos laborales. También en esta temática, el trabajo "Empleo decente digno y salario justo en el crecimiento de la productividad laboral de México", de Andrés Blancas y Rodrigo Aliphat, analiza el crecimiento de la productividad laboral y su potencial a partir de las condiciones de bienestar laboral. 
Un fenómeno vinculado con la fuerza de trabajo en el exterior es el de la migración; en ese sentido, en el capítulo "El Estado de bienestar: ¿puede frenar la migración?", Ana María Aragonés y Uberto Salgado reflexionan sobre las posibilidades que tienen los países expulsores de migrantes para revertir la tendencia de lo que se ha denominado migración forzada.

\section{Ecosistemas y bienestar}

En el capítulo "Medio ambiente: bienestar individual y colectivo", Alonso Aguilar plantea el análisis del bienestar de una sociedad no solo como un aspecto individual -como la economía tradicional neoclásica lo ha considerado tradicionalmente-, sino también colectivo. Después, Sophie Ávila, en "La resiliencia como una medida de bienestar de los hogares", revisa la resiliencia como una manera de estudiar el bienestar de los hogares. La autora presenta las estrategias de vida y la diversificación y los capitales como parte de sus determinantes en sistemas socioecológicos como los hogares. También en esta dirección, el capítulo "Alimentación, bienestar y Sistemas Agroalimentarios Localizados (SIAL)", de Jessica Tolentino, plantea la relevancia de los SIAL y su relación con el concepto de bienestar, así como la necesidad de construir políticas públicas de corte ascendente que consideren los arreglos institucionales en el espacio local y que contribuyan al bienestar de la población. Finalmente, en el capítulo "Un contrapunto entre el 'desarrollo'-'bienestar' y 'los buenos vivires''buena vida' descoloniales en América Latina”, de Hilda Caballero y Boris Marañón, se analizan los "buenos vivires" que abarcan visiones de "bienestar" basadas en ontologías relacionales, en epistemologías que reconocen la totalidad y la diversidad, y en relaciones de poder que privilegian la convivencia horizontal sin opresiones. 


\section{REFERENCIAS}

Aked, J., N. Marks, C. Cordon, C. y S. Thompson [2008], Five Ways to Wellbeing: The Evidence, Londres, New Economics Foundation.

BAche, I., y K. Scott [2018], "Wellbeing in politics and policy", en I. Bache, K. Scott y P. Allin (eds.), The Politics of Wellbeing: Theory, Policy and Practice, Cham, Palgrave Macmillan, pp. 1-22.

Coyle, D. [2014], GDP: A brief but affectionate history, Princeton, Princeton University Press.

HelpAge [2020], The Global AgeWatch Index, <https://www. helpage.org/>.

Kuznets, S. [1962], "How to judge quality", The New Republic, 147:29-32.

LaYard, R. [2006], Happiness: Lessons from a New Science, Londres, Allen Lane.

Legatum Institute [2020], Prosperity Index, <https://n9.cl/zgtzi>. León, Mauricio [2015], Del discurso a la medición: propuesta metodológica para medir el Buen Vivir en Ecuador, Quito, Instituto Nacional de Estadística y Censos.

NDP (New Development Paradigm) Steering Committee and Secretariat [2013], Happiness: Towards a New Development Paradigm. Report of the Kingdom of Bhutan, $<$ https://n9.cl/qbaz>.

NEF (New Economics Foundation) [2020], The Happy Planet Index, <https://n9.cl/uicq>.

OCDE (Organización para la Cooperación y el Desarrollo Económicos) [2020], How's Life? 2020 Measuring WellBeing, París, OCDE.

[2013], oECD Guidelines on Measuring Subjective WellBeing, París, OCDE.

OIT (Organización Internacional del Trabajo) [2020], Trabajo decente, <http://www.oit.org/global/topics/decent-work/ lang--es/index.htm>. 
Oman, S. [2016], "Measuring National Wellbeing: What Matters to You? What Matters to Whom?", en S. White y C. Blackmore (eds.), Cultures of Wellbeing, Basingstoke, Palgrave Macmillan, pp. 66-94.

oPHI (Iniciativa de Pobreza y Desarrollo Humano de la Universidad de Oxford) [2020], Bhutan's Gross National Happiness Index. <https://n9.cl/wbw3>.

[2014], La construcción de una medida de pobreza multidimensional, Oxford, oPHI.

PhÉLAN, M. [2018], "Revisión y comparación metodológica de cinco Índices Alternativos de Desarrollo. Resultados para países de América Latina", en Espacio Abierto, 147:21-45

Seligman, M. [2011], Flourish. A visionary new understanding of happiness and well-being, New York, Simon and Schuster, Inc.

Sen, A. [2000], Desarrollo y libertad, Bogotá, Planeta.

SPI (Social Progress Imperative) [2020], Social Progress Index, $<$ https://www.socialprogress.org/>.

Stiglitz, J., A. Sen y J. P. Fitoussi [2010], Mismeasuring our lives: Why GDP doesn't add up, Nueva York, The New Press. [2009], Report by the Commission on the Measurement of Economic Performance and Social Progress.

Stiglitz, J., J. P. Fitoussi y M. Durand [2018], Beyond GDP: Measuring what counts for economic and social performance, Paris, OECD Publishing.

UNDP (United Nations Development Programme) [2019], Human Development Report 2019, Nueva York, UNDP.

UNIVERSITY OF LEICESTER [2020], University of Leicester produces the first ever world map of happiness, <https://n9.cl/ $\mathrm{q} 4 \mathrm{u} 4 \mathrm{~d}>$.

White, S. [2016], "Introduction: The many faces of wellbeing", en S. White y C. Blackmore (eds.), Cultures of Wellbeing, Basingstoke, Palgrave Macmillan, pp. 1-44. 


HACIA UNA CONSTRUCCIÓN DEL BIENESTAR 



\section{EL BIENESTAR EN LA FILOSOFÍA POLÍTICA, LOS DERECHOSY LA JUSTICIA SOCIOESPACIAL}

Adolfo Sánchez Almanza*

\section{INTRODUCCIÓN}

Este trabajo ofrece un análisis taxonómico sobre el bienestar que incluye una síntesis de las principales corrientes filosóficas que abordan este fenómeno, las estructuras sociales en que se inscribe y los derechos y postulados de la justicia socioespacial que sustentan el diseño de políticas públicas orientadas a la mejoría de la calidad de vida de las personas y las comunidades en el territorio.

En una definición inicial, el bienestar es una forma de la calidad de vida que expresa la satisfacción positiva de las necesidades objetivas y subjetivas de las personas y las comunidades en cada estructura social en un tiempo y un espacio determinados. La calidad de vida, a su vez, es un concepto polisémico, multidimensional y multifactorial, relacional y dinámico, y susceptible de medición cuantitativa y cualitativa. El bienestar constituye una aspiración de las sociedades que tiene como objetivo una vida digna que merezca ser vivida y la superación de fenómenos que generan malestar individual o colectivo como la pobreza, la marginación, la exclusión, la segregación, la discriminación o la desigualdad. El bienestar es resultado de la interacción entre el Estado, el mercado y la sociedad y se ubica en el marco del cumplimiento de los derechos individuales y sociales, con un Estado garante de los mismos,

* Investigador del Instituto de Investigaciones Económicas, UNAM. Correo electrónico: <asag@unam.mx>. 
lo cual permite alcanzar los objetivos de desarrollo y enfrentar el conflicto social. La estructura social y el bienestar manifiestan cambios en el tiempo y presentan características específicas en las diferentes escalas espaciales; por ello, es necesario realizar análisis comparativos con métodos ya sea normativos o descriptivos que visibilicen su complejidad.

El análisis del bienestar puede clasificarse de manera convencional en los enfoques siguientes: a) filosóficos, entre los cuales destacan las teorías de la justicia, el bienestar, las necesidades humanas y básicas; b) de derechos, propuestos por instituciones como la ONU, el PNUD y la OMS; c) europeos, entre los que destacan el escandinavo, el sueco, el de los Países Bajos y otros desarrollados; d) multilaterales, como los propuestos por la OCDE, el BID, el FMI y el Banco Mundial; e) mercantiles, como los elaborados por Mercer, Economist Intelligence Unit y Bimsa, entre otros; f) alternativos, como el desarrollo local, el desarrollo a escala humana y el buen vivir; g) de gobiernos locales realizados para varias ciudades; $\mathrm{y}$ h) estudios y encuestas orientados a captar los aspectos subjetivos o la percepción de las personas sobre su propio bienestar [Sánchez, 2018].

A continuación, se comienza con una revisión de los postulados básicos de las corrientes filosóficas de las cuales se derivan criterios, principios y decisiones que definen los modelos de desarrollo, las estructuras sociales, los regímenes de bienestar y las políticas públicas.

\section{EL BIENESTAR EN LA FILOSOFÍA POLÍTICA}

El bienestar se aborda en la filosofía política, principalmente desde la justicia distributiva o la justicia social, considerando la forma en que la sociedad asigna los recursos o bienes escasos entre sus integrantes, los cuales compiten para cubrir sus necesidades con un acceso semejante a los mismos. Este discurso trata de definir los objetivos y criterios para guiar la acción 
social en la distribución o redistribución de la riqueza y de las cargas para enfrentar la desigualdad social. En el caso del Estado, esta es una función central en la medida en que su razón de ser radica en la búsqueda del interés general o el bien común bajo las ideas de la moral y la justicia, lo que incluye otros conceptos como la libertad o la igualdad de oportunidades.

El bienestar se discute desde la justicia distributiva, por lo menos, en las doctrinas siguientes: a) el utilitarismo y la economía del bienestar; b) el liberalismo radical o libertario; c) el liberalismo igualitario o la teoría de la justicia; d) el comunitarismo; y e) el socialismo o marxismo clásico y analítico. $\mathrm{Al}$ respecto es importante establecer los postulados de cada corriente de pensamiento porque su aceptación y aplicación conduce a estructuras diferentes en cada sociedad, como se expone a continuación.

\section{El utilitarismo y la economía del bienestar}

El utilitarismo es una teoría moral y política en la cual el bienestar se entiende como la máxima utilidad definida por la propiedad de una mercancía que, desde una posición hedonista, produce felicidad, placer o la satisfacción de una preferencia, o bien evita un malestar o el dolor a las personas y, en lo social, se considera como la suma agregada del bienestar de los individuos. Este enfoque supone el carácter reflexivo y ponderado en la conducta individual, así como la racionalización objetiva e imparcial de la vida social. El criterio principal es calcular los costos y beneficios de cada acción o norma para elegir aquella que proporcione el mayor placer, para lo cual se apoya en el empirismo y en las mediciones cuantitativas. El utilitarismo plantea la elección social en términos de la maximización de una función de bienestar social, es decir, se preocupa solo por la utilidad total en la sociedad (la suma de las utilidades individuales o la mayor felicidad del mayor número) y no por la manera como se distribuya entre sus miembros; 
asimismo, se acepta el sacrificio de un grupo de personas en nombre de la utilidad de la mayoría.

Entre las distintas escuelas utilitaristas, ${ }^{1}$ destaca la economía del bienestar que forma parte de la economía normativa y que lo analiza en función de las actividades económicas de los individuos para extrapolar hacia la sociedad la mejor situación. El bienestar se mide de dos modos: a) el cardinal, en dinero, precio, satisfacción relativa o deseo de consumir algún bien o conjunto de bienes (costo-beneficio pero no la distribución del ingreso); y b) el ordinal, como el óptimo de Pareto, que afirma que, dada una asignación inicial de bienes entre un conjunto de individuos, es posible un cambio hacia una nueva asignación de los recursos que al menos mejora la situación de un individuo, pero sin hacer que empeore la situación de los demás y, con ello, el bienestar social se incrementa.

En el marco institucionalista, que endogeniza la evolución y las funciones de las instituciones sociales en el comportamiento económico, el Estado determina las reglas del juego para la distribución social de recursos escasos entre posibles alternativas. En términos de eficiencia productiva, se considera que un cambio en la política aumenta la eficiencia en la asignación de los recursos, siempre y cuando los que se beneficien del cambio ganen más de lo que los perdedores pierden. En consecuencia, el Estado debe crear instituciones de fomento e impulso a la producción de la forma más eficaz. En oposición, desde un enfoque ético, se propone la eficiencia distributiva, por la cual los bienes y servicios sean distribuidos

${ }^{1}$ El utilitarismo clásico tiene sus raíces en Adam Smith, que relacionaba el aumento del bienestar con el aumento de la producción, y en Jeremy Bentham, quien consideraba que el bienestar era resultado de la suma de las utilidades individuales. Estas ideas se enriquecieron con otros autores como John Stuart Mill y George E. Moore, y se vinculan con la economía neoclásica con pensadores como Alfred Marshall, Vilfredo Pareto, Arthur Pigou, Francis Edgeworth, John C. Harsanyi, León Walras, Kenneth Arrow, John Hicks, Nicholas Kaldor, Paul Samuelson o Abram Bergson, entre otros. 
a quienes los necesitan u obtienen la máxima utilidad de los mismos, sobre todo en países con bajos niveles de riqueza [Lerner, 1951]. ${ }^{2}$

Esta corriente enfrenta varias críticas generales. Una inicial es que tolera distribuciones del bienestar individual que son injustas o regresivas; por ejemplo, en sociedades con elevada desigualdad los individuos pobres aprenden a ajustar sus deseos a sus restricciones de ingreso o bien obtienen felicidad con los bienes escasos que poseen. La noción utilitarista y subjetiva de felicidad es errónea porque asume que todos los intereses y utilidades individuales tienen el mismo peso, y no considera preferencias ilegítimas e irracionales desde el punto de vista ético o de la justicia. Por ejemplo, la existencia de diferentes gustos que pueden ser ofensivos (el placer de la tortura), costosos (consumir cierto tipo de vinos) o modestos (comer frijoles), que no pueden ser considerados para definir el bienestar [Rawls, 2002].

Entre los riesgos de justicia se puede afirmar que es una noción mínima de eficiencia que no da por resultado una distribución socialmente deseable de los recursos porque no tiene

${ }^{2}$ El Estado es una institución central en la redistribución de recursos como parte de los regímenes de bienestar. Una forma que asumió fue el Estado de bienestar desarrollista, principalmente, en varios países europeos donde alcanzó su época dorada en la primera mitad del siglo xx, con la aplicación de tesis keynesianas para el crecimiento económico, la captación de recursos fiscales con gasto social, una estructura y dinámica demográfica favorables, estabilidad del mercado laboral y el avance de los derechos sociales y la ciudadanía política. Este tipo de Estado de bienestar entró en crisis por cambios en la estructura económica (globalización, desindustrialización y terciarización con desempleo creciente y segmentado) y en la demografía (reducción de las tasas de natalidad y fertilidad, aumento de la esperanza de vida, envejecimiento y diversificación de las familias), asociados con la privatización y remercantilización de los bienes y servicios públicos, entre otros. El actual Estado de bienestar enfrenta los efectos de las reformas neoliberales, entre las cuales destacan el aumento de la desigualdad y la pobreza absoluta y relativa, así como desafíos redistributivos, en el marco de las nuevas funciones y relaciones entre el Estado, el mercado y la sociedad, pero con requerimientos de justicia, democracia y sustentabilidad ambiental [Kerstenetzky, 2017]. 
como objetivo la igualdad o el bienestar del conjunto de la sociedad y porque admite formas de discriminación para tal fin. En sus criterios, no importa la distribución equitativa de bienes y derechos porque lo sustancial es el saldo agregado resultante de la suma individual. Asimismo, con sus criterios se permite castigar a un inocente cuando se pretende el bien del orden público.

\section{El liberalismo radical o libertario o conservador}

La escuela libertaria surge desde la crítica a la justicia distributiva y las políticas igualitarias con la defensa de la libertad del individuo en la sociedad (ser dueño de sí mismo), de los derechos naturales de propiedad privada, la libre asociación y la distribución de los recursos económicos a través de la economía de mercado. Los libertarios aceptan la idea de igualdad, pero se oponen al establecimiento de pautas que pretendan imponerla a otros contra su voluntad; admiten que el concepto de la justicia es válido a nivel individual, pero rechazan categóricamente la justicia social. Aunque tiene sentido juzgar cierto resultado de una acción individual, premeditada y consciente, como justo o injusto, carece de sentido extender este razonamiento a lo social, ya que los resultados no pueden atribuirse a acciones sociales deliberadas. Cada individuo es propietario de recursos iniciales y de los frutos de sus acciones, de manera que las políticas redistributivas que transfieren recursos o ingresos entre los individuos para lograr su bienestar violan el principio básico de la autopropiedad de los frutos del esfuerzo individual y la riqueza productiva de propiedad privada [Mises, 2011].

En este paradigma, los intercambios comerciales son las relaciones fundamentales de la sociedad ya que garantizan la asignación óptima de los recursos y aseguran la existencia y el mantenimiento de los vínculos sociales. El acto comercial, 
entonces, se afirma como el acto constitutivo de la sociedad y todo lo que se oponga se considera nocivo, incluido el Estado [Hayek, 1944].

La justicia distributiva que emana del mercado se sustenta en la teoría de la titularidad, en la que se plantea como condición que se cumplan tres principios: a) que la apropiación o adquisición inicial de riqueza sea justa; b) que lo adquirido legítimamente se pueda transferir con libertad; y c) que se puedan rectificar las injusticias en las transacciones cuando la titularidad provenga de un origen dudoso.

Los libertarios, en consecuencia, están en desacuerdo con la intervención del Estado (entendido como burocracia y poder político) en la economía con fines redistributivos porque deriva en control político o social y conduce a la servidumbre. Defienden el mercado como la única esfera para el desarrollo de la justicia distributiva y no a alguna autoridad estatal. Esta corriente sostiene que la ley se debe fundamentar en la protección de los derechos negativos o individuales, en eliminar o reducir regulaciones e impuestos con acuerdos voluntarios establecidos bajo el principio de no agresión. En términos sociales, promueve una desigualdad armónica y la concordia de clases en vez de la lucha de clases. Esta corriente de pensamiento afirma que al Estado le corresponde atender la esfera pública, la justicia conmutativa y la justicia distributiva, pero de manera acotada. El bienestar y la atención a los pobres serán resultado de la conciencia y la moral individual de los propietarios, no de la acción estatal y legal. Por ello, aunque en diferente grado y alcance, sus autores proponen reducir la intervención estatal en la vida individual y social, aplicar acciones de privatización, reducir impuestos, desregular y contener o eliminar el Estado de bienestar. La justicia distributiva radicará entonces en la conjunción entre la racionalidad de un mercado amplio y un Estado mínimo [Nozick, 1990].

La virtud moral del mercado, en este sentido, proviene de su capacidad para premiar a los individuos laboriosos y 
eficientes, mientras que castiga a los flojos e ineficientes, de tal manera que el producto final en la distribución de la riqueza se debería considerar justo; es decir, se considera válido cierto darwinismo social. En sintonía con este argumento, se afirma que solo la interacción del interés privado de los individuos podría maximizar la riqueza y el bienestar, bajo el teorema de "la mano invisible del mercado autorregulado", aunque adoptando varios supuestos de competencia perfecta, los cuales no existen en el mundo real donde se observan varias fallas de mercado.

Entre las críticas a este pensamiento libertario destaca que la función del Estado es indispensable ante grados significativos de desigualdad socioeconómica en las asignaciones de bienes y servicios o en fases de crisis. La ausencia de propiedad no es la única forma de propiedad privada ya que también existe, por ejemplo, la propiedad común de los recursos naturales que justifica los derechos ambientales. En esta visión libertaria, la justicia de la adquisición se refiere a la medida en que la apropiación de recursos naturales sin dueño no empeora la condición de nadie, en comparación con la situación en que los recursos permanecen sin dueño (lo cual es inverosímil). Esta es una justificación para la desigualdad en el capitalismo, ya que la distribución de los recursos en este sistema económico no es injusta a priori, se supone que la propiedad y la operación privadas de los activos productivos serían un arreglo superior a la situación de los recursos sin dueño. Así también, para las personas que no posean dotaciones iniciales de capital, como en sociedades con elevada desigualdad, la libertad negativa se convierte en la libertad para perder, o sea que si no existen políticas compensatorias dirigidas a los individuos en la peor situación para que participen en el sistema social, la libertad negativa se reduce a ser la condición para la autodeterminación de algunos de sus integrantes, pero no de la mayoría [Roemer, 1989].

Otra crítica es que aun en la economía neoclásica se reconoce la incapacidad del mercado para generar bienestar ya 
que su objetivo es la ganancia privada y tampoco se autorregula como cuando se generan externalidades negativas, lo que requiere una intervención correctiva. Asimismo, en un escenario en que no existieran fallas, el mercado puede ser un mecanismo eficiente pero no democrático, debido a que la distribución previa de la riqueza entre los grupos o clases sociales y los territorios ya condiciona su participación en las decisiones y el grado de calidad de vida inicial, es decir, preexiste un cierto tipo de determinismo social y geográfico. ${ }^{3}$

\section{El liberalismo igualitario o la teoría de la justicia}

En el marco de la tradición liberal con enfoque social, aunque con críticas al utilitarismo y la economía del bienestar, John Rawls propone un modelo para desarrollar la justicia distributiva enfatizando la igualdad de oportunidades sin que los individuos sacrifiquen su libertad. La justicia la concibe como equidad, aunque existen muchas clases de igualdad y, por tanto, de desigualdad. El destino de las personas, según él, no debe estar determinado por sus circunstancias sociales, sino por su elección individual en una sociedad que ofrezca igualdad de oportunidades. En esta teoría, la justicia es la primera virtud de las instituciones sociales y, ya que estas pueden estar sujetas a una evaluación moral, se consideran "moralmente arbitrarias" las diferencias iniciales de la riqueza, el estatus social y los talentos, las cuales no se deberían suponer

${ }^{3}$ Esta corriente de pensamiento, aunque es heterogénea, fue propuesta por John Locke y reformulada por Ludwig on Mises, Friedrich A. Hayek, Robert Nozick, D. Gauthier y A. Buchanan. Los postulados se extienden hacia autores como Milton Friedman, promotor del neoliberalismo económico monetarista y la defensa del libre mercado desde la Escuela de Chicago, adoptado por Margaret Thatcher en el Reino Unido y Ronald Reagan en Estados Unidos de América, aplicado inicialmente en Chile y después en América Latina, a partir del Consenso de Washington sugerido por John Williamson en 1989 con un conjunto de medidas macroeconómicas de liberalización, estabilización y privatización. 
como principios generales para la justicia social expresada en un contrato social. Por consiguiente, es fundamental reestablecer la igualdad en las posiciones iniciales y las oportunidades. El objetivo de la justicia será que las diferencias en la posesión de riqueza e ingreso sean resultado del mérito y la elección personal más que de la suerte; y cuando no existen condiciones sociales con opciones de desarrollo, los individuos no pueden elegir y pierden su capacidad de autodeterminación. La falta de oportunidades limita su libertad.

Los fines compensatorios de la justicia se expresarían en un contrato social justo que gobernaría la cooperación entre los individuos. Rawls supone una situación imaginaria, una "posición original" donde los seres humanos son racionales, libres y con valores morales, que están sujetos a "un velo de ignorancia" en el cual no conocen ni su posición en la sociedad, ni su clase social, ni las ventajas o desventajas que tienen; cada individuo tiene necesidades, intereses y capacidades que pone en juego para alcanzar sus propias metas, pero negocia los principios de un estatuto de justicia. Bajo este supuesto se evitaría que los intereses personales de los jugadores, negociadores o legisladores afectaran sus posturas en el momento de la elaboración de dicho contrato. Con este planteamiento elimina los efectos nocivos del poder de negociación, lo que, obviamente, no corresponde al mundo real y dicha situación queda solamente como un recurso teórico. A partir de este argumento, la elección racional del individuo que negocia el contrato supondría dos principios de la justicia que garantizarían la imparcialidad para regular la crítica y reformar las instituciones sociales.

Primero, el principio de libertad, mediante el cual cada persona ha de tener un derecho igual al más amplio sistema total de libertades básicas, compatible con un sistema similar de libertad para todos; es decir, que se requiere igualdad en la asignación de los derechos básicos. Las libertades básicas incluidas en este principio son: a) la libertad política, es decir, 
el derecho a votar y ser elegido para ocupar cargos públicos; b) el derecho a la propiedad; c) la libertad de expresión, reunión y movimiento; d) la libertad de conciencia y pensamiento; e) la libertad de la persona, entendida como el derecho a no ser oprimido física o psicológicamente; y f) la libertad frente al arresto o las detenciones arbitrarias. Este principio establece que todas las personas son libres e iguales y que el sistema de reglas que rige a las instituciones sociales debe ser equitativo en el trato a cada individuo.

Segundo, el principio de la diferencia, consistente en que las desigualdades económicas y sociales han de ser estructuradas de manera que sean para: a) mayor beneficio de los menos aventajados, de acuerdo con un principio de ahorro justo; $\mathrm{y}$ b) que estén unidas a los cargos y las funciones asequibles a todos, bajo condiciones de justa igualdad de oportunidades. Las desigualdades socioeconómicas solo podrán justificarse si ofrecen los mayores beneficios para los miembros menos privilegiados de la sociedad, en comparación con cualesquiera otros arreglos institucionales que puedan imaginarse o crearse. Este principio implica que "los bienes sociales primarios" (noción que sustituye el concepto de utilidad), es decir, las libertades, la igualdad de oportunidades, la renta, la riqueza, así como las bases de respeto mutuo que incluyen los derechos políticos básicos se distribuyan por partes iguales en la sociedad, a menos que una distribución desigual favorezca al individuo en la peor situación o que redunde en beneficio de los menos aventajados. El principio de la diferencia tiene dos restricciones: a) el principio de ahorro justo consistente en que la generación actual tiene la obligación moral de transferir a la siguiente una dotación de recursos por lo menos similar a la que recibió; y b) la igualdad de oportunidades, es decir, que la desigualdad se justifica cuando proviene de diferencias en capacidades y no del acceso privilegiado a roles y puestos o bien que sea aprovechada para favorecer a los menos aventajados [Rawls, 2002]. 
Cuando se trata de solucionar un problema de justicia social, existe una jerarquización. Es más relevante el principio de la libertad (civil y política que caracteriza a la democracia liberal), que dominará al principio de la diferencia cuando entren en conflicto; después el principio de igualdad de oportunidades y al final el principio de igualdad de recursos.

En este discurso, surgen dos estrategias prácticas para la formulación de políticas públicas: a) la igualdad de oportunidades sociales se logra a través de la igualdad de los bienes sociales básicos, lo que se traduce en la formulación de una política social amplia, que supone la intervención del Estado; y b) la igualdad de circunstancias naturales se resuelve en el principio de diferencia, argumento que sostiene el diseño y la operación de programas de combate a la pobreza, sobre todo la pobreza extrema, aplicando criterios de discriminación positiva. El efecto instrumental de este planteamiento es que los individuos deben ser dotados exante de algún capital físico y humano antes de ingresar en la dinámica de los mercados para tener capacidad de elección y autodeterminación. A diferencia de la economía del bienestar, donde una situación es más eficiente si alguien está mejor sin que empeore la situación de alguien más, independientemente de que la persona que mejora sea rica o pobre, en la teoría de la justicia importa la identidad de quien avance, ya que se prefiere que mejore la situación de los más pobres de la sociedad.

La consecuencia del planteamiento de Rawls es la conformación de un Estado que garantice la suficiente dotación de recursos a los individuos menos aventajados. La preferencia por el bienestar de estos conduce a la definición y selección de beneficiarios de la acción estatal, en particular a través del diseño y la instrumentación de la política social orientada a la superación de la pobreza focalizada como extrema, mediante la distribución de bienes primarios que les permitan a los más pobres aumentar y mejorar sus capacidades para insertarse de manera más competitiva en el mercado. Los principios del 
contrato social de Rawls se identifican con el objetivo de fortalecer el mercado como el principal mecanismo para la asignación de los recursos sociales y la realización del ser humano.

Entre las críticas a esta propuesta puede mencionarse que, de manera contradictoria, Rawls no acepta la idea del Estado de bienestar, ni la revisión de la posición inicial, ni la redistribución de la acumulación previa de la riqueza, es decir, la desigualdad vigente se acepta para hacer funcionar el sistema. En sociedades reales, como en muchos países subdesarrollados, las libertades políticas asociadas al primer principio están limitadas y no garantizan el amortiguamiento de las desigualdades generadas por la concentración de la riqueza y el poder, que son aceptadas en el principio de la diferencia. Desde el liberalismo radical se le critica y se insiste en la libertad individual sin restricciones, se defiende la autorregulación de la economía sin intervencionismo del Estado, que debe ser mínimo, y se reafirma la racionalidad instrumental del individuo.

El concepto de bienes primarios de Rawls es criticado porque algunos de sus componentes (como el ingreso y la riqueza) son resultado conjunto del esfuerzo responsable y no deberían ser incluidos dentro del listado de cosas a ser igualadas entre los individuos. Por ello, se propone lograr la igualdad de oportunidades "nivelando el campo de juego" para que las personas elijan de manera responsable y en libertad. Esta idea se traduce en el diseño y la aplicación de políticas sociales compensatorias, de discriminación positiva, dirigidas a nivelar el campo de juego ante problemas sociales que están fuera del control de las personas y que condicionan su elección según sus propios valores [Roemer, 1989].

Los bienes primarios como criterio de distribución o niveles de ventaja no toman en cuenta la heterogeneidad en las condiciones de las personas receptoras de dichos bienes, ni su entorno socioespacial; surgen de una moralidad parcialmente ciega; son multidimensionales; no representan la variable a maximizar; no son valiosos en sí mismos (valor intrínseco), 
sino que solo poseen un valor instrumental, es decir, no son el único medio para alcanzar la libertad de elección ni son fines en sí mismos, solamente son medios. El principio de diferencia, a su vez, deja abierta la posibilidad de que al compensar las desigualdades se subsidie el ocio o se produzcan errores de inclusión o exclusión de beneficiarios de los programas sociales, como los típicos de transferencias monetarias condicionadas [Elster, 1999; Dworkin, 1993].

En este contexto, Amartya Sen acepta que la igualdad es un poderoso concepto que distingue a la cultura occidental y a las sociedades capitalistas democráticas, aunque argumenta que ha de contextualizarse con otras exigencias sociales y agrega que debe responderse la pregunta ¿igualdad de qué? [Sen, 1980].

Según Sen, lo importante para lograr el bienestar son las capacidades y los funcionamientos que se encuentran entre los bienes primarios y la utilidad. Desde una posición normativa, considera que el acceso a bienes y servicios constituye un medio para lograr la verdadera realización del individuo. Los bienes permiten que los individuos funcionen de varias maneras, pero el funcionamiento de una persona constituye su capacidad antes que la igualdad de resultados. Las "capacidades" comprenden todo lo que una persona puede hacer o ser para funcionar; esto es, una nutrición adecuada, buena salud o educación entendida como saber leer, escribir y razonar analíticamente, así como tomar parte en la vida comunitaria. Las capacidades básicas no son los bienes, sino los funcionamientos o rasgos personales con los cuales el individuo con libertad puede elegir su propio destino entre diferentes formas de vida, es decir, su autodeterminación. El bienestar se incrementa cuando las personas tienen capacidades, esto es, están bien nutridas o son capaces de escribir, leer y comunicarse, y tomar parte en la vida comunitaria. Las necesidades básicas son parte de las capacidades y aumentan la libertad y la capacidad de elección [Sen, 2000]. 
La economía, para Sen, se ha alejado de las consideraciones éticas y ha ignorado el bienestar de las generaciones futuras o el desarrollo sustentable [Sen, 1984 y 1997]. Las políticas económicas y sociales tienen consecuencias directas en el bienestar humano, a veces positivas en la lógica macroeconómica, pero negativas en relación con el individuo. La economía debe promover el desarrollo de las potencialidades humanas incrementando sus opciones vitales. En este sentido, el proceso de desarrollo consiste en ampliar las opciones reales que permitan el acceso de los individuos a un conjunto de bienes y servicios (pero también a condiciones económicas, sociales, institucionales y cognitivas) frente a las cuales puedan ejercer su capacidad de elección y convertirlas en capacidades y funcionamientos para lograr su bienestar. No se deben confundir medios y fines. Por ejemplo, el crecimiento económico no garantiza la ampliación de las capacidades y el bienestar de los individuos que no tienen acceso a los mercados. El crecimiento económico es condición necesaria pero no suficiente para lograr el desarrollo; son conceptos relacionados, pero diferentes. El objetivo del desarrollo debería ser acrecentar las capacidades de elección del individuo o, en términos filosóficos, ampliar la libertad en sentido positivo, es decir, cuando este es plenamente capaz de ejercer su elección para lograr una mejoría cualitativa en sus condiciones de vida [Sen, 1995; Nussbaum y Sen, 1998].

Sen demuestra que bajos niveles de desarrollo económico no afectan de igual manera a hombres y mujeres; que al interior de los hogares no tienen el mismo acceso a los cuidados de salud o a la nutrición; que el diseño y la instrumentación de las políticas públicas no son neutrales en cuanto al género; y que el hambre en el mundo es resultado de mecanismos injustos de distribución y no de la escasez de alimentos, lo que contradice los principios de la teoría neoclásica.

Entre los resultados de esta posición de igualitarismo liberal se encuentran los cambios de enfoque en el diseño de 
las políticas públicas, en su instrumentación, medición y evaluación. En el caso de los programas focalizados dirigidos a la erradicación de la pobreza, no se comunica la idea de que el receptor sea una persona activa, que opera por cuenta propia, y que hace cosas o reacciona a estímulos, sino que más bien es un receptor pasivo de las políticas sociales [Sen, 2003]. Al respecto, existen dos tipos de errores básicos: a) los de cobertura excesiva o de inclusión de no pobres; y b) los de fallas de cobertura o de exclusión de pobres. Ambos pueden generar elevados costos por lo que si bien se acepta que es necesario hacer alguna discriminación para seleccionar beneficiarios (por grupos vulnerables, ocupación, clases o regiones) y reducir fugas de beneficios hacia los no pobres, también es importante evitar una focalización estrecha. En otras palabras, frente al reto de la superación de la pobreza masiva es preferible orientarse hacia la cobertura excesiva. Esta última afirmación sustenta la formulación de políticas sociales de corte universal, lo que implica un Estado fuerte y eficiente [Cornia y Stewart, 2003].

En términos operativos, se propone medir el bienestar con un enfoque multidimensional que supere el fuerte peso de indicadores económico monetarios agregados como el producto interno bruto por habitante, utilizado durante muchos años como medida equivalente del desarrollo socioespacial. La medición del bienestar sería un proceso integrado por tres componentes: a) el acceso a bienes y servicios; b) una función de conversión -que incorpora la heterogeneidad entre los individuos- de dichos bienes y servicios en opciones reales de planes de vida o medios para alcanzar la realización individual plena; y c) una función de evaluación que transforma la elección adoptada en un nivel de satisfacción o bienestar individual [Sen, 1992 y 2003].

Entre los diferentes resultados de esta posición, que puede considerarse funcional al capitalismo, se pueden mencionar tres. Primero, el Programa de las Naciones Unidas para el Desarrollo ha elaborado el índice de desarrollo humano, 
que se define como una medición compuesta de tres dimensiones e indicadores: vivir una vida larga y saludable (esperanza de vida), recibir educación (matriculación escolar y alfabetización) y gozar de un nivel de vida decoroso (ingresos) (PNUD, 2002]. Segundo, en el Informe de la Comisión sobre la Medición del Desarrollo Económico y del Progreso Social (Comisión Sarkozy) se señaló, en 2008, que una nueva economía política de bienestar debe reconocer que el crecimiento es económico y el desarrollo es humano, y que ambos deben ser simultáneos y complementarios. El crecimiento se debe entender como la creciente disponibilidad de bienes y servicios producidos (oferta) dentro de un ámbito geográfico para satisfacer las necesidades materiales, sociales y espirituales de los seres humanos, y sus aspiraciones. El desarrollo, a su vez, se refiere al mejoramiento del bien-estar por medio de la satisfacción de estas necesidades y aspiraciones (demanda). Tercero, se propone el índice de progreso social ${ }^{4}$ para contar con una medida integral de la calidad de vida de la población, que sea independiente y complementario de indicadores económicos como el PIB [Stiglitz, Sen y Fitoussi, 2015].

\section{El comunitarismo}

El comunitarismo y el colectivismo definen al individuo como un ser gregario que requiere de la comunidad para lograr su autorrealización y el autoconocimiento. El bien es un parámetro que dicta la comunidad y las preferencias individuales son valiosas en tanto contribuyen a conseguir ese bien común; sin embargo, este no es un concepto homogéneo porque cada comunidad es diferente. En este contexto, el papel del Estado consiste en encauzar las preferencias individuales hacia el

${ }^{4}$ El índice de progreso social fue lanzado en 2014 por Michael E. Porter y Michael Green desde la organización Social Progress Imperative. 
bien que establece la comunidad, de manera que se transforma en un Estado perfeccionista.

En esta perspectiva, la justicia distributiva se desarrolla bajo dos principios que deben guardar equilibrio. Primero, la búsqueda de la igualdad, ya que se trata de elevar los niveles de vida de los integrantes de la comunidad hasta alcanzar niveles más o menos equitativos. Segundo, establecer la remuneración a partir de la contribución individual, bajo la premisa de "a cada quien, lo que beneficie a la comunidad; a cada cual, según su contribución a la comunidad", es decir, que si la contribución de un individuo al bien común es mayor que la de los demás, se hace acreedor a una mayor parte de los recursos colectivos, dado que se le debería más de lo que él debe a la comunidad.

Algunos autores señalan que el liberalismo integra valores que son reivindicados por los comunitaristas como necesarios para la cohesión social, como la solidaridad y la integración social [Dworkin, 1996]. Asimismo, se afirma que es posible equilibrar tanto los derechos humanos de la tradición liberal como los derechos diferenciados en función de grupo, lo cual haría posible la satisfacción de las exigencias de las minorías culturales más allá de los derechos individuales [Kymlicka, 1996]. También se puntualiza que existen diferentes esferas de bienes sociales como la salud, la educación, el poder político, la riqueza, la belleza y el honor, y cada una tiene su propio criterio de distribución, de manera que la justicia social debe aplicar criterios de igualdad al interior de cada una de ellas y no han de controlar o interferir unas sobre otras. Esto implica un Estado interventor que formule políticas dirigidas a lograr el equilibrio entre dichas esferas y ofrezca oportunidades a los individuos [Sandel, 1982; Walzer, 1993].

Entre las críticas a esta posición se apunta que en la medida que el bien común se define a partir de la imposición de los intereses de una mayoría intransigente, se pierde el respeto a las minorías y al individuo. Otro problema es que confunde la 
legitimidad que se origina en la participación cívica con la voluntad general. Respecto del Estado perfeccionista, se cuestiona el espacio limitado que se le deja a la sociedad civil. Así también, se pone en duda la idea de autorrealización y autoconocimiento como un ejercicio individual, ya que estos ideales se ubican en el ámbito social. Bajo estos supuestos, el ser humano no tendría la responsabilidad final de la definición de su bienestar, porque este sería una responsabilidad de la sociedad [Gargarella, 1999].

\section{El socialismo o marxismo clásico y analítico}

En el marxismo, en general, la justicia distributiva se concibe desde la igualdad, que constituye la condición necesaria para llegar a una distribución que haga posible la libertad absoluta del ser humano. Las desigualdades sociales y en particular los medios de consumo se relacionan con la propiedad de los medios de producción. Esta es una característica de cada modo de producción desarrollado históricamente. La teoría marxista, al partir del análisis de las clases sociales (no de los individuos como en los criterios liberales) subraya la ventaja relativa de quienes tienen la propiedad de la riqueza productiva en la fijación de las reglas del juego, respecto de la distribución del excedente económico y en la forma que asumen las instituciones básicas de la sociedad.

El marxismo clásico critica el capitalismo y sus desigualdades sociales inherentes a partir de la teoría de la explotación. Esta última se sustenta en la teoría del valor-trabajo, que propone que los trabajadores son la única fuente de la creación de valor; por tanto, la explotación se relaciona con el hecho de que a los trabajadores se les retribuye en forma de salario solo parte del valor que generaron, mientras que el capitalista se apropia del valor excedente o plusvalía. Se produce entonces un intercambio desigual entre los trabajadores y 
los capitalistas. Mientras que el único activo de los trabajadores es su mano de obra, los capitalistas tienen una posición ventajosa gracias a su propiedad del capital productivo, lo que les permite organizar la producción en la empresa y decidir la distribución del excedente económico. En el marco de la democracia burguesa, la clase capitalista cuenta con el poder político dominante en la sociedad a fin de preservar, por medio del aparato estatal, condiciones favorables para la estabilidad y la reproducción del sistema capitalista.

La transición del capitalismo al socialismo estaría caracterizada por un movimiento revolucionario que conduciría a la dictadura del proletariado. Esta versión leninista del marxismo plantea la abolición de la propiedad privada y su transferencia a un Estado transitorio, el cual primero centraliza los medios de producción y la riqueza, para después descentralizarla hacia los autoproductores en el comunismo. En esta etapa, el concepto de justicia distributiva parte de la igualdad derivada de la abolición de la propiedad privada de los medios de producción, la supresión de la figura del capitalista y la conformación de la clase proletaria. El principio básico es el de "remunerar a cada cual según su contribución laboral", entendida como el fruto íntegro del trabajo, con lo cual se aproxima al propósito de eliminar la explotación. Esta solución es subóptima ya que supone aún la división del trabajo, pero es superior al capitalismo en tanto que se logra la plena igualdad proletaria.

El comunismo consiste en superar la escasez de los recursos, con lo cual desaparece el conflicto y es posible prescindir del Estado. Mientras que en el socialismo todos los seres humanos son iguales en tanto proletarios, en el comunismo la riqueza colectiva excedente ofrecería las condiciones objetivas para la autorrealización del individuo. El principio es "de cada cual según su capacidad y a cada cual según su necesidad". Aunque cada quien puede aportar según diferentes habilidades y recibir de acuerdo con distintas necesidades, 
Marx afirma que esta desigualdad no genera privilegios, ni se trata de exigir iguales idénticos, sino de liberar las potencialidades de todos los integrantes de la sociedad [Marx y Engels, 1985].

Entre las críticas al marxismo clásico destacan los siguientes argumentos: el origen de la propiedad privada puede ser ilegítimo, pero también existen otras fuentes legítimas que a su vez justifican las transacciones en el mercado y conducen a formas de desigualdad social; la propuesta de socialización de los medios de producción implica un subsidio a quienes optaron por el ocio aun teniendo capital y la negación del esfuerzo individual acumulado; existen problemas de agregación, cuando hay diferentes tipos de mano de obra calificada y no calificada, o inconsistencias en el tratamiento del trabajo del pasado; y la negación de otros factores de la producción (como el papel del empresario y el trabajo doméstico) en la generación de valor.

En el socialismo real, se abolió la propiedad privada y el gobierno (no el pueblo) se apropió de los medios de producción, pero también de las demás esferas sociales; la dictadura del proletariado se materializó a través del control de la élite de un partido; y la distribución de la riqueza se produjo en función de la disciplina política, más que por la contribución del trabajo. Este fracaso provocó una crítica "desde el interior" del marxismo, que ha intentado elaborar un marco alternativo que insiste en subrayar las desigualdades fundamentales del capitalismo moderno, pero que abandona la teoría de la explotación (y la teoría del valortrabajo) como su fundamento central, sobre todo, porque esta se circunscribe a las relaciones salariales; por tanto, no considera a los grupos que están fuera del mercado de trabajo aunque sean explotados (mujeres, niños en situación de calle, minorías discriminadas, entre otros) o contribuyan indirectamente a la generación de riqueza. Una propuesta alternativa consiste en ubicar el concepto de explotación en el ámbito de la 
justicia distributiva, ya que surge desde la posesión o no del conjunto de los medios de producción y no exclusivamente en relación con el salario [Roemer, 1989].

El supuesto de la abundancia en el comunismo es ilusorio frente a la realidad de la escasez de recursos, por lo que no es posible cumplir con la finalidad de dar a cada quien según sus necesidades. En las versiones neomarxistas, se redefine el concepto de los recursos productivos, que pueden ser externos al individuo (capital, tierra, inmuebles o activos financieros) o internos (talento, habilidades, actitud hacia el riesgo, ambición). No obstante, esta nueva concepción obliga a replantear supuestos marxistas básicos, como el que las relaciones de propiedad son un factor central para determinar las pautas distributivas y las desigualdades sociales. Hay que aclarar cómo modificar los derechos de propiedad de recursos internos (que son inherentemente privados y no transferibles) para lograr una distribución más igualitaria de los recursos de la sociedad, así como establecer los criterios para su remuneración como un factor de la producción. También habría que reconsiderar el concepto de clase social, que en el marxismo clásico se define en función de la propiedad o no del capital, para incluir formas de posesión colectiva de atributos (como la etnia, el talento o los antecedentes familiares) que afectarán su capacidad para crear riqueza y generar ingreso [Gargarella, 1999].

Por otra parte, desde el marxismo analítico, una propuesta alternativa de justicia distributiva se expresa en la idea modernizada de la socialización exante y periódica de los medios de producción, mediante la cual se distribuya el capital de las empresas entre sus trabajadores, lo cual haría posible que, aún bajo las condiciones de una economía de mercado, se reduzca la explotación y la alienación del trabajo, ya que el individuo contaría con información suficiente para tomar decisiones ociotrabajo de manera racional. Esta propuesta enfrenta algunos problemas. Primero, la 
inviabilidad político institucional, ya que no existe un diseño para la instrumentación de acciones tan radicales de redistribución de la riqueza. Segundo, la opción de reasignaciones periódicas de los medios de producción, una vez que se llegue a cierto grado de concentración, afectaría la certidumbre en el funcionamiento de los mercados en el mediano y largo plazos y desincentivaría a los individuos que optarían por el ocio, esperando la nueva etapa de redistribución de riqueza. Y tercero, esta vía subordinaría la voluntad del individuo, su capacidad de elección y su autodeterminación.

En este marco, se plantean propuestas más radicales con base en la noción de la libertad real (no formal) para todos y ante algunas condiciones orgánicas del capitalismo, como el desempleo estructural más que el coyuntural. Es el caso del ingreso básico universal, como "una vía al comunismo", con el objetivo de asegurar a todos los individuos un ingreso pagado por el gobierno que sea suficiente, incondicional, sostenido y suficiente para satisfacer sus necesidades básicas, independientemente de si es rico o pobre, de sus rentas o de con quién y en qué parte del país resida. Esta idea considera los principios de libertad, justicia y solidaridad, así como tres condiciones: a) que existe una estructura de derechos bien definida; b) que cada persona es propietaria de sí misma; y c) que cada individuo tiene la mayor oportunidad posible para hacer cualquier cosa que pudiera querer hacer [Van Parijs y van der Veen, 1987]. ${ }^{5}$

Esta propuesta se encuentra entre el capitalismo óptimo y un socialismo cooperativo inmejorable, pero su instrumentación requiere mecanismos de redistribución de la riqueza socialmente generada, de modo local y global, con políticas

${ }^{5}$ Algunos empresarios dueños de grandes empresas trasnacionales (como Bill Gates, Jeff Bezos o Mark Zuckerberg) o incluso voceros de partidos conservadores aceptan ahora la renta básica como instrumento para amortiguar los efectos negativos en el bienestar derivados de las crisis de origen económico, tecnológico, sanitario o de fenómenos naturales, entre otros. 
públicas solidarias que favorezcan la libertad genuina del ser humano. También presupone un Estado de bienestar que garantice los derechos humanos y sociales frente las presiones del mercado, la competitividad internacional o las crisis. A su vez, sería necesario un nuevo acuerdo social y fiscal eficiente y eficaz para la reasignación de los recursos públicos.

En general, existen diferentes corrientes en la filosofía política que argumentan acerca de los postulados, criterios y supuestos en relación con el bienestar de las personas y las comunidades, que es necesario ubicar cuando se diseñan políticas públicas en estructuras sociales concretas, como se expone a continuación.

\section{LA ESTRUCTURA SOCIAL}

La estructura social es un sistema de posiciones jerarquizado con la configuración de esferas institucionales, reglas y recursos, que atribuye condiciones de vida desiguales a las personas y los actores colectivos en un momento y un lugar determinados. La estructura social cuenta con tres dimensiones:

a) Las esferas institucionales. Constituyen el marco que confiere estabilidad a la estructura social y que puede proveer de bienestar social a la población, y son tres: la estatal, la mercantil y la social (doméstico-familiar, asociativa y comunitaria). Estas esferas se han denominado genéricamente: Estado, mercado y sociedad.

b) Los ejes de desigualdad. Son los espacios de categorización de los individuos considerando los diferentes atributos que poseen: de clase y estrato social; género, etnia, edad y territorio; la condición de sujeto de derechos (ciudadanía); la posición respecto la estructura administrativa del Estado (clientes-servidores o empleados-beneficiarios de servicios sociales); y las capacidades asociativas. 
c) Los actores colectivos. Son "manifestaciones" de la estructura social en el terreno de la acción con individuos que se asocian (partidos, sindicatos, asociaciones gremiales o patronales, etc.) con base en intereses y valores similares [Esping-Andersen, 1993; Adelantado, Noguera, Rambla y Sáez, 1998].

\section{LOS REGÍMENES DE BIENESTAR}

La concreción de las funciones y relaciones entre el Estado, el mercado y la sociedad civil es diferente en cada país; por ello se han propuesto tipologías que caracterizan los regímenes de bienestar social. Las primeras corresponden a países desarrollados y, como todos los modelos, están sujetas a debate y crítica por su carácter formal, estático o ahistórico. Algunos criterios tipológicos son los siguientes:

a) Relaciones públicas-privadas en la provisión de bienestar. Se expresan mediante la satisfacción de algunas necesidades humanas por el Estado y no por el mercado, en función de razones políticas con mayor o menor contenido de justicia social.

b) Grado de desmercantilización de los bienes y servicios sociales. Efecto de la acción del Estado de bienestar en la estratificación social en la medida en que debilita el vínculo monetario a favor de la igualdad, la equidad y la solidaridad social.

c) Derechos sociales de ciudadanía. Pueden ser los universales, los que dependen de la inserción en el mercado de trabajo y del nivel de ingreso mínimo.

d) Desfamiliarización. Expresa el grado de reducción de la dependencia del individuo respecto de la familia o bien el aumento de la autonomía del individuo sobre los recursos económicos familiares, independientemente de las reciprocidades familiares o conyugales [Esping-Andersen, 1993 y 1999]. 
A partir de estas dimensiones se elabora una tipología ${ }^{6}$ de regímenes de bienestar y se clasifican algunos países desarrollados de la manera siguiente:

a) Liberal o de asistencia social residual. Alto grado de mercantilización, residualismo público y papel marginal de las familias. Se asigna un papel central en el bienestar a la responsabilidad de los individuos (Estados Unidos, Canadá, Australia y Gran Bretaña).

b) Conservador o de seguridad social obligatoria, corporativista o institucional. Fuerte grado de familiarismo, con un papel marginal del mercado y una función subsidiaria del Estado (Alemania, Austria, Francia e Italia).

c) Socialdemócrata o moderno. Fuerte creación de instituciones públicas, alto grado de desmercantilización y de desfamiliarización (Suecia, Noruega y Finlandia).

d) Mediterráneo, familiarista o rudimentario. La familia es responsable de los cuidados domésticos, fuerte conservadurismo católico, beneficios ocupacionales en el programa universal de salud y ausencia de programas de ingreso mínimo y discrecionalidad en programas sociales (España, Portugal y Grecia).

e) Posautoritario. Responsabilidad estatal en la cobertura de las necesidades básicas, subordinación de las familias y comunidades al gobierno central (Rusia, antigua República Democrática Alemana o Polonia).

En América Latina se han conformado estructuras sociales con características propias que conforman otra tipología de países como la siguiente:

${ }^{6}$ Entre las críticas a esta tipología destacan dos: el escaso desarrollo del papel de la familia en la caracterización y la dinámica de los regímenes; y la correspondiente a la ausencia de la dimensión de género y la división sexual del trabajo, ya que las mujeres no aparecen en el análisis como un componente de dicha tipología, sobre todo porque no participan en el mercado laboral en las mismas condiciones que los hombres, ni en la misma magnitud, y porque el trabajo doméstico y las tareas de cuidado no se consideran importantes [Carrasco, 1997]. 
a) Universalismo estratificado. Desarrollo temprano de sistemas de bienestar, protección a la mayor parte de la población por medio de mecanismos de seguridad social, altos grados de desmercantilización, fuerte estratificación de beneficios y condiciones de acceso a estos mecanismos, con visión productivista e informalidad (Uruguay-corporativo, Argentina-híbrido y Chile-liberal).

b) Régimen dual. Desprotección de amplios sectores por fuerte heterogeneidad territorial y democracia débil, con modelos segmentados de seguro social vinculados a la posición en el empleo y a clases medias del sector moderno de la economía, con niveles parciales de cobertura y calidad de servicios. La producción del bienestar es familiarista y con redes comunitarias de apoyo, con una combinación liberalproteccionista-informal (Brasil y México).

c) Régimen excluyente. Sistemas elitistas, excluyentes de seguridad social y duales en educación, fuerte control del aparato estatal, extracción de rentas de economías primarias, sin generación de bienes públicos colectivos, con informalidad y asistencialismo (República Dominicana, Guatemala, Honduras, Nicaragua, El Salvador, Bolivia y Ecuador) [Filgueira, 1998; Martínez, 2006].

\section{EL BIENESTAR EN LOS DERECHOS HUMANOS}

Y LA JUSTICIA SOCIOESPACIAL

Existe un amplio conjunto de derechos humanos sustentados en la necesidad de respetar la dignidad de las personas, destacando la necesaria intervención activa del Estado para garantizar un acceso igualitario a los mismos, para compensar las desigualdades que caracterizan las diferencias entre los individuos, las comunidades y los territorios, y generar las condiciones sociales para el ejercicio real de las libertades. Los derechos son universales, imprescriptibles, 
inalienables, irrenunciables y prioritarios, y son los siguientes por generación.

a) Derechos civiles y políticos (primera generación), de los ordenamientos jurídicos internos e internacionales contra las acciones de algún órgano público.

b) Derechos económicos, sociales y culturales (segunda generación), con el objetivo de garantizar el bienestar económico y el acceso al trabajo, la educación y la cultura, de tal forma que asegure el desarrollo de los seres humanos y los pueblos.

c) Derechos colectivos (tercera generación), o derechos de solidaridad o de los pueblos: contemplan aspectos de carácter supranacional como el derecho a la paz y a un medio ambiente sano. Están en proceso de definición y consagrados en diversas disposiciones de algunas convenciones internacionales.

d) Derechos de cuarta generación: incluyen derechos en proceso de incorporación legal, como la integración de la familia, la no discriminación, la igualdad de nacionalidad y la solidaridad; el derecho a la expresión, al acceso a las tecnologías de la información; los de medio ambiente y el desarrollo sostenible, el aprovechamiento de la ecología, la biomedicina y la biotecnología [CESOP, 2017].

En estos grupos de derechos predomina la visión individual y sectorial, pero algunos abordan la calidad de vida y el bienestar en el territorio relacionados con los postulados de la justicia distributiva y la justicia social, y diferentes juicios éticos y morales, tal como se expone en la primera sección de este trabajo y que interesa aquí destacar.

A partir de ellos se atienden demandas conflictivas, se asignan recursos, ingresos y beneficios a la población en diferentes escalas espaciales; se trata de enfrentar procesos y mecanismos que generan distribuciones territoriales injustas con concentración de la riqueza, rezagos socioeconómicos, 
escasez de bienes y servicios, daños o males ambientales, explotación de algunos por otros o intercambio desigual de valores.

Ante ello, la justicia espacial se ha impulsado en algunas corrientes de pensamiento como el derecho a la ciudad, propuesto por Henry Lefebvre, que considera la multidimensionalidad del espacio y la potencialidad de la ciudad como lugar de disfrute con una sociedad justa, en el marco de las normas básicas de la democracia, la igualdad y la ciudadanía, y de un bloque jurídico que asegure los derechos humanos, cívicos, sociales, económicos, culturales y ambientales de la población [Lefebvre, 1978].

En la formulación de corte marxista interesada en la injusticia generada por el proceso de concentración urbana, se propone la justicia social territorial en la cual se considera que

la distribución del ingreso debería ser tal que: a) sean cubiertas todas las necesidades de la población dentro de cada territorio; b) sean asignados recursos a fin de minimizar los efectos multiplicadores regionales (reforzar las externalidades positivas), y c) sean invertidos recursos suplementarios para contribuir a superar dificultades especiales provenientes del medio físico y social; [...] los mecanismos (institucionales, organizativos, políticos y económicos) deben ser tales que las perspectivas de los territorios menos aventajados sean los más favorables posible [Harvey, 1977].

En esta lógica, el Foro Social Mundial formuló la Carta mundial por el derecho a la ciudad (2001), que define este nuevo derecho como el usufructo equitativo de las ciudades dentro de los principios de sustentabilidad, democracia, equidad y justicia social. El propósito es enfrentar las causas y manifestaciones de la exclusión ya sea económica, social, territorial, cultural, política y psicológica. Es una respuesta social de contrapunto a la ciudad-mercancía y como 
expresión del interés colectivo. Exige articular la temática de todos los derechos humanos con la democracia representativa, distributiva y participativa. Estos lineamientos se ordenan a partir de las aspiraciones que perfilan la ciudad que queremos: democrática, incluyente, sostenible, productiva, educadora y habitable. El derecho a la ciudad cuenta con seis fundamentos estratégicos: a) el ejercicio pleno de los derechos humanos en la ciudad; b) la función social de la ciudad, de la tierra y de la propiedad; c) la gestión democrática de la ciudad; d) la producción democrática de la ciudad y en la ciudad; e) el manejo sustentable y responsable de los bienes naturales, patrimoniales y energéticos de la ciudad y su entorno; y f) el disfrute democrático y equitativo de la ciudad [ONU-Hábitat, 2011].

En la geografía moral, inspirada en la justicia liberal de Rawls, los conflictos sociales por la distribución del valor son las causas que explican las estructuras espaciales del bienestar humano en diferentes escalas geográficas; por ello, es necesario estimar índices, como el acceso a los servicios públicos para la satisfacción de las necesidades sociales, con el fin de formular alternativas a la redistribución justa de los recursos [Smith, 1994].

En la geografía cuantitativa, útil para fines de planeación, se consideran tres conceptos de justicia que orientan la toma de decisiones sobre la localización y la asignación de la infraestructura y el equipamiento para mejorar la calidad de vida de la población: a) la eficacia espacial, entendida como la minimización de las distancias entre la oferta de un servicio y su demanda; b) la justicia espacial, que se refiere a la distribución óptima de las infraestructuras; y c) la justicia ambiental, que remite a la localización adecuada de las infraestructuras indeseables al aumentar la distancia [Buzai y Baxendale, 2006].

La justicia ambiental responde a la distribución desigual de daños o males ambientales con principios de las teorías de la justicia aplicados al medio ambiente, los servicios 
ecosistémicos, la ecología o el cambio climático, considerados como elementos del bien común. Existen derechos de acceso sostenible a los recursos naturales vitales para todos en cualquier lugar, con intercambios equitativos en los ámbitos territorial, geográfico e intergeneracional, así como deberes y obligaciones. La justicia ambiental se complementa con el desarrollo sustentable definido como un proceso dirigido al mejoramiento de la calidad de vida y la productividad partiendo de medidas que beneficien el equilibrio ecológico, la protección al ambiente y los recursos naturales, evitando comprometer la satisfacción de las necesidades de las generaciones futuras [Congreso de la Unión, 2018].

En una visión posmodernista, la justicia en su sentido amplio se entiende como la existencia de libertad, igualdad, democracia y derechos civiles, ya que es un fenómeno social, pero también un hecho espacial. La justicia y la injusticia están incrustadas en la espacialidad y se manifiestan en formas de distribución de los recursos, la estructura y la dinámica económica, los bienes y los servicios en las geografías multiescalares, donde se valoran y utilizan de modo social. La justicia socioespacial es una categoría de análisis para las ciencias sociales y constituye la manifestación territorial de las modalidades económicas y sociales de la justicia que no pueden separarse [Soja, 2010].

En este criterio, hay injusticias espaciales sin consecuencias y con consecuencias, que se derivan de geografías exógenas de orden global, y endógenas, las cuales se expresan de manera multiescalar. Ante la injusticia socioespacial se requiere explicar sus procesos causales como, por ejemplo, los efectos de los modelos económicos en la distribución de la riqueza, el empleo y el ingreso, o los efectos de las inversiones públicas y privadas, las políticas y los programas con efecto territorial, como los de urbanización y vivienda, en la conformación de estructuras espaciales tipo centro-periferia con sesgos antipopulares, lo cual se expresa en fenómenos negativos 
como marginalidad, segmentación, segregación, discriminación o vulnerabilidad, entre otros.

Por último, existe una amplia gama de posiciones en la filosofía política que abordan el bienestar y la justicia; en la mayoría se consideran objetivos de toda sociedad, pero ahora adquieren mayor relevancia ante el aumento de la desigualdad socioeconómica derivada de los impactos de la fase de globalización capitalista neoliberal y de sus consecuencias en las sociedades y los territorios. En este sentido, destaca la justicia socioespacial en el diseño de las políticas públicas para el desarrollo asociada, en particular, al marco jurídico de derechos y la planeación urbano-regional que deben considerar la justicia distributiva para promover formas de bienestar en territorios heterogéneos.

\section{REFERENCIAS}

Adelantado, José, José Noguera, Xavier Rambla y Lluís Sáez [1998], "Las relaciones entre estructura y políticas sociales: una propuesta teórica", Revista Mexicana de Sociología, 60(3): 123-156, julio-septiembre.

BuzAi, Gustavo y Claudia Baxendale [2006], Análisis socioespacial con sistemas de información geográfica, Buenos Aires, GEPAMA.

CARrasco, Cristina [1997], "Mujeres y Estado de bienestar: un debate teórico", en Cristina Carrasco, Anna Alabart, Maribel Mayordomo y Teresa Montagut (coords.), Mujeres, trabajos y políticas sociales: una aproximación al caso español, Madrid, Ministerio de Trabajo y Asuntos Sociales, pp. 17-47.

CEsop (Centro de Estudios Sociales y de Opinión Pública) [2017], Los derechos humanos de cuarta generación. Un acercamiento, México, Cámara de Diputados, LXIII Legislatura. 
Congreso de LA Unión [2018], Ley General del Equilibrio Ecológico y la Protección al Ambiente, <https://n9.cl/ks8m1>. Cornia, Giovanni y Frances Stewart [2003], "Subsidios alimentarios: dos errores de focalización", Comercio Exterior, 3(6): 563-573, junio.

Dworkin, Ronald [1996], La comunidad liberal, Bogotá, Siglo del Hombre Editores.

[1993]. Ética privada e igualitarismo político, Barcelona, Paidós.

Elster, Jon [1999], Constitucionalismo y democracia, México, Fondo de Cultura Económica.

EsPing-Andersen, Gösta [1999]. Social foundations of postindustrial economies, Nueva York, Oxford.

[1993], Los tres mundos del Estado de Bienestar, Valencia, Edicions Alfons el Magnànim.

Filgueira, Fernando [1998], "El nuevo modelo de prestaciones sociales en América Latina, eficiencia, residualismo y ciudadanía estratificada", en Brian Roberts, Ciudadanía y politica social latinoamericana, Costa Rica, Flacso/ssRc.

GaRGarella, Roberto [1999], Las teorías de la justicia después de Rawls. Un breve manual de filosofía política, Barcelona, Paidós.

HaRvey, David [1977], Urbanismo y desigualdad social, Madrid, Siglo xxi de España Editores.

HaYeK, Friedrich [1944], Camino de servidumbre: Textos y documentos, <https://n9.cl/p86m9>.

KERSTENETZKY, Celia [2017], El Estado de bienestar social en la edad de la razón. La reinvención del Estado social en el mundo contemporáneo, México, Fondo de Cultura Económica.

Kymuicka, Will [1996], Ciudadanía multicultural, Barcelona, Ediciones Paidós Ibérica.

Lefebvre, Henry [1978], El derecho a la ciudad, Barcelona, Ediciones Península.

LeRner, Abba P. [1951], Teoría económica del control, México, Fondo de Cultura Económica. 
Martínez, Juliana [2006], Regímenes de bienestar en América Latina: zcuáles y cómo son?, Costa Rica, Instituto de Investigaciones Sociales, Universidad de Costa Rica, Fundación Carolina.

Marx, Carlos y Federico Engels [1985], El manifiesto comunista, Moscú, Ediciones Progreso.

Mises, Ludwig von [2011], La acción humana. Tratado de Economía, Madrid, Unión Editorial.

Nozick, Robert [1990], Anarquía, Estado y utopía, México, Fondo de Cultura Económica.

Nussbaum, Martha C., y Amartya Sen (comps.) [1998], La calidad de vida, México, Fondo de Cultura Económica.

ONU-HÁBITAT [2011], Recuperando la primera centralidad de la ciudad, Río de Janeiro.

PNUD (Programa de la Naciones Unidades para el Desarrollo) [2002], Informe sobre desarrollo humano, 2002. Profundizar la democracia en un mundo fragmentado, Nueva York. Rawls, John [2002], Teoría de la justicia, México, Fondo de Cultura Económica.

Roemer, John [1989], Valor, explotación y clase, México, Fondo de Cultura Económica.

SÁnchez, Adolfo [2018], Calidad de vida en la Zona Metropolitana del Valle de México. Hacia la justicia socioespacial, México, Instituto de Investigaciones Económicas, DGAPA, PUED, Universidad Nacional Autónoma de México.

SANDEL, Michael [1982], Liberalism and the Limits of Justice, Cambridge, Cambridge University Press.

SEn, Amartya [2003], "El enfoque de las capacidades y las realizaciones", Comercio Exterior, 53(5): 413-423, mayo. [2000], Desarrollo y libertad, Barcelona, Planeta. [1997], Bienestar, justicia y mercado, Barcelona, Paidós. [1995], Nuevo examen de desigualdad, Madrid, Alianza Editorial.

[1992], "Sobre conceptos y medidas de pobreza", Comercio Exterior, México, 42(4): 310-322, abril. 
[1984], Sobre ética y economía. Madrid, Alianza Editorial.

[1980], "Equality of What", en S. M. McMurrin (ed.), The Tanner Lectures on Human Values, I, Salt Lake City, University of UTA Press.

Sмiтн, David M. [1994], Geography and Social Justice, Oxford, Blackwell.

SoJA, Edward W. [2010], Seeking spatial justice. Minneapolis, University of Minnesota Press.

Stiglitz, Joseph, Amartya Sen y Jean-Paul Fitoussi [2015], Informe de la Comisión sobre la Medición del Desarrollo Económico y del Progreso Social, <https://n9.cl/7hfi>.

VAN PARIJS, Philippe y Robert van der Veen [1987], "A capitalist road to communism", Theory and Society, 15(5): 635$655,<\mathrm{https}: / / \mathrm{n} 9 . \mathrm{cl} / \mathrm{j} 18 \mathrm{y} 3>$.

WaLzER, Michael [1993], Las esferas de la justicia. Una defensa del pluralismo y la igualdad, México, Fondo de Cultura Económica. 



\title{
BIENESTAR EN EL SIGLO XXI
}

\author{
Alberto Castro Jaimes * \\ José Nabor Cruz Marcelo** \\ Verónica Villarespe Reyes*** \\ Bernardo Ramírez Pablo ****
}

\section{INTRODUCCIÓN}

Al menos por los últimos 30 años, el examen meticuloso de las estrategias de crecimiento económico y el desempeño de montos crecientes del gasto social en un contexto global buscó definir las fórmulas de política pública que mejor han paliado los efectos de profundas caídas financieras, crisis humanitarias y reconfiguraciones políticas en el mundo. Gobiernos y estudiosos urgen una combinación óptima entre el desarrollo social, ${ }^{1}$ el fortalecimiento de los Estados democráticos y el crecimiento productivo.

* Profesor de la Facultad de Economía de la UNAM. Correo electrónico: <acj@ unam.mx>.

** Investigador del Instituto de Investigaciones Económicas, UNAM. Correo electrónico: <jnabor@unam.mx>.

*** Investigadora del Instituto de Investigaciones Económicas, UNAM. Correo electrónico:<reyesvv@unam.mx>.

***** Académico del Instituto de Investigaciones Económicas, UNAM. Correo electrónico: <bernar@unam.mx>.

Los autores agradecemos el apoyo de la licenciada Estefany Licona Santillán para la revisión de datos; evidentemente, cualquier error u omisión es nuestra total responsabilidad.

${ }^{1}$ El Banco Mundial define el desarrollo social como la centralidad de las personas en los procesos de desarrollo económico, que por consecuencia requiere materializarse aliviando la vulnerabilidad, la exclusión y la desigualdad de poder. En los debates más elementales sobre el tema interviene el enfoque de necesidades humanas de A. Maslow [1991], que luego será ampliado por la visión de capacidades como forma de emancipación que, dentro de una dimensión individualista, es la base conceptual del desarrollo humano [Sen, 2000]. Sin embargo, también se ha señalado que el desarrollo de capacidades de los individuos requiere la "pre-existencia" de un tejido 
Uno de los parámetros más vastos ha sido el bienestar como calidad de vida. Entre las ciencias sociales, la principal referencia al término proviene de la construcción de regímenes de bienestar de sociedades capitalistas durante el siglo $\mathrm{xx}$. El contexto principal de este término puede ubicarse en la época dorada de crecimiento capitalista en el siglo xx y la alternativa real de progreso que representó en su momento. En el México actual, de acuerdo con el Plan Nacional de Desarrollo 2019 a 2024, bienestar es el eje discursivo de la política pública, aun así al momento se carece de una definición precisa del concepto y se aleja de un acercamiento claro para medir el impacto de la política pública. El incentivo para contribuir a un constructo teórico del bienestar es que trasciende la visión transitoria de política pública orientada a superar la pobreza y se aboca a una postura normativa de largo plazo, que delimita efectos amplios sobre la ciudadanía como conjunto. Si el bien común es el objeto del pacto social, un agente imprescindible para alcanzar este objetivo es el Estado mismo.

El capítulo atrae el debate conceptual más conocido, cuya revisión muestra una trayectoria polémica entre tradiciones metodológicas y posturas teóricas, en un contexto público en el que prevalece cierta ligereza en el uso de los términos desarrollo social y bienestar; no obstante, el común denominador de estos enfoques consiste en ofrecer medidas de desarrollo o progreso social que reflejen un correlato del crecimiento económico y de los ingresos de las familias. El registro del ingreso, el crecimiento de la

institucional, que tiene un carácter histórico y cultural, y que se expresa en una capacidad colectiva formada por individuos, grupos e instituciones [Ojeda, 2010: 4546]. Una revisión conceptualmente rica sobre el desarrollo social puede encontrarse en Chávez [2011], quien establece que envuelve la satisfacción de necesidades y aspiraciones de las personas, y se integra por un entorno social e institucional, que, para favorecerle, es necesario fortalecer la soberanía nacional, así como la cooperación, la sostenibilidad, la seguridad, la cohesión y gobernabilidad, entre otros elementos clave. Asimismo, se vincula dinámicamente con el desarrollo económico; no obstante, pudiera estudiarse desde la perspectiva de derechos o bien desde la transformación integral de capacidades, necesidades y potencialidades del ser humano. 
producción y el empleo son ya insuficientes para reconocer avances o limitantes de las políticas públicas. A la luz de restricciones ideológicas a la intervención estatal, el bajo ritmo de crecimiento económico requiere calibrar mejor sus objetivos de política.

La pregunta fundamental frente al gran dinamismo económico global es si el modelo de crecimiento actual es capaz de generar un bienestar robusto para todos. Para contestarla se revisan los derechos sociales que garantiza un régimen de bienestar y en el centro del argumento se visita la transformación histórica de los mecanismos de protección que funcionaron en México durante el siglo xx y se cuestiona si son vigentes en una economía abierta con una alta proporción de trabajadores informales o precarios y grandes brechas de acceso a la tecnología.

Nuestro planteamiento principal sustrae los componentes de bienestar garantizados por estos mecanismos de protección social como derechos sociales para indagar si al sistema actual le es posible ofrecer bienestar una vez desmantelado el entramado institucional que protegía el empleo y otros riesgos propios del ciclo de vida. Con ello se busca responder qué tipo de bienestar debería perseguir el Estado actual y con qué mecanismos cuenta para ello.

A pesar de establecer que una definición de bienestar delimita el contenido de aquello que el régimen busca otorgar a sus ciudadanos, el capítulo concluye sin pretender una construcción definitiva, aunque conduce hacia algunas propiedades del concepto que sin duda contribuirán a una clara medición del bienestar, a la vez que delimita el papel de la intervención pública y de la sociedad civil en la construcción del bienestar como capacidad colectiva. Se propone considerar sus propiedades como las de un bien público, con una visión integral e incluyente, que necesitará la participación activa de todos los actores y una importante capacidad de coordinación del Estado. Por tanto, el Estado de bienestar logró en su momento acuerdos con actores sociales representados, dirigía el esfuerzo colectivo y afrontaba los retos de manera central para dar curso claro al desarrollo. La dispersión 
de intereses y las interconexiones económicas del modelo de crecimiento actual requieren desarrollar capacidades, pero la suma de las capacidades individuales no será suficiente para impulsar una cualidad que cubra a todos sus miembros. Concluimos que se requiere una capacidad colectiva para manejar los riesgos del ciclo de vida en un momento determinado.

\section{BIENESTAR SUBJETIVO Y BIENESTAR OBJETIVO}

De acuerdo con la bibliografía del bienestar, se encuentran dos vertientes elementales que definen sus dimensiones: el bienestar objetivo y el subjetivo. El primero se refiere a las condiciones materiales que inciden sobre la calidad de vida y el segundo se centra en la percepción individual autorreferida [Landa, 2017: 8-14].

Ruut Veenhoven puntualiza que el bienestar subjetivo se utiliza como sinónimo de satisfacción vital y, las más de las veces, se emplea en lugar de felicidad. Calidad de vida con frecuencia alude al sentido de pertenencia, por lo que el término se considera un referente social que a menudo se relaciona con la felicidad: "la felicidad es el grado en el que una persona evalúa positivamente la calidad de su vida actual en su conjunto. En otras palabras, cuánto le gusta a una persona la vida que lleva" [Veenhoven, 2001: 4].

Ya en los siglos XVIII y XIX, la felicidad era materia de reflexión de la filosofía económica. Jeremy Bentham, fundador de la doctrina utilitarista, sostuvo que el propósito ulterior del Estado debía ser el logro de la mayor felicidad para el mayor número. Sus criterios sobre "la mayor felicidad para el mayor número" se manifiestan en An Introduction to the principles of morals and legislation, texto publicado en 1780 [Villarespe, 2002: 88-89]. Más tarde, Alfred Marshall, representante de la revolución marginalista y fundador de la escuela neoclásica, representó el dolor y el placer expuestos por Bentham como beneficio y agravio. 
$\mathrm{Al}$ respecto de los seguidores de Bentham, que habían usado los conceptos de dolor y placer, Marshall señala que se habrían supuesto equivocadamente. La acción "normal" en economía es la correcta en la esfera moral. La cuestión entonces para Marshall no es el placer y el dolor como conceptos morales, sino su traducción a conceptos económicos, es decir: el beneficio y el agravio, de los cuales se desprendió el concepto de utilidad marginal [Villarespe, 2002: 196].

Por su parte, Gabriela Delsignore se refiere a las reflexiones de Veenhoven preguntándose en qué medida el Estado de bienestar (Welfare State) contribuye al bienestar de las personas (Well-being); si el incremento del presupuesto del Estado garantiza una distribución equitativa del bienestar o si, en cambio, su incidencia es mínima y solo influye en la distribución del ingreso; si elimina la privación de las clases más desprotegidas o solo reduce su resistencia a aquella, incluso si opera como paliativo de la socialdemocracia al capitalismo [Delsignore, 2017: 4-5].

De cara a los desarrollos teóricos con largo aliento y a la puesta en marcha de amplias estrategias de protección social en el mundo, los

primeros esfuerzos por comprender la felicidad y el bienestar subjetivo usando instrumentos de medición para [...indagar] sus posibles relaciones causales con el comportamiento humano y darles seguimiento en el tiempo, tuvieron lugar en la segunda década del siglo xx. A partir de ese momento se comenzaron a sentar las bases de lo que algunos han denominado la "ciencia de la felicidad" para hacer referencia al conjunto de [generalizaciones...] sustentadas en mediciones subjetivas orientadas a la comprensión de los factores que influyen en el bienestar de las personas [Castellanos, 2012: 137].

Hornell Hart diseñó el euphorimeter, método por el cual la felicidad podía medirse [Moreno, 1942: 652-653]. En realidad, Hart diseñó dos euforímetros: uno para medir la felicidad 
percibida de forma inmediata y otro para medir el nivel general de (in)felicidad en el largo plazo. Esta fue una de las primeras propuestas de medición que distinguían entre felicidad inmediata y la satisfacción de largo plazo. La primera está asociada sobre todo con la experiencia emotiva más cercana y con la ausencia o presencia de placer y dolor; la segunda se encuentra vinculada con una evaluación de la vida en su conjunto [Castellanos, 2012: 139].

La dimensión subjetiva que se acerca al concepto de felicidad refiere a la percepción individual, que considera una posición relativa del individuo en la sociedad y la fortaleza de sus lazos. La consistencia y la comparabilidad de los índices de bienestar personal subjetivo entre diferentes culturas los han probado como válidos, confiables y sensibles a los valores de escalas psicométricas, pero las diferencias culturales podrían ser la principal dificultad para asegurar comparabilidad entre sistemas de valores distintos [Cummins y Mcpherson, 2005].

El desarrollo del marco de análisis sobre el bienestar subjetivo buscará en adelante resolver estas limitantes desde un marco científico, siempre y cuando no impute un bienestar desde un esquema moral particular. Lo relevante, relata Mariano Rojas, es comprender desde una postura descriptiva y evitar caer en el error de formular juicios desde la posición social del investigador o de un sistema de valores determinado (etnocentrismos, por ejemplo) y, principalmente, debe evitarse la apropiación de la voz de los segmentos sociales estudiados, limitando su capacidad de autorreferir lo que para ellos es relevante al bienestar propio [Rojas, 2011].

En cambio, en muy distinta condición, el bienestar objetivo se refiere al acceso y la calidad de la alimentación, la salud, la educación y otros indicadores asociados con la satisfacción material, por lo general con un ingreso monetario o consumo imputables que permiten medir las condiciones de vida de la población, y, obviamente, no a la percepción que tiene cada miembro de la sociedad sobre su condición de vida (bienestar subjetivo). 
Desde nuestro punto de vista, el registro del bienestar objetivo está íntimamente ligado a la medición multidimensional de la pobreza, estimada en México desde $2008^{2}$ [Coneval, 2019]. Su desarrollo, sin embargo, echó mano de estudios previos para la evaluación de la política social desde la percepción de los beneficiarios. A principios del milenio, en una encuesta realizada por la entonces Secretaría de Desarrollo Social llamada "Lo que dicen los pobres", la respuesta de los encuestados a aquello que mejor describía el bienestar se decantó por la satisfacción de necesidades inmediatas. Con esta información se obtuvo un primer acercamiento para debatir las dimensiones concretas a las que la política social debería enfocarse; dado que se asumía que la política pública en México no sería capaz de resolver la pobreza, las acciones comenzarían por "aquello que los pobres valoran más" [Székely, 2003: 12].

$\mathrm{El}$ enfoque de la pobreza multidimensional incorpora una perspectiva de medición basada en las dimensiones del bienestar económico y en carencias que entran en el orden de capacidades individuales o del hogar, compuestas por acceso a servicios básicos y calidad de la vivienda, así como educación y salud. Algunos criterios previos, como el método combinado, ya incorporaban un flujo de ingresos, satisfactores materiales y elementos de reproducción de capacidades como el tiempo para educación y el tiempo libre [Boltvinik, 2003], por lo que su innovación realmente fue incorporar este método como referente oficial del desarrollo social [Coneval, 2019].

Si bien la metodología de medición de pobreza multidimensional expresa carencias sociales materiales, el umbral que delimita la carencia es en sí una referencia a un estándar social tolerable en relación con los niveles de vida que goza la mayor parte de la población. El cálculo de umbrales para

${ }^{2}$ Cabe señalar que los elementos multidimensionales de la medición de la pobreza en México están consignados en el Artículo 36 de la Ley General de Desarrollo Social de 2004. 
la medición oficial de pobreza introdujo un importante debate sobre condiciones de acceso que terminan acotando y empalmándose con los objetivos de la política social. En una visita a México para hablar sobre la serie de 10 años de medición de pobreza multidimensional en el país, David Gordon hace suyas palabras de A. Atkinson al argumentar que "las mejores medidas sobre pobreza son aquellas cuya medida depende del propósito de la política [...] las medidas de pobreza, umbrales y unidades de análisis no dependen siempre de cuestiones técnicas, sino de los objetivos de política pública" ${ }^{3}$ En la práctica, la referencia de la política social a esta medición, obligada por ley a los indicadores, logró poner en orden el diseño de los programas; no obstante, estrecha la visión y las ambiciones de la propia intervención estatal.

\section{ACERCAMiEntos ReCientes AL BIENESTAR}

Frente a los resultados de la política social de los últimos años y de cara a la emergencia sanitaria causada por el virus SARS-CoV-2, expandido a nivel mundial durante el primer semestre de 2020, el propósito de una medida de bienestar debe reflejar un esquema integral que parta de las necesidades básicas y sirva como instrumento de planeación integral de las intervenciones públicas con efectos profundos. El estudio del bienestar ha considerado fundamentales ambas dimensiones, tanto material como subjetiva, aunque también aprecia valores del contexto para nutrir con un sentido de planeación estratégica la representación de condiciones y condicionantes.

Esta multidimensionalidad, como método combinado, en la actualidad es un ejercicio ya establecido para las referencias

${ }^{3}$ Conferencia "Ten Years of multidimensional poverty measurement in Mexico: Challenges and perspectives" impartida por el doctor David Gordon el 12 de noviembre de 2019 en la Ciudad de México. 
al bienestar. Todos los avances al momento parten de que el criterio de ingresos es insuficiente para explicar el progreso social, también aquellos limitados a las carencias. Los índices más influyentes han sido impulsados por organismos internacionales, aunque existen revisiones y construcciones nacionales con gran valía.

Entre los más relevantes, algunos criterios parecen estandarizar la calidad de vida, las condiciones materiales y una dimensión importante de sustentabilidad a lo largo del tiempo [OCDE, 2011]. Estas dimensiones recogen el debate de la Comisión para Medir el Desempeño Económico y el Progreso Social del gobierno francés que en 2008 encargó a importantes economistas la revisión de indicadores, al margen de los ingresos, con capacidad para reflejar mejor el progreso social en herramientas estadísticas viables, ligando el bienestar con la calidad de vida, que poco podrían reflejar el crecimiento de la producción y los mercados, ni como mera derivación de estos, que dieran cause a las decisiones de política social. Sus recomendaciones mantienen la necesidad primordial de continuar midiendo la actividad económica como fuente de riqueza y empleos, pero reconocen cambios significativos en las dimensiones no económicas por la complejidad que han ganado actualmente la producción, la diversidad de servicios especializados y los mecanismos de distribución que se han adaptado al mundo en que vivimos [Stiglitz, Sen y Fitoussi, 2009].

Para estos autores el bienestar material también debería captarse por lo que se consume y no solo por lo que se produce, dado que refleja un aspecto material de la calidad de vida de las personas. ${ }^{4}$

${ }^{4}$ La participación del Estado es clave para proveer servicios públicos como parte de este consumo y describen ejemplos que indican muy diversas combinaciones entre los servicios públicos y privados para consumo individual, como la educación o la salud, que afectan directamente la calidad de vida de los ciudadanos [Stiglitz, Sen y Fitoussi, 2009]. La forma de medir sus efectos, a pesar de haber crecido de modo considerable después de la Segunda Guerra Mundial, declaran, es claramente perfectible. 
Es importante señalar que tanto la aproximación por ingresos como por consumo, se preocupan por el acceso individual a servicios provistos por entidades públicas. Los efectos de los beneficios sociales son delimitados a beneficios en los hogares. Es decir, su unidad de análisis son los individuos y los hogares. Para medir la calidad de vida, evalúan al menos una de alguna aproximación de carácter subjetivo; 2) la perspectiva de adquisición de capacidades; y 3) la ponderación de las dimensiones no monetarias asignadas con criterios de justicia social. El resultado de este ejercicio fue un importante acercamiento a condiciones de progreso social y económico, que atrajo la atención internacional.

Tan pronto como este ejercicio tuvo eco, el Governance and Social Development Resource Centre (GSDRC) publicó un estudio comparativo de las medidas de pobreza y bienestar multidimensionales más robustas y de uso extendido para ofrecer un panorama actualizado [Haider, 2011]. Entre estos indicadores, se refiere al índice de desarrollo humano, al índice de desarrollo social, al compendio de indicadores de los Objetivos de Desarrollo del Mileno y a los índices de pobreza multidimensional, en los cuales no nos detendremos. ${ }^{5}$

El informe analiza por separado las medidas que incorporan la dimensión del bienestar subjetivo, como el índice de mejor vida de la OCDE y el U-Index, que indica la respuesta de Princeton a la iniciativa de la comisión francesa, como un ejercicio para representar la proporción de tiempo que pasan los individuos en un estado desagradable o no deseable (U por

${ }^{5}$ El GSDRC compara diversos indicadores para la medición tanto subjetiva como objetiva del bienestar así como de la pobreza, con un enfoque multidimensional en línea con la propuesta metodológica de Alkire y Foster [2011a, 2011b]: el índice de desarrollo humano [UNDP, 2019], el índice de pobreza multidimensional [oPHI, 2019], los índices de desarrollo social [IISs, 2018], el índice global de brechas de género [WEF, 2020], el índice de oportunidades económicas de las mujeres [EIU, 2012], el índice de igualdad de género [EIGE, 2019], el índice de felicidad nacional bruta [CBS, 2015], el índice para una vida mejor [OCDE, 2020], el programa de encuestas mundial Gallup World Pool [2006] y el U-Index [Kahneman y Krueger, 2006]. 
Unpleasant-Undesirable). En conjunto, las dimensiones que incorporan estas metodologías abarcan los ámbitos de participación cívica, elementos de cohesión social y libertad de asociación interpersonal. Consideran también la dimensión ambiental, la gobernanza, la percepción de seguridad y la satisfacción con la vida; y, por supuesto, el uso del tiempo libre y el orden balanceado entre el trabajo y la vida personal [Haider, 2011].

Este ejercicio comparativo da un rico panorama de las consideraciones de los principales índices del bienestar y permite observar que su construcción en general considera el ejercicio de derechos de las familias, pero también otras condiciones complejas que solo son visibles en escala regional, como el ambiente, la cohesión y la gobernanza.

En Canadá, se publica desde 2011 el informe sobre el índice canadiense de bienestar ${ }^{6}$ [ciw, 2016], que es tal vez uno de los planteamientos más completos para referir esfuerzos de síntesis en la formalización de medidas del bienestar. Su representatividad es de escala provincial y nacional, y contiene ocho dominios particulares: la vitalidad comunitaria (que describe diferentes situaciones tanto positivas como negativas en el ámbito comunitario), el compromiso democrático, la educación, el ambiente, la salud de la población, el acceso a la cultura y el esparcimiento, así como uso del tiempo y estándares básicos de vida (registrados como el progreso material de las familias). Este último resume las condiciones laborales y el porcentaje de población con bajos ingresos, por ejemplo.

Por último, debe considerarse que el fortalecimiento de los gobiernos de izquierda en Sudamérica durante la transición al nuevo milenio permitió la construcción de estrategias alternativas de desarrollo con visión local, con base en la cosmovisión indígena local y no como un referente latinoamericano

\footnotetext{
${ }^{6}$ Canadian Index of Wellbeing.
} 
per se. Las designaciones "buen vivir" y "vivir bien" son referencias a la traducción de un término similar al bienestar en aymara y quechua, que fueron instrumentadas en el Estado Plurinacional de Bolivia y el Ecuador, respectivamente, como modo de recuperar los valores de convivencia de las naciones indígenas y su coexistencia armónica con el entorno; en especial como alternativa para alzar la mirada a procesos desmercantilizados de reproducción social que el Estado asumió como signo de reconocimiento y representación, dado que las naciones que lo instrumentan se componen de población mayoritariamente indígena. ${ }^{7}$

\section{Estado, BIEnestar social y REPRESEnTación en MÉxico}

Por lo visto, hasta ahora podría plantearse que el bienestar en nuestros días es un estado conjunto que puede representarse desde la dimensión subjetiva hasta la disposición de colaboración y convivencia pacífica entre habitantes en un momento determinado, que no excluye la dimensión de desarrollo material, pero la considera parte de amplios campos de influencia.

Es preciso recuperar dentro del contexto de las propuestas teórico-metodológicas sobre la cohesión social, que en especial considera la dimensión subjetiva, que los lazos de confianza y pertenencia pueden verse desde la referencia a círculos más íntimos hasta ámbitos de interacción indirecta o indeterminada con un "otro generalizado", que abarca ámbitos como la convivencia en el barrio o hasta la idea de todos los connacionales [Mora, 2015].

${ }^{7}$ Algunos trabajos han compilado propuestas y experiencias alternativas, como la compilación hecha por Sempere, Acosta, Abdallah y Ortí [2010]. Estas experiencias también se han vinculado con otros esfuerzos locales de coordinación colectiva solidaria y social que pueden consultarse en las compilaciones realizadas para México, Argentina y Ecuador en: Marañón [2013], Coraggio [2017] y en Castro, Cruz y Vargas [2018]. 
Recientemente en México, eventos naturales, como los terremotos de 2017, han marcado tragedias colectivas que sorprenden a las generaciones más jóvenes con hurras y aplausos idealizados por muestras de solidaridad espontánea, desinteresada. La motivación para colaborar debe ser importante para entender el bienestar social, pero es difícil de cultivar desde una política pública concreta. ¿Podemos confiar en otros como ciudadanos? ¿Podemos pretender desde el Estado que esta confianza surja como un dominio público que puede sembrarse? ¿Podemos cultivar el respeto común a estas normas de confianza para evitar abusos?

Las respuestas atraviesan concepciones básicas de la sociología que han podido encontrar tierra firme en conceptos clave como el capital social ${ }^{8}$ o la cohesión, recién recuperada como cohesión democrática [Sojo, 2017]. En ambos debates, la confianza entre miembros de un colectivo es esencial para mantener la estabilidad en el sistema social. El pacto social con el Estado representa un gozne fundamental entre actores del escenario nacional. Este pacto asimila y resguarda el respeto de las normas sociales. En ambos debates, la equidad y la reciprocidad entre miembros son procesos elementales de autoconservación colectiva. Así, el equilibrio de condiciones entre ciudadanos puede propiciar la disposición a colaborar, por pertenencia, pero requiere el trato equitativo y transparente para mantenerse en el tiempo. ${ }^{9}$ En el pasado, la atención a las necesidades de todos los miembros del pacto legitimaba la acción pública del Estado de bienestar. Los acuerdos sociales tuvieron espacios concretos de actuación que materializaban la pertenencia al colectivo a través de un sistema de

\footnotetext{
${ }^{8}$ Ver principalmente los trabajos compilados por Dasgupta y Serageldin [1999].

${ }^{9}$ Con base en el conocimiento de construcción de capital social, la motivación de participación y confianza requieren mantener un trato recíproco y simétrico, que es a lo que la transparencia y el trato equitativo se refieren, como una condición y no como un hecho normativo. Pueden verse los comentarios breves de K. Arrow en Dasgupta y Serageldin [1999].
} 
protección social. Este sistema fue característico de las sociedades capitalistas, en especial como estrategia de recuperación de la Gran Depresión durante los años treinta del siglo xx, y se basó en el diseño de diferentes estrategias políticas en las que la intervención estatal introdujo una combinación de impuestos de tipo pigouviano con pautas de protección social al empleo y derechos sociales frente al acuerdo con empresas [Galbraith, 1989: cap. 3].

Sin embargo, estos sistemas de intervención no son exclusivos de la recuperación de entreguerras. Gösta EspingAndersen [1990] clasifica los regímenes de bienestar con referencias a procesos históricos y formaciones políticas particulares como: a) autoritarios, del tipo corporativo o basados en la intervención del Estado a partir de cuerpos gremiales, como en la Alemania de Bismarck; b) liberales, del tipo anglosajón, también llamado residual, que se refiere a la intervención mínima del Estado, con la participación de amplios sectores privados en los ámbitos de salud, educación y empleo; y c) el tipo socialdemócrata, que se basa en el modelo escandinavo, donde el sistema de seguridad social es público y ofrece acceso universal a todo individuo como derecho de ciudadanía.

Como bien sintetiza Ordóñez - estudioso de estas transformaciones-, las tipologías del Estado de bienestar reconocen variantes de "un modelo de intervención estatal que con diferente intensidad protege a sus ciudadanos contra los principales riesgos que enfrentarán a lo largo del ciclo de vida” [Ordóñez, 2017: 39].

El régimen de bienestar en México surgió como una plataforma de coordinación social entre cuerpos políticos y gremiales (con espacios de participación y mecanismos de gratificación para cada uno). El crecimiento de un entramado burocrático con alcance nacional, al que también pertenecían los trabajadores de la educación, fue base de su estructura política y económica. Durante la segunda mitad del siglo xx, el Estado fue construyendo gradualmente un sistema de control de 
precios, de intermediación de conflictos y demandas sociales mediante un entramado de pertenencia grupal. ${ }^{10}$

Después de la Revolución mexicana, el Estado buscó legitimar su autoridad ante la sociedad incorporando la demanda de las masas populares y creando espacios de representación que fomentaron la construcción de un andamiaje corporativo. No se trataba de la inclusión de cualesquiera miembros de la sociedad por derecho de ciudadanía, sino aquellas fracciones revolucionarias que ganaron voz y cuyas demandas adquirieron representación durante el levantamiento civil y expresión en el marco institucional nacional. Sus intereses son incorporados en la Constitución de 1917, a través de los derechos sociales contenidos en el Artículo $4^{\circ}$ constitucional, pero también en los artículos 27, 28, 123 y 131, que ofrecen los cimientos institucionales para garantizar y coordinar los sistemas de propiedad, de precios, de protección laboral y de protección comercial [Ayala, 2001; Ordóñez, 2017].

Son estos actores los que consolidaron la formación de un Estado capitalista, sustentado en una clase de trabajadores, campesinos propietarios enclavados en un régimen de propiedad emanada del régimen y propietarios emprendedores o empresarios que se convirtieron en la cabeza del régimen. El régimen emanado de la Revolución, puntualiza A. Córdova [1981: 34], impulsó un desarrollo capitalista basado en la defensa de la propiedad privada y en mecanismos de conciliación entre clases sociales. La acción pública los mantenía ligados al régimen a través de instituciones de atención a la salud, la educación y sistemas de protección social.

Esta construcción es pilar del nacionalismo electoral de los años 20, lo mismo que del nacionalismo económico de la

${ }^{10}$ Aunque no es el objetivo central de este documento, al revisar a Fuentes y Arellano [2019], se podrá ubicar una amplia revisión de las estadísticas oficiales que exhiben la desigualdad (en el sentido de Humboldt como lo explican los autores) que se registró entre 1790 y 1930 a través de los diversos registros y censos que llevó a cabo lo que hoy se denomina Estado mexicano. 
presidencia de Lázaro Cárdenas. El sector público tomó las riendas del crecimiento económico, pero no solo mediante los instrumentos que la Constitución le otorgaba para dirigir la inversión y el crecimiento, sino que logró que la clase política se volviera propietaria de empresas [Ayala, 2001: 98]. A partir del periodo de reconstrucción económica, el modelo permitió el surgimiento de una burguesía nacional al amparo del ensanchamiento del Estado y de los instrumentos de política económica. Por ello se afirma que la relación corporativa del Estado mexicano acotó el fortalecimiento de los sistemas de recaudación y el incremento de la productividad ${ }^{11}$ Los gremios de trabajadores y empresarios se volvieron grupos de presión que exigían subsidios y altas coberturas de servicios, por lo que el sistema de protección social se mantuvo subordinado a un sistema de producción paternalista,${ }^{12}$ señalado como el origen de la ineficiencia en la operación burocrática y en el ejercicio de recursos públicos, inadmisibles en un contexto como el de la crisis de la deuda de los años ochenta.

Buscando combatir esta inoperancia, en la década de 1990 se emprendió un camino distinto del desarrollo y desde entonces se fueron reformando los artículos 27, 28, 131 y más adelante el 123 para establecer un marco de participación de agentes privados, donde el Estado se planta como un ente

${ }^{11}$ Por convención, el referente de los sistemas más avanzados de protección social es el modelo socialdemócrata escandinavo, que requiere altas cargas fiscales como contraparte. Para alcanzar sus metas de cobertura y atención es necesario un sector privado que genere empleos de calidad y que retribuya en impuestos los beneficios indirectos de pertenecer a una esfera de paz social y productividad [Ordóñez, 2017]. Es decir, su realización es viable en una sociedad con altos ingresos salariales, que también retribuye impuestos, con los cuales se financian servicios públicos de calidad, como educación y salud.

${ }^{12}$ El paternalismo se entiende como una pretensión de dominio; la intervención autoritaria para regular la vida y el trazo de una comunidad o una nación [Alemany, 2005]. El mayor debate sobre esta tentativa se vuelca sobre la defensa de la autonomía y la libertad de los individuos desde la filosofía utilitarista [Santana, 2016] y su efecto sobre la economía es signo de ineficiencia y concentración de riqueza. 
vigilante, mas no coordinador de los emprendimientos [Ayala, 2001; Ordóñez, 2017].

A partir de 1997, con el surgimiento del Programa de Educación, Salud y Alimentación (Progresa), el Estado mexicano inauguró una etapa de focalización de la política social, como estrategia transitoria para confrontar el empobrecimiento masivo que despegó como consecuencia acumulada de la crisis de 1994 y anteriores, con un estricto control en la ejecución del gasto. Con base en datos del Coneval, en particular entre 1994 y 1996, la pobreza patrimonial se expandió casi 17 puntos porcentuales, mientras que el porcentaje de mexicanos en situación de pobreza alimentaria pasó de $21.2 \%$ a $37.4 \%$, es decir, casi se duplicó. ${ }^{13}$ En ambos casos, tuvieron que transcurrir ocho años, hasta 2002, para retomar los niveles previos a la crisis de 1994.

La adhesión del país a marcos internacionales también permitió que el gobierno mexicano reconociera un entramado de derechos humanos. Es decir, derechos que no otorga el Estado, sino que solo reconoce por principio, pues recaen en el ciudadano [CNDH, 2016]. La reforma consecuente del Artículo $1^{\circ}$ logró este reconocimiento. La posterior reforma del Artículo $4^{\circ}$ fortaleció el reconocimiento de derechos sociales. ${ }^{14}$

En el último piso de la estructura que resulta de estas reformas, el Estado mexicano se despojó formalmente de un sistema de protección social residual, aunque con prácticas

${ }^{13}$ Consultado el 1 de marzo de 2020, <https://n9.cl/n8mqu>.

${ }^{14}$ Los derechos humanos son reconocidos por la Constitución Política de los Estados Unidos Mexicanos y en sus leyes secundarias. En 2011 se publicó en el Diario Oficial de la Federación una modificación al Artículo $1^{\circ}$ que reconoció los principios de universalidad, interdependencia, indivisibilidad y progresividad de los derechos humanos [CNDH, 2016]. Además, reconoció los instrumentos jurídicos internacionales que hasta entonces "guardaban una jerarquía menor a los nacionales" [Arroyo, 2018: 95]. Aunado a lo anterior, el Artículo $4^{\circ}$ señala que se reconocen como derechos sociales: la protección a la salud, la vivienda digna y decorosa, la alimentación nutritiva y de calidad, además de un medio ambiente adecuado para su desarrollo y bienestar. 
corporativas de facto, a uno avanzado, aparentemente de tipo socialdemócrata, sin la capacidad fiscal ni operativa para garantizar el servicio universal de salud, educación y protección social; a pesar de ello, algunos servicios comenzaron a ser transferidos a la oferta de mercado, sin que por ello se garantizase que la combinación de oferta pública y privada lograra una complementariedad de la demanda de estas dimensiones del bienestar como consumo satisfecho de servicios públicos. Además, las brechas de calidad y alcance entre ambos sectores profundizan las diferencias sociales [Ordóñez, 2017].

Es decir, el reconocimiento de derechos humanos en la Constitución estableció una pretensión de universalidad de los sistemas de protección, si bien el diseño actual de los sistemas de protección social y la operación complementaria de sus mayores proveedores de servicios, como el IMss, el ISSSTE, el Ejército y la Marina, se constituyen como derechos derivados de adscripción. Fuera de estas instituciones, la provisión de servicios busca complementar la demanda, aunque sin una coordinación general y sistémica esta continuará siendo residual. Un servicio de calidad universal requeriría un giro drástico al diseño y una carga tributaria alta y estable de largo plazo, con las condicionantes y limitaciones que ello representa.

Más aún, los servicios adquiridos por derecho derivado (como la adscripción laboral) son provistos en condiciones de precariedad y en relativa rivalidad con los servicios privados. La competencia entre los servicios públicos y los privados atiende al sector formal del empleo y de la producción. Por otro lado, la precarización de empleos y la expansión del empleo informal desde el primer sexenio del siglo xx fueron objeto de un sistema de protección residual, aunque monumental, que profundizó la estratificación y las diferencias de acceso, calidad y disponibilidad en el ejercicio de derechos. El avance en diseños de política que resuelvan de modo terminante esta problemática requerirá información precisa y los indicadores que captan estas brechas de acceso reflejan disparidades sociales, mas no una medida 
efectiva contra los mecanismos de discriminación que se han normalizado [Rodríguez, 2018].

En este contexto, en noviembre de 2019 se publicó la conformación del Instituto de Salud para el Bienestar, ${ }^{15}$ el cual, según el Artículo 77 bis 35, tendrá por objeto proveer y garantizar la prestación gratuita de servicios de salud, medicamentos y demás insumos asociados con las personas sin seguridad social, así como impulsar, en coordinación con la Secretaría de Salud, en su calidad de órgano rector, acciones orientadas a lograr una adecuada integración y articulación de las instituciones públicas del Sistema Nacional de Salud. Lo anterior constituye un reto de amplias dimensiones para el Estado mexicano en el mediano y largo plazos.

Lo cierto es que el sistema de derechos derivados del corporativismo, respaldados en la incorporación de demandas del sector obrero y agrario de la Revolución, sostuvo los derechos sociales sujetos a una dinámica de crecimiento y empleo formal. La reforma constitucional de 2011, antes aludida, enuncia una universalidad, que deja espacio a la oferta de servicios privados, consciente de una diferenciación en la calidad y el costo de servicios, que es una manifestación de la estratificación en la ciudadanía, sin considerar la supervisión, el control, la integralidad o la coordinación de la oferta, para asegurar complementariedad y no competencia en los ámbitos sociales de la salud, la educación y los sistemas de previsión social.

Aunado a los anteriores planteamientos, entre marzo y abril de 2020 se realizaron los procedimientos jurídicos para reformar el Artículo $4^{\circ}$ de la Constitución Política de los Estados Unidos Mexicanos, donde se han incluido de manera sintética los siguientes programas sociales con garantía presupuestal federal: pensiones para adultos mayores de 68 años y para población indígena mayores de 65 años de edad, transferencias de dinero para personas con discapacidad con prioridad

${ }^{15}$ Consultado el 1 de marzo de 2020, <https://n9.cl/8fqg2>. 
a mexicanos menores de 18 años e indígenas de hasta 64 años, becas para estudiantes de todos los niveles que viven en condiciones de pobreza y atención médica gratuita para aquellos que no gocen de protección social. Lo anterior, representa jurídicamente un fuerte cambio de paradigma en las últimas cuatro décadas de la política pública del Estado mexicano.

La retracción del Estado a partir de las llamadas reformas estructurales, que fundamentaron la estrategia de desarrollo basada en el crecimiento de mercado, distrajo los avances en el sistema de protección social y, en consecuencia, redujo la habilidad del sistema para proteger a la población de riesgos, como el desempleo y el empobrecimiento, que ante la incapacidad de lograr altas tasas de crecimiento económico, ya no volvió a recuperar.

En ese entendimiento, ¿podemos saber si era bienestar lo que el Estado generaba al fortalecer su autoridad?, ¿cómo podría lograrlo en el contexto actual? Se adujo que el paternalismo estatal restaba a la sociedad capacidad de innovación y libertad, pero surge la interrogante de cómo lograr que la organización social actual active mecanismos de protección contra riesgos diversos. La contingencia sanitaria por el contagio de covid-19 en 2020 muestra la relevancia de por qué a todos los sectores sociales debería importarles la incapacidad colectiva de contener los riesgos de salud.

Desde la década de 1990 se ha insistido en que la recuperación económica y el rumbo del crecimiento deberían hacerse acompañar por una mezcla de políticas de protección social e impulso productivo. ${ }^{16}$ Para lograr un desarrollo integral y equi-

${ }^{16}$ Stiglitz y Pleskovic [1997], entonces jefe de economistas del Banco Mundial, argumentó que la crisis de la deuda inclinó la atención a que el crecimiento solo era posible en un ambiente macroeconómico estable sin intervención; sin embargo, el mercado y los gobiernos deben verse como complementos. Defendió la necesidad de una regulación financiera, inversión en capital humano y cualquier medio para formar infraestructura, siempre y cuando también funcionen estrategias de combate a la pobreza y equidad en el bienestar total. 
librado, el Estado debe ser capaz de coordinar los intereses de todos los sectores mediante un trato simétrico, pero también debe contar con las instituciones adecuadas, que no siempre son de mercado. ¿Puede lograrse un bienestar social sin el aparato estatal que se tuvo desde los días de posguerra o antes?

Preocupados por el marco de crecimiento económico, en diferentes momentos autores como J. Stiglitz [Stiglitz y Pleskovic, 1997; Stiglitz, Sen y Fitoussi, 2009], H. J. Chang [2011] y D. Rodrik [2011] argumentaron que las reformas económicas que se enzarzaron en las fuerzas del mercado al fin del siglo xx de ningún modo serían suficientes para lograr un desarrollo robusto. Para Stiglitz, ninguna postura dogmática aseguraba los mejores resultados y recomendó, en consecuencia, que las naciones usasen los mercados a su favor, sin cancelar el camino para que los gobiernos se hicieran cargo de externalidades y otras fallas [Stiglitz y Pleskovic, 1997: 21-23]. Al plantear que en esa ruta las agencias financieras internacionales podían ayudar a colocar recursos en préstamo y a establecer el entramado institucional que requieren los países en desarrollo para atraer capitales, Stiglitz

Entre las críticas más profundas a la primera ola de estrategias de desarrollo apegadas a la apertura comercial y financiera, H. J. Chang [2011] revisó los procesos históricos de industrialización exitosos y recomendó perseguir sistemas que permitan afrontar mejor los riesgos de mercado y otros. Su preocupación se centró en los mecanismos de fomento de nuevas actividades productivas con mayor valor agregado, para lo cual insistió en crear un organismo de instituciones funcional al objetivo de actualizar la función de las economías en el mercado mundial. Pero son estas instituciones un sistema de reglas tan complejo que deben iniciar con políticas focalizadas en sectores específicos combinadas con instituciones que permitan socializar el riesgo de las inversiones novedosas [Chang, 2001: 195-198].

Por su parte, D. Rodrik [2011] planteó un interesante análisis entre los resultados de políticas de crecimiento económico frente a las recomendaciones adoptadas por el llamado Consenso de Washington. Al discutir sobre las principales condicionantes concluyó que aunque los mercados están incrustados en esas instituciones sociales (como los marcos jurídicos que dan certeza a la celebración de contratos y a la defensa de la propiedad privada), también deberían fortalecer aquellas que dan estabilidad y continuidad al sistema social pero existen, insiste Rodrik, para atender necesidades sociales y políticas y pueden incluso limitar "el libre actuar de fuerzas del mercado" [Rodrik, 2011: 222-226]. 
definió que este entramado era finalmente un "bien público", por lo que no podría esperarse que el sector privado proveyera ayuda adecuada para su establecimiento [Stiglitz y Pleskovic, 1997: 26].

Por ello, H. J. Chang [2011] recomienda que las políticas de desarrollo productivo vean más allá del costo-beneficio individual de las inversiones, dada una posible "discrepancia con los beneficios sociales". El éxito de las políticas de innovación, sentencia, "depende del diseño específico de las medidas y de la habilidad y voluntad del Estado de ponerlas en práctica" [Chang, 2011: 195-198]. Así, lo importante de una política de crecimiento económico no solo sería la atracción de capitales mediante un marco jurídico que respaldase las transacciones, sino la persecución de un beneficio colectivo. En una postura similar, D. Rodrik [2011] señala que las reformas de impulso comercial y productivo apegadas al Consenso de Washington pusieron poca atención en los mecanismos de protección y previsión social. Estos son arreglos institucionales fuera del mercado que los economistas dan por sentado, pero sirven para legitimar y estabilizar la función del mercado en el desarrollo. Para ello, insiste, conviene diseñar estas instituciones desde sistemas políticos democráticos, participativos, porque el sistema económico debería propiciar instituciones de protección social adecuadas a las necesidades locales para hacer a la sociedad más resistente a choques externos. Es decir, diferentes marcos de análisis desembocan en que se requiere una configuración de reglas, prácticas, mecanismos de atención y espacios de participación que, junto con los mercados, se erija como un órgano de socialización de riesgos que permita a los privados obtener el mayor beneficio, pero también construir una suerte de beneficio colectivo.

\section{EL BIENESTAR SOCIAL EN CONTEXTO}

Con las reformas constitucionales de 2011, México asimiló en su entramado normativo un marco de derechos humanos por 
el que el Estado se obliga a agotar los recursos a la mano para garantizar accesibilidad, calidad y disponibilidad en los mecanismos para ejercer derechos de manera progresiva [Vázquez y Serrano, 2013]. La capacidad de intermediación de demandas, que antes fortalecía la presencia del Estado, ahora se delimita en una agenda universalmente aceptada para resolver rezagos sociales, mas no limita una línea estratégica frente al desarrollo que minimice la participación del Estado.

La construcción de indicadores de carencias sociales define, en general, a los grupos de población vulnerable. Esta vulnerabilidad "social" se refiere a la dificultad individual para enfrentar riesgos, por ejemplo, por un deficiente suministro de servicios, insuficiente infraestructura o un rezago en capacidades. Si bien el Estado tiene la obligación expresa de garantizar los mecanismos de acceso universal, su capacidad de intervención efectiva se ha visto agotada y, además, requiere esquemas de intervención que superen los alcances del esquema de atención focalizada. Desde 1997, el gobierno mexicano comenzó a sentar las bases de la política social focalizada por necesidades. Desde entonces la proporción de población en condiciones de pobreza ha visto redundar las cifras sin una acción de erradicación contundente de la pobreza más profunda.

La población en pobreza y con carencias es vulnerable a los efectos adversos del lento crecimiento, pero también es vulnerable a desastres por eventos naturales, como inundaciones, sequías, terremotos e incluso epidemias. En estos casos se incrementa el desempleo y se acentúa la incapacidad de ahorrar o enfrentar riesgos a la salud. Los riesgos son contabilizados como la suma de vidas y pérdidas individuales, pero tienen secuelas en el bienestar colectivo. Un ejemplo importante es la emergencia registrada en el transcurso de 2020 en todo el mundo y que muestra que la vulnerabilidad por acceso deficiente a servicios de salud es mayor para los segmentos de población en pobreza, pero traspasa el bienestar de la sociedad en conjunto. Del mismo modo en que las sociedades 
debieron coordinar los cuidados para la emergencia sanitaria reciente, la capacidad misma de protección de estos derechos se trata de una construcción cotidiana que debe cambiar la dinámica social y política de nuestra era. Por lo anterior, resulta imperativo que se discuta y analice la capacidad para enfrentar riesgos, y la protección de los derechos de cada individuo en una sociedad debe ser preocupación de todos los miembros de la sociedad.

Las metas de equidad social requieren que las capacidades adquiridas por cada miembro de la sociedad funcionen para bien del conjunto social. El pacto social entre la sociedad y el Estado ha honrado su origen liberal centrado en la propiedad privada pero, de acuerdo con nuestra Constitución Política, debe resguardar los derechos fundamentales de todos sus ciudadanos. Así, la idea central de Adam Smith sobre la suma de contribuciones individuales al valor de lo producido en la sociedad, que es base de la riqueza nacional, también lo es del bienestar en sentido amplio. El capital humano (en el sentido de Becker) ${ }^{17}$ es la habilidad adquirida por los individuos para ser productivos, aunque asume la combinación activa de capacidades individuales y condiciones de acceso que sirvan como vehículo para aportar al conjunto social mediante empleos productivos. La atención a las carencias por rezago educativo y por servicios de salud es un principio importante para el desarrollo del capital humano, pero no debe olvidarse que el bienestar social demanda que la construcción de capacidades productivas vincule en paralelo las capacidades individuales con un ciclo de crecimiento de empleos formales bien remunerados. Es esta una capacidad colectiva, que depende del esfuerzo conjunto, lo que el Estado debe garantizar.

${ }^{17}$ De acuerdo con Becker, "el determinante principal del estándar de vida de un país es cómo tiene éxito desarrollando y utilizando sus habilidades, conocimiento, salud y hábitos de su población” [Becker, 1995:1]. Para mayor referencia en torno a este concepto, consultar Becker [1984]. 
Otra referencia a la atención conjunta de vulnerabilidades puede revisarse entre la salud y la disposición de servicios médicos. La cobertura básica como suma de capacidad de atención individual es necesaria y un debate vigente. La prevención de riesgos a la salud, como la obesidad y las adicciones, que anteceden la adquisición de enfermedades crónicas, podría lograrse como la suma de tres ángulos fundamentales: el fomento de hábitos individuales y conocimiento, la disposición de servicios públicos de calidad y un entramado institucional que permita al Estado coordinar un enfoque transversal en la oferta de servicios (públicos y privados). El conjunto puede ser considerado una capacidad social para enfrentar el riesgo de padecer calamidades (individual y colectivamente) y no solo como resultado de una focalización de carencias individuales.

La construcción de un sistema de protección social más avanzado no necesita retroceder en los logros del sistema democrático y federal nacionales, requiere formar habilidades de prevención, capacidad de intervención de los servicios sin acentuar las disparidades sociales y el desarrollo de competencias de reacción de la esfera pública. Los servicios de atención pública pueden ser universales con altos cargos fiscales o bien combinar sistemas de co-aseguramiento con subsidios progresivos que aseguren el diferencial de costos, pero no el diferencial de calidad de servicios. ${ }^{18} \mathrm{Al}$ enunciar carencias de

${ }^{18}$ Frente al inevitable proceso de envejecimiento poblacional observado en Japón en las últimas décadas, la expansión de servicios de atención y cuidado desde los años 80 ha evolucionado desde estrategias de cobertura universal gratuita a un sistema de coaseguramiento contributivo que promueve el crecimiento de instalaciones y servicios de cuidado en casa progresivamente subsidiados. El Estado subsidia el aseguramiento de los beneficiarios, pero no costea el total del servicio. La expansión ha requerido también atender estrategias de prevención de enfermedades previa al envejecimiento para reducir la carga total de costos fiscales. El resultado es un sistema preocupado por guiar a un envejecimiento activo basado en el usuario y respaldado por un sistema de aseguramiento social subsidiado progresivamente con fondos nacionales, municipales y cuotas individuales, que permite la competencia entre proveedores, pero asegura calidad y accesibilidad [MHLW, 2016]. 
población vulnerable, los riesgos son casi evidentes, pero no suelen enumerarse. Debe distinguirse entre la descripción de carencias y la definición de aquello a lo que las personas son vulnerables. Se propone que el estudio de las desigualdades sociales en un marco de bienestar debe identificar tres fases del riesgo: a) exposición a las causas sociales que limitan el manejo de riesgos, entre las que puede verse el desempleo crónico o la exclusión por lugar de origen; b) las carencias específicas de la población identificada por rezago educativo o carencia de acceso a agua potable, por ejemplo; y c) la capacidad de acceder a un sistema de protección de estos riesgos mediante acciones focalizadas o coordinadas, de manera que se comprenda el tipo de acciones que es necesario impulsar.

De cara a la emergencia sanitaria que vive el mundo en 2020, mientras se escriben estas páginas, queda expuesto que la salud precaria de una persona pone en riesgo de contagio a otras alrededor, aunque las demás cuenten con acceso a servicios médicos y tengan mejor probabilidad de recuperación. Las causas de la vulnerabilidad de la salud de toda la población deben importar a la sociedad en conjunto.

Sin pretensión de verdad generalizable, la pobreza puede plantearse dentro del marco de riesgos que un Estado de bienestar podría administrar de manera colectiva. Si el fin último de la política social, o incluso el objeto sustancial del contrato social, es dirigir la construcción del bien colectivo, entonces la vulnerabilidad por salud implica desprotección individual si las condiciones y el contexto social no son propicios (pobreza en individuos o familias). ${ }^{19}$ No obstante, se torna un

En Suecia, por otro lado, el sistema de cuidados para adultos mayores ofrece un servicio preventivo universal, cuidado opcional en domicilio y transporte para personas con discapacidad y pensión, con altos subsidios estatales y cuotas no mayores de $4 \%$ del costo total del servicio para los usuarios [Gobierno Sueco, 2018].

${ }^{19}$ La utilidad de definir la pobreza como una batería de necesidades básicas insatisfechas desde la perspectiva individual marcó una diferencia; se estableció una pauta de la discusión sobre la medición de pobreza. 
riesgo colectivo si la salud de cada miembro de la sociedad reta la capacidad de mantener sano al conjunto presionando la capacidad operativa de respuesta por cobertura o por cargas fiscales. Valdría la pena iniciar estudios, por ejemplo, acerca de si una combinación de afectaciones subjetivas o carencias objetivas tiene implicaciones en el bienestar colectivo. La pista se encuentra en los niveles de violencia o en la disposición de redes de apoyo y confianza.

Del mismo modo podrá reflexionarse en torno a los riesgos que implican la contaminación ambiental o padecer un desastre natural. En México, se cuenta con avanzados mapas de riesgo por sequía, inundación, terremoto y erupción volcánica, pero también se sabe que estos riesgos se acentúan frente a condiciones de pobreza e infraestructura precaria. Los riesgos son sociales dado que el costo fiscal de rescatar zonas productivas y el ingreso de personas frente a una contingencia puede llegar a ser alto. Las estrategias de prevención e infraestructura son por ello de interés público. La planeación estratégica y transversal del bienestar debería ser sensible a estos riesgos al examinar alternativas y costos al diseño de política púbica, aunque es verdad que la disponibilidad de información y la capacidad de considerar estos elementos haría interminable el diseño de intervenciones públicas.

Otro ejemplo puede verse en el desplazamiento por violencia. El hecho viola derechos básicos de la población expulsada, pero también presiona la disponibilidad de vivienda, servicios y empleos de la región receptora, por lo que el interés por mecanismos de pacificación y desarrollo social es de interés nacional, similar a lo que hoy ocurre en Tapachula, al sur del país. Es esta una de las principales razones por las que el bienestar colectivo debería considerar la coordinación del riesgo tanto en dimensiones individuales como colectivas.

En términos llanos, la preocupación por agregar efectos de indicadores focalizados ha limitado la visión integral de los problemas sociales nacionales, en la que el beneficio conjunto 
es aún mayor que la suma de las partes, pues también los riesgos del conjunto son mayores que los individuales. Además, los costos de oportunidad individuales, sumados, serán siempre mayores que la solución integral. Así definido, el bienestar tomaría el perfil de una externalidad, más que un catálogo de acciones

Para la sociedad en conjunto puede valorarse el costo de oportunidad y el costo económico de mantener un ambiente institucional propicio para el desarrollo de tecnología, capital humano e inversiones productivas. En igual grado es necesario propiciar paz social, compromiso y capacidad de coordinación del Estado. Las consideraciones alrededor de condiciones políticas y sociales favorables a la inversión han sido ampliamente estudiadas. ${ }^{20}$ Los costos individuales asociados a la protección social también requieren reflexión frente a la violencia que atraviesa el país. Estas son bases para afirmar que tanto

${ }^{20}$ El Informe de Desarrollo del Banco Mundial (2017) ofrece un acercamiento a los marcos institucionales democráticos y las condiciones de paz, las cuales son condiciones que impactan en el desarrollo económico. Para ellos, algunos riesgos que enfrenta la población son sistémicos y, por ende, colectivos. La definición de niveles tolerables de riesgo requiere un proceso político para decidir qué margen de riesgo la sociedad permite hacer cargo al mercado y qué parte puede encarar la intervención pública. Estos procesos están definitivamente vinculados con la gobernanza [Banco Mundial, 2017: 80].

Similar a la competitividad sistémica, el concepto elemental acuñado por M. Porter enfatiza que la ventaja competitiva se vincula y depende de un contexto nacional favorable. Para desarrollarlo es necesario mantener un sistema de valores, instituciones, arreglos políticos y sociales que favorezcan la disposición de colaboración entre sectores sociales y actores económicos [Grant, 1991]. El desarrollo de condiciones favorables para la competencia demanda el acceso a mano de obra calificada, como factor productivo, además del desarrollo adecuado de instituciones y ambientes seguros. Esta formación debe construirse continuamente y requiere condiciones de estabilidad social, cohesión e inversiones en infraestructura y servicios.

Por el contrario, entre marzo y julio de 2018 en México, empresas como Femsa, Pepsico y Bimbo cerraron operaciones en el estado de Guerrero por el nivel de inseguridad, que afectó las rutas de distribución de productos y sufrió extorsiones. Pueden consultarse notas periodísticas en Animal Político [2020], Celis [2018] y Reyes [2018]. 
la paz social como la seguridad se transforman en una capacidad colectiva que atraviesa la cohesión, los mecanismos para resolver conflictos, la generalización de valores de reconocimiento y respeto, así como el acceso equitativo a diferentes servicios y derechos.

La capacidad de resiliencia frente a eventos naturales o el manejo de emergencias, como la sanitaria actual, destaca si se considera la disponibilidad de infraestructura, junto con la suma de capacidades individuales, la disposición de colaboración y la capacidad de coordinación del Estado en todos los niveles de gobierno. De modo que el logro conjunto de estos elementos es un objetivo enterrado del Bienestar. Aquello que perseguía el Régimen de Bienestar a través de pactos sociales y un marco de servicios públicos que buscaban garantizar derechos sociales desde un margen de cooperación consciente de su capacidad de proteger riesgos de manera colectiva, coordinada e incluyente.

A la luz de lo anterior, no es arriesgado estudiar si la concepción de bienestar reúne las características de un bien público, compuesto en sus ámbitos esenciales como una combinación de capacidades individuales, una habilidad de coordinación social del Estado y disponibilidad de infraestructura en un momento determinado. La acción simultanea de esos elementos propicia externalidades que, al fortalecerse, proponemos, también incrementan un beneficio colectivo indivisible, no rival y no excluyente..$^{21}$ Esta caracterización, de

${ }^{21}$ Formalmente los bienes públicos se definen como efectos indivisibles, cuyo goce no rivaliza con la posibilidad de consumo de otros, ni tiene posibilidad de limitar o excluir a otros de su aprovechamiento. El beneficio externo de esta última característica dificulta su aprovechamiento por mecanismos de mercado y pierde incentivos para asumir el costo privado de su producción o conservación. La provisión de estos bienes por lo general corre a cargo del Estado, que encuentra la dificultad de cuantificar el beneficio social que generan [Musgrave y Musgrave, 1992]. Por otro lado, cuando la disponibilidad de algunos bienes o recursos comunes en el largo plazo adquiere rivalidad por consumo irracional o por contaminación, su consumo corresponsable se torna imposible, a lo que Hardin llama "la tragedia de 
hecho, permitiría agrupar también la idea de desarrollo social en un marco jurídico que busca garantizar accesibilidad, disponibilidad y calidad de los derechos sociales bajo los principios de indivisibilidad, universalidad, interdependencia y progresividad.

De hecho, la desigualdad de trato, las asimetrías en la distribución de oportunidades o en la asignación de infraestructura entre diferentes grupos sociales, cuando son parte de un proceso de discriminación o exclusión, contravendrían el principio de inalienabilidad, despojando a otros del derecho de gozar plenamente de un aspecto del bienestar. Si del goce de un servicio público o un bien de uso común se excluye a un sector de población, por asimetrías de poder en una sociedad, entonces nos acercamos a señalar la desigualdad como un límite a la construcción del bienestar colectivo o bienestar social.

La idea de coordinación y colaboración colectiva de Ostrom [2015] para inhibir la tragedia de los comunes colabora con esta propiedad. La intervención del Estado justo como centro de coordinación social abona, en ambos casos, a un estricto sentido de simetría que permite la conservación y explotación racional de bienes comunes, pero también la construcción de un bienestar social, que podemos entender como capacidad colectiva para enfrentar riesgos.

Por esta vía también se fortalece nuestra postura: las mediciones de pobreza son al menos tan importantes para reconocer las carencias puntuales, la incidencia y la profundidad de la pobreza, como lo sería un atributo de agregación que

\footnotetext{
los comunes". Muchos recursos naturales, como el agua o el aire, son de uso común y de difícil restricción. Los costos externos de su contaminación elevan el costo de cuidado, que también requiere el esfuerzo colectivo, dado que el costo de conservación privado se vuelve inalcanzable. La solución que propone Hardin es privatizar los recursos; la solución de Elinor Ostrom requiere participación colaborativa, que podría estar limitada por normas y reglas aprendidas. La cooperación para compartir bienes comunes es una solución de juego para estabilizar la explotación racional que busque evitar externalidades negativas [Ostrom, 2015].
} 
refiera a un componente colectivo, que requiere una intervención estatal equitativa y justa tal que delimite una asignación de recursos a lo largo del tiempo para crear y mantener en operación la infraestructura y los servicios públicos en favor de garantizar calidad, accesibilidad y disponibilidad de cada derecho. La diferencia del enfoque es que esta provisión, en estricta indivisibilidad, admite márgenes de interacción con el sector privado, pero necesita la coordinación de una visión integral de largo plazo para ser efectiva.

\section{CONSIDERACIONES PARA UNA MEDICIÓN}

DEL BIENESTAR SOCIAL

A lo largo de este libro se encuentran ejercicios de medición del bienestar que consideran enfoques de corte productivo, ambiental, socioespacial y laboral. La revisión que emprendemos en este capítulo, como propuesta conceptual, trata de establecer una referencia para el debate de aquello que las propuestas metodológicas expresan. En todos estos prevalecen dimensiones objetivas subyacentes, pero también aquellas vinculadas con la subjetividad de los individuos. En los últimos años, el bienestar subjetivo ha logrado un impulso importante en el debate académico conforme supera barreras metodológicas para construir indicadores robustos y comparables [Veenhoven, 2001; Stutzer y Frey, 2006; Rojas, 2011]. Las aproximaciones a sistemas de valores compartidos que motivan actitudes de confianza, solidaridad y disposición de colaborar (que incluyen la disposición a invertir), como la cohesión social, la gobernanza o la propia competitividad, podrían aproximar la capacidad de coordinación del Estado.

Otras dimensiones contextuales, como disponibilidad, calidad, frecuencia o distribución de infraestructura y servicios, también son indicadores que reflejan procesos de coordinación 
en la asignación justa de recursos y ofrecen una idea de construcción de capacidades colectivas. ${ }^{22}$

Será forzoso entender el bienestar objetivo como una condición colectiva, no solo individual, ligada a un régimen de bienestar, que lo rige a través de la política pública tanto para el bienestar de los miembros de una sociedad como para el avance y desarrollo productivo. En resumen, esa combinación de políticas públicas que privilegie el bienestar (cercanas a la concepción convencional del Welfare State o Estado de bienestar) es la que puede ofrecer propuestas para el florecimiento humano (bienestar objetivo y bienestar subjetivo). Dejando abierto el debate para construir una definición, esta debe señalar con claridad el contenido de derechos y aspiraciones que envuelve un proceso de construcción colectiva.

En un sentido similar, la referencia de la medición de pobreza en población vulnerable podría perder sustancia sin indicar qué tipo de derechos vulnera cada una de las carencias que sufre la población en particular. Una definición clara del bienestar debería progresar hacia la indicación de los riesgos asociados, así como a la definición de metas de política pública, que siempre necesita inversiones y servicios públicos, aunque también debe acompañarse del crecimiento económico para lograr un cambio.

La configuración de un régimen de bienestar en el siglo XXI demanda trascender delante de la focalización de necesidades insatisfechas. Por un lado, las vulnerabilidades son una cara de la moneda: señalan que una población es incapaz de conseguir los medios básicos para resolver funciones diarias; deberá reconocerse que, además, se encuentra un riesgo de empeorar

${ }^{22}$ Algunos ejemplos se encuentran en Lucas [2012] y Akerkar, Joshi y Fordham [2016] quienes exponen cómo la distribución equitativa de servicios de transporte, frecuencia y calidad en Australia representan limitaciones para la distribución. Coneval, en México, cuenta con un avance de la distribución geográfica de carencias sociales por escala municipal, así como una estimación para áreas geoestadísticas básicas que muestra las desigualdades territoriales. 
su situación frente a contingencias individuales o colectivas, tal como define Esping-Andersen los riesgos en cada etapa del ciclo de vida. Por otro lado, la suma de riesgos normalmente se representa como incidencia de carencias individuales, que son también riesgos colectivos. La argumentación en este capítulo apunta de manera enfática a considerarlo también como un riesgo colectivo.

Dado que, con base en lo definido por la Ley General de Desarrollo Social, el desarrollo social se interpreta como la suma de un catálogo de derechos sociales, los cuales también son peligrosamente equiparados al bienestar. Debe trabajarse aún para llenar los vacíos que implican tantas concesiones. Una opción aquí presentada es avanzar en su representación como bien público, considerando el efecto colectivo y no solo la agregación de derechos satisfechos o de beneficios privados que observen los mecanismos necesarios de inclusión. Considerar esta característica ayudaría a apuntar los esfuerzos para construir un plano observable del debate moral que pioneros como A. Pigou comenzaron por reconocer formalmente.

El debate sobre agregación es esencial para el diseño de políticas y la evaluación de resultados. Si hoy por hoy las políticas deben tomar un diseño restringido al plano individual, con plena confianza de que la suma de las partes refleja el efecto agregado total de la intervención pública, es imperativo avanzar en la medición de efectos colectivos para mostrar la bondad de esta concepción. En ese caso, la representación de capacidades, bienes y servicios coordinados por una oferta pública y privada hará énfasis en el efecto combinado y en los mecanismos que garanticen un acceso equitativo.

Esta visión colectiva es potencialmente un diseño de protección social capaz de responder a una sociedad con alta informalidad laboral, baja productividad y bajos ingresos; es el mecanismo de bienestar social que deberíamos observar en el futuro, que no dependa, pero engarzado con, una estrategia de desarrollo productivo. 
Sin lugar a duda estamos ante un cambio de paradigmas socioeconómicos, en otro momento de cambio en la relación de las fuerzas sociales y en el peso de actores políticos y económicos. La retracción del Estado en los ámbitos económicos y sociales de años recientes limita la intervención estatal directa y demanda tomar estrategias indirectas para coordinar agentes relevantes, que provean servicios y encabecen transformaciones (sociales y productivas). El Estado de bienestar del siglo XxI debe iniciar por reconocer que su estructura fiscal y su relación con los mercados lo orilla a coordinar esfuerzos entre actores y niveles de gobierno; también a proveer servicios y transferencias, pero más a conseguir que los agentes del crecimiento económico comprometan el respeto de derechos y condiciones de trabajo. La construcción de capacidades colectivas en servicios, provisión de empleos, reducción de riesgos de violencia, de desastre y otros, requiere la colaboración de todos los sectores en un ejercicio civilizatorio al tiempo global.

\section{REFERENCIAS}

Akerkar, S., P. C. Joshi y M. Fordham [2016], "Cultures of entitlement and social protection: Evidence from Flood Prone Bahraich, Uttar Pradesh, India”, World Development, 86: 46-58.

Alemany García, M. [2005], El concepto y la justificación del paternalismo, Tesis, Facultad de Derecho de la Universidad de Alicante, España.

ALKIRE, S. y J. Foster [2011a], "Counting and multidimensional poverty measurement”, Journal of Public Economics, 95(7-8): 476-487.

[2011b], "Understandings and misunderstandings of multidimensional poverty", Journal of Economic Inequality, 9(2): 289-314. 
Animal Político [2020], "Bimbo suspende distribución en siete rutas de Acapulco, Guerrero, por inseguridad", Animal Político, 20 de julio, <https://n9.cl/9zow7>.

ARroyo, I. [2018], "Desafíos metodológicos para la medición de la pobreza en México desde el enfoque de derechos", en G. Hernández, R. Aparicio y F. Mancini (coords.), Pobreza $y$ derechos sociales en México, México, Coneval e iIs-unam. Ayala, J. [2001], Estado y desarrollo. La formación de la economía mixta mexicana en el siglo xx, México, Facultad de Economía, UNAM.

Banco Mundial [2017], World Development Report 2017: Governance and the Law, Washington, The World Bank.

BECKER, G. S. [1995], Human capital and poverty alleviation, Human Resources Development and Operations Policy Working Paper, <https://n9.cl/ea3rq>.

[1984], Human capital: A theoretical and empirical analysis with special reference to education, Chicago, The University of Chicago Press.

Bentham, J. [1780], Introduction to the principles of morals and legislation (edición de 1823 reeditada en 1905), Gran Bretaña, Oxford University Press.

Boltvinik, J. [2003], "Tipología de los métodos de medición de la pobreza. Los métodos combinados", Revista Comercio Exterior, 53(5), mayo.

Castellanos, R. [2012], "El bienestar subjetivo como enfoque e instrumento de la política pública: una revisión analítica de la literatura", Revista Chilena de Administración Pública, 19:133-168.

CAstro, A., J. Cruz y J. Vargas (coords.) [2018], Modelo económico justo y solidario, Machala, Utmach.

CBS (Centre for Buthan Studies) y GNH Research [2015], Provisional Findings of 2015 GNH Survey (CBS Report), $<$ https://n9.cl/scu26>.

Celis, F. [2018], "Embotelladora de Pepsi confirma cierre de operaciones en Guerrero", Forbes, 11 de junio, <https://n9.cl/zhoi> . 
Chang, H. J. [2011], Pateando la escalera. El desarrollo estratégico en una perspectiva histórica, México, Fundación México Social Siglo xxi y Juan Pablos Editor.

ChÁvez, M. Rita [2011], "Los referentes conceptuales del desarrollo social", Ixaya Revista Universitaria de Desarrollo Social, Universidad de Guadalajara.

CIW (Canadian Index of Wellbeing) [2016], How are Canadians Really Doing? The 2016 CIW Report, Waterloo, ON: Canadian Index of Wellbeing and University of Waterloo.

CNDH (Comisión Nacional de Derechos Humanos) [2016], Los principios de universalidad, interdependencia, indivisibilidad y progresividad de los Derechos Humanos (Cartilla CNDH, México), <https://n9.cl/q2zyz>.

Coneval (Consejo Nacional de Evaluación de la Política de Desarrollo Social) [2019], Metodología para la medición multidimensional de la pobreza en México, México, Coneval.

CoragGio, J. L. (coord.) [2017], Miradas sobre la economía social y solidaria en América Latina, Buenos Aires, Ediciones UnGS e Instituto de Altos Estudios Nacionales.

CóRdova, A. [1981], La formación del poder político en México, México, Era.

Cummins, R. A., y W. McPherson [2005], "An investigation into the cross-cultural equivalence of the personal wellbeing index", Social Indicator Research, 72(3): 403-430.

Dasgupta, P., e I. Serageldin (eds.) [1999], Social capital. A multifaceted perspective, Washington, D. C., World Bank.

Delboscy A. y C. Graham [2011], "Using Lorenz curves to assess public transport equity", Journal of Transport Geography, 19(6): 1252-1259.

Delsignore, G. [2017], "Del crecimiento económico a la satisfacción con la vida: medir la felicidad en ciencias sociales", en A. Serrano-Sanz (coord.), Políticas públicas y sociales: globalización, desigualdad y nuevas insurgencias, Prensas Universitarias, Universidad de Zaragoza. 
EIGE (European Institute of Gender Equality) [2019], Gender Equality Index 2019 Work-life balance (EIGE Report), $<$ https://n9.cl/2boa9>.

Esping-Andersen, G. [1990], The three worlds of welfare capitalism, Princeton, Princeton University Press.

EUI (Economic Intelligence Unit) [2012], Women's Economic Opportunity Index 2012 (EUI Report), <https://n9.cl/x4rgt>. Fuentes, M. L., y S. Arellano [2019], Nuevo ensayo político-social de la República Mexicana. Recuento de las desigualdades y la pobreza en México, 1790-1930, México, UNAM.

Galbraith, J. K. [1989], Historia de la economía, México, Ariel. Gallup World Pool [2006], World Poll Questions (Gallup World Pool Survey), <https://cutt.ly/EhvgOCa>.

Gobierno Sueco [2018], Elderly care in Sweden (documento descriptivo), <https://n9.cl/29ogi>, 19 de febrero de 2018.

Grant, R. [1991], "Porter's Competitive Advantage of Nations': An assessment. Strategic", Strategic Management Journal, 12(7): 53-548.

Haider, H. [2011], Poverty and wellbeing Indices, Governance and Social Development Resource Centre, <https://gsdrc. org/publications $>$.

IISS (International Institute of Social Studies) [2018], Annual Report Indices of Social Development 2018, <https://n9.cl/ iazc>.

Kahneman, D., y A. B. Krueger [2006], "Developments in the measurement of subjective well-being", Journal of Economic Perspectives, 20(1): 3-24.

LANDA, M. [2017], Apuntes teóricos, empíricos y metodológicos para el estudio del bienestar subjetivo, Glastree Academic Publishing.

LuCAS, K. [2012], "Transport and social exclusion: Where are we now?", Transport Policy, 20:105-113.

Marañón, B. (coord.) [2013], La economía solidaria en México, México, IIEc, UNAM. 
Marshall, A. [1963], Principles of economics: An introductory volume, Londres, Macmillan and Co. Limited, St. Martins Street, 8va ed., 1949. Véase también Principios de Economía, Madrid Aguilar, cuarta edición, 1963.

Maslow, A. [1991], El hombre autorrealizado: hacia una psicología del ser, Barcelona, Editorial Kairos.

MHLw (Ministry of Health, Labour and Welfare) [2016], Policies on population ageing: long-term care insurance system in Japan and International cooperation on Active Aging in ASEAN, <https://n9.cl/y24fc >.

Michalos, A. C., B. Smale, R. Labonté et al. [2011], The Canadian Index of Wellbeing, Technical Report 1.0, Waterloo, Canadian Index of Wellbeing and University of Waterloo.

Mora, M. [2015], Cohesión social: balance conceptual y propuesta teórico-metodológica, México, Coneval-Colmex.

Moreno, J. L. [1942], "Chart of hapipiness. Hornell hart", American Journal of Sociology, 47(4): 652-653, enero.

Musgrave, R. y P. Musgrave [1992], Hacienda pública teórica y aplicada, Madrid, Editorial McGraw-Hill.

Nan, L. [2001], Social capital. A theory of social structure and action, Cambridge, Cambridge University Press.

OCDE (Organización para la Cooperación y el Desarrollo Económicos) [2020], How's life? 2020: Measuring well-being, París, OECD Publishing.

[2011], Compendium of OECD well-being indicators, OECDBetter Life Iniciative, $<$ https://n9.cl/a9b90>.

OJEDA Salazar, A. [2010], El enfoque del desarrollo social, Documento de trabajo, Dirección General de Políticas de Desarrollo Social del Ministerio de la Mujer y el Desarrollo Social, Perú, <https://n9.cl/dilc9>.

OPHI (Oxford Poverty \& Human Development Initiative)-UNDP [2019], Global Multidimensional Poverty Index 2019, Illuminating Inequalities, <https://n9.cl/qanm>. 
ORDóÑEz, G. [2017], El Estado social en México. Un siglo de reformas hacia un sistema de bienestar excluyente, México, Colegio de la Frontera Norte-Siglo xxI.

Ostrom, E. [2015], Comprender la diversidad institucional, México, UAM-FCE.

Reyes, L. [2018], "Coca-Cola Femsa cierra operaciones en Altamirano, Guerrero", Expansión, 23 de marzo, <https:// n9.cl/xi561>.

RodRíGuez, J. [2018], "Discriminación y pobreza. Cómo identificar la desventaja social", en G. Hernández, R. Aparicio y F. Mancini (coords.), Pobreza y derechos Sociales en México, México, Coneval e iIs-unam.

RoDRIK, D. [2011], Una economía, muchas recetas. La globalización, las instituciones y el crecimiento económico, México, Fondo de Cultura Económica.

RoJAs, M. [2011], "Más allá del ingreso: progreso y bienestar subjetivo", en M. Rojas (coord), La medición del progreso y del bienestar. Propuestas desde América Latina, México, Foro Consultivo Científico y Tecnológico.

Santana Ramos, E. [2016], "El paternalismo a debate", Revista de Dereito da Cidade, Universidade du estado do Rio de Janeiro, Brasil, 8(3), <https://n9.cl/b3oq>.

Sempere, J., A. Acosta, S. Abdallah y M. Ortí (coords.) [2010], Enfoques sobre bienestar y buen vivir. Selección de recursos documentales, Madrid, Centro de Investigación para la $\mathrm{Paz}$ (cIP-Ecosocial).

Sen, A. [2000], Development as freedom, Nueva York, Anchor. Sojo, A. [2017], La cohesión social democrática, brújula indispensable en una época de desconcierto, Agencia Española de Cooperación Internacional para el Desarrollo.

Stiglitz, J. E., A. Sen y J. P. Fitoussi [2009], Report by the Commission on the Measurement of Economic Performance and Social Progress, París, Commission on the Measurement of Economic Performance and Social Progress. 
y B. Pleskovic (eds.) [1997], Annual World Bank Conference on Development Economics, Washington, D. C., The World Bank.

Stutzer, A., y B. Frey [2006], What happiness research can tell us about self-control problems and utility misprediction, Working Paper, núm. 267, enero, Zurich, Institute for Empirical Research in Economics, University of Zurich. SzÉKely, Miguel [2003], "Lo que dicen los pobres", Cuadernos de desarrollo 13, México, Secretaría de Desarrollo Social. UNDP (United Nations Development Programme) [2019], $\mathrm{Hu}$ man Development Report 2019, <https://n9.cl/e65n5>.

Vázquez, D., y S. Serrano [2013], Principios y obligaciones de derechos humanos: los derechos en acción, México, Comisión de Derechos Humanos del Distrito Federal, Suprema Corte de Justicia de la Nación, Oficina del Alto Comisionado de las Naciones Unidas para los Derechos Humanos. Veenhoven, R. [2001], "Qualita' della vita e felicita: non propio la stessa cosa", en G. de Girolamo et al. (eds). Sallute e Qualita della Vita, Torino, Centro Scientifico Editore, pp. 67-95, <https://n9.cl/rq1yx>.

Villarespe, V. [2002], Pobreza: teoría e historia, México, IIEcUnAM-Casa Juan Pablos.

WEF (World Economic Forum) [2020], Global Gender Gap Report 2020 (WEF Insight Report), <https://n9.cl/rga9>. 


\title{
POLÍTICA PÚBLICAY BIENESTAR SOCIAL: UN ENFOQUE DE DERECHOS SOCIALES
}

\author{
Humberto Ríos Bolívar* \\ Isidro Cerón Palma**
}

\section{INTRODUCCIÓN}

El bienestar es fundamental para las personas y la sociedad, y una prioridad dentro de los propósitos de todos y cada uno de los gobiernos de los países del mundo. Para los individuos el bienestar es un estado que pretenden mejorar continuamente. Para la población un mayor bienestar representa el mejoramiento de las condiciones de vida en los aspectos tanto objetivos como subjetivos que afectan a cada uno de los miembros que la componen. En el caso de los gobiernos, por lo menos de aquellos que están comprometidos con un enfoque de derechos humanos, el mayor bienestar de las personas y la población debería ser su razón de existir. Aquí cabe la necesidad de plantear como principio de cuentas, ¿qué es el bienestar?, ¿qué es el bienestar de las personas?, ¿qué es el bienestar de una sociedad?, y ¿cuáles son los componentes que inciden en lograr cada una de estas acepciones de bienestar?

En un sentido amplio y general, el bienestar es un concepto multidimensional que comprende aspectos económicos y sociales de las necesidades básicas de los individuos; algunas de estas necesidades pueden ser objetivas y algunas otras

\footnotetext{
* Sección de Estudios de Posgrado e Investigación, ESE-IPN. Correo electrónico: $<$ hrios@ipn.mx>.

** Sección de Estudios de Posgrado e Investigación, ESE-IPN. Correo electrónico: <isidrocepal@gmail.com>.
} 
subjetivas o de percepción. Así, el bienestar no solo contempla aspectos materiales o económicos -como el ingreso real o el consumo real de las personas-y de acceso a servicios básicos, como salud y educación, sino también las valoraciones y experiencias que las personas tienen de su vida y su entorno. Es decir, el bienestar no solo incluye elementos objetivos sino también subjetivos. El bienestar subjetivo comprende una multiplicidad de situaciones y procesos en la vida de las personas, como la felicidad, la satisfacción, la alegría, el orgullo y muchos otros aspectos subjetivos.

Existen grandes exponentes del tema que sostienen que el bienestar está estrechamente conectado con conceptos como calidad de vida, desarrollo social y progreso social. El informe de la Comisión Stiglitz-Sen-Fitoussi [Stiglitz, Sen y Fitoussi, 2009: 13] destaca la relación bienestar-calidad de vida. Se dice que la "La calidad de vida depende de las condiciones objetivas en las cuales se encuentran las personas y sus capacidades dinámicas." La calidad de vida estaría conformada por varios elementos de orden económico, social, cultural y medioambiental, pero también de la percepción que los individuos tienen de su vida.

Como parte de la información necesaria para evaluar la calidad de vida se encuentra lo relacionado con las capacidades, los funcionamientos y las libertades. "El bien-estar de una persona puede entenderse considerando la calidad [...] de su vida. La vida puede considerarse como un conjunto de 'funcionamientos' interrelacionados, consistentes en estados y acciones. La realización de una persona puede entenderse como el vector de sus funcionamientos" [Sen, 2010: 53]. Las capacidades de las personas serían, así, fundamentales para la calidad de vida de las personas.

Independientemente del enfoque de la concepción de bienestar, en particular del bienestar social, existe discusión sobre el indicador estadístico que represente el concepto bienestar y sobre el conjunto de variables que condicionan y 
determinan el mejoramiento del bienestar. Sin embargo, hay consenso acerca del uso de la política pública como mecanismo para instrumentar acciones que permiten a los gobiernos el ejercicio del gasto para subsanar las carencias sociales que impiden a la población gozar de bienestar social. Una política pública basada en el enfoque de derechos sociales puede darnos luz del posible uso de variables como la educación para promover el bienestar social.

El propósito de este trabajo es brindar algunos elementos conceptuales de las distintas acepciones del bienestar y su medición, así como introducir algunos elementos de política pública que ayuden a delimitar y justificar el uso de variables comprendidas en los derechos sociales de la población que se establecen en la Ley General de Desarrollo, en particular el acceso a la educación, la salud y la alimentación, entre otras, para determinar el bienestar de la población. Para tales propósitos, en el siguiente apartado se exponen las serias limitantes del producto interno bruto (PIB) como posible aproximación al concepto de bienestar; a continuación se aborda el tema de la medición del bienestar y luego se analizan algunas perspectivas del Estado mexicano sobre el bienestar social, con énfasis en el enfoque de derechos sociales. Por último, se usan métodos econométricos para brindar evidencia de la relevancia que el gasto tiene en tres rubros: educación, salud y alimentación, sobre el bienestar social.

\section{Algunas CONSIDERACIONES SOBRe}

LA MEDICIÓN DEL BIENESTAR

Varias instituciones a niveles internacional y nacional han intentado realizar la medición del bienestar. Las metodologías son diversas y los resultados dependen de lo que se entiende o cómo se conceptualiza el bienestar. Han sido varios los esfuerzos por lograr una medida sintética de la calidad de vida como 
aproximación al bienestar, a pesar que la naturaleza del concepto se caracteriza por su pluralidad y que por ello se necesitan varios indicadores.

A nivel internacional, el Programa de las Naciones Unidas para el Desarrollo (PNUD) ideó una metodología que contempla la medición del llamado índice de desarrollo humano (IDH), compuesto por indicadores de salud, educación y esperanza de vida. En esta medida del bienestar, se ha ido más allá del ingreso per cápita de los países, esto es, de los aspectos económicos, para considerar factores de orden social. A pesar de la importancia de este y otros tipos de índices compuestos que tienen el propósito de medir el bienestar, adolecen en conjunto de la consideración y medición del aspecto subjetivo del bienestar.

Por su parte, la Organización para la Cooperación y el Desarrollo Económicos (OCDE), para medir temas fundamentales del bienestar, creó el proyecto Measuring Progress, que busca desarrollar medidas de progreso social para tener claridad en el diseño de políticas públicas dirigidas al logro de un mayor bienestar de la población. La Organización identificó como esenciales para el bienestar 11 variables económicas, sociales, ambientales y de naturaleza subjetiva agrupadas en el aspecto condiciones materiales de vida y calidad de vida. Las variables que considera dentro de la dimensión condiciones materiales de vida son: empleo, ingresos y vivienda; y dentro de la calidad de vida: comunidad, educación, equilibrio laboral-personal, medio ambiente, participación ciudadana, salud, satisfacción ante la vida y seguridad [OCDE, 2011].

Entre los estudios y propuestas creados para tratar las cuestiones relacionadas con el bienestar y que han tenido una trascendencia enorme en los estudios y las mediciones del bienestar y la discusión de términos relacionados, como desarrollo económico y progreso social, se encuentra la llamada Comisión Stiglitz, Sen-Fitoussi. 
La comisión para la medición del desarrollo económico y el progreso social (conocida como Comisión Stiglitz-Sen-Fitoussi o Comisión Sarkozy) se formó por instancia del gobierno francés en 2008. Sarkozy, presidente de Francia, solicitó al equipo formado por los premios Nobel Joseph Stiglitz y Amartya Sen y al economista francés Jean-Paul Fitoussi realizar un estudio "para determinar los límites del PIB como indicador de los resultados económicos y del progreso social, reexaminar los problemas relativos a la medición" [Stiglitz, Sen y Fitoussi, 2009: 4], así como lo relativo a los datos e instrumentos de medición de dichos temas.

Sin lugar a dudas, esta comisión ha estudiado la relación del bienestar con la libertad y las capacidades y habilidades de los ciudadanos que puede conducir al progreso, cuyos principios se encuentran en los trabajos previos de S. Anand y A. Sen [1994, 1995 y 1997]. Asimismo, ha considerado la relación existente entre el bienestar subjetivo y la felicidad y calidad de vida. Este planeamiento implica que para medir el bienestar subjetivo ha de hacerse investigación directa de las personas, ya que, se sostiene, solo las personas pueden proporcionar información de sus valores, valoraciones y situaciones personales que afectan su calidad de vida.

La Comisión considera que la definición del bienestar tiene que ser pluridimensional para delimitar su contenido conceptual. Esta característica implica que el bienestar tiene varias dimensiones que deben considerarse y que entre las más importantes a tomar en cuenta están: a) las condiciones económicas como ingreso, consumo y riqueza; b) la salud; c) la educación; d) las actividades personales, como el trabajo; e) los logros y las relaciones sociales; f) el estado actual y presente del medio ambiente; y g) la inseguridad, tanto económica como física [Stiglitz, Sen y Fitoussi, 2009: 13].

La trascendencia del informe Stiglitz-Sen-Fitoussi ha sido enorme y se ha reflejado en el trabajo académico, en la influencia sobre los estudios y propuestas de política pública de 
los organismos internacionales y en el ámbito de recolección y procesamiento de la información que realizan las instituciones nacionales de estadística.

\section{ESTADO DE BIENESTAR}

En términos teóricos conceptuales es complicado dar una definición del llamado "Estado de bienestar"; lo más que puede hacerse es proporcionar una aproximación conceptual a dicho concepto. En términos históricos, tampoco es sencillo hablar de "el Estado de bienestar" y más bien se tiene que hablar de los Estados de bienestar.

$\mathrm{Ni}$ siquiera hay una clara diferencia entre el concepto de Estado de bienestar y el de Estado social (o Estado social de derecho); algunos consideran que son expresiones sinónimas, otros que son distintos y otros más que el Estado social ha sido una primera fase del desarrollo del Estado de bienestar europeo. Algo similar se debate para el caso de América Latina, donde para algunos autores nunca ha existido un Estado de bienestar, pero sí un estado social; sin embargo, se habla de que en México se instauró un Estado de bienestar después de la Segunda Guerra Mundial. Anotados estos puntos problemáticos de la temática, seleccionaremos una definición conceptual para interpretar el aserto del gobierno federal actual de que uno de los objetivos del nuevo régimen de gobierno que se busca consolidar es lograr un Estado de bienestar en México.

Existe más de una propuesta teórica conceptual acerca de lo que puede entenderse por Estado de bienestar. Cada una destaca un aspecto que se considera importante: va desde considerarlo un pacto social, pasando por la cuestión de los derechos sociales, hasta una simple categoría de análisis. En nuestro caso, adoptamos la definición siguiente: el Estado de bienestar está conformado por un 
conjunto de instituciones estatales que garantizan una serie de derechos sociales ejercitables por la inmensa mayoría de los ciudadanos -universalismo protector-desarrollado a través de políticas y programas de carácter redistributivo en base a la solidaridad intergeneracional y apoyados en la idea básica de "ciudadano trabajador" que es sujeto de derechos sociales y residualmente como "ciudadano necesitado" [Marbán, s/f].

El Estado de bienestar surge propiamente en el contexto de la Gran Depresión del 29 y de la Segunda Guerra Mundial. Los graves problemas económicos materializados en enormes caídas de la producción y creciente desempleo configuraban una situación que podría desembocar en profundos problemas sociales y políticos. De esta forma, se propone la intervención del Estado en la economía para contener los efectos negativos de la economía de libre mercado sobre las instituciones políticas y sociales de los países capitalistas desarrollados. Esta intervención se hace necesaria, además, porque la economía de libre mercado no garantiza ni conduce a la justicia social ni a la prosperidad económica compartida con todos los individuos o clases sociales.

El Estado de bienestar pudo consolidarse gracias a un conjunto de factores y fuerzas sociales y políticas que lograron un consenso para darle forma a una organización del Estado donde se construyeron y ampliaron esquemas de seguro obligatorio, se logró el establecimiento del salario mínimo, se legisló sobre leyes de protección al trabajo, se reconocieron los sindicatos y se estableció el derecho y la expansión de los servicios de salud, educación y vivienda, entre otros.

El Estado de bienestar fue aceptado por todas las fuerzas políticas en los países capitalistas desarrollados. Las fuerzas conservadoras lo aceptaron por los beneficios que aportaba al logro de un sistema socioeconómico que funcione de forma armónica y eficiente con integración social. Esto garantizaba y promovía la libertad ciudadana, propósito último de la existencia del Estado, según el punto de vista conservador. 
En el caso de las fuerzas socialdemócratas, el Estado de bienestar significaba la protección y profundización de la democracia vía reconocimiento y legitimación, así como el reconocimiento de los derechos, los sindicatos, las comunidades y las minorías sociales en el marco constitucional, además de representar, para algunos, un avance reformista hacia el socialismo.

En la actualidad, y a pesar del embate contra el Estado de bienestar en la década de los 80 del siglo pasado por los gobiernos neoliberales, sus formas de funcionamiento, logros y alcances, así como sus propósitos y objetivos, todavía mantienen su legitimidad y justifican su existencia. "Los Estados de bienestar, con todas sus imperfecciones, son vitales para la estabilidad social y la legitimidad. Son un importante creador de las condiciones de mercado que resultan necesarias para la reproducción exitosa del capitalismo como sistema político y económico" [Gamble, 2017: 15].

\section{Perspectiva institucional del Estado}

MEXICANO SOBRE EL BIENESTAR SOCIAL

El Estado, en su papel de dar cumplimiento a los estatutos comprendidos en las leyes que promueven el bienestar de las personas y de la sociedad en lo general, está comprometido en generar acciones y programas sociales que coadyuven al cumplimiento del propósito de alcanzar el bienestar social.

\section{Plan Nacional de Desarrollo}

En el apartado II, Política Social del Plan Nacional de Desarrollo 2019 a 2024, se deja claramente asentado que el propósito sexenal del gobierno en turno está enfocado de manera prioritaria a lograr que la población mexicana viva en un Estado de bienestar. 
En los últimos 30 años y hasta el comienzo del actual gobierno federal, el régimen que privaba era el neoliberal, por tanto, el pretendido Estado de bienestar está en construcción. Se reconoce que para ello se requiere una "fuerte presencia del sector público en la economía" [Gobierno de México, 2019: 6]. Para lograr este régimen, se tiene el apoyo jurídico-político de la Constitución Política de los Estados Unidos Mexicanos (CPEUM), principalmente sus artículos 3, 27 y 123.

La instauración del Estado de bienestar requiere una serie de acciones de política económica y social que se concretan en dotar a la población de "servicios universales y gratuitos de educación y salud, las vacaciones pagadas, la jornada máxima de trabajo y los salarios mínimos" [Gobierno de México, 2019: 40]. Por tanto, "el gobierno federal impulsará una nueva vía hacia el desarrollo para el bienestar, una vía en la que la participación de la sociedad resulta indispensable" [Gobierno de México, 2019: 42].

El gobierno federal actual, desde su inicio, ha estado abocado a lograr la creación de las condiciones y situaciones que posibiliten un Estado de bienestar para la población mexicana. Esto evidentemente ha requerido negar los fundamentos de la política económica y pública de los gobiernos anteriores.

En lo que va del gobierno actual, se han buscado cambios en la estructura salarial para beneficiar a los trabajadores más desfavorecidos con un aumento y, en general, lograr la recuperación del poder adquisitivo de la clase trabajadora. Las acciones concretas en materia laboral han sido impulsar la disminución de las remuneraciones de los servidores públicos de jerarquía superior, permitir el fortalecimiento de los sindicatos y buscar que el salario mínimo se encuentre por encima de la línea de bienestar, es decir, que la percepción del salario mínimo no ubique a un trabajador y su familia en una situación de pobreza.

El fortalecimiento de los trabajadores se está logrando con las modificaciones a la Ley Federal del Trabajo en su beneficio. Entre las modificaciones se encuentra la destrucción del 
sindicato charro al prohibir que los dirigentes sindicales ostenten el cargo a perpetuidad, además de que la selección de los dirigentes sea por medio del voto personal de los trabajadores, de una forma libre, directa y secreta. Asimismo, entre los cambios a la Ley Federal del Trabajo queda establecido que las trabajadoras domésticas tienen derechos a la seguridad social y a descansar un día y medio.

El Plan Nacional de Desarrollo, 2018-2024, establece que el gobierno federal busca que la población mexicana sea beneficiada por un desarrollo sostenible. Mediante este proceso de desarrollo, se espera que terminen la desigualdad, la injusticia, la pobreza y la marginación al impulsar el crecimiento económico envuelto en un proceso más equitativo de distribución del ingreso.

\section{La perspectiva del Coneval}

El Consejo Nacional de Evaluación de la Política de Desarrollo Social (Coneval) considera fundamental la medición de la dimensión bienestar económico en sus estudios, pues cree que la capacidad de las personas para contar o no con los recursos económicos para adquirir bienes y servicios que satisfagan sus necesidades alimentarias y no alimentarias determinará fundamentalmente su bienestar y su inclusión o no en el grupo de la población en situación de pobreza. En la evaluación que hace de los programas sociales que operaron en 2019, encuentra que poco más de $25 \%$ contribuye a aumentar el ingreso de los hogares, lo cual es parte fundamental del aporte de los programas al bienestar de las familias. En la evaluación de los programas sociales en su contribución al bienestar económico, se toman en cuenta los efectos de los bienes y servicios entregados a los hogares en los flujos monetarios y no monetarios y que repercuten en su ingreso corriente.

El problema de insuficiencia de ingresos de los hogares requiere la coordinación de políticas que abarque un conjunto 
de programas que brinden protección social y apoyos económicos. En el caso de los productores rurales es necesario apoyar el ingreso mediante precios de garantía y el fomento de proyectos productivos, y que se eviten las prácticas de intermediación que suelen provocar la aparición del mercado negro. Asimismo, y como parte fundamental de la estrategia, se deberían hacer inversiones en bienes públicos para apoyar el ingreso de los hogares productores en el largo plazo. Por otro lado, se hace necesario el apoyo prioritario a las micro y pequeñas empresas para contribuir a la generación del ingreso de amplios sectores de la población.

Algunos ELEMENTOS DE POLÍTICA PÚBLICA PARA EL BIENESTAR SOCIAL

Para comprender el significado de política pública en el bienestar social es necesario dilucidar los significados de términos relacionados como "ámbito público" y "problema público", primero desde una perspectiva de derechos humanos y después desde un enfoque de política social.

\section{Perspectiva general del bienestar como problema público}

Analizar el tema del bienestar como una necesidad de la sociedad motiva abordarlo desde una perspectiva de un problema público. Para Cardozo y Mundo [2012:8], los problemas públicos son "aquellas situaciones en las que se ve afectado el bienestar de la población en un espacio y tiempo determinados y, por consiguiente, requieren atención por parte de las agencias gubernamentales para intentar modificarlo."

De esta forma, podemos entender que existe un problema público cuando se encuentra afectado el bienestar de la población por algún factor que haga necesaria la intervención 
gubernamental. En cualquier país en desarrollo, existe un déficit o profundas carencias en aspectos esenciales como la salud, la educación, la alimentación y la vivienda, entre otros, que demanda la intervención del gobierno para subsanar el problema público en cuestión

Frohock [1979] elaboró una definición de políticas públicas que se considera de las mejores en virtud de que, según Ruiz Sánchez [1996:15], es la más amplia y completa y porque se adapta mejor a la realidad de la nación mexicana. La definición es la siguiente: "Una política pública es: 1. Una práctica social y no un evento singular o aislado; 2 . Ocasionado por la necesidad de: 2.1. reconciliar demandas conflictivas o, 2.2. establecer incentivos de acción colectiva entre aquellos que comparten metas, pero encuentran irracional cooperar con otros". Para este autor, entonces, una política pública es una práctica social que nace de la necesidad de reconciliar demandas conflictivas o para establecer incentivos de acción colectiva.

Resumiendo, el ámbito de lo público es aquella dimensión de la actividad humana que es necesario regular o intervenir por parte del gobierno. Así, cuando el bienestar de la población está siendo afectado tenemos un problema. La política pública es una práctica social que media entre demandas conflictivas y establece los incentivos adecuados para determinados grupos sociales.

Desde otra perspectiva, Aguilar Villanueva [2012: 21] afirma que la política pública puede entenderse "como un proceso de solución de problemas públicos". A partir de la existencia de problemas públicos, el gobierno desarrolla las políticas públicas. Una situación social se califica como problema público "cuando debido a sus propiedades actuales y a sus efectos en la vida de las personas" difiere por alguna razón de la que "una sociedad y su gobierno valoran y prefieren, por lo que se le descalifica y se exige sea removida, disuelta, delimitada, corregida, mejorada". La situación social es un problema público cuando sociedad y gobierno consideran que debe ser 
modificada o eliminada. Un problema público es tal cuando conjuntamente sociedad y gobierno valoran que lo es; se necesitan los dos actores para definir el problema público.

Según Aguilar Villanueva [2012: 5], se entiende genéricamente por política pública "Las acciones de gobierno que tienen como propósito realizar objetivos de interés público y que los realizan con eficacia”. Estas acciones poseen una dimensión tanto política como técnica. La dimensión política nace en tanto busca "realizar objetivos de interés y beneficio social general". La dimensión técnica se hace presente por las técnicas, los métodos y procedimientos que se utilizan para cumplir los objetivos de interés y para que las decisiones de los gobernantes se concreten y conviertan en hechos sociales. Puede establecerse que las políticas públicas son un conjunto de acciones públicas cuya intención y causalidad son definidas por gobierno y sociedad, aunque la decisión de emprenderlas queda en manos de las autoridades públicas que puede realizarlas de por sí o en asociación con actores sociales y privados. Las acciones públicas están orientadas al cumplimiento de objetivos de interés o beneficio público; se reproducen en el tiempo de forma estable y coherente, según los lineamientos que las rigen y con base en sus recursos y metodologías ya validadas.

Las políticas públicas pueden clasificarse como distributivas o regulatorias. Se utilizan las políticas distributivas cuando el problema público puede resolverse por medio de una mejor distribución o asignación de recursos económicos y humanos. Se utilizan las regulatorias cuando el problema entraña regular "las conductas de las personas mediante prohibiciones, prescripciones y se generan los incentivos y controles para promover la observancia de la norma" [Aguilar Villanueva, 2012: 22]. Los distintos gobiernos utilizan ambos tipos de política pública ya que son complementarios y útiles para enfrentar los problemas públicos que la realidad social plantea. 
Las políticas públicas se concretan en un conjunto de programas que un gobierno cualquiera desarrolla para atender un problema o situación social particular.

Los países capitalistas en desarrollo están llenos de problemas públicos que requieren el diseño y la implementación de las políticas públicas adecuadas. En efecto, las economías en desarrollo pueden describirse como economías con baja capacidad productiva; población con bajo capital humano y de poca calidad; bajo o nulo desarrollo tecnológico; instituciones públicas débiles, poco consolidadas y de mala calidad; ingresos per cápita medios o bajos; y una pésima distribución del ingreso y la riqueza. Todas estas características, sobre todo de orden económico, se concretan en el plano social en la existencia de una enorme masa de gente pobre que correlativamente cuentan con un bajo o precario nivel educativo, de salud y de vivienda e incluso hambre.

Estos problemas de orden económico y social de las naciones capitalistas en desarrollo dan origen a una serie de problemas públicos que deben enfrentarse con un conjunto de políticas públicas. En específico, hay diversos problemas públicos de carácter social, como la falta o insuficiencia de educación, salud y alimentación, que se enfrentan con la llamada política social.

Esta última está constituida por un conjunto de programas sociales. Para Cardozo y Mundo [2012:14], "Un programa define con precisión sus objetivos operativos, los medios para alcanzarlos, así como las acciones a realizar en un corto tiempo [...] mientras que la política constituye un sistema concatenado y sinergético de los mismos, que requiere del desarrollo de importantes procesos de coordinación y articulación para lograr el cumplimiento de su misión”. De esta forma, podemos entender un programa social como aquel que define con precisión sus objetivos operativos, así como los medios y acciones para alcanzarlos y es parte de una política social. Toda política social está formulada en el marco de un conjunto de principios que la rigen. 


\section{Políticas públicas dirigidas a los derechos humanos}

Las políticas públicas dirigidas a los derechos humanos pueden entenderse "como la articulación racional de acciones y omisiones del Estado, y los resultados de estas, orientadas a la realización de derechos de la población" [González, 2010], basadas en las obligaciones contraídas voluntariamente por los Estados y la participación de la sociedad. Las obligaciones estatales se contraen cuando los Estados firman y ratifican tratados internacionales, así como cuando promulgan normas en el ordenamiento jurídico nacional. Por su parte, la participación de la sociedad desde este enfoque es fundamental, sobre todo la de aquellos que han sido víctimas de violación a sus derechos o que sufren la desigualdad y la exclusión.

Las políticas públicas dirigidas a los derechos humanos no son neutrales, "son producto de las relaciones de poder que existen dentro del Estado y en la sociedad" [González, 2010] por lo que en gran medida acaban actuando en beneficio de los grupos más fuertes que imponen sus visiones y proyectos de sociedad. El testimonio de esto es que en América Latina se encuentra la más profunda desigualdad que existe en el mundo, porque las políticas nunca han respondido coherentemente ni de forma persistente a favor de los grupos pobres, marginados o excluidos.

En este tipo de políticas, el diseño y la implementación se guían por el criterio de que debe privar el bienestar, producto del desarrollo y, por tanto, la vigencia y el disfrute de los derechos sociales, económicos y culturales de todas las personas. Esta perspectiva excluye situaciones en las que se violen los derechos humanos con base en la justificación de sacrificios necesarios para el buen o correcto funcionamiento de la economía. Por otro lado, este tipo de políticas reconoce la discriminación estructural en la sociedad y señala la obligación de la no discriminación. De aquí se deriva la política de 
la discriminación positiva en todos los campos de la política pública (tributaria, presupuestaria y de promoción de la participación en la esfera política). También se plantea que se requiere un proceso permanente de democratización en todos los ámbitos de la vida social para eliminar las desigualdades, exclusiones y asimetrías de poder entre los diferentes grupos. Finalmente, este tipo de políticas supone la existencia de un Estado fuerte que cuenta con legitimidad y fortaleza para corregir las inequidades. "Tanto como un Estado fuerte, el enfoque de derechos supone una sociedad fuerte, que incida en las decisiones que la afectan" [González, 2010].

Aspectos generales de la política social del gobierno federal, periodo 2018 a 2024

En el Plan Nacional de Desarrollo 2018 a 2024, el Ejecutivo federal plasma el ideal de que durante su periodo de gobierno se instaure un Estado de bienestar mediante una estrategia general de desarrollo sostenible.

Como parte de esta estrategia, se contempla lograr una política social basada en programas sociales que se caractericen por su universalidad y por diseñarse y aplicarse bajo una concepción que transite de la visión anterior que sustentaba que los programas sociales son oportunidades a la idea de que los beneficios sociales, económicos y culturales son derechos de las personas, buscando, asimismo, que la política social se institucionalice para erradicar cualquier forma de discrecionalidad en el manejo de los recursos y la promoción del clientelismo. En esta nueva concepción, la política social deja de ser una política de desarrollo social para convertirse en una política de bienestar. Esto puede considerarse un avance en la medida en que la política de desarrollo implementada por los gobiernos que fortalecieron el modelo neoliberal era focalizada, asistencial y clientelar, y 
no fomentaba un verdadero desarrollo social, mientras que el gobierno actual ha buscado que los programas tengan un carácter universal y se conviertan en derechos reconocidos constitucionalmente. Muestra de ello son el reconocimiento en la Constitución de los programas sociales de pensiones para adultos mayores, las becas para estudiantes de bajos recursos y discapacitados, y el sistema de salud para quienes carecen de seguridad social.

El gobierno federal actual se encontró al inicio de su periodo con 158 programas sociales de carácter federal, de los cuales se eliminaron 18 pero se crearon 14 para un total de 146 programas sociales vigentes. Dentro de los 14 programas se ha dado prioridad a los siguientes: Programa para el Bienestar de las Personas Adultas Mayores, Programa para el Bienestar de las Personas con Discapacidad, Jóvenes Construyendo el Futuro y Programa de Beca Universal para Estudiantes de Educación Media Superior Benito Juárez. La importancia de estos programas sociales radica en que atienden a grupos sociales que para los gobiernos anteriores habían estado invisibilizados y en el carácter universal de los programas. La universalidad de los programas sociales garantiza que los recursos de estos no sean utilizados de manera discrecional y evita la formación del clientelismo electoral, ya que toda persona que cumpla con los requisitos tiene derecho a su inscripción en el programa independientemente de sus preferencias electorales. La universalidad no significa necesariamente que los beneficios tengan que llegar a toda persona o familia sin consideración de su capacidad económica, sin que medie algún criterio de selectividad. Al respecto, la CEPAL [2000: 74] dice: "la focalización o la selectividad no es una política social, sino una condición que bien aplicada, hace más eficaz la universalización de los programas sociales [...] Priorizar la asignación de subsidios en la población más pobre, esencial para la equidad, no contradice el principio de universalidad". 
Aspectos generales de la política social contenida en la LGDS y la LDS-DF

Para el caso mexicano, en la actualidad la política social federal halla su sustento jurídico en la Ley General de Desarrollo Social (LGDS), publicada en el 2004. El objetivo de la ley es que la población mexicana goce de desarrollo social. La ley postula que el gasto público en desarrollo social anual en términos per cápita no puede disminuirse de un año fiscal a otro, ya sea de forma absoluta o como proporción del PIB. Entre los principios que la sustentan está ausente el principio de universalidad y se destaca, en cambio, el de focalización. Esta es una seria limitación de la ley ya que no garantiza un nivel de vida social adecuado en ausencia de recursos propios.

La LGDS, en su Artículo 3, estipula que la política de desarrollo social estará sujeta a un conjunto de principios, los cuales se enuncian a continuación: libertad, justicia distributiva, solidaridad, integralidad, participación social, sustentabilidad, respeto de la diversidad, libre determinación y autonomía de los pueblos indígenas y sus comunidades, transparencia y perspectiva de género.

En el Distrito Federal, hoy Ciudad de México, rigió la misma política social que a nivel federal hasta el año 1997. Esta se modificó por completo con el cambio de gobierno. La nueva política social instaurada estaría basada en derechos, para lo cual se conformó un nuevo marco institucional, normativo y programático. En este nuevo marco se recuperaba la noción de Estado social de derecho; en esta concepción, el Estado garantiza un conjunto de derechos sociales que logran mínimos de bienestar para toda la población

La Ley de Desarrollo Social para el Distrito Federal (LDS-DF) se publicó en el año 2000. El ordenamiento legal que contiene reconoce y eleva a rango de ley los derechos sociales, estipula que la política social debe regirse por un conjunto de principios sociales entre los cuales destacadamente se encuentran 
el principio de universalidad y el de exigibilidad, lo cual es un gran avance pues permite a la ciudadanía beneficiarse de los programas sociales y también exigir su cumplimiento.

La LDS-DF, en su Artículo 4, establece los principios que deberán tomarse en cuenta en el diseño de la política social: universalidad, igualdad, equidad de género, equidad social, justicia distributiva, diversidad, integralidad, territorialidad, exigibilidad, participación, transparencia y efectividad.

Hay principios compartidos entre ambas leyes de desarrollo social, entre ellos la justicia distributiva, la integralidad y la participación. Principios presentes en las dos leyes, pero con nombres diferentes, son: equidad de género y perspectiva de género, y equidad social y respeto a la diversidad. La LGDS federal contiene en exclusiva los principios de libre determinación y autonomía de los pueblos indígenas y sus comunidades, sustentabilidad y solidaridad. Por su parte, la LDS-DF incluye en exclusiva los principios de universalidad, igualdad, diversidad, territorialidad, exigibilidad y efectividad.

\section{ESPECIFICACIÓN Y ESTIMACIÓN DEL MODELO}

Partiendo de la consideración de que el índice de bienestar social y el índice de desarrollo humano son variables cuyos componentes tienen que ver con el concepto de bienestar social, la idea es analizar la interacción de estas variables con algunas variables representativas de los derechos sociales educación, salud y alimentación, utilizando el concepto de variable proxy a través del gasto de gobierno en dichos rubros para de esta manera realizar alguna aseveración acerca de la función de la política pública en el cumplimiento de los derechos sociales y del propio bienestar social.

Así, este apartado tiene un doble propósito: por un lado, analizar la relevancia del gasto del gobierno federal en el bienestar agregado de la población en México, visto dicho 
gasto como un instrumento de política pública con enfoque de derechos sociales, y, por otro lado, analizar el bienestar a nivel de los hogares de México en función del gasto que estos derogan en los rubros de educación, salud y alimentación. Para el primer propósito, se plantea y estima un modelo econométrico mediante el método de mínimos cuadrados generalizados (MCG), para el cual se utiliza información de series de tiempo del periodo 1990 a 2018 tomada del Instituto Nacional de Estadística y Geografía (Inegi). Para el segundo propósito, y tomando en consideración las limitantes de la información estadística empleada en la estimación por MCG, optamos por usar una base de datos más amplia, la Encuesta Nacional de Ingresos y Gastos de los Hogares (ENIGH), diseñada por el Inegi, del año 2016, dada la amplitud de esta nueva base de datos, óptima por utilizar la técnica de regresión cuantílica propuesta por Koenker y Basset [1978], una técnica más adecuada para manejar grandes bases de información estadística y que permite analizar la información por grupos, según sea el nivel de ingreso de los hogares.

\section{Estimación mediante $M C G$}

El método de regresión econométrica es un instrumento que se utiliza cuando se pretende conocer la relación existente entre dos o más variables; el objetivo principal consiste en determinar la relación de un conjunto de variables exógenas o explicativas sobre una variable dependiente. El método más habitual es el de mínimos cuadrados ordinarios (MCO); no obstante, este método de MCO requiere una serie de supuestos sobre el comportamiento del término de error al calcular dicha regresión, supuestos que la hacen ser muy rígida.

Dada la rigidez los estimadores MCO y ante la presencia de heterocedasticidad en la información estadística de que disponemos, optamos por utilizar el método de MCG junto con una 
transformación adecuada de la información estadística y permitiendo la relajación de las hipótesis básicas sobre el termino de error.

\section{Especificación del modelo $M C G$}

La idea es plantear una relación funcional que permita analizar el índice de bienestar social en términos del gasto de gobierno como mecanismo de política pública.

$$
\begin{gathered}
\text { Índice de bienestar social }=f(\text { política pública }) \\
I B S=f(G E, G S, G A)
\end{gathered}
$$

La forma funcional está especificada en la siguiente expresión:

$I B S_{t}=\beta_{Y} Y_{t}+\beta_{G E} G E_{t}+\beta_{G S} G S_{t}+\beta_{G A} G A_{t}+\varepsilon_{t}$

$Y_{t}$ : producto interno bruto

IBS: índice de bienestar social

$G E$ : gasto en educación

GS: gasto en salud

$\beta_{Y}, \beta_{G E}, \beta_{G S}, \beta_{G A}$ : conjunto de regresores asociados a cada una de las variables exógenas

$\varepsilon_{t}$ : término de error

La información estadística para la estimación econométrica de la expresión (1) proviene del Inegi [2018]; dicha información consiste en datos anuales para el periodo 1990 a 2018, correspondientes a las variables exógenas: producto interno bruto, gasto federal en educación, salud y alimentación. Las variables dependientes, índice de desarrollo humano, fueron tomadas del PNUD [2019] y la variable dependiente, índice de bienestar social, consiste en un índice calculado mediante el 
concepto que se utiliza en OCDE [2019]. Los cálculos de las regresiones se hicieron mediante el programa $R$, un software de acceso libre que permite hacer análisis estadísticos. Las bondades de usar este programa es que se trabaja en un ambiente de programación muy flexible, lo cual lo hace fácil de adaptar a nuestras propias necesidades. Para el cálculo de la regresión MCG, usamos como variables dependientes dos indicadores del bienestar: un índice de bienestar social (IBS) y el índice de desarrollo humano (IDH), tomando como referencia los conceptos de dichos índices de la OCDE y el PNUD, respectivamente; planteamos tres pruebas de la hipótesis, basada cada una de ellas en la relevancia que tiene el gasto federal en tres rubros que dan sustento a las variables explicativas: gasto en educación (GE), gasto en salud (GS) y gasto en alimentación (GA). Los resultados de la estimación se muestran en el cuadro 1.

Cuadro 1. Resultados de la estimación mediante MCG

\begin{tabular}{lcccc}
\hline \multirow{2}{*}{$\begin{array}{l}\text { Variable } \\
\text { exógena }\end{array}$} & \multicolumn{2}{c}{$\begin{array}{c}\text { Índice de bienestar social } \\
\text { (IBS) }\end{array}$} & $\begin{array}{c}\text { Índice de desarrollo humano } \\
(\mathrm{IDH})\end{array}$ \\
\cline { 2 - 5 } & Coeficiente & $\operatorname{Pr}(>|\mathrm{t}|)$ & Coeficiente & $\operatorname{Pr}(>|\mathrm{t}|)$ \\
\hline$l P I B_{t-1}$ & 0.000 & 0.061 & 0.001 & $0.053^{*}$ \\
$l G E_{t-1}$ & 0.080 & $0.052^{*}$ & 0.036 & $0.042^{*}$ \\
$l G S$ & 0.390 & $0.001^{*}$ & 0.431 & $0.001^{*}$ \\
$l G A$ & 0.280 & 0.081 & 0.310 & $0.053^{*}$ \\
\hline
\end{tabular}

* Denota significancia al $5 \%$ de confianza.

Fuente: elaboración propia con información de Inegi [2018].

Una lectura de estos resultados muestra que el modelo MCG presenta un nivel de ajuste aceptable y significativo en cada uno de sus parámetros, es decir, a mayor gasto representado en cada una de las variables explicativas: $l_{G E}$, $l_{G S}$ y $l_{G A}$, este se ve reflejado en un aumento en ambas variables dependientes, a saber IBS e IDH. Ambas estimaciones reflejan un mayor 
impacto del gasto en educación, despues en alimentación y menor el gasto en educación.

\section{Estimación mediante regresión cuantílica}

El método de regresión cuantílica es una técnica que se usa como alternativa del método de MCo, ante la ineficiencia de los estimadores MCO, como consecuencia de presencia de valores atípicos de las variables exógenas. La regresión cuantílica tiene como objetivo estimar la mediana condicional de la variable dependiente en muestras homogéneas de información divididas en cuantiles y resolver la ineficiencia de la esperanza condicional. Dicha técnica de regresión cuantílica, que fue utilizada por primera vez por Koenker y Basset en 1978, consiste en la minimización de desviaciones absolutas ponderadas con pesos asimétricos que no se ven afectadas por cambios estructurales o por datos extremos.

Así, ante una situación de heterocedasticidad, presencia de valores atípicos o cambio estructural, la regresión cuantílica ofrece la posibilidad de estimar una regresión para cada cuantil de la variable dependiente. La especificación del modelo de regresión cuantílica, está dada por:

$$
y_{i}=X_{i} \beta_{\theta}+u_{\theta i}
$$

Donde $y_{i}$ es la variable dependiente, $X_{i}$ representa la matriz de variables exógenas, $\beta_{\theta}$ es el parámetro a estimar, correspondiente al cuantil $\theta$, mientras que $u_{\theta i}$ es el término de error asociado al cuantil $\theta$. De donde el problema de estimación de parámetros mediante el método de regresión cuantílica se obtiene mediante un proceso de minimización dado por:

$$
\min _{\beta_{\theta} \in \mathrm{R}}\left[\sum_{Y_{i} \geq X_{i} \beta_{\theta}} \theta\left|Y_{i}-X_{i} \beta_{\theta}\right|+\sum_{Y_{i} \geq X_{i} \beta_{\theta}}(1-\theta)\left|Y_{i}-X_{i} \beta_{\theta}\right|+\right]
$$


La expresión (3) representa el cuantil de la variable dependiente $Y$, correspondiente al cuantil de información de cada variable exógena $X_{i}$. El proceso consiste ahora en minimizar las desviaciones absolutas ponderadas con pesos específicos asimétricos, es decir, que a cada desviación correspondiente a la observación $i$ se le da un peso conveniente, dependiendo del cuantil donde se está estimando la regresión.

Para el cálculo de la regresión cuantílica, empleamos como variables dependientes dos indicadores del bienestar: un índice de bienestar social (IBS) y el índice de desarrollo humano (IDH), tomando como referencia los conceptos de dichos índices de la OCDE y del PNUD, respectivamente; planteamos tres pruebas de la hipótesis, basada cada una de ellas en la relevancia que tiene el gasto federal en tres rubros que dan sustento a las variables explicativas: gasto en educación (GE), gasto en salud (GS) y gasto en alimentación (GA), información obtenida de la Encuesta Nacional de Ingresos y Gastos de los Hogares para el año (2016); finalmente, usamos como variable de robustez del modelo el producto interno bruto rezagado un periodo $\left(P I B_{t-1}\right)$ con el propósito de analizar su capacidad potencial sobre el bienestar de las familias en México.

El cuadro 2 presenta los resultados de las regresiones cuantílicas sobre la variable dependiente IBs; las estimaciones se realizaron para cinco cuantiles diferentes, a saber: cuantil 5, 25, 50 (mediana), 75 y 95 de la distribución del bienestar representada por IBS.

Los resultados de la estimación cuantílica reflejados en el cuadro 2 muestran evidencia de los estimadores para los cuantiles 5, 25, 50, 75 y 95. En general se observa una relación congruente con el signo esperado; de igual forma, cada uno de los parámetros tiene asociado un nivel de significancia aceptable a $95 \%$ de confianza. Se observa variabilidad del valor de los parámetros cuando pasa de un cuantil a otro cuantil. Para los cuantiles 5 y 25 tiene mayor poder de explicación $G A$, luego $G S$ y menor relevancia $G E$. En el caso de los cuantiles 50 y 
Cuadro 2. Resultados de la estimación mediante regresión cuantílica para IBS

\begin{tabular}{|c|c|c|c|c|c|}
\hline$(\%)$ & 5 & 25 & 50 & 75 & 95 \\
\hline$l P I B_{t-1}$ & $\begin{array}{c}0.04 \\
(2.14)^{*}\end{array}$ & $\begin{array}{c}0.09 \\
(2.25)^{*}\end{array}$ & $\begin{array}{c}0.43 \\
(1.80)^{*}\end{array}$ & $\begin{array}{c}0.64 \\
(3.31)^{*}\end{array}$ & $\begin{array}{c}0.11 \\
(1.56)\end{array}$ \\
\hline$l G E$ & $\begin{array}{c}0.07 \\
(2.13)^{*}\end{array}$ & $\begin{array}{c}0.11 \\
(1.98)^{*}\end{array}$ & $\begin{array}{c}0.39 \\
(2.14)^{*}\end{array}$ & $\begin{array}{c}0.28 \\
(3.21)^{*}\end{array}$ & $\begin{array}{c}0.31 \\
(1.46)\end{array}$ \\
\hline lGS & $\begin{array}{c}0.18 \\
(1.79)^{*}\end{array}$ & $\begin{array}{c}0.23 \\
(2.13)^{*}\end{array}$ & $\begin{array}{c}0.25 \\
(1.69)\end{array}$ & $\begin{array}{c}0.19 \\
(2.56)^{*}\end{array}$ & $\begin{array}{c}0.28 \\
(2.19)^{*}\end{array}$ \\
\hline$l G A$ & $\begin{array}{c}0.31 \\
(3.11)^{*}\end{array}$ & $\begin{array}{c}0.27 \\
(1.74)\end{array}$ & $\begin{array}{c}0.41 \\
(2.23)^{*}\end{array}$ & $\begin{array}{c}0.34 \\
(1.95)^{*}\end{array}$ & $\begin{array}{c}0.27 \\
(1.47)\end{array}$ \\
\hline Constante & $\begin{array}{c}0.00 \\
(3.25)^{*}\end{array}$ & $\begin{array}{c}0.00 \\
(1.07)^{*}\end{array}$ & $\begin{array}{c}0.00 \\
(1.14)\end{array}$ & $\begin{array}{c}0.00 \\
(1.13)\end{array}$ & $\begin{array}{c}0.00 \\
(3.14)^{*}\end{array}$ \\
\hline$R^{2}$ & 0.38 & 0.52 & 0.42 & 0.34 & 0.41 \\
\hline \multicolumn{6}{|c|}{ Prueba conjunta: F-Sat $(\operatorname{Pr}>\mathrm{F})$} \\
\hline $5 \%$ & & $(0.07)$ & $(0.31)$ & $(0.17)$ & $(0.26)$ \\
\hline $25 \%$ & & & $(0.00)$ & $(0.00)$ & $(0.31)$ \\
\hline $50 \%$ & & & & $(0.00)$ & $(0.00)$ \\
\hline $75 \%$ & & & & & $(0.00)$ \\
\hline
\end{tabular}

* Denota significancia al $5 \%$ de confianza.

Fuente: elaboración propia con información de Inegi [2018].

75 , presenta mayor importancia $G A$, luego $G E$ y menor importancia GS Finalmente en el cuantil 95 se invierte la situación: tiene mayor peso $G E$, luego $G S$ y evidencia menor relevancia $G A$.

El cuadro 3 muestra los resultados de las regresiones cuantílicas sobre la variable dependiente IDH. Las estimaciones se realizaron, de igual forma, para cinco cuantiles, a saber: cuantiles 5, 25, 50 (mediana), 75 y 95 de la distribución del bienestar representada por $I D H$. 
Cuadro 3. Resultados de la estimación mediante regresión cuantílica para IDH

\begin{tabular}{|c|c|c|c|c|c|}
\hline$(\%)$ & 5 & 25 & 50 & 75 & 95 \\
\hline$l P I B_{t-1}$ & $\begin{array}{c}0.00 \\
(3.11)^{*}\end{array}$ & $\begin{array}{c}0.00 \\
(2.21)^{*}\end{array}$ & $\begin{array}{c}0.00 \\
(1.70)\end{array}$ & $\begin{array}{c}0.01 \\
(1.07)\end{array}$ & $\begin{array}{c}0.03 \\
(1.82)^{*}\end{array}$ \\
\hline$l G E$ & $\begin{array}{c}0.09 \\
(2.34)^{*}\end{array}$ & $\begin{array}{c}0.17 \\
(3.10)^{*}\end{array}$ & $\begin{array}{c}0.42 \\
(2.10)^{*}\end{array}$ & $\begin{array}{c}0.37 \\
(1.80)^{*}\end{array}$ & $\begin{array}{c}0.34 \\
(1.92)^{*}\end{array}$ \\
\hline lGS & $\begin{array}{c}0.28 \\
(2.00)^{*}\end{array}$ & $\begin{array}{c}0.23 \\
(2.00)^{*}\end{array}$ & $\begin{array}{c}0.25 \\
(2.01)^{*}\end{array}$ & $\begin{array}{c}0.19 \\
(2.00)^{*}\end{array}$ & $\begin{array}{c}0.31 \\
(1.98)^{*}\end{array}$ \\
\hline$l G A$ & $\begin{array}{c}0.37 \\
(2.14)^{*}\end{array}$ & $\begin{array}{c}0.31 \\
(1.79)\end{array}$ & $\begin{array}{c}0.29 \\
(1.63)\end{array}$ & $\begin{array}{c}0.31 \\
(1.82)^{*}\end{array}$ & $\begin{array}{c}0.31 \\
(1.18)\end{array}$ \\
\hline Constante & $\begin{array}{c}0.00 \\
(1.43)\end{array}$ & $\begin{array}{c}0.00 \\
(1.92)^{*}\end{array}$ & $\begin{array}{c}0.00 \\
(2.34)^{*}\end{array}$ & $\begin{array}{c}0.00 \\
(1.68)\end{array}$ & $\begin{array}{c}0.00 \\
(2.17)^{*}\end{array}$ \\
\hline$R^{2}$ & 0.52 & 0.42 & 0.45 & 0.47 & 0.38 \\
\hline \multicolumn{6}{|c|}{ Prueba conjunta: F-Sat $(\mathrm{Pr}>\mathrm{F})$} \\
\hline $5 \%$ & & $(0.00)$ & $(0.00)$ & $(0.07)$ & $(0.02)$ \\
\hline $25 \%$ & & & $(0.00)$ & $(0.00)$ & $(0.03)$ \\
\hline $50 \%$ & & & & $(0.00)$ & $(0.06)$ \\
\hline $75 \%$ & & & & & $(0.57)$ \\
\hline
\end{tabular}

* Denota significancia al $5 \%$ de confianza.

Fuente: elaboración propia, con información de Inegi [2018].

Los resultados de la estimación cuantílica reflejados en este cuadro 3 muestran evidencia de los estimadores para los cuantiles 5, 25, 50, 75 y 95. En general, los resultados son persistentes a los obtenidos en el cuadro 2 ; de igual forma se mantienen los niveles de eficiencia y se observa variabilidad del valor de los parámetros entre cuantiles. Para los cuantiles 5 y 25 tiene mayor poder de explicación $G A$, luego $G S$ y menor relevancia $G E$. En el caso de los cuantiles 50 y 75 , presenta mayor importancia $G E$, luego $G A$ y menor importancia $G S$. Finalmente en el cuantil 95, se invierte el resultado: tiene mayor peso $G E$, luego $G S$ y menos relevancia $G A$. 


\section{Conclusiones}

En un sentido amplio y general, el bienestar es un concepto multidimensional que comprende aspectos económicos y sociales de las necesidades básicas de los individuos. Es cierto también que el bienestar tiene que abordarse desde dos perspectivas: por un lado, la propia autodeterminación que deben tener los individuos para alcanzar un posible nivel de bienestar, $y$, por otro, las acciones y los compromisos que debe realizar todo gobierno para coadyuvar al propósito de lograr el bienestar para toda la sociedad.

Desde una perspectiva de orden conceptual, se logró sintetizar algunos elementos de las distintas acepciones del concepto de bienestar. Pasando por el planteamiento de la imposibilidad que presenta el PIB como posible aproximación al concepto de bienestar, se plantearon algunas aseveraciones sobre el tema de la medición del bienestar. También fue posible hacer un esfuerzo por plantear algunas perspectivas del Estado mexicano acerca del bienestar social, con énfasis en el enfoque de derechos sociales.

En lo que respecta a la evidencia empírica, logramos aportar evidencia empírica del papel fundamental que tiene el Estado mexicano mediante la política de gasto en educación, salud y alimentación para impulsar el bienestar de la población en general, lo que se muestra en el cuadro 1, la cual registra los resultados del modelo MCG: en general, los resultados revelan que a mayor gasto representado en cada una de las variables explicativas: $l_{G E}, l_{G S}$ y $l_{G A}$, este se ve reflejado en un aumento del bienestar, representado por las variables dependientes IBS e IDH.

Finalmente, en el propósito de evidenciar el papel que tiene la propia autodeterminación de los individuos para impulsar su bienestar, en los resultados de los cuadros 2 y 3 queda manifiesta la importancia que el gasto de los hogares tiene en rubros como educación, salud y alimentación, con algunas 
variantes basadas en el cuantil en que se encuentran los hogares.

En líneas generales, tomando en consideración una aproximación al concepto de bienestar, cabe destacar dos aspectos que en conjunto podrían ser la estrategia más acertada para impulsar el bienestar. Por un lado, la autodeterminación de los hogares para ejercer el gasto en rubros estratégicos como la educación, la salud y la alimentación, y, por otro lado, el compromiso y cumplimiento de la autoridad del Estado mexicano para ejercer mayor gasto federal en dichos rubros. La conjunción de ambas estrategias lograría el bienestar de las personas en lo particular y de la sociedad en lo general.

\section{REFERENCIAS}

Aguilar Villanueva, Luis F. [2012], Política Pública. Una visión panorámica, La Paz, PNUD-Bolivia, Embajada de Suecia, Observatorio de Análisis de Política Pública.

Almagro, Vázquez, Francisco y Fernández García, Óscar [2011], "Alcances y limitaciones del producto interno bruto como medidor del crecimiento económico, bienestar y desarrollo", Eseconomía, México. 6(31), tercer trimestre.

AnAnd, S., y A. Sen [1997], "Concepts of Human Development and Poverty. A Multidimensional Perspective", en Poverty and human development: Human development papers 1997, Nueva York, United Nations Development Programme.

[1995], "Gender inequality in human development: Theories and measurement", en Background papers: $\mathrm{Hu}$ man development report 1995, Nueva York, United Nations Development Programme.

[1994], Human development index: Methodology and measurement, Nueva York, Human Development Report Office. 
Asamblea Legislativa del Distrito Federal [2000], Ley de Desarrollo Social para el Distrito Federal, Distrito Federal, Asamblea Legislativa del Distrito Federal.

BARRo, Robert J. y X. Sala I Martin [2009], Crecimiento económico, Barcelona, Reverte.

Cámara de Diputados del H. Congreso de la Unión [2004], Ley General de Desarrollo Social, México, Cámara de Diputados del H. Congreso de la Unión.

CARdozo, Miriam y Ángel Mundo [2012], Guía de orientación para la evaluación de políticas y programas de desarrollo social, México, Evalúa-DF.

CEPAL [2000], "Capítulo 3. Principios de la política social y lucha contra la pobreza", en Equidad, desarrollo y ciudadanía, CEPAL.

Coneval [2020], Ingreso (Bienestar económico). Programas que son relevantes para esta dimensión, México, Consejo Nacional de Evaluación de la Política de Desarrollo Social, $<$ https://cutt.ly/KhvkoRm>.

Froнock, Fred [1979], Public Policy: Scope and Logic, Englewood Cliffs, Prentice Hall.

Gamble, Andrew [2017], La era de la perplejidad: repensar el mundo que conocíamos. El estado de bienestar y las políticas de austeridad, Madrid, BBVA, OpenMind, Penguin Random House Grupo Editorial.

Gobierno De México [2019], Plan Nacional de Desarrollo, 2019-2024, México.

González Plessmann, Antonio [2010], Políticas públicas con enfoque de derechos humanos: una propuesta para su conceptualización, Universidad Andina Simón Bolívar, Sede Ecuador; Programa Andino de Derechos Humanos, <http:// hdl.handle.net/10644/1022>.

INEGI (Instituto Nacional de Estadística y Geografía) [2018], Encuesta Nacional de Ingresos y Gastos de los Hogares 2019, ENIGH, Nueva serie, Descripción de la base de datos, $<$ https://cutt.ly/MhvhMlE $>$. 
[2014 y 2016], Encuesta Nacional de Ingresos y Gastos de los Hogares (ENIGH), Módulo de Condiciones Socioeconómicas.

[2008, 2010 y 2012], Encuesta Nacional de Ingresos y Gastos de los Hogares (ENIGH), Módulo de Condiciones Socioeconómicas.

Koenker, R., y G. Basset [1978], "Regression quantiles", Econometrica, 46(1): 33-50.

Mankiw, N. Gregory [1998], Principios de economía, México, McGraw Hill.

Marbán, Vicente [s/f], Tema 7. "El Estado de bienestar: modelos, regímenes y objetivos", <https://n9.cl/6wqid>.

ocDE [2018], Estudios económicos de la ocDE: México, Publishing, <https://doi.org/10.1787/fde7bbbe-es>.

[2011], Better Life Index.

PNUD (Programa de las Naciones Unidas para el Desarrollo) [2019], Life expectancy at birth. <https://cutt.ly/EhvjrcN>.

[2014], Informe sobre Desarrollo Humano 2014. Sostener el progreso humano: reducir vulnerabilidades y construir resiliencia, Washington, D. C., Programa de las Naciones Unidas para el Desarrollo.

[2010], Informe sobre Desarrollo Humano 2010, Edición del Vigésimo Aniversario, Nueva York, Programa de las Naciones Unidas para el Desarrollo.

Ruiz Sánchez, Carlos [1996], Manual para la elaboración de políticas públicas, México, UIA/Pyv.

SEN, Amartya [2010], Nuevo examen de la desigualdad, Madrid, Alianza Editorial.

Stiglitz, Joseph, Amartya Sen y Jean-Paul Fitoussi [2009], Informe de la Comisión sobre la Medición del Desarrollo Económico y del Progreso Social, Francia. 


\title{
¿QUÉ REOUIERE EL CRECIMIENTO ECONÓMICO PARA AUMENTAR EL BIENESTAR?
}

\author{
Moritz Cruz*
}

\section{INTRODUCCIÓN}

Por lo general, se tiende a aceptar que para mejorar el bienestar de la población (no solo desde la perspectiva del ingreso sino desde cualquiera de sus dimensiones) es condición sine qua non el crecimiento económico. La lógica en que se sostiene esta idea es que únicamente la generación de riqueza produce bienestar. Con mayor riqueza es posible redistribuir a los estratos de menor ingreso, así como dirigir recursos a canales (infraestructura e instituciones, entre otras) que impacten en el bienestar de la sociedad. De otra forma, es decir, sin crecimiento económico y generación de riqueza, solo se estarían transfiriendo recursos de quienes tienen mayor ingreso a quienes tienen poco y en este sentido se les estaría despojando de su bienestar; se tendría, en otras palabras, un mecanismo que va contra las reglas del mercado al castigar a quienes más tienen y que tendría como resultado final desincentivar a quienes generan riqueza, lo que perpetuaría el estancamiento económico.

Curiosamente, la lógica arriba mencionada tiene al menos dos debilidades fundamentales. La primera es su visión estática e inmutable del bienestar; es decir, al suponer que cada agente económico gana su ingreso en función de sus habilidades, la

\footnotetext{
* Investigador del Instituto de Investigaciones Económicas, UNAM. Correo electrónico:<aleph398@gmail.com>.
} 
distribución del ingreso (y el bienestar en general) es inmutable: así lo ha determinado el mercado y nada, o muy poco, hay que hacer al respecto. En este sentido, los individuos son los únicos responsables de mejorar sus habilidades para lograr mayor ingreso. Esta lógica tiene sentido para quienes disfrutan de elevado ingreso (y bienestar), pero no es así para aquellos que tienen poco ingreso (y bienestar). Estos últimos carecen, entre otras, de las mismas oportunidades que sus contrapartes de ingresos mayores de acceso a y conclusión de, por ejemplo, la educación en general y en particular la universitaria.

La segunda tiene que ver con el contraste empírico. De ser cierto el condicionamiento del bienestar al crecimiento económico, entonces se tendría que observar una mejoría en el bienestar siempre que se observe crecimiento, sin importar cuál sea su dinámica. Al respecto, son excepcionales las economías que, desde inicios de la década de los 80 a la fecha, a la par de crecer registran mejoría en el bienestar. Por ejemplo, la participación del salario en el ingreso (una medida de bienestar) cayó cinco puntos porcentuales o más en economías desarrolladas entre 1980 y 2006 a 2007. Aunque en economías en desarrollo este patrón no es generalizable, es posible observar que solo algunas economías registraron mejoría y esta fue de carácter temporal [UNCTAD, 2012].

En el caso particular de la economía mexicana, es sabido que el crecimiento promedio de $2 \%$ entre 1980 y 2019 no se tradujo en mayor bienestar general sino por el contrario, el mismo se acompañó de poca o nula mejoría. Por ejemplo, la participación de los salarios en el ingreso declinó de manera sostenida y el número de pobres ha ido en aumento. En este contexto, es claro que si se mantiene el objetivo de aumentar el producto por el simple hecho de que debe hacerse, poco o nada se logrará en términos de bienestar y, por lo mismo, la cuestión relevante es qué necesita el crecimiento económico para generar bienestar para la mayoría. La intención de este trabajo es responder esa pregunta mediante la identificación de los 
mecanismos que deben acompañar al crecimiento económico para generar bienestar. Para lograr tal objetivo, se hace una revisión de lo que sucedió durante la llamada época dorada del capitalismo, cuando el avance del bienestar fue relevante y general. En este contexto, el capítulo está estructurado como sigue. La segunda sección aborda de manera sucinta los argumentos que sostienen que el bienestar de unos pocos es un resultado normal del capitalismo. La tercera sección analiza qué elementos caracterizaron el bienestar en la época dorada del capitalismo. La cuarta sección se enfoca en México e intenta exponer las razones detrás del poco avance del bienestar desde 1980. Por último, se presentan las conclusiones.

\section{Dos ARGUMENTOS: UN MISMO RESULTADO}

Como señalamos, de modo tradicional se ha supuesto que la condición sine qua non para generar bienestar es el crecimiento económico. La lógica de este argumento descansa esencialmente en la idea de que el mercado recompensa las habilidades de los factores de producción (agentes económicos vistos como capitalistas y asalariados) a través de su contribución marginal a la producción o productividad (que se refleja en la ganancia y el salario, respectivamente). Quienes son más hábiles y talentosos, incluso cuando las circunstancias iniciales son adversas, son quienes generalmente harán una contribución mayor a la producción o incrementarán la productividad y, por tanto, recibirán una compensación mayor. Es el mercado, como consecuencia, el que fija quiénes deben tener un mayor ingreso y quiénes uno menor. El bienestar, visto por la distribución funcional del ingreso o la remuneración a los factores de producción, en este sentido se determina de manera "natural" y nada debe hacerse por cambiarlo [Friedman y Friedman, 1980]. No hay incluso injusticia en la forma como se establece y, por el contrario, 
tratar de alterarla menoscabará las fuerzas del mercado al desincentivar a quienes son más productivos. Si el capitalista, por alguna razón de política, es decir, debido a la intervención del gobierno, ve disminuida su ganancia, perderá incentivos para ser más productivo, lo que llevará a un ciclo de menor inversión y menor crecimiento económico y como resultado el bienestar empeorará. En todo caso, bajo esta visión y en esencia, el gobierno solo debe garantizar que las reglas del sistema sean iguales para todos, de tal suerte que no existan barreras a la entrada ni se creen ventajas artificiales. El bienestar, visto por el lado de la distribución funcional del ingreso, no es, en otras palabras, algo que deba corregirse.

Aunada a esta visión de cómo el bienestar es determinado de manera "natural" por las fuerzas del mercado, está la visión de largo plazo en la que el cambio estructural o el desarrollo económico mantienen una relación inversa con el bienestar hasta cierto umbral. En efecto, la propuesta de Kuznets [1955; UNCTAD, 2012] señala que durante las etapas iniciales de desarrollo económico (léase, cuando tanto la fuerza de trabajo como el PIB están dominados por el sector agrícola) será normal observar un deterioro del bienestar. La razón: los salarios del sector urbano crecen más rápido que los del resto de los sectores porque la productividad de las empresas manufactureras, que dominan en las ciudades, es mayor que la del sector rural o primario. Recordemos que las empresas manufactureras se caracterizan por tener rendimientos crecientes. Por el contrario, la tecnificación y, por tanto, la productividad y los salarios crecen de modo más lento en las actividades rurales. Esto hará que los ingresos de los trabajadores urbanos sean mayores que los de los rurales y disparará la brecha salarial entre ambos sectores.

No obstante, continúa el argumento, esto cambiará tan pronto la productividad del sector primario, debido tanto al uso de tecnología más moderna como a la disminución de los 
trabajadores, aumente, y con ello los salarios. La brecha salarial entre trabajadores urbanos y rurales comenzará a reducirse, dando inicio a un aumento generalizado del bienestar. Es decir, la relación inversa entre desarrollo económico y bienestar cambiará, lo que marcará la etapa en que la sociedad se torna más y más igualitaria.

En ambas visiones, como puede verse, predomina el argumento de que el bienestar es un proceso natural producto de las fuerzas del mercado o del mismo progreso económico. Y en ambos casos, poco o nada debe hacerse para alterar dicho resultado natural. De hacerlo, en el primer caso, se desincentivaría a los más productivos, con lo que el bienestar general podría deteriorarse indefinidamente. En el segundo caso, alterar el transcurso del cambio estructural podría generar un umbral prematuro donde la brecha de ingresos comienza a reducirse. Por ejemplo, pensemos en el caso en que el gobierno incremente los salarios del sector rural con el fin de reducir la brecha de ingresos en ambos sectores. Esto podría causar que los incentivos para migrar al sector urbano disminuyeran, originando una reducción de la mano de obra y, por lo mismo, un incremento del salario, lo cual reduciría la tasa de ganancia en el sector. La inversión, como consecuencia, disminuirá, provocando menor empleo y estancamiento de la productividad debido a la reducción de recursos para comprar o innovar en nueva maquinaria. Con el estancamiento de la productividad, los salarios no crecerán y la brecha entre salarios urbanos y rurales se cerrará de manera prematura. El aspecto negativo de esto es que no habría incentivo para que la productividad crezca, por lo que se observaría un tipo de estancamiento económico precario. Así, en suma, la mejor opción de política para mejorar el bienestar es no distorsionar el mercado.

Curiosamente, incluir la demanda en el análisis del bienestar permite plantear escenarios donde el mismo puede incrementarse, con independencia del estado de desarrollo. Por ejemplo, los impuestos progresivos al ingreso proveen 
de mayores recursos al Estado para que realice acciones diversas que pueden impulsar la demanda efectiva, de manera tanto directa como indirecta, aumentando así los ingresos y las ganancias de las empresas. Si el Estado usa esos recursos para proveer servicios de salud, los trabajadores no necesitarán usar parte de su ingreso para pagar por dichos servicios y los destinarán al consumo; es decir, su ingreso disponible se canalizará a la demanda de bienes y servicios. Así, contrario a desincentivar la inversión, el mero hecho de que la demanda se mantenga estable o aumente será factor para que los planes de inversión se mantengan constantes y se materialicen. Como consecuencia de lo anterior, el empleo se mantendrá o crecerá, dando mayor poder de negociación a los asalariados, por lo que su salario real puede mantenerse. Esto puede alterar la distribución del ingreso ya que el salario real y el consumo aumentarán. Lo mismo puede pensarse cuando el gobierno destina recursos para establecer la infraestructura para proveer educación o bien cuando los ocupa para garantizar un ingreso cuando el trabajador pierde temporalmente su empleo. $\mathrm{Al}$ hacerlo, insistimos, la demanda no caerá.

Visto así, el bienestar puede ser en realidad producto del conjunto de políticas que el Estado implemente para distribuir los recursos que obtiene a través de los impuestos o de deuda, sin que, y es muy importante recalcarlo, los incentivos que son intrínsecos al mercado desaparezcan.

\section{¿QUÉ TUVO DE ESPECIAL LA ÉPOCA DORADA \\ DEL CAPITALISMO PARA EL BIENESTAR?}

La llamada época de oro del capitalismo, esto es, el periodo que va desde inicios de las década de 1950 hasta mediados de la década de 1970, se caracterizó no solo por la dinámica elevada y sostenida del crecimiento económico (5.4\% promedio anual para el conjunto de países de Alemania, Estados Unidos, Francia, 
Italia, Japón y Reino Unido) acompañada de bajo desempleo e inflación, de alrededor de $2 \%$ y $3 \%$, respectivamente [Cornwall y Cornwall, 2009], sino por el aumento generalizado del bienestar en las economías capitalistas. De acuerdo con la UNCTAD [2012: 48], la participación de los salarios en el ingreso en países desarrollados como Francia creció ocho puntos porcentuales entre 1950 y 1975 , de $62.2 \%$ a $70.3 \%$; casi siete en Estados Unidos en el mismo periodo, de $57.5 \%$ a $63.7 \%$; y cuatro puntos en el Reino Unido, de $66.8 \%$ a $70.6 \%$. Países en desarrollo, como Argentina y Chile, vieron que la participación salarial se mantuvo constante en dicho periodo, en alrededor de $47 \%$ y $45 \%$, respectivamente. Es importante notar que esta mejoría de la participación del salario en el ingreso total estuvo acompañada por una disminución del ingreso del 1\% más rico de los hogares de los países avanzados y en desarrollo [UNCTAD, 2012].

¿Cómo explicar esta mejoría en el bienestar? Desde luego, una primera respuesta viene del crecimiento y el empleo generados. Como mencionamos, este periodo se significó por un ritmo de crecimiento alto y estable. Y en este contexto resulta relevante destacar el impulso que tuvo dicho crecimiento por parte del Estado. Como se sabe, durante esos años dominó la visión macroeconómica keynesiana, misma que sostiene que el gobierno tiene la prioridad de mantener la dinámica económica tan alta como sea posible mediante la administración de la demanda efectiva. Para que esta sea alta, debe inyectar recursos a través de su gasto tanto en consumo como en inversión, incurriendo cuando sea necesario en déficits fiscales [Davidson, 2007]. Aunque es imposible demeritar la relevancia que tuvo la implementación de políticas keynesianas para impulsar el crecimiento, como señalamos, el mero aumento del crecimiento y el empleo no garantiza la mejoría sostenida del bienestar, pues, por ejemplo, los trabajados generados pueden ofrecer salarios bajos, lo que perpetúa la desigualdad. No hay, en realidad, insistimos, mecanismo automático de mercado que garantice el incremento del bienestar. Habría entonces que mirar más 
allá, en los mecanismos de política que se implementaron en aquella época para entender mejor por qué y cómo aumentó el bienestar.

Una respuesta al respecto es la dada por Cornwall y Cornwall [2009], quienes ponen el acento en acuerdos en el mercado laboral que permitieron, en efecto, aumentar el bienestar. El principal de estos acuerdos fue el principio de justicia que regiría la fijación de los salarios. En dicho principio, se acordó que las negociaciones salariales aseguraran que el factor trabajo recibiera un pago justo, a través de una prima que garantizara el crecimiento del salario real y una parte equitativa en el ingreso total.

Dicho principio debía estar en concordancia con las metas de pleno empleo, productividad e inflación. Cuando las negociaciones salariales se llevaron a cabo sin intermediación gubernamental que fijara un tope al aumento del salario monetario, la inflación se desbocó. Esta fue una de las causas del aumento inflacionario en la década de 1970. Por otra parte, cuando el principio se rigió bajo la base de una negociación social, en la que el crecimiento salarial estuvo en concordancia con las metas de pleno empleo, productividad e inflación, dicha estrategia logró mantenerse sin desequilibrios macroeconómicos. Más aún, dicha negociación social incluyó penalizaciones tanto para los empleadores como para los trabajadores y se acompañó de otras medidas para mejorar el bienestar. $\mathrm{Al}$ respecto, estuvieron la integración de un sistema de seguridad social con capacidad de proteger contra enfermedades, desempleo, vejez, maternidad y viudez y con el propósito de cubrir a toda la población, el establecimiento de un ingreso mínimo de subsistencia necesario, subsidios familiares y la adopción del objetivo de pleno empleo [Ordóñez, 2002]. El establecimiento de un Estado de bienestar, en otras palabras, fue pieza clave para alcanzar mejoras importantes en los estándares de vida de la población.

Desde luego, los recursos para financiar todo este andamiaje institucional de bienestar provinieron de un Estado que 
también aumentó su recaudación. Entre 1950 y 1970, países como Francia aumentaron su recaudación siete puntos porcentuales, al pasar de $29.2 \%$ a $36.7 \%$ del PIB, casi el mismo incremento registrado por Estados Unidos, que pasó de $20.6 \%$ a $26.7 \%$ del PIB; Suecia lo duplicó al pasar de $21.7 \%$ a $37.9 \%$ del PIB en el mismo periodo.

$\mathrm{Al}$ parecer, entonces, son tres los factores comunes y necesarios para entender la evolución del bienestar entre 1950 y 1975: intervención del Estado a través de su gasto para garantizar una demanda efectiva estable y/o al alza, manteniendo el crecimiento económico lo más cercano posible al pleno empleo; acuerdos de negociación gobierno-sector privado-sindicatos que prioricen el aumento del salario real en concordancia con las metas macroeconómicas de pleno empleo e inflación; y creación (o en su defecto reforzamiento o modificación) del marco institucional que garantice la seguridad social de calidad y gratuita, lo que incluye un seguro de desempleo y una pensión digna. Finalmente, la implementación de medidas fiscales que garanticen ingresos públicos robustos, enfatizando en la progresividad a los ingresos, y otros impuestos a la riqueza.

¿Es Posible InCREMENTAR EL BIENeStAR EN MÉxico?

Los requerimientos descritos para mejorar el bienestar han ido desapareciendo paulatinamente en la mayoría de las economías, lo cual ha generado una época de declive en el bienestar (con ciertas excepciones regionales, como China en Asia o Finlandia, Suecia y Noruega en Europa; o bien, por ciertos periodos: América Latina durante la primera década de 2000 [UNCTAD, 2012]). En efecto, con el arribo de la estanflación durante los años 70 del siglo pasado, las políticas keynesianas y el Estado de bienestar fueron desapareciendo de manera lenta, dando lugar a medidas que buscaban la corrección de los 
déficits público y externo y el control de la inflación. Dichas medidas implicaban sobre todo austeridad en el gasto público (y disminución de impuestos a los hogares de mayores ingresos), ajuste cambiario y adopción, según conviniera al control inflacionario, de un régimen fijo o flexible, subida de la tasa de interés y reducción de la oferta monetaria y del crédito.

Aunque dichas medidas se adoptaron en países avanzados, fueron las economías en desarrollo las que las vivieron en toda su magnitud a través de los programas de ajuste y choque sugeridos y en ocasiones implementados por el Fondo Monetario Internacional (FMI) y el Banco Mundial (BM) en la década de 1980. A partir de entonces, comenzó a implementarse el modelo de corte neoliberal denominado Consenso de Washington, modelo de crecimiento liderado por las exportaciones o bien modelo de globalización liderado por las finanzas. La esencia ha sido la misma: austeridad fiscal, que implica reducción del gasto público en inversión, en consumo, en el Estado de bienestar y en todas aquellas áreas donde no es considerado esencial, incluida la salud; la austeridad fiscal también conlleva la privatización de gran parte de los bienes públicos (agua, energía y educación, entre otras) con el doble propósito de disminuir el gasto y hacerse de ingresos; en paralelo, en la parte impositiva se sugiere la introducción de gravámenes al consumo masivo (tipo IVA) y la reducción de impuestos a las ganancias y los estratos de mayores ingresos con el objeto de estimular la inversión [Blyth, 2013]. Una segunda medida de trascendencia ha sido la liberalización tanto de la cuenta corriente como de la cuenta de capital con el objetivo de que sean las exportaciones las que promuevan el crecimiento económico y que sean las fuerzas del mercado las que determinen tanto la tasa de interés doméstica como el tipo de cambio. Lograr la liberalización comercial y financiera conlleva remover y renunciar a la políticas comercial, monetaria y cambiaria [Cruz y Lapa, 2012]. El contexto generado por este modelo ha facilitado e incentivado a las empresas a obtener ganancias 
de corto plazo en los mercados de valores, priorizando la inversión de cartera sobre la productiva [UNCTAD, 2012].

Finalmente, se ha enaltecido como enemigo público número uno a la inflación: su combate es el gran (y a veces único) objetivo de la gran generalidad de las economías capitalistas bajo el argumento de que quienes más sufren en periodos de elevada inflación son los pobres. Para tal efecto, la política fiscal debe estar en armonía con el objetivo inflacionario propuesto por el Banco Central, por lo general alrededor de $3 \%$, más o menos. En este contexto, la principal herramienta para combatir la inflación es la tasa de interés, misma que, se asume, afecta la inversión y como consecuencia la demanda agregada [Carlin y Soskice, 2015]. Más aún, para controlar la inflación, y en aras de la "competitividad", los salarios deben aumentar lo menos posible o si es posible no crecer. Esto y la abundancia de ahorro, toda vez que el gobierno no gasta más de lo que recauda, deben dar impulso a la inversión. Es decir, se genera el supuesto clima de confianza tan necesario para que la inversión se materialice.

México ha sido fiel implementador del modelo descrito desde inicios de la década de 1980. En primera instancia, siguió (le fueron impuestos) los modelos de ajuste y estabilización sugeridos por el FMI y el BM en todas las crisis que padeció entre 1980 y 1995. En 1982, 1986 y 1994-95, la respuesta o solución fue austeridad fiscal, contracción monetaria, alza del tipo de interés y ajuste cambiario, seguidas de lucha inflacionaria. Después, embrazó el modelo neoliberal con la convicción de que era el único camino a seguir para lograr las metas de crecimiento. Así, privatizó diversas empresas y sectores públicos (como el financiero, el de las telecomunicaciones y después el energético), abrió la economía al comercio (mediante el Tratado de Libre Comercio con Estados Unidos y Canadá, la adhesión a la Organización Mundial del Comercio y la firma de un sinnúmero de tratados comerciales con diversos países alrededor del orbe), desreguló el sector financiero permitiendo la 
libre entrada y salida de capitales, adoptó un régimen cambiario flexible y, finalmente, puso el control inflacionario como el principal objetivo de política a seguir. Cada una de las crisis padecidas sirvió, de hecho, para profundizar el modelo: mayor austeridad, más privatización, mayor desregulación, etcétera. Desde luego, en el proceso, los ajustes salariales al alza se contuvieron por medio de las recomendaciones que la Comisión Nacional de Salarios Mínimos hacía, dejando en franco rezago el salario real [Calva, 2020] y como colofón se fue desmantelando el Estado de bienestar. Por ejemplo, mediante el cambio del modelo de pensiones de uno de beneficio definido, en el que el Estado es el único responsable y rector de los recursos, a uno de contribución definida o capitalización individual, en el que la responsabilidad del Estado disminuye y la administración, la inversión y los pagos aportados por los trabajadores quedan a cargo de empresas privadas ligadas al sector financiero [Martínez, 2019].

La expectativa de crecimiento y desarrollo económicos no se cumplió: entre 1980 y 2018, la economía mexicana creció en promedio $2 \%$ anual y el crecimiento del ingreso per cápita fue casi nulo. No resulta extraño, por tanto, observar que cuando la economía ha crecido relativamente bien el bienestar ha estado estancado o mejorado muy poco o, en el peor caso, ha retrocedido. Más de tres décadas perdidas en este sentido. La gráfica 1, por ejemplo, muestra la evolución de la distribución funcional del ingreso de 1970 a 2010. Lo que observamos es, en esencia, la caída vertiginosa de la participación de los salarios en el ingreso a partir de 1980, lo cual sugiere una disminución del bienestar cuando se mide por esa vía. En efecto, como puede apreciarse, a partir de inicios de la década de 1980 se identifica una tendencia a la baja de la participación de los salarios en el ingreso, misma que se detiene en 1988, para entonces presentar una cierta pero muy breve recuperación hasta 1994, volviendo a su senda decreciente a partir de 1995. Hasta 2010, los salarios no han vuelto a recuperar el peso en 
el ingreso observado en 1976, de 40\%. Por el contrario, las ganancias han pasado de tener una participación en el ingreso de $52 \%$ en 1970 a una de $62 \%$ en 2010 . En suma, es claro que el bienestar, visto desde esta perspectiva, se ha deteriorado y que el periodo de su declive coincide con la adopción del modelo neoliberal.

Gráfica 1. México: distribución funcional del ingreso, 1970 a 2010

(Porcentaje del PIB)

70

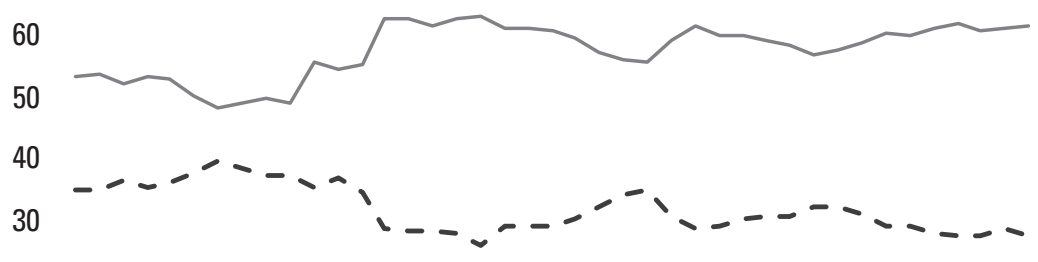

20

10

0

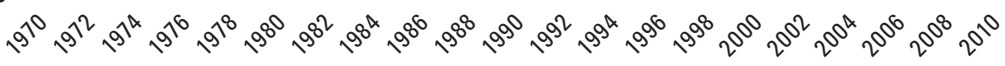
- - Salarios Ganancias

Fuente: Inegi, <www.inegi.org.mx>.

Otros indicadores reflejan un avance apenas significativo del bienestar (cuadro 1). Por ejemplo, en el caso del coeficiente de Gini, entre 1989 y 2002 la desigualdad del ingreso apenas disminuyó: de 54.3 a 50.1. Entre 2012 y 2018, el avance fue un poco más rápido ya que el coeficiente pasó de 48.7 a 45.4. No obstante estos avances, la desigualdad del ingreso sigue siendo sustancialmente alta. Esto también lo soporta el coeficiente de Palma de 4.05 en 1989 y de 3.09 en 2012. Es decir, el ingreso del decil de mayor ingreso supera hasta en tres veces el ingreso de $40 \%$ de la población más pobre. En la misma tesitura está el lentísimo avance del bienestar cuando se 
analiza el índice de desarrollo humano, que, como se sabe, incluye diversas dimensiones del bienestar (ingreso, educación y salud). Este índice muestra que entre 1990 y 2018 se ha avanzado en 11 décimas de punto, lo cual deja la economía todavía lejos de las economías con mejores registros, como las de Noruega o Suiza, con índices de 0.95 y 0.94 , respectivamente, en 2017; incluso lejos de su similar, Chile, la economía latinoamericana mejor posicionada de la región con un índice de 0.84 en ese mismo año.

Cuadro 1. México: indicadores de bienestar (años selectos)

\begin{tabular}{cccc}
\hline Año & $\begin{array}{c}\text { Coeficiente } \\
\text { de Gini }^{\mathrm{a}}\end{array}$ & $\begin{array}{c}\text { Índice de desarrollo } \\
\text { humano }^{\mathrm{b}}\end{array}$ & $\begin{array}{c}\text { Coeficiente } \\
\text { de Palma }^{\mathrm{c}}\end{array}$ \\
\hline 1989 & 54.3 & - & 4.05 \\
1990 & - & 0.65 & - \\
1996 & 54.8 & 0.67 & - \\
2002 & 50.1 & 0.72 & - \\
2012 & 48.7 & 0.74 & 3.09 \\
2018 & 45.4 & 0.76 & - \\
\hline
\end{tabular}

Fuentes: ${ }^{a}$ World Development Indicators, $<$ https://n9.cl/3kxcw>.

${ }^{b}$ United Nations Development Programme, <https://n9.cl/fle9>.

c Palma resources, <http://uncuonted.org >.

La razón de este deficiente desempeño del bienestar radica, como lo señalamos, en que con la adopción del modelo neoliberal los elementos predominantes para que mejore con el crecimiento económico han desaparecido. Asimismo, la política de crecimiento impulsada por el gasto público y cuyo objetivo es el pleno empleo es casi inexistente; el Estado de bienestar se ha eliminado paulatinamente; y la preocupación por garantizar mejoras salariales acordes con las metas macroeconómicas va en detrimento del mismo salario. Por último, la reducción 
de impuestos a los hogares de mayores ingresos se ha reducido, factor relevante para debilitar los ingresos públicos.

En este escenario es posible sugerir que para que el crecimiento económico sea en realidad condición sine qua non para incrementar el bienestar requiere un conjunto de políticas complementarias a fin de que tal crecimiento se refleje en el bienestar de la mayoría, para que sea, en términos más actuales, un crecimiento incluyente [Love, 2016].

La economía mexicana, por tanto, necesita abandonar el modelo de crecimiento neoliberal y reinstaurar uno que contemple la intervención del Estado para administrar la demanda, buscando como objetivo el pleno empleo y dejando en segundo término el control inflacionario; implementar acuerdos de negociación salarial que prioricen el aumento del salario real en concordancia con objetivos inflacionarios y de productividad; recuperar el Estado de bienestar, mediante el fortalecimiento del sistema de salud público, por ejemplo, y garantizando un sistema de pensiones digno, entre otras medidas; y, finalmente, realizar la tan anhelada reforma fiscal que grave de modo progresivo los ingresos y la riqueza. Esto es indispensable para que el Estado de bienestar se materialice.

\section{ConcLusiones}

En este trabajo, discutimos acerca de las condiciones necesarias para que el crecimiento económico se traduzca en bienestar para la mayoría de la población. Con base en lo que aconteció durante la época dorada el capitalismo, cuando se observó una mejoría considerable del bienestar a nivel global, encontramos varios elementos que deben acompañar al crecimiento económico. Uno de ellos es la administración de la demanda para mantener estable y al alza, lo más cercano posible al pleno empleo, la actividad económica. En este sentido, la reorientación de los objetivos de política en la búsqueda de 
pleno empleo es un factor crucial. Paralelamente está la instauración de un acuerdo social que garantice el crecimiento del salario real en concordancia con las metas de pleno empleo, inflación y productividad y, en tercer lugar, la instrumentación de todo el Estado de bienestar a través de instituciones de salud, pensiones dignas, seguro de desempleo y subsidios a los hogares más pobres, entre otros. Finalmente, el Estado garantizó recursos para realizar las tareas anteriores y para tal efecto instrumentó toda una reforma fiscal en la que los impuestos progresivos a los ingresos fueron la fuente principal.

Todo este aparato es contrario al modelo neoliberal prevaleciente. Y en este sentido, no ha resultado extraño el marginal progreso del bienestar desde la década de 1980. México no ha sido la excepción. Por lo mismo, para recuperar la senda de crecimiento acompañado de bienestar es indispensable que la economía mexicana retomé el marco instaurado durante la época dorada del capitalismo. Es decir, dar una vuelta de timón fijando los objetivos macroeconómicos en función del pleno empleo. Con esto en mente, instaurar un acuerdo social en el que se priorice el aumento del salario real en concordancia con las metas de inflación y productividad. Asimismo es indispensable que se reinstaure el Estado de bienestar. Un primer paso en esta dirección es fortaleciendo el sistema de salud y en segunda instancia abandonando el sistema de pensiones vigente. Para finalizar, debe garantizar los ingresos públicos mediante una reforma fiscal progresiva al ingreso y la riqueza.

\section{REFERENCIAS}

Bцyтн, M. [2013], Austerity. The history of a dangerous idea, Oxford, Oxford University Press.

CALVA, J. L. [2020], "Retos nodales del desarrollo económico en México para el quinquenio 2020-2024", Problemas del Desarrollo, 51(202): 25-44. 
CARLIN, W., y D. Soskice [2015], Macroeconomics, Institutions, Instability, and the Financial System, Reino Unido, Oxford University Press.

Cornwall, J., y W. Cornwall [2009], "Why do some economies have lower unemployment than others?", en P. Arestis y J. McCombie (eds.), The missing links in the unemployment relationship, Reino Unido, Palgrave Macmillan, pp. 31-50. Cruz, M., y J. Lapa [2012], "Crisis y recuperación económica: el papel de la política fiscal", Problemas del Desarrollo, 43(168): 95-116.

Davidson, P. [2007], John Maynard Keynes, Reino Unido, Palgrave.

Friedman, M., y R. Friedman [1980], Free to choose, Londres, Secker \& Warbur.

KUZNETS, S. [1955], "Economic growth and income inequality", America Economic Review, 45(1): 1-28.

Love, P. [2016], Debate the issues: New approaches to economic challenges, París, OCDE.

MarTínez, J. [2019], México: propuesta técnica para un nuevo sistema de pensiones, Nota técnica 1, Confederación Interamericana de Seguridad Social.

ORDóÑez Barba, G. [2002], "El Estado de bienestar en las democracias occidentales: lecciones para analizar el caso mexicano", Región y Sociedad, 44(24): 99-145.

UNCTAD (United Nations Conference on Trade and Development) [2012], Trade and Development Report. Policies for inclusive and balanced growth, Ginebra, UNCTAD. 

Finanzas PÚblicas PARA EL BIENESTAR 



\title{
EL BIENESTAR EN LA POLIITICA SOCIAL: ALCANCESY LIIMITES
}

\author{
Berenice P. Ramírez López*
}

\section{INTRODUCCIÓN}

El bienestar en la perspectiva del actual gobierno federal (2018 a 2024) se identifica con el derecho a la salud, la alimentación, el trabajo, la vivienda, la seguridad social, el agua, la educación, la cultura, el medio ambiente sano y el esparcimiento [Gobierno de México, 2019].

Con la definición descrita, el bienestar tiene una relación directa con los derechos humanos y sociales que para ser efectivos tienen que concretarse en acceso universal, que cubran las necesidades de forma suficiente y eficiente, y puedan ser sostenidos fiscalmente. Ante este gran reto, en este artículo se discutirá lo siguiente: ¿la persistencia y el crecimiento de las transferencias monetarias directas a la población más vulnerable, que se asocia con una perspectiva asistencialista, impactará en el bienestar de las personas? o ¿puede significar la permanencia del paradigma neoliberal en la construcción de la política social?

Para abordar las preguntas formuladas se desarrollarán los siguientes apartados: a) breve recorrido de la noción de

* Investigadora Titular de la Unidad de Investigación en Desarrollo y Políticas Públicas del Instituto de Investigaciones Económicas, UNAM. Correo electrónico: <berenice@unam.mx>. Agradezco el trabajo estadístico de Gabriel Badillo, Técnico Académico del IIEc (correo electrónico: <gbadillo@iiec.unam.mx>). 
bienestar y de los paradigmas que explican la política social; b) los paradigmas de la política social en México y la trayectoria del gasto social; c) acceso y disfrute de ingresos por pensión de las personas mayores de 68 años; y d) caminos a recorrer en la construcción del bienestar.

BREVE RECORRIDO DE LA NOCIÓN DE BIENESTAR

Y DE LOS PARADIGMAS QUE EXPLICAN

LA POLÍTICA SOCIAL

El bienestar ha sido objeto de atención de la filosofía, la ciencia y las disciplinas sociales, y por ello tiene connotaciones históricas y éticas determinadas por el espacio socioeconómico y su construcción política. El punto de partida pareciera ser su antónimo: cómo superar el malestar y las carencias. La Real Academia de la Lengua Española lo define como el "Conjunto de las cosas necesarias para vivir bien", pero qué es vivir bien: una construcción social e histórica que expresa relaciones de clase, de poder y, por ello, de diferenciación. Dicha situación ha dado lugar a la participación activa del Estado a partir de una política pública específica que condense en acciones e instituciones determinadas, acuerdos, consensos o al menos lineamientos que conduzcan a una idea de bienestar. En esta dirección, se asignó a la economía del bienestar el objetivo de procurar extender a todos los sectores sociales los servicios y medios fundamentales para una vida digna. Y regresamos de nuevo a un punto de partida histórico social: qué es la vida digna.

Deaton [2015] inicia su investigación sobre el bienestar con el análisis y la trayectoria de la salud como origen y dice que es obvio este punto de partida, ya que para tener una buena vida necesitas primero tenerla y asegurarla. Entiende por bienestar, cosas buenas para la vida de una persona, como bienestar material (ingreso, riqueza), bienestar físico y psicológico, 
con salud y felicidad, educación y capacidad de participar en la sociedad civil a través de la democracia y el imperio de la ley. Es una definición básica, clara, que intenta, aunque no lo logra, superar la perspectiva del individualismo metodológico. ${ }^{1}$ Reconoce que el capitalismo ha traído un mundo diferente para buena parte de la humanidad; le ha dado, en el ámbito del bienestar, la oportunidad de vivir más años, de tener menos susceptibilidad frente a las enfermedades, pero también ha ocasionado otros males, más enfermedades asociadas con la creciente urbanización y las consecuencias de la contaminación ambiental; además, registra que a pesar de los logros, la sociedad es hoy inconmensurablemente más desigual que hace 300 años [Deaton, 2015: 41].

Para Niklas Luhman [2014], el bienestar ha de significar más que la simple asistencia social o que la compensación de desventajas; ya que el bienestar es un principio correspondientemente indefinido [Luhman, 2014: 56], debiera dejar de ser situado solamente como meta política; no obstante, para alcanzar ese objetivo o al menos encauzarlo, se tendría que construir colectivamente una perspectiva de bienestar que aunque se establezca para una nación o situación concreta, tendría que colocarse en el centro de las decisiones económicas.

Una de las concepciones de bienestar que más influencia ha tenido es la de Amartya Sen, sobre todo por sus contribuciones al estudio del desarrollo económico y a la ubicación de la pobreza como privación de capacidades. De igual forma, se reconoce su participación en la construcción de indicadores para la identificación, la medición y la agregación de la pobreza, así como en la construcción del índice de desarrollo humano (IDH). Él mismo señala que su punto de partida es lo realizado

\footnotetext{
${ }^{1}$ Se refiere a la ubicación del individuo como el único que determina su devenir en la sociedad correspondiente con su particular naturaleza, resaltando una posición antropocéntrica que es reforzada con una perspectiva eurocéntrica. Ver Osorio [2004: 14] y Beltrán [2001].
} 
por John Rawls y sus consideraciones de justicia redistributiva y que lo que lo distingue es su hincapié en las capacidades y las funciones como enlace entre bienes y bienestar, para dejar sentado que el acceso a los recursos posibilita la igualdad de oportunidades y que las diferencias en los resultados o las posibilidades de igualación se derivarán de la responsabilidad individual [Sen, 2012].

Señala que la naturaleza del Estado de bienestar "consiste en ofrecer algún tipo de protección a las personas que sin la ayuda del Estado puede que no sean capaces de tener una vida mínimamente aceptable según los criterios de la sociedad moderna, sobre todo la Europa moderna" [Sen, 2012]. Con esta definición, muestra un elemento que ha permeado la construcción de los Estados de bienestar; por ejemplo, en América Latina se ha tratado de aplicar lineamientos y contenidos de política pública, mediante la creación de instituciones nacidas en y para Europa en realidades tan diversas, heterogéneas y desiguales, con concepciones holísticas que integran al hombre en el espacio de todos los seres vivos y su relación con la naturaleza, con prácticas solidarias diferentes, con grupos de población no reconocidos, lo que conducirá a que sea hasta el siglo xxI que muestren al mundo otras posibilidades de bienestar de prácticas comunitarias de muy larga data, como lo sería la del buen vivir. ${ }^{2}$ No obstante, en los procesos de construcción del bienestar, sigue siendo una asignatura pendiente la reflexión de Sen, quien se cuestiona cómo será posible combinar los méritos del Estado de bienestar con la cultura de la autoayuda y la responsabilidad social.

Otro de los autores clásicos en el estudio del estado de bienestar es Esping-Andersen quien ha señalado con mucha precisión lo que desde Off [1990] se ha documentado, que "el Estado de Bienestar no es sólo un mecanismo que interviene en la estructura de la desigualdad y posiblemente la corrige,

\footnotetext{
${ }^{2}$ Ver más adelante el capítulo referido a Economía solidaria y buen vivir.
} 
sino que es un sistema de estratificación en sí mismo, es una fuerza activa en el ordenamiento de las relaciones sociales" [Esping-Andersen, 2011: 44]. Cabe recordar que el Estado de bienestar es una de las fuentes de gestión de los riesgos sociales; las otras dos son el mercado y la familia [Esping-Andersen, 2011: 50]. Gestionar los riesgos sociales se convirtió en un requisito de gobernanza que se deriva de la interacción que la modernidad establece entre los tres ámbitos señalados (el mercado, el Estado y la sociedad). Opera primordialmente corrigiendo o apoyando las directrices o las ausencias del mercado de trabajo, de la falta de ingresos ante el desempleo y ante la vejez, de la enfermedad, de la falta de comida, de la falta de escuela y de vivienda. En la construcción de la modernidad, una constante ha sido establecer qué tipo de economía produce mejores condiciones de vida. La tríada mercado, Estado y sociedad ha participado de manera diferenciada. Se han instrumentado modelos de desarrollo en los que los riesgos sociales derivados del ciclo vital (enfermedad, maternidad, desempleo, discapacidad, riesgo de trabajo, vejez y muerte) son asumidos por el Estado por medio de sus servicios e instituciones de carácter público; en otros, como en el neoliberal, el mercado gestiona, participa o encabeza muchas de las áreas de atención de los riegos sociales. La función de la sociedad se ha invisibilizado, salvo el de la organizada que disputa algunos espacios con una perspectiva de incidencia y participación política, a veces partidista, en otras ocasiones religiosa. Las organizaciones de carácter cooperativista y comunitario que se mantienen en muchas sociedades no han sido incluidas como formas de representación válida en el otorgamiento de derechos sociales. Esping-Andersen señala que "la economía familiar es el alfa y omega de cualquier resolución de los principales dilemas postindustriales, y, acaso, el más importante fundamento social de las economías postindustriales" [Esping-Andersen, 2011: 15]. De cierta forma, estaría de acuerdo en su consideración si se analiza la trayectoria que ha tenido el trabajo asalariado 
subordinado que a medida que la revolución científico-tecnológica avanza y elimina prácticas tradicionales de trabajo, se reorganiza mediante nuevas y diversas formas de organización laboral, aumentan los trabajadores autónomos y se mantienen las microempresas familiares que en muchas ocasiones convierten el hogar en unidad económica. En América Latina, la unidad económica de los hogares es el espacio que le han dejado a la población que no puede incorporarse al mercado laboral como asalariados subordinados en las empresas, los servicios o el gobierno, y se ha convertido en la que llega a generar entre $20 \%$ y $40 \%$ de las ocupaciones y los ingresos; en México, genera $27 \%$ del producto interno bruto (PIB) [Inegi, 2017, 2018, 2019, 2020]. Desde esta mirada, el hogar construido por diversos arreglos familiares supera la perspectiva nuclear de la familia consanguínea; se convierte en espacio de producción y distribución de mercancías y ha coadyuvado enormemente al sostenimiento del mercado interno [Ramírez, 2019a y 2019b] al participar como proveedor del consumo de las personas de ingresos bajos y medios. La unidad económica de los hogares, en muchas ocasiones, pasa a constituir organizaciones comunitarias; para México y América Latina, este tipo de organización puede ser el alfa y el omega en la gestión de los riesgos sociales de todos aquellos que no han tenido voz ni representación, ni acceso a prestaciones y servicios públicos, ni son sujetos de derechos laborales y sociales, ni se les han ofrecido oportunidades en condiciones diferentes.

En el estudio de los regímenes de bienestar, existe una amplia bibliografía enfocada en el análisis de las características del Estado latinoamericano, la política social instrumentada y sus repercusiones en la construcción de bienestar. Se han orientado principalmente en caracterizar y definir tipologías de acuerdo con sus contenidos y alcances: desde la ya clásica tipología de los regímenes de seguridad social realizada en los años 80 por Mesa-Lago [1985 y 2004], la tipología de los Estados sociales elaborada por Fernando Filgueira [1998 
y 2005], la caracterización de los regímenes de bienestar de Carlos Barba [2003] y la caracterización de las políticas sociales de Martínez Franzoni [Barba, 2019], por mencionar algunas. En este artículo, me inclino por destacar los paradigmas que sostienen las directrices de las políticas sociales como sistemas de estatificación alternativos a la estratificación generada por el mercado, instrumentadas después de la segunda posguerra y que, según Dubet, se identifican como el paradigma de la igualdad de posiciones y el paradigma de la igualdad de oportunidades [Dubet, 2017]; ambos tienen ventajas y límites y se han impuesto de acuerdo con los patrones de acumulación o modelos de desarrollo instrumentados en la economía mundial. La igualdad de posiciones tuvo mayor expresión en la época de oro del capitalismo y, por tanto, en el modelo de sustitución de importaciones para América Latina, con la conducción del Estado, a partir de favorecer el crecimiento de la industria manufacturera, el empleo asalariado subordinado y la inclusión de la representación sindical en la construcción de los pactos sociales.

La igualdad de posiciones reconoce que el capitalismo es una sociedad de clases y persigue que exista menos distancia en las posiciones opuestas para que ello permita mayor igualdad. Por ello, los Estados de bienestar clásicos se orientaron a establecer una base de protección y seguridad social de carácter universal y al énfasis en el establecimiento de bienes y servicios públicos para toda la población mediante el fortalecimiento de instituciones.

$\mathrm{Al}$ arribar la mundialización como patrón de acumulación (finales de los años 70), cimentado en economías abiertas en las que el mercado asume el papel preponderante de la conducción no únicamente económica sino social y cultural, un periodo comúnmente conocido como neoliberalismo, el Estado asume una función subsidiaria, es decir, centra su atención en aquellos que no pueden resolver sus necesidades de salud, educación y otros riesgos del ciclo vital en el mercado. Es así 
como el modelo de bienestar que mejor responde a sus objetivos es el que promueve la igualdad de oportunidades, ya que ofrece a todos la posibilidad de ocupar las mejores posiciones en función de un principio meritocrático. Construye a los actores sociales alrededor del trabajo y la utilidad, y enfatiza en las competencias individuales lo que, en un contexto de desigualdades estructurales, de actores no visibilizados, de trabajo no reconocido, ha profundizado enormemente las desigualdades, el individualismo y la ausencia de solidaridad.

Por estas razones, las propuestas más recientes de modelos de bienestar vuelven a centrar su atención en la igualdad de posiciones, la función central del Estado, la construcción de bienes públicos y la posibilidad de contar y tener acceso a servicios públicos de seguridad y protección social. Y después de observar resultados en los niveles de desigualdad, entonces sí fortalecer algunos de los instrumentos propuestos por la igualdad de oportunidades.

Un camino diseñado por los organismos internacionales para lograr mejores resultados ha sido el de instrumentar, por fin, la igualdad de derechos, que está señalada en muchas de las constituciones políticas de los países y refrendada en la Declaración Universal de Derechos Humanos formulada en 1948 por la Organización de las Naciones Unidas (ONU). Las evidencias del crecimiento de la desigualdad, desde los años 90 del siglo pasado, orientaron a la onU a formular los Objetivos de Desarrollo Internacional en 1996, que en el año 2000 se plasmaron en los Objetivos del Milenio, para llegar en 2015 a la firma de los Objetivos de Desarrollo Sostenible (oDs), cuyo horizonte temporal se extenderá hasta 2030 [Sanahuja, 2014].

La Organización Internacional del Trabajo (ОIT), por su parte, ha seguido refrendando la observancia del convenio 102, que data de 1952 y que define nueve ramas de la seguridad social y en el caso de las pensiones determina que estas no podrán ser menores de $40 \%$ del salario de referencia, 
o el convenio 128 de 1967, que eleva estándares de protección frente a las contingencias de invalidez, vejez y supervivencia, para llegar a proponer junto con la Organización Mundial de la Salud, en 2009, la Iniciativa de Piso de Protección Social, que busca promover la garantía de accesos a servicios esenciales y a transferencias de ingresos para todas las personas, procurando prevenir que caigan en pobreza extrema o para facilitar su salida de tal situación [Bertranou, 2010].

En lo que corresponde a la Comisión Económica para América Latina y el Caribe (Cepal), ha venido haciendo hincapié en que la igualdad de derechos es un compromiso ético ineludible y un valor intrínseco de la ciudadanía y el humanismo moderno, que a su vez debe consolidarse en instituciones, estructuras y políticas que permitan avanzar hacia el cierre de las grandes brechas económicas y sociales que caracterizan a la región [Cepal, 2020: 7]. ¿Será posible hacer realidad este discurso y desafíos en el caso mexicano?

LOS PARADIGMAS DE LA POLÍTICA SOCIAL eN MÉxico Y La TRAYECTORIA DEL GASTO SOCIAL

La política pública incluye funciones y objetivos de crecimiento (acumulación) que corresponden al modelo de desarrollo que se persiga; incluye también objetivos de bienestar y legitimación que permitan a los gobiernos ejercer el poder e imponer su hegemonía. Es así como la política social se articula en un conjunto de decisiones y actuaciones público-administrativas generadas en la esfera estatal que inciden directamente y de formas diversas sobre la organización y distribución de los recursos destinados al bienestar de las personas y lo hace mediante regulaciones, servicios y transferencias [Ramírez, 2011].

En el transcurso de un siglo, hemos atravesado al menos por tres diferentes proyectos de país que han incidido en los 
contenidos de la política social que se instrumenta. La Revolución mexicana de 1910 y después la Constitución Política de los Estados Unidos Mexicanos de 1917 elevaron a rango de derechos y garantías sociales algunas de las dispersas políticas asistenciales que se habían establecido en el periodo de construcción del Estado mexicano.

Refiriéndose a la perspectiva de bienestar, la Constitución Política de los Estados Unidos Mexicanos (CPEUM) [CPEUM, 2020] hace alusión explícita al mismo en cinco artículos:

1. En el inciso II h, del artículo tercero, referente al derecho a la educación, señala que esta será integral y educará para la vida, con el objeto de desarrollar en las personas capacidades cognitivas, socioemocionales y físicas que les permitan alcanzar su bienestar [CPEUM, 2020; inciso adicionado DOF, 15-05-2019].

2. El Artículo $4^{\circ}$, que en 1917 únicamente garantizaba la igualdad de profesión, industria, comercio en trabajo lícito, fue reformado en 2011 para dar garantías a la igualdad de género, la decisión de procreación, el derecho a la alimentación, la salud, el ambiente sano, el agua, la protección a la niñez, a la cultura y la práctica del deporte. Garantías, por cierto, que todavía no son universales. En la mención al derecho a un medio ambiente sano incluye textualmente: "para su desarrollo y bienestar". Este párrafo fue adicionado en 1999, reformado en 2012 y es hasta la fecha uno de los que registra más violaciones [CPEUM, 2020; adicionado DOF, 28-06-1999 y reformado DOF, 08-02-2012].

3. El Artículo 27 refiere que la propiedad de las tierras y aguas comprendidas dentro de los límites del territorio nacional corresponde originariamente a la nación. En 1934 se agregaron párrafos para garantizar que el Estado promoviera las condiciones para el desarrollo rural integral, con el propósito de generar empleo y garantizar a la población campesina el bienestar y su participación e incorporación en el desarrollo nacional. La población campesina 
ha sido una de las más abandonadas; registra las tasas más altas de migración interna y externa y sigue mostrando los niveles más altos de pobreza y marginación. [CPEUM, 2020; reformado DOF, 10-01-1934, adicionados DOF,13-102011 y DOF, 03-02-1983].

4. En el Artículo 31, que señala la obligación de los mexicanos, deja establecidas las responsabilidades frente a hijas e hijos menores de 18 años y la orientación de velar siempre por su bienestar y desarrollo, mandato que tampoco se cumple, al observar las estadísticas de violaciones a los derechos de los niños.

5. El Artículo 123, que establece el derecho al trabajo digno y socialmente útil, así como las bases para expedir leyes sobre el trabajo, determina en la fracción XXIX que es de utilidad pública la Ley del Seguro Social y ella comprenderá seguros de invalidez, de vejez, de vida, de cesación involuntaria del trabajo, de enfermedades y accidentes, de servicios de guardería y cualquier otro encaminado a la protección y bienestar de los trabajadores, campesinos, no asalariados y otros sectores sociales y sus familiares [CPEUM, 2020; adicionados DOF, 06-09-1929 y DOF, 31-12-1974]. El principio de seguridad social como base del bienestar está referido como derecho laboral para los trabajadores y su familia, aspecto que limita las posibilidades de universalización y que obliga necesariamente a que trascienda como derecho social y humano.

Como pudo observarse, las consideraciones de Estado sobre el bienestar se han incluido en diversos momentos de la realidad nacional en concordancia con el modelo de desarrollo imperante. Los resultados han sido más que deficientes si consideramos que para 2018, 43.4\% de la población se registra en condición de pobreza y no de bienestar, y el índice de Gini (0.50) se ubica por encima del valor promedio en América Latina (0.47) [Cepal, 2019], lo que nos dice que el bienestar que 
se ha construido está muy concentrado y no incluye a la totalidad de los mexicanos.

De los años 40 a finales de los años 70 del siglo xx, la política social que acompañó al desarrollo estabilizador y la sustitución de importaciones, que orientaron el desarrollo nacional y el del mercado interno, se caracterizó por instrumentar la igualdad de posiciones. Lo que se logró fue el establecimiento de un Estado de bienestar restringido, conservador y corporativista que protegió poco, ya que solamente se concentró en los asalariados dependientes, prioritariamente urbanos y organizados. Al establecer una estrecha relación de colaboración mutua con los sindicatos de las industrias estratégicas para el desarrollo del país (ferrocarriles, petróleo, electricidad, magisterio, etc.), se les concedió, en palabras de Schmitter, "un explícito monopolio de la representación sindical, a cambio de observar ciertos controles en la selección de sus líderes y en la articulación de sus demandas y apoyos" [Schmitter, en Medina, 1995]. Fue el periodo de crecimiento de la urbanización y, por tanto, de las ciudades capitales, de la clase media, la educación pública, las instituciones de seguridad social y los servicios públicos de salud, deporte y cultura.

Se crearon las instituciones nacionales de seguridad social con sus respectivos servicios de salud, las prestaciones monetarias ante enfermedades y riesgos de trabajo, las pensiones para mantener ingresos frente a los riesgos del ciclo vital, los servicios de guardería y las instituciones para la promoción de la vivienda. En 1943, se funda el Instituto Mexicano del Seguro Social (IMSS) para atender a los trabajadores del sector privado y sus familias; en 1959, surge el Instituto de Seguridad Social y Servicios Sociales de los Trabajadores del Estado (ISSSTE). En 1961, la ley de retiro y pensiones de los militares se convierte en la Ley de Seguridad Social para las Fuerzas Armadas.

El gasto social pasó de representar 18\% del presupuesto federal en el gobierno de Cárdenas (1934 a 1940) a $32 \%$ en 
el gobierno de Díaz Ordaz (1964 a 1970). La inversión social pasó de $9.6 \%$ de la inversión pública en el gobierno de Cárdenas a $25.2 \%$ en el de Díaz Ordaz y $13.9 \%$ en el de López Portillo (1977 a 1982), tiempo en que ya era evidente la crisis de la sustitución de importaciones con el crecimiento exponencial de la deuda externa, la caída de los precios internacionales de materias primas y la devaluación que, junto con otros factores, ponían de manifiesto el crecimiento del déficit público [Moreno y Ros, 2014: 139, 140, 171].

La centralidad en la toma de decisiones, la diversidad y dispersión de instituciones creadas sin visión y acción estratégica de conjunto y la asignación de recursos por criterios políticos más que por necesidades sociales destacan en la instrumentación de la política social durante este periodo; se llegó a documentar la utilización del gasto social como un importante elemento de control que permitía neutralizar el conflicto social mediante el compromiso político y las promesas de beneficios sociales para aquellos con quienes negociaba. Los mayores beneficios no eran para los sectores más necesitados (campesinos, no asalariados, indígenas, trabajadores autónomos, pequeña y mediana industrias), sino para los mejor organizados. Las políticas sociales funcionaron como el más eficaz mecanismo de control en México [Farfán, 2009; Ramírez, 2011]. Pese al verticalismo y el autoritarismo, fueron un vehículo que permitió la construcción de un Estado de bienestar restringido, con creación de empleo, distribución del ingreso y movilidad social.

A partir de la instrumentación del modelo neoliberal (1982) y acorde con las directrices del mercado, el sector privado y los organismos internacionales, la política social cambió su paradigma y se encaminó a sostener un Estado liberal, residual, con políticas focalistas y asistenciales, que se ocupará de administrar la pobreza y de atender únicamente a los que no puedan acudir al mercado a comprar educación, salud y pensiones. 
Ante la profunda crisis económica de los años 80 y las restricciones del gasto público, aunadas al cambio en el modelo económico, se da inicio a las políticas de focalización; de esta forma inicia en 1988 la instrumentación del Programa Nacional de Solidaridad como proyecto social eje de la administración de Carlos Salinas de Gortari (1988 a 1994). Pronasol, como se denominó comúnmente, se propuso desarrollar en tres frentes el combate a la pobreza: el bienestar social, el apoyo a la producción y el desarrollo regional, y generó un efecto contrario a lo que decía perseguir: clientelismo por solidaridad, corrupción por bienestar y concentración del desarrollo regional en los cultivos para exportación. De 1981 a 1994, el РIB manufacturero registró una tasa de crecimiento de $2 \%$, y de $0.1 \%$, el empleo. La década anterior, de 1970 a 1981, el crecimiento del PIB manufacturero fue de $6.1 \%$ y el del empleo de $3.6 \%$ [Moreno y Ros, 2014: 257]. El crecimiento de la inversión pública fue negativo de 1988 a 1991. El gasto público en desarrollo social fue de $7.1 \%$ de 1988 a 1994, de $8.9 \%$ de 1995 a 2000 y de $10.1 \%$ de 2000 a 2006 [Moreno y Ros, 2014: 276].

Pronasol tuvo pocos resultados evidentes en cuanto a disminuir la pobreza o aumentar la cobertura de servicios públicos a la población, pero dejó diversos elementos que requieren examinarse: algunos de los objetivos que dijo perseguir se fortalecieron dando paso a un Estado liberal y residual y se mantienen como objetivos de la actual política social, como el inicio de las transferencias monetarias; no obstante, significó también el final de la perspectiva de la igualdad de posiciones. Esto se observó en los apoyos ofrecidos por Pronasol como materiales de construcción y despensas para promover el trabajo colectivo en la construcción de infraestructura y mejorar las condiciones de vida. Los créditos a la palabra para la producción del campo quedaron en el limbo ya que, más que avanzar, la seguridad alimentaria retrocedió; además, el impacto de la apertura comercial y financiera, así como las orientaciones al fortalecimiento de la inserción a la economía mundial 
provocaron que se volcara prioritariamente a formar parte de las cadenas externas de valor.

Las transferencias monetarias condicionadas o no, ${ }^{3}$ pero al fin transferencias, hasta nuestros días, se han quedado destacando el carácter asistencial de la política social; se replica lo instrumentado a finales de los años 80, las becas para niños, la entrega de despensas [Rojas, 1992]. En ese momento, inicia el camino de la individualización de la política social y su mercantilización, de intentar convencer mediante mínimos apoyos monetarios la filiación política, lo que ha contribuido a destruir agrupaciones sociales y comunitarias e incentivado el individualismo y la monetización del consumo básico, lo cual ha trastocado principalmente la nutrición, la salud y la organización social.

El gobierno de Ernesto Zedillo (1994 a 2000) elimina Pronasol e instrumenta el Programa de Educación, Salud y Alimentación (Progresa). Debilita la participación familiar y comunitaria y se concentra en las transferencias individuales. El bloque dominante, antes que ceder ante la desigualdad, optó por privatizar las pensiones de los trabajadores afiliados en el IMss en 1995, seguidos por los del IsssTe en 2007, introducir al sector privado en la gestión de los servicios públicos, incrementar y mantener los privilegios de los sectores de mayor poder adquisitivo, concentrar más la riqueza y aumentar enormemente la distancia de ingresos; en un contexto de crisis económica, el resultado fue el crecimiento de la pobreza, la precariedad y la vulnerabilidad social.

Progresa representa el paradigma de la igualdad de oportunidades en lo que se refiere al tipo de apoyo que ofrecía: en

${ }^{3}$ Existe una amplia documentación y análisis para América Latina acerca de las características e impactos de las transferencias monetarias condicionadas ligadas a una perspectiva de protección social basada en derechos. Cecchini et al. [2015] hacen énfasis en la perspectiva de apoyos mínimos y focalizados que se han quedado en una perspectiva asistencial y cuyos resultados han sido marginales en cuanto a la superación de la pobreza. 
vez de subsidios o canastas de productos, se optó por entregar dinero en efectivo y algunos apoyos específicos en especie, como el complemento nutricional. La perspectiva del mercado entra de lleno en la política social; la entrega de los recursos monetarios correrá a cargo de la Banca Popular (Bansefi), el sistema de giros telegráficos (Telecom) y la banca privada (BBVA-Bancomer), vehículos que siguen vigentes en el desempeño de la actual política social.

Se denominan transferencias condicionadas por los requisitos que se impone a la población objeto de estos beneficios. Niños, mujeres, ancianos deberían mantenerse en la escuela, acudir al centro de salud y consumir los complementos nutricionales. Les hacen suponer que les están ofreciendo posibilidades mediante el reconocimiento de su identidad y de las discriminaciones que sufren, para que mejoren sus condiciones en función de un principio meritocrático y que si no lo consiguen será resultado de su desempeño individual.

La igualdad de oportunidades cambia profundamente las representaciones de la sociedad. Las clases sociales son sustituidas por grupos que pasan a ser definidos con base en las discriminaciones que sufren en relación con raza, cultura, género y capacidades especiales [Dubet, 2017]. Más que efectos de explotación y dominación, son las condiciones de género, edad y raza lo que destaca, en una realidad que sigue manifestando las diferencias de clase, acentuadas aún más por el colonialismo, el patriarcado y la sobredeterminación del mercado.

La perspectiva sexenal de los programas sociales no cambia con el arribo del Partido Acción Nacional (PAN) a la presidencia de México en el año 2000. En 2002, se crea el Programa Nacional de Desarrollo Humano Oportunidades, con lo que desapareció Progresa. La perspectiva de la igualdad de oportunidades y de la responsabilidad individual se fortalece.

Hasta nuestros días, la cobertura de la seguridad social no ha aumentado; al contrario, hubo años en los que 
disminuyó aún más por el crecimiento de la informalidad laboral que el país ha registrado, lo que expresa una franca crisis de la seguridad social contributiva. Crecieron los programas focalizados y se generó confusión y ambigüedad entre los propósitos y alcances de la seguridad social, los seguros sociales, la asistencia social, la protección social y la atención a la salud. A la reforma constitucional de 1984, que estableció el derecho a la salud, le siguió 20 años después el establecimiento del Sistema de Protección Social en Salud que incluía los programas de Seguro Popular, Embarazo Saludable, Seguro Médico para una Nueva Generación, Oportunidades en su componente de salud y cirugía extramuros, y cuyos principales problemas fueron su carácter voluntario, no ausente del cobro de cuotas y su falta de infraestructura y personal sanitario.

La focalización y la efectividad han seguido caminos opuestos. De acuerdo con información del Consejo Nacional de Evaluación de la Política Social [Coneval, 2013], en 2010 sumaban 273 programas y acciones federales y 401 los ejecutados por derecho social o por dimensión de bienestar económico. El crecimiento de los programas de focalización y de transferencias condicionadas aumentaba, lo mismo que la participación del gasto social en el PIB, que pasó de $7.8 \%$ en 2000 a $9.3 \%$ en 2006 (periodo de gobierno de Vicente Fox) y a $11.2 \%$ en 2012 (periodo de gobierno de Felipe Calderón), pero quedó aún muy por debajo del promedio en América Latina, que se situaba en $18.6 \%$. El presupuesto asignado a los programas pasó de 72122.23 millones de pesos en 2004 a 692 003.81 en 2011. Entre 2004 y 2007, se incrementó 17\% el número de programas y $1 \%$ el presupuesto de los mismos. Entre 2008 y 2011 el número de programas aumentó $11 \%$ y el presupuesto $42 \%$ [Coneval, 2013]. En 2016, Coneval reportó 610 programas y acciones de desarrollo social vinculados con la dimensión de bienestar económico; de estos, 570 eran estatales y 40 del gobierno federal [Coneval, 2018: 113]. 
Durante este periodo de expansión de programas focales, la pobreza se mantuvo casi en las mismas proporciones, al pasar de $43 \%$ del total de la población en 2008 a $41.9 \%$ en 2018. Por la orientación de los programas sociales, dirigidos a la población más vulnerable, es posible que coadyuvaran en alguna medida a la disminución de la pobreza extrema, la cual pasó de $11 \%$ a $7.4 \%$ durante el mismo periodo [Coneval, 2019: 8-9], pero sin ningún impacto en la disminución de la desigualdad.

Antes de 2010, el gasto social en México se distribuía para los siguientes rubros: educación, salud, seguridad social. De 1996 a 2002, se distribuía también para desarrollo regional y urbano, abasto y asistencia social y laboral. De 2003 a 2010, estos últimos cambiaron su nominación a: urbanización, vivienda y desarrollo regional, agua potable y alcantarillado, y asistencia social. De 2010 a 2018, los nombres de los rubros del gasto social se modificaron para ajustarse a los nuevos objetivos que la política social perfilaba: protección del medioambiente, vivienda y servicios comunitarios, salud, actividades recreativas, cultura y religión, educación y protección social. Estas modificaciones abrieron el espacio para apuntalar programas sociales focalizados e insistir en la protección social más que en la seguridad social y con ello abrir su gestión a sectores privados y de la sociedad civil, e introducir una perspectiva conservadora, alejada de la laicidad al destinar gasto social a actividades religiosas.

Con la llegada de un nuevo gobierno a partir de 2019, los rubros a los que se destina el gasto social son: protección social, educación, salud, vivienda y servicios a la comunidad, recreación, cultura y otras manifestaciones sociales, protección ambiental y otros asuntos sociales.

El gasto social como porcentaje del PIB pasó de $6.7 \%$ en 1996 a $12.2 \%$ en 2015 (gráfica 1), disminuyó a 10.4\% en 2017 y empezó a crecer de nuevo a partir de 2019 (10.9\%). 


\section{Gráfica 1. Gasto Social como porcentaje del PIB} 1996 a 2019

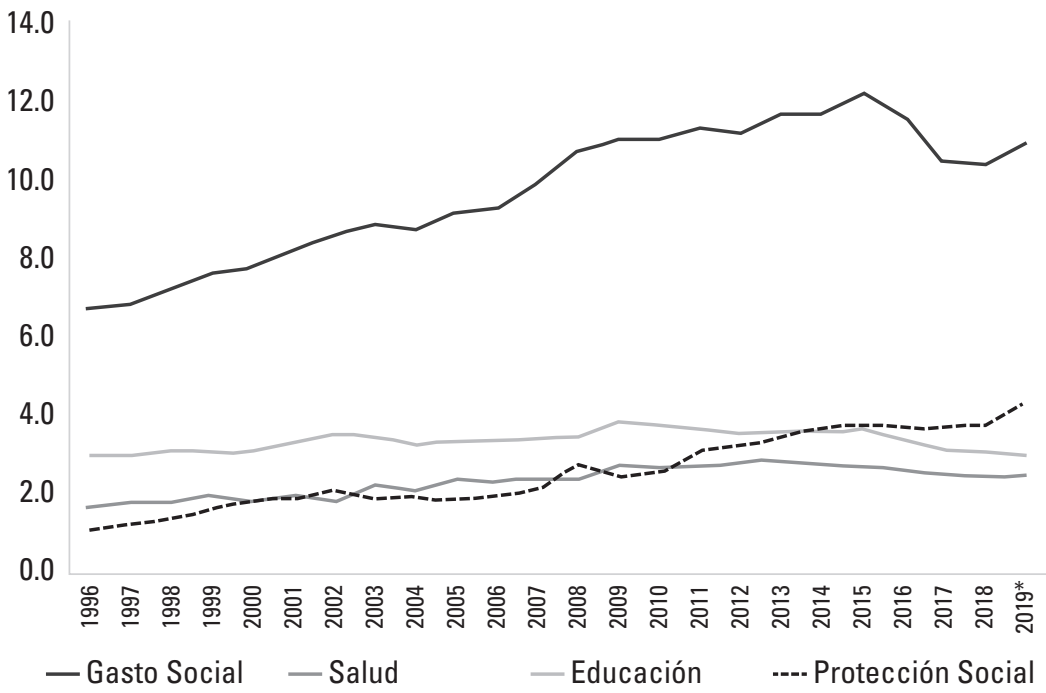

Fuente: elaboración de Gabriel Badillo con datos de la Secretaría de Hacienda y Crédito Público.

La inversión en educación, que era de 3\% del PIB en 1996, continúa en esa proporción y la inversión en salud pasó de 1.7\% en 1996 a $2.5 \%$ para 2019 . El gasto en protección social es el que más ha crecido: de 1\% en 1996 a 4.3\% del PIB en 2019.

A pesar de la mayor participación del gasto social en el PIB (11\%), México se encuentra en el último lugar de los países de la Organización para la Cooperación y el Desarrollo Económicos (OCDE), cuyo gasto promedio es de $18 \%$ del PIB; los de más alto gasto son Francia y Finlandia, con 30\% del PIB [OCDE, 2019: 55]. Las repercusiones de la crisis y de la menor disponibilidad de gasto público en términos reales se expresan en los contrastes que presenta la tasa de crecimiento del gasto social, las cuales fueron negativas en 2009 (-4.5\%), 2016 (-0.1\%) y 2017 (-7.2\%), según datos de la Secretaría de Hacienda y Crédito Público de 2018. 
El crecimiento del gasto social también se manifiesta en una mayor participación en el gasto programable, que de 1996 a 2001 pasa de $53.1 \%$ a $62.7 \%$; después tendrá menor participación con años de franca disminución: 2003, 2009 y 2016. La participación empieza nuevamente a crecer en 2017 y es hasta 2019 que se registra crecimiento: de $59.9 \%$ en 2018 a $63.7 \%$ en 2019 y $63.6 \%$ en 2020 [shcP, 2020].

De los más de 600 programas y acciones de desarrollo social que se registraron en 2016, se mantuvieron 148 durante 2019; la evaluación realizada por Coneval determinó que 103 eran relevantes. En el presupuesto de egresos de la Federación de 2020, continuaron 87.

ACCESO Y DISFRUTE DE INGRESOS POR PENSIÓN DE LAS PERSONAS MAYORES DE 68 AÑOS

Resultado de sistemas de pensiones excluyentes, fragmentados, desiguales e inequitativos, las personas mayores de 68 años que reciben pensión derivada de contribuciones representan 30\% [Inegi, 2017]. Si lo dividimos por género, 40\% de los hombres y $23 \%$ de las mujeres de 68 años y más, que representan $6.3 \%$ de la población, cuentan con pensiones de alguna institución de seguridad social: $79 \%$ las otorga el IMss y $15 \%$ el ISSSTE; $99.9 \%$ de las pensiones de los hombres son directas, resultado del seguro de retiro, cesantía en edad avanzada y vejez o de jubilaciones por tiempo de servicios. En el caso de las mujeres, $51 \%$ lo constituyen pensiones derivadas, es decir, por su condición de beneficiarias, y se trata principalmente pensiones de viudez.

El monto de la pensión es bajo y desigual: $43 \%$ alcanzan hasta un salario mínimo, $33 \%$ hasta dos salarios mínimos y $24 \%$ más de dos salarios mínimos. En el cuadro 1, se muestra que en el caso de las mujeres, $51 \%$ de las pensiones alcanza hasta un salario mínimo y $26 \%$ hasta dos salarios mínimos. 
Cuadro 1. Monto mensual de la pensión de personas de 68 y más años (\%)

\begin{tabular}{lccc}
\hline \multicolumn{1}{c}{ Nivel salarial } & Total & Hombre & Mujer \\
\hline Total & 100 & 100 & 100 \\
Hasta 1 & 43 & 37 & 51 \\
De 1 a 2 & 33 & 37 & 26 \\
Más de 2 & 24 & 25 & 23 \\
\hline
\end{tabular}

Fuente: elaboración de Gabriel Badillo con base en Inegi [2017].

La falta de pensión derivada de contribuciones para $70 \%$ de las personas de 68 y más años determina que se mantengan en actividades laborales hasta que la falta de capacidades motrices y mentales se los impida. De acuerdo con la Encuesta Nacional de Ocupación y Empleo (ENOE) (4to trimestre de 2019), se estima que $24 \%$ de las personas de 68 y más años sigue perteneciendo a la población económicamente activa (PEA), 37\% de los hombres y $13 \%$ de las mujeres. Las ocupaciones informales definen el trabajo de $77 \%$ de los hombres y $84 \%$ de las mujeres en estos tramos de edad. Ya sea que trabajen en el sector informal (29\% de los hombres y $60 \%$ de las mujeres) o en condiciones de informalidad, en las que predominan los trabajadores por cuenta propia ( $58 \%$ de los hombres y $62 \%$ de las mujeres); todos ellos carecen de acceso a la seguridad social. Los hombres realizan predominantemente actividades agropecuarias (43\%) y de servicios (27\%), y las mujeres en el comercio (46\%) y los servicios (34\%) según la misma encuesta.

Esta condición de mantenerse trabajando hasta que la capacidad física lo permita tiene muchas probabilidades de crecer ante la falta de pensiones contributivas o en su defecto se observará un mayor empobrecimiento en la vejez. La capitalización individual de administración privada, mejor conocida como sistema Afores, ofrecerá muy pocas pensiones y de muy bajo monto. Las razones se concentran en las siguientes: 
1. La dinámica del mercado de trabajo no permite a un trabajador promedio afiliado al IMss cubrir los requisitos de ley de cotizar 1250 semanas o 25 años si se es afiliado al ISSSTE para ser sujeto de derecho a una pensión de retiro o de vejez en un tiempo laboral acorde con la esperanza de vida; es decir, el predominio de las actividades en el sector informal y en mayor medida en condiciones laborales precarias e informales se traduce en densidades de cotización bajas. La densidad promedio para México se ha establecido en 42.3\% [Castañón y Ferreira, 2017]. Con ese promedio, para alcanzar los requisitos que la ley señala se requieren al menos 54 años de trabajo en escenarios en los que se registra que los jóvenes logran insertarse al mercado formal después de los 30 años de edad.

2. El otro factor sustancial es la tasa de reemplazo que se obtendrá con la capitalización individual de administración privada. La OCDE proyectó en 2015 una tasa de reemplazo para México de $26 \%$, que se refiere a la proporción que la pensión tendría con el último salario recibido como trabajador activo; es la segunda tasa más baja de reemplazo de los que forman parte de la OCDE. Si el salario promedio de los que ahorran en Afores son tres salarios mínimos, la pensión no será mayor a un salario mínimo. Los primeros pensionados en el IMSS bajo este sistema están registrando una tasa de reemplazo promedio de 17\% [ASF, 2020]. El resultado de la baja tasa de reemplazo no solamente es consecuencia de la dinámica del mercado de trabajo o de una baja cotización, como algunos señalan, sino también de la baja rentabilidad y el oneroso costo de las comisiones, que llegarán a representar la cuarta parte del ahorro total del trabajador. Haber anulado la perspectiva de seguridad social, así como de solidaridad, por la individualización y exclusivamente el ahorro forzoso dejará a muchos trabajadores sin pensión y sin protección en la vejez.

Como hemos reseñado, desde la construcción de la seguridad social en los años 40, las asignaciones familiares han 
formado parte de los programas sociales focalizados a la población, sobre todo rural y en extrema pobreza. A partir del año 2001, cuando gobernaba Andrés Manuel López Obrador en el Distrito Federal, inicia la puesta en marcha del programa de apoyo alimentario, atención médica y medicamentos gratuitos para adultos mayores de 70 años. Este programa se convirtió en ley en 2003. El beneficio se estableció para las personas sin ingresos y se determinó como "una pensión diaria no menor a la mitad del salario mínimo vigente en el Distrito Federal" (Gaceta Oficial de 2013). Inicia así el reconocimiento de un mínimo de ingreso con enfoque de derecho. En 2009, cuando ya funcionaba el Programa 70 y más derivado del Programa Federal Oportunidades, se empieza a otorgar a partir de los 68 años.

El objetivo del Programa 70 y más fue otorgar una pensión de vejez para la población en extrema pobreza que habitara en entidades de hasta 30000 habitantes. Para 2012 este programa amplió su cobertura a las personas que no recibieran una pensión de alguna institución de seguridad social y en 2013 se extendió para todas aquellas con 65 años y más. De ese modo se convierte en la pensión para adultos mayores (PAM) de cobertura nacional para personas de 65 y más años, de nacionalidad mexicana o con un mínimo de 25 años de residencia en el país. El apoyo económico era de 580.00 MXN mensuales, entregados de manera bimestral; cubrió un padrón de beneficiarios activos de la PAM de más de 5.7 millones.

El actual gobierno (2019 a 2024) ha declarado que persigue construir un Estado de bienestar igualitario y fraterno a favor de los pobres, débiles y olvidados. En el ámbito de la política social, continúa instrumentando transferencias monetarias a los beneficiarios de forma directa, sin intermediarios. Establece alrededor de 20 programas, entre los que destaca la pensión para el bienestar de las personas adultas mayores, de carácter universal para todos los de 68 años y más, así como de 65 años y más, si son población originaria que continúan viviendo en sus comunidades indígenas o afromexicanas o tienen 
alguna discapacidad. Recibirán también transferencias las personas discapacitadas que pertenezcan a grupos indígenas del país de 0 a 64 años de edad, así como niñas, niños y jóvenes con discapacidad permanente de 0 a 29 años que vivan en municipios y zonas urbanas de alta y muy alta marginación.

También son parte de esos programas el Apoyo para el cuidado y atención infantil de las niñas y niños a cargo de madres, padres solos o tutores que trabajan, buscan empleo o estudian y que no tienen acceso directo o por parentesco a los sistemas de seguridad social; el Programa Sembrando Vida con apoyos monetarios, en especie (semillas) y auxilio técnico para sujetos agrarios, mayores de edad que habiten en localidades rurales, con ingreso inferior a la línea de bienestar rural, propietarios o poseedores de 2.5 hectáreas disponibles para ser trabajada en un proyecto agroforestal; las becas de estudio en todos los niveles para estudiantes de bajos ingresos; y el Programa Jóvenes Construyendo el Futuro, que consiste en apoyo monetario para jóvenes de 18 a 29 años de edad para que se formen, capaciten e incorporen exitosamente al mercado laboral y formen un patrimonio. La pensión universal de bienestar también incluye a personas adultas mayores de 65 a 67 años inscritas en el padrón de derechohabientes del PAM activos a diciembre del ejercicio 2018.

El objetivo de cobertura de la Pensión para el Bienestar de las Personas Adultas Mayores asciende a 8.5 millones de personas, el beneficio monetario que se establece es otorgar el doble del monto que daba la PAM, así como convertirla en derecho universal. Para ello, el presidente de la república envió en noviembre de 2019 una iniciativa de proyecto de decreto para reformar y adicionar el artículo 4 de la Constitución Política de los Estados Unidos Mexicanos. El pasado 8 de mayo, el Diario Oficial publicó el decreto aprobado por la Comisión Permanente del Honorable Congreso de la Unión que reforma y adiciona el Artículo $4^{\circ}$ y establece que el derecho a la protección de la salud y su acceso será mediante la concurrencia de 
la Federación y las entidades federativas en materia de salubridad general, con la finalidad de garantizar la extensión progresiva, cuantitativa y cualitativa de los servicios de salud para la atención integral y gratuita de las personas que no cuenten con seguridad social [Congreso de la Unión, 2020]. Además, se establece la garantía del Estado en el otorgamiento de las becas, pensiones y prestaciones, con lo que queda establecido el enfoque de derecho para las prestaciones sociales descritas y con garantía constitucional de parte del Estado.

El monto de los recursos asignados, en el Presupuesto de Egresos de la Federación y en el presupuesto de las entidades federativas del ejercicio fiscal que corresponda, para los programas de atención médica y medicamentos gratuitos, de apoyo económico para personas que tengan discapacidad permanente, de pensiones para personas adultas mayores, y de beca para estudiantes que se encuentren en condición de pobreza, no podrá ser disminuido, en términos reales, respecto del que se haya asignado en el ejercicio fiscal inmediato anterior [Congreso de la Unión, 2020].

A nivel fiscal quedan así resguardados los recursos, lo que tendrá que expandirse en el corto plazo son los ingresos públicos para que las transferencias monetarias que se están otorgando no queden únicamente como una política más de corte asistencialista encaminada a sostener un mínimo consumo en lugar de constituirse en una plataforma de seguridad económica que podría acortar distancias de ingreso. Lo que hoy se observa son apoyos mínimos en un contexto de bajo gasto público. Actualmente la pensión de bienestar es de 1310 pesos mensuales (55.5 dólares), que representa $36 \%$ de salario mínimo y se encuentra por arriba de la canasta alimentaria de pobreza extrema rural (1 157.33 pesos), no así de la urbana (1 623.19). También ha sido evidente el crecimiento del gasto en protección social como proporción del gasto social 
total, pero si este ha sido bajo y ha enfrentado caídas en su proporción ante el PIB, - $1.3 \%$ de 2015 a 2019, esa redistribución significa proporcionalmente menor inversión en dos rubros sustanciales: educación y salud, como se observa en la gráfica 2.

\section{Gráfica 2. Distribución del gasto social en México como proporción del gasto social, 2005 a 2020}

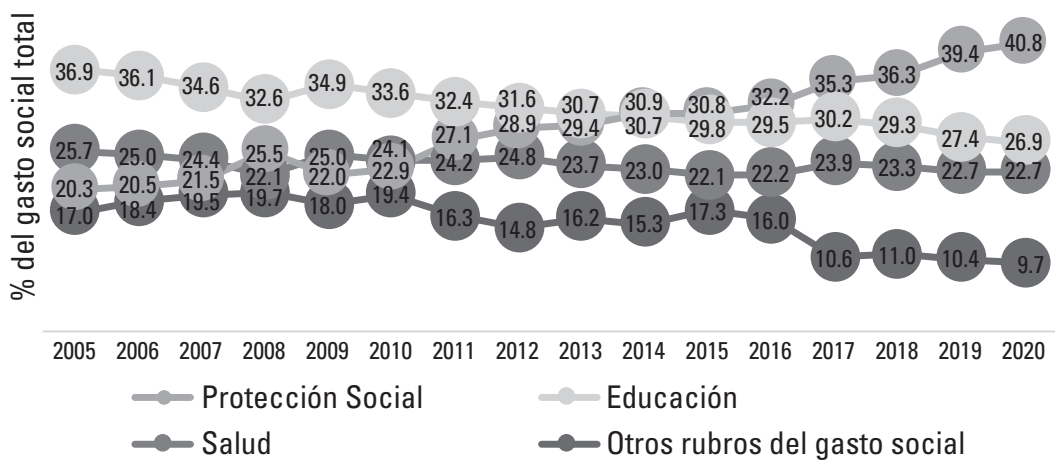

Fuente: elaboración de Gabriel Badillo con datos de la Secretaría de Hacienda y Crédito Público.

CAMINOS A RECORRER EN LA CONSTRUCCIÓN DEL BIENESTAR

Las decisiones tomadas por el actual gobierno en cuanto al ejercicio del gasto social tienen componentes que parecieran apoyarse en la perspectiva neoliberal al mantener las transferencias monetarias individualizadas y plantear como objetivo "primero los pobres". Situar solamente la pobreza como el problema principal y dejar en los mismos niveles la desigualdad mantendría también dicha perspectiva. Un condicionante es el poco espacio fiscal que se tiene por la débil recaudación que caracteriza al país. Sin embargo, conforme pasan los meses de ejercicio de gobierno se aprecian diferencias que es necesario 
conocer y analizar para derivar los escenarios que se le presentan a la construcción de bienestar.

Impulsar 20 programas prioritarios condujo a la presidencia a eliminar, modificar, reducir y concentrar los más de 600 programas y acciones de desarrollo social vinculados con la dimensión de bienestar económico registrados en 2018. Concentrarse en las transferencias monetarias directas eliminando intermediarios que pudieran desviar recursos ha significado la lenta construcción de un padrón de beneficiarios en el que se ha invertido tiempo de trabajo para depurar, corroborar y dejarlo confiable para la actual administración y concluir que, ante el aislamiento en que se encuentran las comunidades más pobres y la deficiente comunicación y conectividad que presentan, así como por los errores de exclusión cometidos en el pasado, nuevamente se requieren los servicios de la banca privada.

Al Banco Azteca, señalado por el alto cobro de comisiones y por el alto números de sucursales, se le propuso activar las tarjetas de bienestar o entregar en efectivo las transferencias monetarias, mientras se construyeran más sucursales del Banco de Bienestar. Estas transacciones financieras, que se identifican como la bancarización de las personas, tienen un doble filo que pone en riesgo las posibilidades del bienestar; son el vehículo para obtener la ayuda monetaria, pero también conducen a las personas a participar más en el sistema financiero, voraz y concentrado como el que opera en México. Y sin capacitación sobre la actuación del sector financiero y de las empresas trasnacionales de alimentos, se les ofrecen mayores posibilidades de consumo, incluidos alimentos de alto poder calórico y baja nutrición, o ser sujetos de endeudamiento más que de créditos favorables.

La ausencia de una banca de desarrollo que podría haber realizado, además de sus funciones sustanciales de impulso a la inversión productiva, la dispersión de estos recursos, ha puesto en evidencia el desmantelamiento de instituciones 
fundamentales que son requisito para salir de la sola administración de la pobreza y encaminarse por la necesaria instrumentación de políticas redistributivas de amplio espectro. Una posibilidad en el futuro puede ser el Banco del Bienestar, pero requerirá buen diseño en el impulso de la inversión productiva y del crédito a las unidades económicas representadas por familias, talleres, cooperativas, así como la pequeña y mediana industrias, que permita la generación de empleo protegido y, por tanto, salarios e ingresos que puedan ir sustituyendo o fortaleciendo el monto de las transferencias.

Ya que ha sido publicada en el Diario Oficial de la Federación la reforma del Artículo $4^{\circ}$ que garantiza el gasto público a los programas esenciales, se tendría que mejorar el nivel de apoyo y debería al menos cubrir una canasta alimentaria urbana para que deje de ser asistencial. El gasto que el gobierno realiza para la pensión de bienestar es bajo: considerando únicamente a la población de 68 y más años y que se mantenga el crecimiento de $3 \%$ anual de la pensión, como se observó en 2020 y con tres escenarios de crecimiento del gasto público, representaría menos de 0.40 del PІB (cuadro 2); si esta lógica sigue hasta 2050, no superaría 0.53 del producto interno bruto.

Si los ingresos públicos aumentan y los objetivos que ha planteado el actual gobierno se mantienen, habría posibilidades de fortalecer el gasto social, pero también habría que hacer una redistribución porque lo que ha prevalecido hasta el momento es la agudización de las desigualdades a partir de la distribución del gasto público. El pago de las pensiones derivadas de contribuciones, de las personas que se pensionan por los regímenes anteriores (ley 73 del IMSs y Artículo 10 transitorio del ISSSTE) y de otras pensiones públicas que se agrupan en el Ramo 19, registran una tasa de crecimiento de $8 \%$ anual durante el periodo de 2010 a 2020 y, los compromisos asumidos representan para 2019 el 3.3\% del PIB, que se destina para los que cuentan con este beneficio. Cabe recordar que representan a $30 \%$ de los que tienen 68 y más años. Así, los 


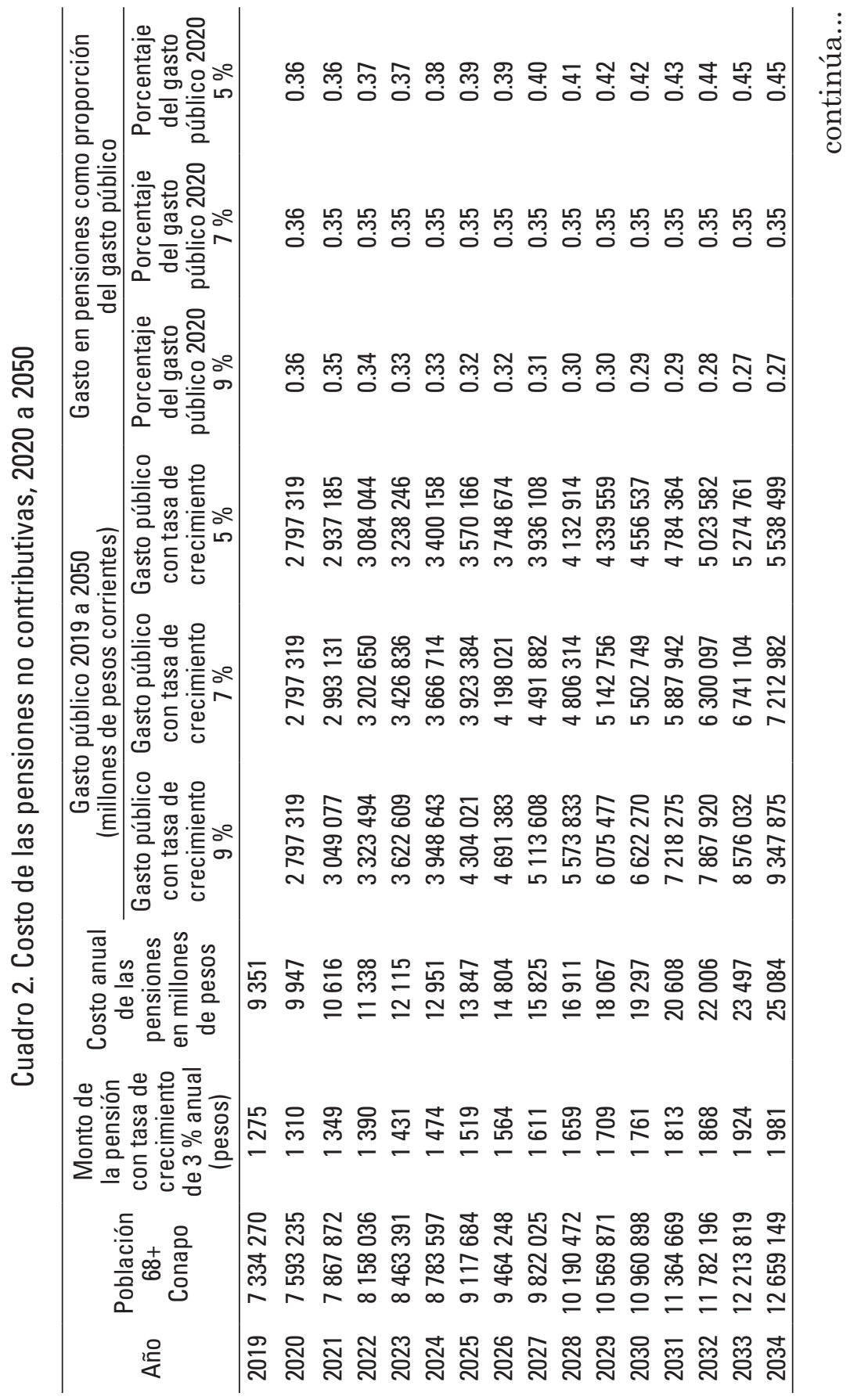




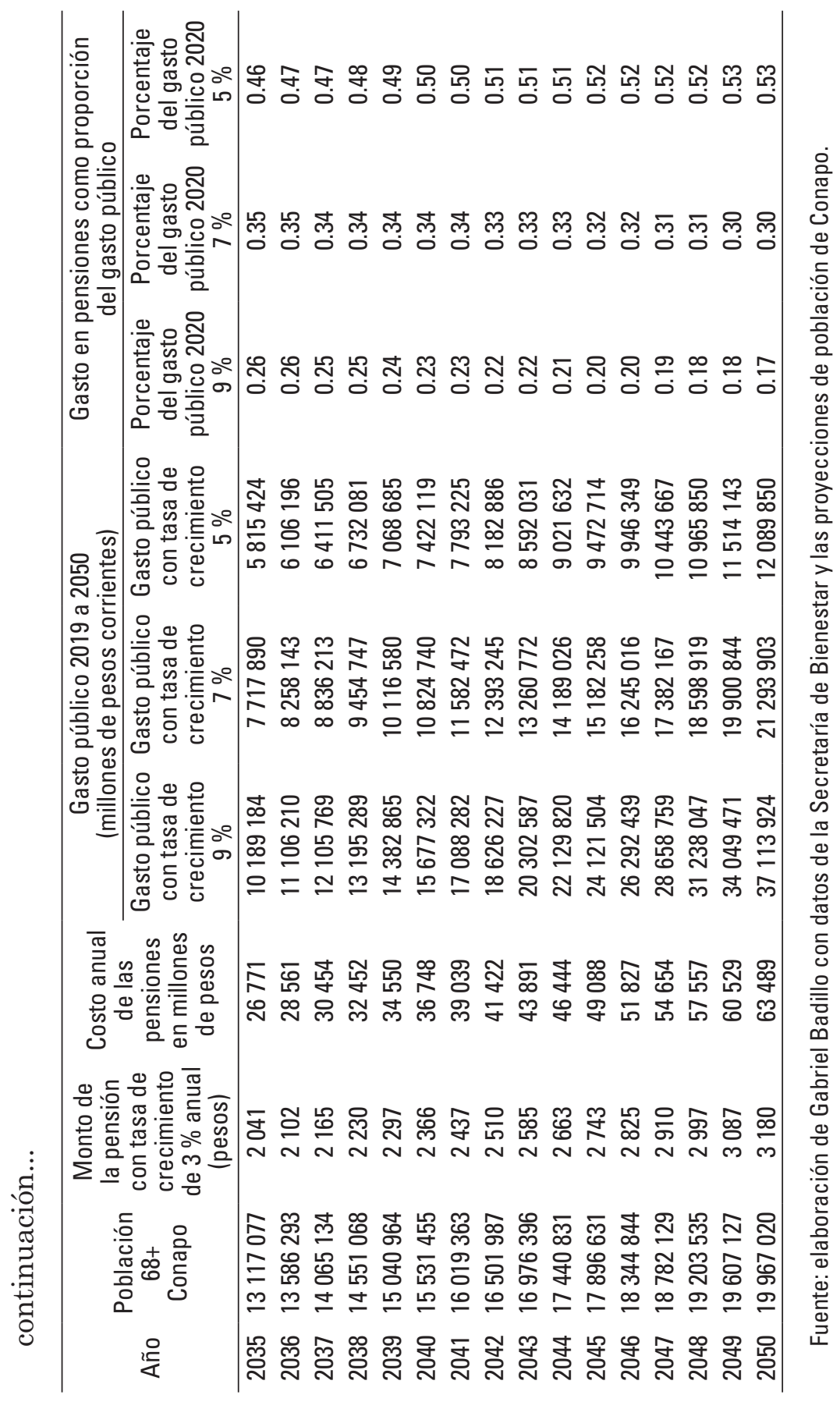


recursos que administran las Afores derivados de la capitalización individual de administración privada representan $15 \%$ del PIB, mientras que el gasto en las pensiones de bienestar representa $0.3 \%$ del PIB. Son comparaciones que no necesitan más explicación, pero sí una modificación urgente.

La dificultad del actual gobierno para impulsar políticas diferentes parte del diagnóstico de la situación y de las concepciones imperantes en el país. Hubo un desmantelamiento sistemático de los bienes públicos, y con ellos de los servicios públicos, que posicionó al mercado en todos los ámbitos de la vida, a lo que se sumó la perspectiva de bienestar a partir de la igualdad de oportunidades, lo que condujo a priorizar las diferencias de raza, género y edad más que la estructurales derivadas de la condición de clase, del colonialismo y del patriarcado. El impulso de las transferencias monetarias a los pobres y desprotegidos pareciera situarse en la perspectiva de la igualdad de posiciones estableciendo una base que reduzca distancias, pero el aporte monetario es tan bajo que será difícil reducir esas distancias de ingreso si no se acompaña de la generación de trabajo remunerado y protegido por derechos sociales, salarios en ascenso y bienes e instituciones públicas que brinden servicios de salud, educación, de cuidados, culturales y deportivos y constituyan la plataforma del bienestar. En esa dirección, se observa favorablemente la transversalidad y comunicación que están expresando las diversas secretarías de Estado para impulsar los programas sociales con los productivos. Si se logran resultados favorables y crecientes en los programas Sembrando Vida y Jóvenes Construyendo el Futuro, será porque se articularon además con el sector productivo mediante la banca de desarrollo o con dinámicas de inversión que puedan sostenerse en el tiempo, o con universidades e instituciones educativas públicas que pudieron apoyar con innovación y nuevas formas de organización del trabajo.

$\mathrm{Al}$ ser un régimen capitalista, es necesario expresar claramente la división entre lo público y lo privado, los espacios que 
no se mercantilizan y la configuración de las relaciones entre ambos; la empresa mixta que se estableció en los años 40 no fue lo mismo que las alianzas público-privadas que surgieron en el neoliberalismo, en las que se observa una clara transferencia de recursos de lo público a lo privado. La empresa tendrá que invertir y obtener su rentabilidad sin depender del gobierno. Falta mucho por desmercantilizar en los bienes públicos, así como configurar y renovar otros, y discutir ampliamente los horizontes de bienestar que se persiguen, ya que hasta las asociaciones civiles o las instituciones sin fines de lucro se construyeron mediante apoyos públicos y se habituaron a las transferencias estatales y a la compra de sus servicios.

La creación del Instituto de Salud para el Bienestar (Insabi) ha sido, desde mi perspectiva, un acierto y está mostrando las posibilidades de cambiar el modelo curativo prevaleciente en la atención de la salud hacia el impulso de la medicina preventiva. La universalidad y la gratuidad se observan como los mecanismos institucionales que deban acompañar los programas sustanciales de gobierno. Habrá que seguir proponiendo las bases de financiamiento que den sostenibilidad a las propuestas.

Una base sólida de bienestar puede derivar de la construcción de una solidad seguridad social que pudiera avanzar de la perspectiva de derechos a la construcción de la seguridad humana, al reconocer el ejercicio del cuidado de la vida, quiénes lo realizan y qué apoyos requieren. Esto llevaría a continuar discutiendo el modelo de seguridad social para el siglo XXI: si se requiere separar la atención a la salud, por un lado, y en concordancia con todos los institutos abocados a ello y, por otro, la previsión social; cómo se combinarían las fuentes de financiamiento y cómo se fortalecerían como bienes públicos; cómo construir el equilibrio entre contribuciones que derivan de los niveles salariales o contribuciones que derivan de impuestos a la riqueza. Mientras todo esto no se discuta, pudiera suceder que sin este contexto las transferencias monetarias 
solamente servirían para establecer un mínimo ingreso que no resolvería el bienestar, ni la pobreza, ni la desigualdad.

\section{REFERENCIAS}

ASF (Auditoría Superior de la Federación) [2020], Informe del Resultado de la Fiscalización Superior de la Cuenta Pública 2018. Auditoría de Desempeño: Consar 2018-5-06D0007-0057-2019 57-GB, México, Asf, 168 pp.

Barba Solano, Carlos E. [2019], "Desigualdad y regímenes de bienestar. Una mirada teórica”, en Cristina Bayón, Las grietas del neoliberalismo. Dimensiones de la desigualdad contemporánea en México, México, Instituto de Investigaciones Sociales, UNAM, pp. 145-195.

[2003], El nuevo paradigma de bienestar social residual $y$ deslocalizado. Reformas de los regímenes de bienestar en la OCDE, América Latina y México, 3 tomos, tesis, Universidad de Guadalajara/Centro de Investigaciones y Estudios Superiores en Antropología Social.

BeLtrán Villalba, Miguel [2001], "Sobre la noción de estructura social", Revista Internacional de Sociología, Madrid, 30:7-28, septiembre-diciembre.

Bertranou, Fabio [2010], Iniciativa del piso de protección social. Piso de Protección Social en Argentina, Buenos Aires, Organización Internacional del Trabajo.

Castañón Ibarra, V. y Olaf F. Ferreira Blando [2017], Densidades de cotización en el Sistema de Ahorro para el Retiro en México, México, Consar, 28 pp.

Cecchini, S., et al. (eds.) [2015], Instrumentos de protección social: caminos latinoamericanos hacia la universalización, Santiago, Cepal, <https://n9.cl/gizm>.

Cepal [2020], Protección social universal en América Latina y el Caribe, Santiago, Cepal, 290 pp. 
[2019], Panorama Social de América Latina 2018, Santiago, Cepal, 229 pp.

Cepalstat [2020], Gasto Público Social, 2020, Santiago, Cepal, $<$ https://n9.cl/hyy3a>.

Coneval (Consejo Nacional de Evaluación de la Política de Desarrollo Social) [2019], Diez años de medición de pobreza multidimensional en México: avances y desafíos en política social, Comunicado de prensa núm. 10, México, 5 de agosto, $66 \mathrm{pp}$.

[2018], Evaluación Estratégica de Protección Social en México, México, Coneval, 168 pp.

[2013], Informe de evaluación de la política de desarrollo social en México 2012, México, Coneval, 250 pp.

Congreso de LA Unión [2020], "Decreto por el que se reforma y adiciona el artículo 4o. de la Constitución Política de los Estados Unidos Mexicanos", Diario Oficial de la Federación, 8 de mayo.

CPeum (Constitución Política de los Estados Unidos Mexicanos) [2020], México, Secretaría de Gobernación, <https:// n9.cl/qbitm>.

DeATON, Angus [2015], El gran escape: salud, riqueza y los orígenes de la desigualdad, México, Fondo de Cultura Económica, $403 \mathrm{pp}$.

Dubet, François [2017], Repensar la justicia social, Buenos Aires, Siglo XXI, $127 \mathrm{pp}$.

Esping-Andersen, Gosta [2011], Fundamentos sociales de las economías postindustriales, Barcelona, Ariel, $267 \mathrm{pp}$.

FARFÁn Mendoza, Guillermo [2009], Los orígenes del seguro social en México: un enfoque neoinstitucionalista histórico, México, Unam, $265 \mathrm{pp}$.

Filgueira, Fernando [2005], Welfare and democracy in Latin America: The development, crises and aftermath of universal, dual and exclusionary social states, Draft Working Document, Ginebra, United Nations Research Institute for Social Development. 
[1998], Tipos de welfare y reformas sociales en América Latina. Eficiencia, residualismo y ciudadanía estratificada, Ponencia presentada en el Seminario "A Reforma de Administracão Pública no Brasil: Possibilidades e Obstáculos", Recife, Fundación "Joaquim Nabuco".

Gobierno de México [2019], Plan Nacional de Desarrollo 20192024, México, Gaceta Parlamentaria, año XXII, núm. 5266-XVIII, martes 30 de abril.

INEGI (Instituto Nacional de Estadística y Geografía) [2017], Encuesta Nacional de Empleo y Seguridad Social (ENESS), tercer trimestre, México, Inegi, <https://cutt.ly/ whQ5U6H>.

[2017, 2018, 2019, 2020], Encuesta Nacional de Ocupación y Empleo (ENOE), tercer trimestre, México, Inegi, $<$ https://n9.cl/fbvxp>.

Luhman, Niklas [2014], Teoría política en el Estado de bienestar, Madrid, Alianza Universidad, $170 \mathrm{pp}$.

Medina Núñez, I. [1995], "Reseña de 'El nuevo Corporativismo' de Philippe C. Schmitter", en Rigoberto Ocampo Alcántar (comp.), Espiral, 1(2): 193-209, <https://n9.cl/ xfn5i>.

Mesa-Lago, C. [2004], Las reformas de pensiones en América Latina y su impacto en los principios de la seguridad social, Santiago de Chile, Cepal, <https://n9.cl/5wwnk>.

[1985], Desarrollo de la seguridad social en América Latina, Estudios e informes de la Cepal núm. 43, Santiago de Chile, Naciones Unidas, <https://n9.cl/52kc>.

Moreno-Brid, J. C., y J. Ros Bosch [2014], Desarrollo y crecimiento en la economía mexicana: una perspectiva histórica, México, Fondo de Cultura Económica.

ocDE (Organización para la Cooperación y el Desarrollo Económicos) [2019], Estudios Económicos de la OCDE: México 2019, París, oECD Publishing, <https://n9.cl/vlfc4>.

[2015], Estudio de la OCDE sobre los sistemas de pensiones, México, OCDE-Consar, 174 pp. 
Off, Clauss [1990], "La política social y la teoría del Estado" en Contradicciones en el Estado de Bienestar, Madrid, Alianza Editorial, pp. 73-104 y 135-150.

OsoRIo, J. [2004], Crítica de la economía vulgar: reproducción del capital y dependencia, Zacatecas, Universidad Autónoma de Zacatecas, $96 \mathrm{pp}$.

Ramírez López, B. P. (coord.) [2019a] Vivir al día. Estrategias y experiencias de trabajadores en empleo informal en México, México, IIEc-Unam-WIEGo, 189 pp.

[2019b], "El binomio formalidad/informalidad en el mercado de trabajo mexicano", Equidad y Desarrollo, 1 (33): 89-103.

[2011], "La política social del gobierno mexicano", La política social en el nuevo contexto: Enfoques y experiencias, Montevideo, Unesco-Flacso, pp. 135-163.

RoJAs, Carlos [1992], El Programa Nacional de Solidaridad: hechos e ideas en torno a un esfuerzo", Comercio Exterior, México, 42(5): 440-448, mayo.

SanahuJa, José Antonio [2014], "De los Objetivos del Milenio al desarrollo sostenible: Naciones Unidas y las metas globales post-2015”, en Manuela Mesa (coord.), Focos de tensión, cambio geopolítico y agenda global. Anuario 2014-2015, Madrid, Centro de Investigación y Educación para la Paz, Fundación Cultura de Paz, pp. 49-83.

SHCP (Secretaría de Hacienda y Crédito Público) [2020], Presupuesto de Egresos de la Federación, México, <https:// n9.cl/0o $7 \mathrm{v}>$.

Secretaría de Hacienda y Crédito Público, Cuenta Pública. México, <https://n9.cl/t8rk>.

Secretaría del Bienestar [2019], Programa Pensión para el Bienestar de las Personas Adultas Mayores, México, $<\mathrm{https}: / / \mathrm{n} 9 . \mathrm{cl} / \mathrm{zq} 6 \mathrm{~d} 9>$.

Sen, Amartya [2012], La idea de la justicia, Madrid, Taurus, $478 \mathrm{pp}$. 


\section{FINANCIAMIENTO DEL GASTO PÚBLICO: ¿RETO PARA ALCANZAR EL BIENESTAR SOCIAL?}

Marcela Astudillo Moya*

\section{INTRODUCCIÓN}

Uno de los primeros significados del término bienestar fue la satisfacción de necesidades físicas. El concepto se amplió después al ámbito laboral, social y biológico, entre otros. El Diccionario de la Real Academia Española lo define como: "conjunto de las cosas necesarias para vivir bien". Una segunda acepción es "vida holgada o abastecida de cuanto conduce a pasarlo bien y con tranquilidad".

Como se observa, la definición es tan amplia que abarca muy diversos campos; de ello se deriva que en lo individual es un término muy subjetivo, pero cuando se refiere a la sociedad entonces se denomina bienestar social. Precisamente es en este campo donde el Estado desempeña una función de gran importancia, pues una de sus funciones es coadyuvar y proveer las condiciones básicas para que todos los sectores de la sociedad puedan disfrutar de una calidad de vida que les permita estar bien, en otras palabras: alcanzar el bienestar.

En este capítulo se estudia el bienestar social en lo que se refiere tanto a la política social como al combate a la pobreza. Su objetivo es el análisis del gasto destinado a financiar las

*Investigadora del Instituto de Investigaciones Económicas, UNAM. Correo electrónico: <marcelaa@unam.mx>.

La autora agradece a Raúl Porras Rivera el apoyo en la conformación de datos y gráficas. 
políticas de bienestar social en el presupuesto de egresos de la federación durante los últimos siete años.

Las cuestiones a resolver son: ilas actuales condiciones de las finanzas públicas del gobierno federal tienen la capacidad para financiar las acciones planteadas en el Plan Nacional de Desarrollo (PND) 2019 a 2024 destinadas al bienestar de la población? y ¿dichas acciones cuentan con el financiamiento suficiente en el Presupuesto de Egresos para alcanzarlas? La metodología a seguir es en primer término una revisión de la bibliografía especializada sobre la función del producto interno bruto (PIB) como guía para orientar el gasto social. Posteriormente se estudia el marco macroeconómico de las finanzas públicas tomando como base los Criterios Generales de Política Económica, ya que una de las cuestiones a dilucidar es si las actuales condiciones de las finanzas públicas del gobierno federal tienen la capacidad para financiar el gasto necesario que permita alcanzar el bienestar de la población. En un tercer apartado, se analiza el marco normativo referente al bienestar, para lo cual se examinan tanto la Constitución Política de los Estados Unidos Mexicanos como el PND 2019 a 2024. Luego se detallarán los rubros presupuestarios destinados al bienestar social durante los últimos cinco años del gobierno de Peña Nieto, 2019 como periodo de transición y el año 2020, que es el primero en el que el presupuesto lo elabora por completo el actual régimen presidencial. Finalmente se plantean los retos para financiar una política de bienestar que garantice el ejercicio de los derechos sociales de la población.

\section{EL PIB Y EL GASTO SOCIAL}

Ante la gran desigualdad entre pobres y ricos que priva en la mayoría de los países, se ha hecho hincapié en la necesidad de mejorar las herramientas para perfeccionar el análisis económico, la capacidad de anticipación y el diseño de 
políticas públicas. En la actualidad, se ha puesto en duda si el pIB es el indicador adecuado para evaluar el progreso de los países o se requiere otro más vinculado con el bienestar de la población para que los gobiernos tomen mejores decisiones de gasto. Según la Organización para la Cooperación y el Desarrollo Económicos (OCDE), utilizar el PIB como único indicador del progreso económico de los países ha dado lugar a una gran desigualdad en la mayoría de estos. Prueba de ello son las enérgicas protestas sociales en diversas partes del mundo.

La OCDE [2020] propone un crecimiento incluyente cuya medición implica seguir utilizando el PIB, pero el parámetro fundamental será el bienestar de las personas medido en términos de ingresos disponibles, acceso a la educación, la salud, el empleo de calidad, la certidumbre en el trabajo y otras variables. Tomar en cuenta el PIB y al bienestar de las personas permitirá a los gobiernos dirigir sus políticas de ingresos y gastos para lograr un crecimiento inclusivo.

Ante el aumento en la desigualdad, inclusive el Fondo Monetario Internacional (FMI) ha intensificado en la última década su interés por las cuestiones relacionadas con el gasto social. Así, el FMI utiliza "pisos" de gasto social en los programas que respalda.

En los Objetivos de Desarrollo Sostenible (oDs) para 2030 se plantea el compromiso mundial de apoyar el crecimiento inclusivo. Para ello, se considera el gasto social como una herramienta esencial de política para abordar cuestiones relacionadas con el bienestar de la sociedad, como la educación y la salud.

Para Joseph Stiglitz [2002], el objetivo de la actividad económica es incrementar el bienestar de los individuos. Considera que basarse exclusivamente en indicadores como el PIB ha dado lugar a políticas ineficientes, como la austeridad a ultranza. Si se mide lo incorrecto, las políticas que se implementen no serán las apropiadas. Stiglitz señala que no obstante los aumentos en el PIB, que es una medida económica y no de 
bienestar, no todo está bien; en la actualidad, hay una gran crisis de desigualdad que se pone de manifiesto en el descontento político que se propaga por diversos países.

Inclusive, ante las crecientes desigualdades y conflictos políticos resulta relevante la pregunta: ¿los gastos gubernamentales en bienestar favorecen la paz? Justinoa y Martoranob [2018], mediante un panel con datos de 12 países latinoamericanos durante el periodo 1970 a 2010 , demostraron que el gasto en bienestar ha conducido a una reducción sustancial de conflictos en la región.

Nueva Zelanda es el primer país que presenta un "presupuesto del bienestar". La mitad del gasto público está destinado a las prioridades sociales: la salud mental de la población, la pobreza infantil, el apoyo a las comunidades indígenas, la transición a una economía baja en emisiones y el impulso de la innovación [Bedford, 2010]. También Islandia y Escocia pretenden contribuir a cambiar el modelo económico para hacerlo más humano y sostenible, mejorar el bienestar más allá del PIB [WeAll, 2018].

Hoy día, la crisis de desigualdad ha dado lugar a que diversos organismos internacionales y, en general, en las publicaciones especializadas se cuestione el PІB por sus limitaciones como indicador de progreso. Autores como López-Calva y Lustig [2011] consideran que el рів tiene serias deficiencias; por ejemplo, deja fuera el trabajo doméstico, el daño ambiental causado en la producción y los activos financieros, y tampoco considera la economía sumergida ni la evasión de impuestos. Otra medida del grado de desigualdad es el coeficiente de Gini, que también tiene grandes fallas porque no se conoce con exactitud el ingreso de los ciudadanos. En general, estos indicadores utilizan la desigualdad relativa y no las diferencias absolutas que es donde realmente se refleja la disparidad.

Según otros autores [Soumitra y Lanvin, 2019], para medir el progreso hay que considerar tres elementos: detectar el sentimiento de la gente (medido a través de su comportamiento), 
un indicador dinámico para que pueda compararse en el tiempo y el tercer elemento es incluir los objetivos de la sociedad, los cuales difieren de las zonas rurales a las urbanas, y dependen del país y la época; las formas en que las personas desarrollan su existencia dependen de sus particularidades individuales y del contexto histórico, económico, social y político en que viven. Otra cuestión que debe considerarse es introducir variables digitales en los indicadores, pues el acceso a la tecnología puede ser uno de los elementos de exclusión social. En la Unión Europea, se ha planteado que para lograr el bienestar de la sociedad se requieren políticas que tomen en cuenta la sostenibilidad, la productividad, la estabilidad económica y la justicia social.

Así pues, no hay duda que es indispensable cambiar el modelo económico para hacerlo más humano; para ello, se necesitan nuevos indicadores a fin de que cuando se mida el crecimiento económico también se considere el bienestar. La cuestión pendiente a debatir es ¿qué medir? y ¿qué peso se le da a cada variable? Por ejemplo, para algunos es más importante la salud que la educación o la seguridad. Todo depende, como señala Soumitra, de la sociedad y la época en que se haga la medición.

Uno de los intentos para determinar los indicadores más adecuados para calcular el bienestar lo realizó Martin Burt [2109], creador de la Fundación Paraguaya, quien confeccionó un tablero con 50 variables para que los ciudadanos elaboraran su plan personal para salir de la pobreza. Esta prueba la aplicó en 30 países y los resultados los compiló en su libro, en el cual llega a la conclusión que la mitad de los indicadores que evalúan el bienestar son subjetivos, cuestión que puede dar origen a distorsiones por parte de los políticos. Burt es partidario de añadir métricas a las existentes. Otra alternativa para definir las políticas públicas destinadas a garantizar el respeto a los derechos sociales de la ciudadanía es mediante la desagregación de gastos para identificar las diversas 
prioridades de los diferentes sectores de la población [Justinoa y Martoranob, 2018].

Además se plantea la pregunta ¿cómo se presentará el indicador de bienestar?, ¿se tratará de un menú de indicadores o se integrará en uno? En fin, aún hay mucho qué dilucidar para determinar después los recursos que se destinarán al bienestar de la población.

Como se observa, en términos generales la bibliografía está orientada a la búsqueda de indicadores que permitan medir el bienestar, pero poco se estudia la causa del malestar de la población, que es la gran concentración del ingreso y la riqueza en un sector muy pequeño de la población. Si se atacara este problema, se estarían resolviendo sus causas estructurales. Desde luego que una política de este tipo debe ser a nivel global, ya que los capitales fácilmente se fugarían a los paraísos fiscales si lo hiciera un solo país.

\section{MARCO MACROECONÓMICO}

En el ámbito externo del entorno macroeconómico en que se aplicará la política fiscal para 2020 destaca la incertidumbre en los mercados internacionales, la cual afecta unas finanzas públicas debilitadas, tanto por el monto de las exportaciones como por las fluctuaciones del precio de las materias primas que exportamos. Dos mil diecinueve fue un año en el que la desaceleración de la economía, especialmente del sector de manufacturas de Estados Unidos, causó una baja en las exportaciones mexicanas que no llegó a afectar la balanza comercial porque también las importaciones disminuyeron.

Por lo que corresponde a las fluctuaciones en el precio del petróleo, en la Ley de Ingresos se calculó en 49 dólares el precio del barril. En febrero bajó a 39 el barril, lo cual también tiene un efecto negativo para las finanzas del gobierno federal. 
De acuerdo con los Criterios Generales de Política Económica, en el ámbito interno entre los estimadores para 2020 destacan los siguientes (cuadro 1):

Cuadro 1. Estimadores para 2020

Tasa de interés

Tipo de cambio nominal

Tasa de inflación nominal fin del periodo

Déficit en cuenta corriente

\section{$7.1 \%$}

20 MXN por USD

$$
3 \%
$$

$-1.8 \%$ del PIB

Fuente: elaboración propia.

La alta tasa de interés favorece que los capitales se orienten al sector financiero en lugar del sector productivo. Las otras variables dependen en gran medida del comportamiento del mercado externo.

Ahora bien, con respecto a la estructura de los ingresos destacan los siguientes cuatro componentes, que en conjunto representan $90.6 \%$ del total de los ingresos:

Cuadro 2. Componentes de estructura de ingresos (\%)

Impuestos

57.4

Ingresos por venta de bienes y servicios

17.5

Ingresos derivados de financiamiento (deuda)

Cuotas y aportaciones a la seguridad social

Total

90.6

Fuente: elaboración propia. 
El incremento de los ingresos con respecto a 2019 se presenta principalmente en impuestos, ingresos petroleros y deuda. Los impuestos con mayor capacidad recaudatoria son el ISR, el IVA y el IEPS, los cuales representaron $13.3 \%$ del PIB en 2019.

Por lo que corresponde al gasto público, resalta su incremento moderado con respecto a 2019: de $0.8 \%$, su participación en el PIB es de $23.2 \%$ en el año 2020. Desde el punto de vista de la clasificación administrativa, se observa una reasignación del gasto: disminuye en términos absolutos en la Presidencia de la República, el turismo y la economía, así como la tasa de crecimiento de la deuda y el Programa de Apoyo a Deudores de la Banca, entre otros. Por el contrario, aumentan bienestar, educación y energía.

El bienestar de la población se menciona como una de las prioridades del actual régimen en los lineamientos de la política económica señalados en el PND 2019 a 2024. Para ello, el gasto destinado al desarrollo social representa $45.9 \%$ del gasto neto total del gobierno federal. La cuestión a dilucidar es si el entorno macroeconómico permitirá que la política de ingresos públicos sea capaz de financiar el gasto presupuestado para 2020.

Desde luego que para aclarar la cuestión anterior debe tenerse en cuenta, en primer término, el contexto en que se aplicará la política presupuestaria. En este ámbito resalta la falta de crecimiento de la economía mexicana. Resulta indispensable revertir esta situación para que la política fiscal sea exitosa.

Por el lado de los ingresos, el decrecimiento de la economía redundará en menor recaudación, ya que al no haber producción, el empleo cae y con ello disminuye la percepción de impuestos a los ingresos y al consumo. La Organización Internacional del Trabajo (огт) estima que, como resultado del menor dinamismo de la economía, la tasa de desocupación en México pasará de $3.4 \%$ de la población económicamente 
activa (PEA) en 2019 a $3.7 \%$ en 2020. Otra situación que afecta de forma negativa los ingresos públicos es la elevada informalidad; de acuerdo con datos del Instituto Nacional de Estadística y Geografía (Inegi), 57\% de las personas que trabajan en el país están ocupadas en actividades no reguladas.

Además, buena parte de los ingresos depende de la alta volatilidad del precio de materias primas, como se señaló antes; una de ellas es el petróleo. Por todo lo anterior, se visualiza difícil alcanzar la meta de ingresos para 2020.

En cuanto al gasto, $28.1 \%$ es no programable, por lo que la posibilidad de modificar su uso disminuye, lo que genera que la inversión pública se reduzca cuando es necesario hacer ajustes presupuestarios. Por otra parte, las finanzas públicas están sujetas a la regla fiscal aprobada en la Ley Federal de Presupuesto y Responsabilidad Hacendaria (LF$\mathrm{PRH})$ de 2014 y su respectivo reglamento. Dicha regla establece una restricción al déficit presupuestario de hasta $2 \%$ del PIB solo si la inversión es mayor a este déficit; además fija una meta anual de los Requerimientos Financieros del Sector Público (RFSP) determinada por la capacidad de financiamiento del sector público federal. Finalmente, establece el Límite Máximo del Gasto Corriente Estructural (LMGCE), que en la LFPRH de 2014 se define como el monto correspondiente al gasto neto total, excluyendo los gastos por concepto de costo financiero, participaciones a las entidades federativas, a los municipios y demarcaciones territoriales del Distrito Federal, adeudos de ejercicios fiscales anteriores, combustibles utilizados para la generación de electricidad, pago de pensiones y jubilaciones del sector público, y la inversión física y financiera directa de la administración pública federal.

Como se observa, las finanzas públicas no están promoviendo la expansión de la actividad económica; contrario a ello, la postura fiscal es contractiva, no promueve la expansión, lo que explica el actual estancamiento de la economía. 


\section{MaRCo NORMATIVO}

\section{Constitución Política de los Estados Unidos \\ Mexicanos (CPEUM)}

En la Constitución se encuentran seis artículos que establecen derechos que están íntimamente relacionados con el bienestar de la población.

El Artículo $3^{\circ}$ señala que es un derecho recibir educación por parte del Estado (los sujetos obligados a proporcionarla son los gobiernos federal, estatales y municipales) y además garantiza la calidad de la educación obligatoria, o sea, desde la educación preescolar hasta la media superior. El Congreso de la Unión es el encargado de fijar las aportaciones económicas para cubrir ese servicio público.

El Artículo $4^{\circ}$ establece la igualdad entre hombres y mujeres. Además señala que el Estado garantizará los siguientes derechos a las personas:

1. A la alimentación nutritiva, suficiente y de calidad.

2. A la protección de la salud (establece concurrencia entre la federación y las entidades federativas).

3. A un medio ambiente sano para su desarrollo y bienestar.

4. Al acceso, disposición y saneamiento de agua (señala la participación de los tres ámbitos de gobierno y la ciudadanía).

5. A la vivienda digna y decorosa.

6. A la identidad.

7. $\mathrm{Al}$ acceso a la cultura.

8. A la cultura física y la práctica del deporte.

9. La niñez tiene derecho a la satisfacción de necesidades de alimentación, salud, educación y sano esparcimiento para su desarrollo integral.

El Artículo $5^{\circ}$ se refiere al derecho al trabajo lícito y el $6^{\circ}$ al derecho de acceso a la información y a las tecnología de la información y comunicación. 
El Artículo 27 otorga a la nación el derecho de regular en beneficio social el aprovechamiento de tierras, aguas y bosques. Con este derecho se pretende específicamente hacer una distribución equitativa de la riqueza pública, lograr el desarrollo equilibrado del país y el mejoramiento de las condiciones de vida de la población rural y urbana.

Por último, en el artículo 123 se retoma el tema del trabajo. Por un lado, otorga el derecho de toda persona al trabajo digno y socialmente útil y, por otro, establece la obligación del Estado de promover la creación de empleos.

\section{Plan Nacional de Desarrollo 2019 a 2024}

Como uno de los objetivos del PND vigente, se señala el bienestar de todos y todas, garantizando el goce de los derechos sociales y económicos establecidos en la Constitución. Para ello se plantea una reingeniería profunda del gasto público con el fin de reorientar los recursos hacia los programas que generen mayor bienestar y así lograr una mejor calidad de vida y el bienestar de las y los ciudadanos.

La política de desarrollo está regida por 12 principios, uno de los cuales es la economía para el bienestar, la cual se visualiza como crecimiento con distribución de la riqueza. Se determina que para impulsar el bienestar de toda la población se requiere "austeridad, disciplina fiscal, cese del endeudamiento, respeto de las decisiones autónomas del Banco de México, creación de empleos, fortalecimiento del mercado interno, impulso al campo, a la investigación, la ciencia y la educación" [SHCP, 2019a: 25].

El PND está estructurado en tres ejes generales: 1. Justicia y Estado de Derecho; 2. Bienestar; y 3. Desarrollo económico. Cada uno de estos ejes cuenta con un objetivo general y varios objetivos particulares. Además, se plantean tres ejes transversales: igualdad de género, no discriminación e inclusión social; 
combate a la corrupción y mejora de la gestión pública; y territorio y desarrollo sostenible.

Programas transversales DEL Gasto PÚBlico FEDERAL

De acuerdo con el Artículo 2 III Bis de la LFPRH de 2019, son programas transversales:

donde concurren Programas Presupuestarios, componentes de estos y/o Unidades Responsables, cuyos recursos son destinados a obras, acciones y servicios vinculados con el desarrollo de los siguientes sectores: Igualdad entre Mujeres y Hombres; Atención de Niños, Niñas y Adolescentes; Desarrollo Integral de los Pueblos y Comunidades Indígenas; Desarrollo de los Jóvenes; Programa Especial Concurrente para el Desarrollo Rural Sustentable; Programa de Ciencia, Tecnología e Innovación; Estrategia Nacional para la Transición Energética y el Aprovechamiento Sustentable de la Energía; Atención a Grupos Vulnerables; y los Recursos para la Mitigación de los efectos del Cambio Climático.

Con base en ello se tiene la información que se describe en el diagrama 1, en el cual se observa que el programa de Atención a Niñas, Niños y Adolescentes, el de Desarrollo de los Jóvenes y el Programa Especial Concurrente para el Desarrollo Rural Sustentable absorben $69.4 \%$ de los recursos asignados a los programas transversales; mientras que el programa de Estrategia de Transición para Promover el Uso de Tecnologías y Combustibles limpios y el de Adaptación y Mitigación de los Efectos del Cambio Climático, en conjunto, solo representan $3 \%$ del total del gasto asignado a los mencionados programas transversales.

Como ya se señaló, en el PND se plantean tres ejes generales. Por lo que corresponde al eje bienestar, su objetivo general 


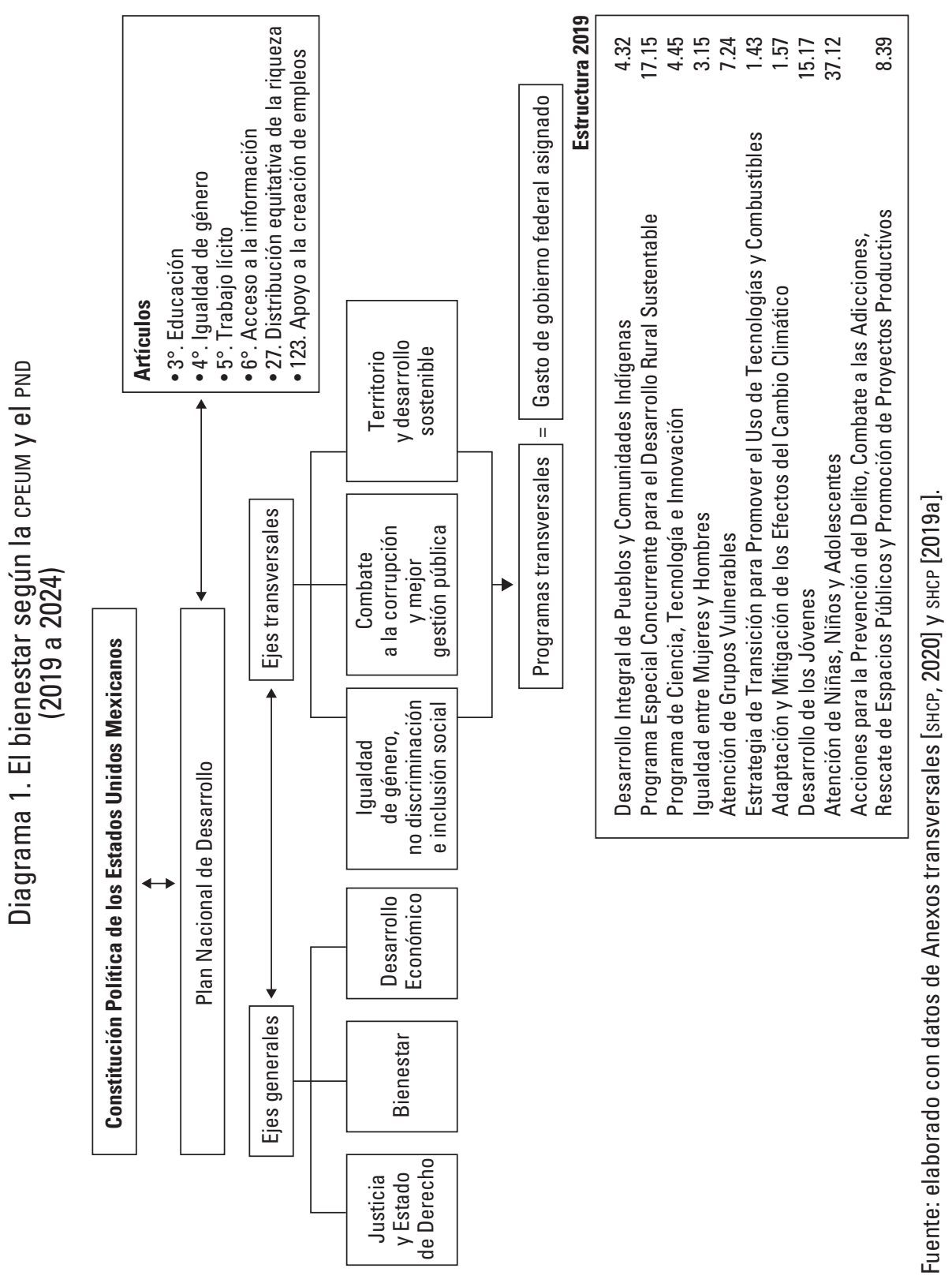


es garantizar el ejercicio de los derechos económicos, sociales, culturales y ambientales. Uno de los objetivos particulares es reducir las brechas de desigualdad sociales y territoriales.

Entre los objetivos particulares que cuentan con acciones específicas que requieren financiamiento presupuestal se encuentran:

1. Garantizar el derecho a la educación laica, gratuita, incluyente y de calidad en todos los niveles y para todas las personas. En este caso, una de las acciones es mejorar la infraestructura básica y el equipamiento de los espacios educativos en todas las modalidades.

2. Promover y garantizar el acceso universal y gratuito de toda la población a los servicios de salud, la asistencia social y los medicamentos. Para ello, se planea mejorar y ampliar la infraestructura de salud, el equipamiento y el abasto de medicamentos en las unidades médicas y de rehabilitación.

3. Garantizar el acceso al agua potable en calidad y cantidad y al saneamiento. La acción específica es promover la inversión en infraestructura sostenible y resiliente para satisfacer la demanda de agua potable para consumo doméstico, priorizando a los grupos históricamente discriminados. Además, se pretende mejorar la infraestructura hidráulica, lo que incluye el tratamiento y la reutilización de aguas residuales y calidad de los servicios de saneamiento.

4. Apoyar el acceso a una vivienda adecuada. Para el ejercicio de este derecho se plantea otorgar financiamiento de vivienda, principalmente para la población en situación de precariedad económica.

5. Fortalecer la rectoría y el ordenamiento territorial y ecológico de los asentamientos humanos. Para el logro de este objetivo, se plantea promover que la infraestructura, el equipamiento y los servicios básicos se realicen con enfoque de un hábitat inclusivo.

6. Garantizar la cultura física y la práctica del deporte. Para ello se impulsará la construcción y rehabilitación de 
infraestructura para la práctica del deporte con prioridad en las zonas de alta marginación.

7. Garantizar el acceso a un trabajo digno, con seguridad social, por medio de la capacitación en el trabajo, la política de recuperación de salarios y el cumplimiento de la normatividad laboral. Se busca otorgar servicios de seguridad social, incluidas las prestaciones sociales y económicas.

En este eje se presentan otros objetivos para cuya consecución no se señalan acciones específicas que requieran financiamiento, como brindar atención prioritaria a grupos históricamente discriminados; promover y garantizar el derecho a la alimentación nutritiva y de calidad; garantizar el derecho a un medio ambiente sano; y promover el derecho humano de acceso a la cultura de la población.

El tercer eje general, Desarrollo económico, tiene por objetivos incrementar la productividad, el uso eficiente de los recursos y contribuir a un crecimiento económico equilibrado.

Entre las acciones específicas que requieren recursos que afectan las finanzas públicas se señalan:

1. Mejorar los regímenes fiscales y la simplificación administrativa asociada con el pago de impuestos.

2. Impulsar la inversión pública y privada en infraestructura resiliente y accesible.

3. Estabilidad macroeconómica y finanzas públicas sostenibles. Para este objetivo se plantea incrementar la recaudación disminuyendo la evasión y la elusión fiscales, y mediante el ejercicio eficiente y transparente del gasto público.

4. Establecer una política energética soberana. Para lo que se plantea fortalecer la posición financiera de las empresas productivas del Estado y asegurar el abasto de energéticos a precios accesibles.

5. Desarrollar una infraestructura de transporte con enfoque multimodal (ferroviario, aeroportuario, transporte marítimo, transporte masivo) a costos competitivos. 
6. Desarrollar infraestructura de radiodifusión y telecomunicaciones, con énfasis en internet y banda ancha.

7. Apoyos para la capitalización en insumos, infraestructura y equipamiento a los sectores agropecuarios y acuícolapesquero en los territorios rurales.

8. Promover la inversión pública en medidas de mitigación y adaptación al cambio climático.

Como se observa, el PND 2019 a 2024 está alineado a lo establecido en la Constitución en lo que corresponde a los derechos relacionados con el bienestar. Por desgracia, la contracción de la economía en 2019 demostró que para impulsar el bienestar no es suficiente la austeridad, la disciplina fiscal ni el cese del endeudamiento; se requiere, además, la inversión para crear empleos y ampliar el mercado interno. Ahora bien, ¿se cuenta con los recursos suficientes para financiar las acciones mencionadas en objetivos específicos, como el mejoramiento y ampliación de la infraestructura de los espacios educativos, de salud, agua potable, hidráulica, de transporte, radiodifusión y telecomunicaciones, entre otros?

\section{RUBROS PRESUPUESTARIOS DESTINADOS}

A FINANCIAR LA POLÍTICA DE BIENESTAR

La gráfica 1 destaca que en los primeros dos años del actual régimen se observa cierta reingeniería del gasto público, tal como se menciona en el PND 2019 a 2024 y que pretende reorientar los recursos hacia los programas que generen bienestar.

Otros gastos incluyen: adeudos de ejercicios fiscales anteriores (ADEFAS), programas de apoyo a deudores de la banca y costo financiero de empresas productivas del Estado.

$\mathrm{El}$ gasto federal en desarrollo social durante el periodo 2014 a 2018 creció anualmente a una tasa media de $3.88 \%$, mientras que de 2019 a 2020 se incrementó en $6.44 \%$, con lo 


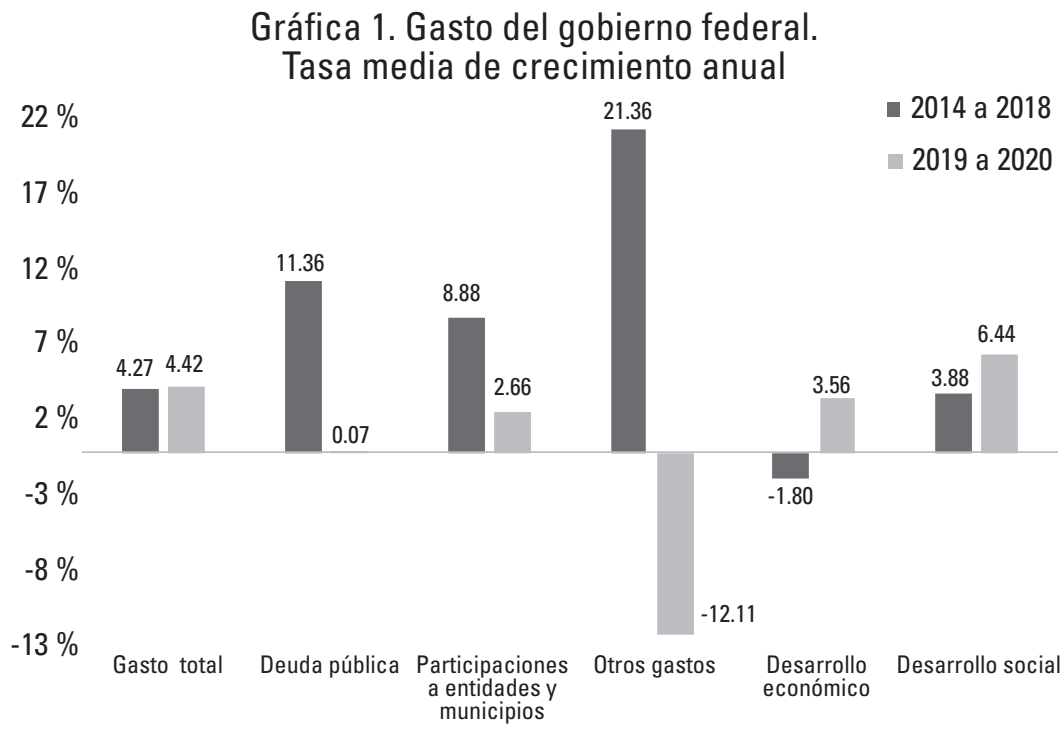

Fuente: elaborada con datos de la SHCP. Presupuesto de egresos de la Federación, varios años.

que pasó de representar $45.7 \%$ del total del gasto del gobierno federal en 2014 a $45.9 \%$ en 2020 , aunque el gasto neto total presentó tasas medias de crecimiento anual similares: $4.27 \%$ en el primer periodo señalado y $4.42 \%$ en los últimos dos años. Cabe mencionar que se registran variaciones a la baja en el periodo 2019 a 2020 en los rubros de deuda pública, participaciones a entidades y municipios, y otros gastos, que incluyen ADEFAS, programas de apoyo a deudores de la banca y costo financiero de empresas productivas del Estado. Los únicos dos rubros que se incrementaron fueron el gasto en desarrollo social, como ya se mencionó, y el gasto en desarrollo económico, que durante el periodo 2014 a 2018 decreció a una tasa media anual de $1.80 \%$, mientras que de 2019 a 2020 se incrementó en 3.56 por ciento.

Desde el punto de vista de la participación del gasto en desarrollo económico en el total del gasto del gobierno federal, 
Gráfica 2. Gasto público federal (participación porcentual en el total del gasto)

55

45

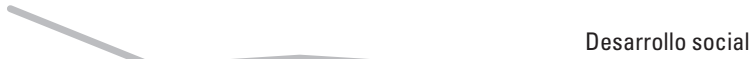

35

25

Desarrollo económico

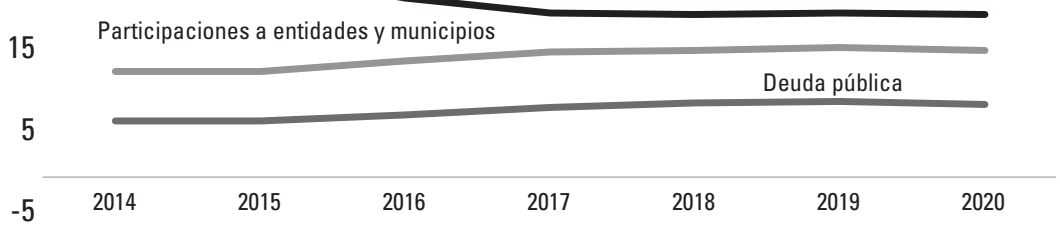

Fuente: elaborada con datos de la SHCP. Presupuesto de egresos de la Federación, varios años.

como se constata en la gráfica 2, presentó una disminución importante durante el primer periodo mencionado ya que en 2014 se destinó $25.3 \%$ del total del gasto, en 2018 decreció a $19.9 \%$ y en 2019 a 2020 se incrementó, aunque no al nivel de 2014. Este rubro es relevante porque en las acciones específicas se mencionan obras de infraestructura cuya construcción da empleo y su uso es en beneficio de la población. Sin embargo, en 2020 se modifica ligeramente la tendencia a la baja que como se observa en el periodo de estudio viene desde 2014.

En 2018, se creó la Secretaría de Bienestar, antes Secretaría de Desarrollo Social, que es la encargada de diseñar y ejecutar las políticas de desarrollo social y calidad de vida. Entre sus funciones está fortalecer el bienestar, el desarrollo y la cohesión social en el país mediante políticas como el combate a la pobreza y de inclusión de sectores vulnerables como niños, ancianos, discapacitados y pobladores de zonas rurales. Se señala que esta secretaría busca un cambio de fondo en el que la 
prioridad sea la gente, sobre todo quienes menos tienen [Secretaría de Bienestar, 2020].

En el Presupuesto de Egresos de la Federación correspondiente al ejercicio de 2020, a la Secretaría de Bienestar se le asignan 173 mil millones de pesos (mmdp), cantidad solo superada por la Secretaría de Educación Pública; la Secretaría de Salud es la tercera en importancia. En el rubro de gasto social, se presentan 14 programas prioritarios operados por la Secretaría de Bienestar, entre los cuales se señalan: 1. Pensión para el bienestar de personas adultas mayores; 2 . Pensión para el bienestar de las personas con discapacidad permanente; 3 . Sembrando vida; 4. Programa de apoyo para el bienestar a madres trabajadoras; 5. Programa Nacional de Reconstrucción; 6 . Becas bienestar para educación básica, educación media superior y educación superior; 7. Fertilizantes para el bienestar; 8. Tandas para el bienestar; 9. Programa de atención a jornaleros agrícolas; 10. Jóvenes construyendo el futuro; 11. Desarrollo de zonas prioritarias; y 12. Abasto rural de Diconsa; entre otros. De los 14 programas, los primeros cuatro mencionados representan $58 \%$ del total asignado a este rubro.

Además, en el proyecto de presupuesto para 2020 se contempla destinar $28.5 \mathrm{mmdp}$ para programas estratégicos que contribuyan a un desarrollo incluyente. El monto representa $9.5 \%$ de la inversión física presupuestada. Estos programas comprenden 24 obras que forman parte del Programa Nacional de Infraestructura para el Bienestar. Los ejemplos incluyen el Tren Maya, el Programa de Conservación de Caminos Rurales de Oaxaca, el Programa para el Desarrollo del Istmo de Tehuantepec, Programa Zona Libre de la Frontera Norte y el Aeropuerto Internacional "Felipe Ángeles" en Santa Lucía, entre otros.

Orientados a la autosuficiencia alimentaria y el rescate del campo, se señalan los siguientes programas: 1. Programa producción para el bienestar; 2. Programa de apoyo a cafetaleros y cañeros del país; 3. Programa de precios de garantía para 
los cultivos de maíz, frijol, trigo panificable, arroz y leche; 4 . Crédito ganadero a la palabra; 5. Distribución de fertilizantes químicos y biológicos; y 6. Creación del organismo Seguridad Alimentaria Mexicana (Segalmex).

En el PND 2019 a 2024, no se mencionan programas específicos para ciencia y tecnología. Por lo que corresponde a deporte se mencionan tres: 1. Es una prioridad la activación física; 2. El deporte para todos; y 3. Apoyo al deporte de alto rendimiento con transparencia.

En enero de 2020, se creó el Instituto de Salud para el Bienestar (Insabi), un órgano descentralizado de la Secretaría de Salud que sustituye al Seguro Popular. En el Presupuesto de Egresos, no se establece el monto de los recursos que se ejercerán por este concepto durante el presente año.

Cabe aclarar que en el Programa Nacional de Infraestructura para el Bienestar 2020 a 2024, la presidencia proyecta que la inversión en infraestructura durante los próximos cinco años, tanto privada como pública, contribuirá a que se alcance un crecimiento anual promedio del PIB de $4 \%$ durante ese periodo. El monto de este programa es $13.2 \%$ inferior al programa del sexenio anterior. Se estima que la inversión privada será $56 \%$ del total, a diferencia del sexenio anterior, que fue de $37 \%$ del total. De ahí que la reactivación de la economía en buena medida depende de la inversión privada, lo cual no es lo ideal. Un ejemplo son las asociaciones público-privadas que tanto en México como a nivel internacional han significado un costo muy alto para la población.

\section{CONSIDERACIONES FINALES}

En el PND 2019 a 2024, se observa una voluntad política de favorecer el bienestar de la población; sin embargo, el gran obstáculo para que el régimen actual pueda proveer las condiciones básicas para que todos los sectores de la sociedad 
alcancen el bienestar es la insuficiencia de los ingresos públicos, lo que a su vez se explica por la caída del crecimiento económico de $0.1 \%$ respecto de 2018 de acuerdo con el Inegi, situación que empeora en 2020 por efecto de la pandemia de covid-19. Se calcula que la contracción de la economía puede ser de dos dígitos, pero aún es prematuro conjeturar su efecto en la economía porque la pandemia no ha llegado a su fin y tampoco se sabe cuándo concluirá.

En buena medida dicha caída se explica, además de por la pandemia, por la falta tanto de inversión pública de inversión privada. Una parte importante del gasto público se destina al gasto en desarrollo social y los recursos sobrantes son insuficientes para las obras de infraestructura que se requieren para el bienestar. Por ello, en el Programa de Inversión se plantea que $56 \%$ de la inversión será privada, misma que no se ha concretado debido a la falta de confianza en el actual régimen; además, con una tasa de interés de referencia de $4.5 \%$, los capitales se dirigirán preferentemente al sector financiero.

Otra opción de financiamiento sería recurrir a la deuda pública, pero, como ya se dijo, la regla fiscal establecida en 2014 señala un déficit presupuestario máximo de $2 \%$ del PIB y violar la ley implicaría el riesgo de que las tasas de interés de la deuda externa se incrementen, pues en la actualidad prevalece la idea de que la política de presupuesto balanceado o con un ligero déficit produce un mayor crecimiento y con ello mayor bienestar a la población que una política de deuda que se incremente a tasas muy altas [Greiner, 2016].

Está demostrado que la política de austeridad no ha sido suficiente para crecer a $4 \%$ como se proyectó en el PND, ni tampoco el combate a las prácticas de evasión y elusión por parte de grandes empresas e incluso de la clase política. Todo parece indicar que la solución está en atacar las causas estructurales de la pobreza y que se remiten a la altísima concentración del ingreso y la riqueza en muy pocas manos. El remedio no está en elevar las tasas de impuestos indirectos ni de impuestos 
locales como lo propone el FMI, sino en una reforma fiscal progresiva que grave los ingresos más altos, las herencias y los activos financieros, entre otros. Cabe subrayar que esta tarea no es de un solo país; en años recientes, la OCDE ha propuesto medidas para que a nivel mundial las empresas tecnológicas paguen impuestos en el país donde obtienen ingresos. También ha planteado mecanismos para regular los precios de transferencia que utilizan las empresas multinacionales para el pago de sus impuestos en cada uno de los países donde operan.

El crecimiento económico permitirá aumentar la capacidad de gasto social del gobierno, generar empleos y mantener la estabilidad en el mercado laboral; pero si la economía no crece, los ingresos públicos no serán suficientes para el desarrollo social. Los programas asistencialistas no eliminan de raíz el problema de la pobreza, solo lo aminoran en el corto plazo. En el largo plazo, la política de empleo desempeña una función fundamental en el bienestar de las personas, pues la falta de este condena a las personas a vivir con escasos recursos económicos. A su vez, el desempleo puede deberse a salud o educación deficientes; en cualquier caso, las personas tendrán una precaria condición de vida, que en una crisis económica puede afectar a la población o ser específica de un individuo o grupo. De ahí la importancia de que los recursos públicos se destinen a crear empleos, con lo que se podrá incrementar la recaudación y, a su vez, financiar la educación y la salud para la población. La formación del capital humano es la fuente del crecimiento económico, por lo que destinar recursos a la educación no es un gasto sino una inversión.

Finalmente, de acuerdo con el Informe de la Secretaría de Hacienda y Crédito Público sobre las Finanzas Públicas y la Deuda Pública correspondiente al cuarto trimestre de 2019, se registró un subejercicio, pues el gasto neto pagado fue inferior al presupuestado en 15600 millones de pesos. Por otra parte, del lado de los ingresos, el gobierno federal recaudó menores recursos de los estimados en la Ley de Ingresos de la 
Federación; pese a ello, en 2019 se alcanzó un superávit primario de $1.1 \%$ del PIB, mayor al superávit de $1.0 \%$ del PIB estimado en el Paquete Económico 2019. Esta situación ilustra de manera fehaciente el acatamiento a la política de austeridad impuesta por los organismos financieros internacionales y que se deja de lado una política anticíclica que promueva el crecimiento económico y permita obtener mayores recursos para cubrir el gasto en desarrollo social.

\section{REFERENCIAS}

BEDFORD, Jackie [2010], "Efforts to create freer and fairer trade opportunities", Orchardist, 83(6): 5859.

BuRT, M. [2019], ¿Quién es el dueño de la pobreza?, Red Press Ltd.

FMI [2019], "Una estrategia para la participación del FMI en el gasto social", <https://cutt.ly/HhvQnav>.

Greiner, A. [2016], "Human capital formation and public debt: growth and welfare effects of three different deficit policies", Journal of Economic Policy Reform, 19(4): 369-385.

JustinoA, Patricia y Bruno Martoranob [2018], Welfare spending and political conflict in Latin America, 1970-2010, Reino Unido, Institute of Development Studies.

LóPEZ-CALVA, Luis y Nora Lustig (comps.) [2011], La disminución de la desigualdad en América Latina. ¿Un decenio de progreso?, México, Fondo de Cultura Económica.

OCDE [2020], "Together, we create better policies for better lives", <oecd.org/about/>, 8 de enero.

Portulans Institute [2019], Network Readiness Index 2019, Washington D. C.

SeCRETARía DE Bienestar [2020], “QQué hacemos?”, <https:// n9.cl/1unz>, 16 de enero.

SHCP (Secretaría de Hacienda y Crédito Público) [2020], Presupuesto de Egresos de la Federación, <https://n9.cl/tkn0>. 
[2019a], Plan Nacional de Desarrollo 2019-2024, $<$ https://n9.cl/jip80>.

[2019b], Criterios Generales de Política Económica 2020.

[2014], Ley Federal de Presupuesto y Responsabilidad Hacendaria.

Soumitra D. y B. Lanvin [2019], The Network Readiness Index 2019: Towards a Future-Ready Society, Washington D. C., Portulans Institute.

Stiglitz, Joseph [2002], "Empleo, justicia social y bienestar de la sociedad", Revista Internacional del Trabajo, 121(1-2). WeAll (Wellbeing Economy Alliance) [2018], "Scottish Parliament passes ambitious Climate Bill including Citizens Assemblies, Toward a Sustainable Wellbeing Economy", $<$ https://cutt.ly/Ghk2MWu>, 15 de enero. 


\title{
¿SON LOS IMPUESTOS INSTRUMENTO PARA PROMOVER EL BIENESTAR?
}

\author{
José Manuel Márquez* \\ Mildred Espíndola**
}

\section{INTRODUCCIÓN}

La valoración del bienestar es compleja y controvertida, pues implica la medición de las necesidades del ser humano que le permiten tener una vida plena. Su evaluación resulta fundamental para tener un diagnóstico tanto de las condiciones generales de la sociedad como de sus necesidades y a partir de ellas formular políticas públicas. Ante la preocupación de incluir la mayor parte de los factores que involucran el bienestar para conseguir una valoración más cercana a la realidad, se ha trabajado para mejorar su medición. De esta manera, se han desarrollado diversos criterios y metodologías, y se han agregado distintos factores e indicadores para su estimación, lo que da lugar a diferentes definiciones y dimensiones del bienestar.

De acuerdo con Deaton [2015], el bienestar se relaciona con todas las cosas buenas para una persona, que hacen que la vida sea buena. Esto incluye el bienestar material, como el ingreso y la riqueza; el bienestar físico y psicológico, representado por la salud y la felicidad; y la educación y la capacidad de participar en la sociedad civil a través de la democracia y el imperio de la ley. Amartya Sen, uno de los principales estudiosos del bienestar, señala la importancia de medirlo a partir de las capacidades,

* Académico del Instituto de Investigaciones Económicas, UnAM. Correo electrónico: <jmmarquez@iiec.unam.mx>.

** Académica del Instituto de Investigaciones Económicas, UNAM. Correo electrónico: <etmy@prodigy.net.mx >. 
que comprenden todo lo que una persona puede hacer o ser para funcionar; esto es, una nutrición adecuada, buena salud o educación, entendida como saber leer, escribir y razonar analíticamente, así como tomar parte de la vida comunitaria. Para este autor, las capacidades básicas no son los bienes, sino los funcionamientos o rasgos personales con los cuales el individuo puede elegir, con libertad, su propio destino entre diferentes formas de vida, es decir, su autodeterminación [Sen,1980].

El informe del Programa de las Naciones Unidas para el Desarrollo (PNUD) 2019 retoma la visión de Sen y enfatiza la necesidad de transitar de las capacidades básicas de los individuos a una nueva etapa de capacidades aumentadas vinculadas con el uso de tecnología o con la posibilidad de enfrentar crisis ambientales [PNUD, 2019: 7]. La ONU relaciona el bienestar con la capacidad de vivir una vida sana en comunidades pacíficas e inclusivas y tener relaciones equitativas con factores esenciales de bienestar individual y colectivo.

Por su parte, la Organización para la Cooperación y el Desarrollo Económicos (OCDE) habla de la necesidad de una visión multidimensional del bienestar y define 11 indicadores para valorar el bienestar: la vivienda, los ingresos, el empleo, la comunidad, la educación, el medio ambiente, el compromiso cívico, la salud, la satisfacción ante la vida, la seguridad y el equilibrio vida-trabajo.

Así, nosotros entendemos por bienestar la condición en la que las personas gozan de manera efectiva y equitativa de los derechos humanos (civiles, económicos, sociales, políticos, culturales y ambientales) que les garantiza la ley (Constitución Política de los Estados Unidos Mexicanos), en un espacio determinado territorial y temporalmente. En particular, en este trabajo nos enfocaremos a medir el llamado bienestar económico, entendido como el acceso efectivo a los derechos económicos de los individuos, mediante el análisis de la estructura distributiva de los sectores económicos, utilizando la matriz de contabilidad social.

En México, el gobierno federal ha señalado como un objetivo prioritario promover el bienestar, por lo que incluyó una 
serie de programas sociales en el Plan Nacional de Desarrollo (PND) 2019 a 2024, con una perspectiva de acceso efectivo a los derechos de los individuos. De acuerdo con su visión, "el crecimiento económico, el incremento de la productividad y la competitividad no tienen sentido como objetivos en sí mismos sino como medios para lograr un objetivo superior: el bienestar general de la población" [Gobierno de México, 2019: 7]. Sin embargo, para llevar a cabo esta tarea se requiere que el gobierno tenga una recaudación de ingresos importante para solventar estos programas y gastos, por lo que el cobro de impuestos se vuelve una herramienta importante para este fin ya que es su principal fuente de ingresos: representa anualmente alrededor de $60 \%$ de este rubro.

En atención a la necesidad de reflexionar acerca de cómo mejorar el bienestar de la población en México, el objetivo de este trabajo es mostrar el potencial de la matriz de contabilidad social (MCs) como una herramienta que permite medir aspectos económicos de carácter estructural y capturar diferentes aspectos del bienestar que no se consideran de manera integral en la bibliografía económica, discutiendo en particular la función de los impuestos como instrumento para mejorar el bienestar de la población en México. El diseño de la MCs tiene la ventaja de medir e identificar efectos impulso y proporciona a detalle el origen y destino de los recursos generados en un país, considerando la estructura productiva y redistributiva de los diferentes circuitos de la economía, además de que se basa en datos reales. Por ello lo emplearemos para medir el impacto de los impuestos por deciles de ingreso de la población e identificar sus formas de redistribución.

\section{MEDiCiÓN DEL BIENESTAR}

Una de las medidas más usadas para la medición del bienestar es el producto interno bruto (PIB) por persona, el cual capta el 
crecimiento económico en un país; sin embargo, resulta inadecuada porque el crecimiento no garantiza un mayor bienestar, ni un mayor bienestar lleva a una mayor renta por habitante. Además, suponer que un mayor crecimiento produce un mayor bienestar para el conjunto de la sociedad da poca importancia al problema de la distribución [Molpeceres, 2008: 1] y no permite ver los efectos positivos o negativos que provoca en la sociedad, tampoco las externalidades diferidas a futuro, ni toma en cuenta actividades que producen valor fuera del mercado. Al respecto, el documento ¿Cómo va la vida? 2015: medición del bienestar publicado por la ocDE, muestra evidencia de que países con niveles de PIB por habitante similares pueden tener medidas de bienestar muy diferentes.

De ahí que surgiera la necesidad de contar con una medida de bienestar más completa abordada por diversos trabajos de grupos multidisciplinarios, los cuales incluyeron actividades que se realizan al margen del mercado, aspectos cualitativos, así como distributivos que considerarán cambios en los niveles de ingreso. Molpeceres [2008] agrupa estos trabajos de acuerdo con las siguientes formas de medición:

1. Medidas monetarias: los trabajos que toman esta metodología coinciden en medir el bienestar tomando como variable proxy el consumo personal estimado a partir de las cuentas nacionales, pues refleja la capacidad de satisfacer necesidades por medio de la compra de bienes y servicios. Incorpora además la desigual distribución de la renta como un aspecto determinante del bienestar, calculando la distribución del ingreso a partir del consumo personal (antes de cualquier ajuste) por un índice que mide la desigualdad, como la renta total acumulada por la primera quintila de su distribución (pasando por la medida de Atkinson) o el índice de Gini.

2. Baterías o sistemas de indicadores sociales: se componen de indicadores sociales cuyas unidades pueden o no ser monetarias y se caracterizan por no resumir la información en un único valor. 
3. Medidas sintéticas no monetarias: su objetivo es brindar una visión de conjunto del bienestar combinando factores de diferentes unidades y de distinta naturaleza, por lo que emplean mecanismos de agregación no monetaria para ello.

4. Encuestas sobre la satisfacción o la felicidad: se basan en la propia evaluación de los sujetos y obtienen la información mediante encuestas de opinión para medir el bienestar.

Por su parte, la Comisión sobre la Medición del Desempeño Económico y del Progreso Social, encabezada por Joseph Stiglitz, señala que para medir el bienestar se requiere una definición multidimensional y propone los siguientes dominios para el cálculo: estándares de vida material (ingreso, consumo y riqueza); salud; educación; actividades personales, incluida la del trabajo; voz política y buen gobierno; conexiones y relaciones sociales; medio ambiente (condiciones presentes y futuras); e inseguridad, de naturaleza económica y física [Stiglitz, Sen y Fitoussi, 2009].

Asimismo, la oCDE ha señalado la importancia de realizar análisis tanto a partir de indicadores objetivos (principalmente indicadores de ingreso observables por terceros) como subjetivos (basados en los que las propias personas pueden informar de sus sentimientos y condiciones internas). Con base en dichas recomendaciones, hizo un análisis multidimensional del bienestar en el que consideró importantes 11 dimensiones y cuatro tipos de recursos para sostener el bienestar de largo plazo [OCDE, 2015: 26]. Dividió en dos subgrupos las dimensiones para medir el bienestar individual: a) calidad de vida, que incluye las dimensiones de salud, equilibrio vida-trabajo, educación y competencias, relaciones sociales, compromiso cívico y gobernanza, calidad del medio ambiente, seguridad personal, bienestar subjetivo; y b) condiciones materiales, conformado por ingresos y riqueza, empleo y salario, y vivienda. Además, esta medición tiene la particularidad de considerar la sostenibilidad del bienestar en el tiempo mediante la preservación del capital natural, el económico, el humano y el social [OCDE, 2015: 25]. 
Si la población nace bajo un entorno de pobreza extrema de ingresos, no contará con los recursos para cubrir sus necesidades básicas de alimentación, lo que indudablemente afectará otras dimensiones del bienestar como la salud y la esperanza de vida, e inclusive puede impedir su acceso a la educación y otros servicios. En otro sentido, si buena parte de la sociedad no cuenta con las capacidades básicas de bienestar, es poco probable que pueda transitar, en conjunto, hacia una nueva etapa de capacidades aumentadas. Por ello, la distribución del ingreso es un elemento esencial para entender el rezago en prácticamente todas las dimensiones del bienestar. ${ }^{1}$

Por otra parte, la concentración del ingreso puede condicionar el ejercicio del poder de los diferentes sectores de la sociedad y alterar las decisiones de políticas sociales [PNUD, 2019:13], por lo que las políticas de reducción del desequilibrio en los ingresos y la riqueza son importantes para fortalecer el bienestar medido por el poder político del conjunto de la sociedad.

Políticas efectivas de este tipo ayudan a disminuir la posibilidad de que aquellos que concentran el ingreso influyan en las decisiones de política pública a su favor [PNUD, 2019: 12] y en contra de los menos favorecidos, por lo que inciden no solo en la dimensión económica del bienestar, sino en el acceso efectivo a servicios básicos y a la igualdad de oportunidades, procurando sus derechos.

Nos referiremos al bienestar económico como a una situación, sostenible y sustentable en el tiempo, en la cual los individuos u hogares pueden solventar sus necesidades básicas, y persiste una razonable igualdad de oportunidades e inequidad

${ }^{1}$ Cabe destacar que aun en presencia de un gran desequilibrio en los ingresos, la evaluación del bienestar puede ser mejor de lo esperado en algunos países debido a la percepción de los individuos. Por ejemplo, la evaluación realizada por la OCDE [2015] señala que México, Suecia, Canadá, Dinamarca, Finlandia y Suiza coinciden en su nivel de satisfacción ante la vida, aunque México tiene un indicador de desigualdad mucho mayor que el de estas otras economías. 
mínima entre ellos. Para medir esto es ideal utilizar o construir parámetros o indicadores objetivos y cuantificables que permitan evaluar y comparar el bienestar económico.

Por ello, pensando en esta problemática, este trabajo se centra en la evaluación de la dimensión económica del bienestar medida a partir de la redistribución del ingreso. Dicha medida es relevante sobre todo en países con una gran desigualdad en la distribución del ingreso, como México, donde el acceso de buena parte de la población a satisfactores básicos se complica por falta de recursos, lo que afecta el desarrollo pleno de sus capacidades. En una evaluación de dicha medición, la apertura de las cuentas sociales resulta útil, pues por medio de ella se pueden rastrear los pasos de los impuestos a través de los circuitos de la economía y su destino final, por lo que nos da una visión más amplia del mecanismo de redistribución de los impuestos en nuestro país como promotores del bienestar económico.

\section{Concentración DEL INGREso en MÉXico}

En México, la persistente concentración del ingreso ha llevado al empobrecimiento de un alto porcentaje de la población. De acuerdo con un reporte del Consejo Nacional de Evaluación de la Política de Desarrollo Social (Coneval), 16.8\% de la población tenía ingresos inferiores a la línea de pobreza extrema por ingresos y $49 \%$ de la población tenía ingresos inferiores a la línea de pobreza por ingresos en 2008 , mientras que en 2018 estos valores representaron $16.8 \%$ y $48.8 \%$, es decir, en 10 años no hubo avances en esta materia. ${ }^{2}$

${ }^{2}$ La línea de pobreza por ingresos permite identificar a la población que no cuenta con los recursos suficientes para adquirir los bienes y servicios que requiere para satisfacer sus necesidades (alimentarias y no alimentarias), mientras que la de pobreza extrema identifica a aquellos que, aun gastando todo su ingreso en la compra de alimentos, no puede adquirir lo indispensable para tener una nutrición adecuada [Coneval, 2018]. 


\section{Gráfica 1. Pobreza por entidad federativa} (porcentaje de la población)

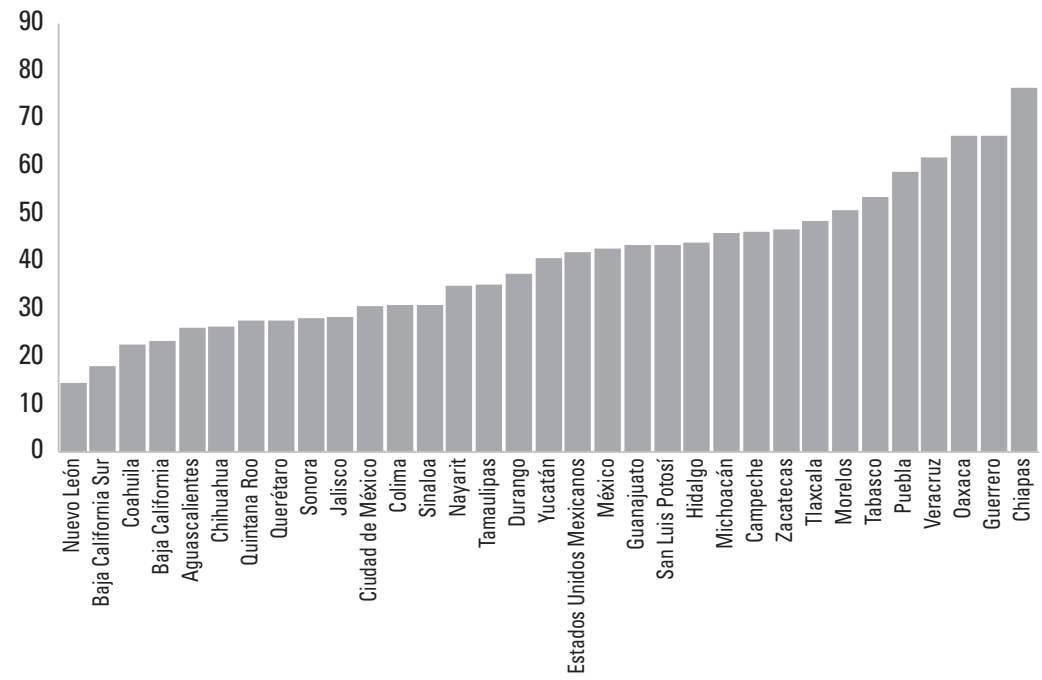

Fuente: Coneval [2018].

El documento ¿Cómo va la vida en México?, publicado por la OCDE en 2017, da cuenta de dicha desigualdad al señalar que aunque el ingreso familiar disponible neto en nuestro país se recuperó después de la crisis de 2009, acumulando una ganancia de $11 \%$ durante la década (superando el promedio de la oCDE de $8 \%$ ), persiste la desigualdad en los ingresos familiares entre hogares; las personas que ocupan el $20 \%$ superior de la escala de ingresos ganan 10 veces más que las que ocupan el $20 \%$ inferior [OCDE, 2017: 2 y 4]. También existe una disparidad importante entre regiones en México (gráficas 1 y 2). De acuerdo con Coneval, en 2018, 76.4\% de la población en Chiapas (región sureste) vivía en pobreza y $29.7 \%$ en pobreza extrema; en contraste, en Nuevo León (región noreste) estos valores representaron 14.5\% y $0.5 \%$ de la población. Además, en Chiapas la población con ingresos inferiores a la línea de la pobreza de ingresos se ubicó en $78.9 \%$ y de pobreza extrema en $50.7 \%$, mientras que en Nuevo León estas cifras fueron $21.1 \%$ y $3.1 \%$ de la población. 


\section{Gráfica 2. Pobreza extrema por entidad federativa (porcentaje de la población)}

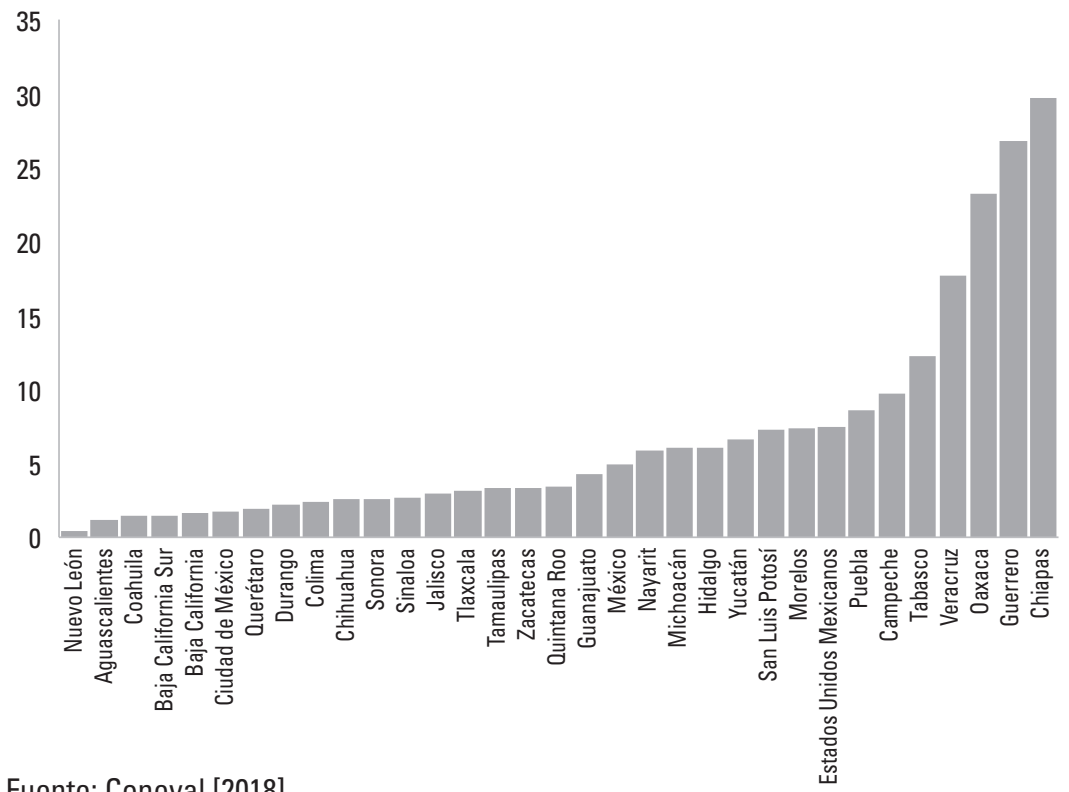

Fuente: Coneval [2018].

Es evidente que la creciente brecha en el ingreso impacta no solo en el consumo en general de la población, sino incluso en el consumo básico de la sociedad, relacionado con el consumo mínimo de subsistencia. De ahí la necesidad de evaluar qué tan equitativo está siendo el sistema fiscal mexicano y cómo afecta esto al bienestar.

El Estado mexicano dispone de mecanismos y herramientas para formular políticas cuyo objetivo sea redistribuir la riqueza, de acuerdo con los principios de libertad y equidad, que contribuyan al bienestar social. Los impuestos y las transferencias, así como el gasto, son los instrumentos con los que cuenta para contrarrestar la desigualdad. Sin embargo, en los últimos 40 años se dejó de lado la visión del Estado promotor del bienestar por una de mínima política social, se promovió la intervención del sector privado en la provisión de servicios que 
antaño estaban a cargo del Estado, se implementaron permanentes políticas de austeridad y se mantuvo la tendencia de contraer el gasto público con fines de preservar "finanzas públicas sanas" [Ortiz y Cummins, 2019: 8].

Sin embargo, la economía de mercado ha probado su incapacidad para promover el bienestar del conjunto de la sociedad, por lo que la participación del Estado en la reducción de la desigualdad debe ser prioritaria. Para lograrlo, es indispensable que el Estado cuente con los recursos necesarios para promover el bienestar y los gaste de manera estratégica y eficiente. En este contexto de restricción, la eficiente distribución del ingreso se vuelve imprescindible si se quiere mejorar el bienestar de la sociedad, ya que las decisiones fiscales tienen gran impacto en la vida de las personas.

Así, la formulación de políticas de ingreso y gasto públicos es el mecanismo con el que el gobierno cuenta para mejorar la distribución del ingreso, pues a través de ellas establece los esquemas de contribución y los beneficiarios de los tributos, lo que en última instancia debe mejorar el bienestar. La eficiencia de los instrumentos de redistribución del ingreso del Estado también depende de la fortaleza de sus instituciones [PNUD, 2019: 17].

Hay medidas y coeficientes que intentan capturar la desigualdad utilizando sus propiedades funcionales, como la distribución y la varianza estadística de los datos o los índices analíticos de Atkinson y de Theil, pero dada su sencillez de cálculo y de interpretación el más usado es el índice de Gini, el cual es un indicador normativo que permite comparar los niveles de desigualdad del ingreso entre diferentes países.

De acuerdo con el Fondo Monetario Internacional (FMI), en 2017 el índice de Gini para las economías avanzadas antes de impuestos y transferencias fue de 0.48 y después de estas 0.31 , en tanto que para los mercados emergentes y países en desarrollo los valores fueron 0.49 y 0.45 , respectivamente. Estos datos revelan que los sistemas tributarios de las economías avanzadas son más eficientes en la redistribución del ingreso que los 
de mercados emergentes y países en desarrollo [PNUD, 2019: 18]. En cuanto a América Latina y el Caribe, la ocDE señala que el poder distributivo de la política fiscal en la región es menor al promedio de los países de la OCDE, ya que la brecha entre el ingreso antes y después de impuestos es 2.8 puntos porcentuales en promedio en contraste con los 17.8 puntos porcentuales promedio en los países de la ocDE [ocDE, 2016:11]. Para México, el índice de Gini antes de impuestos y transferencias es de 0.48 y después de impuestos, 0.46 ; en contraste, para el promedio de la OCDE va de 0.47 a 0.32 , lo que muestra el poco poder distributivo de los impuestos en nuestro país (cuadro 1).

Cuadro 1. Índice de Gini para países de la OCDE

\begin{tabular}{lcc}
\hline \multicolumn{1}{c}{ Países } & $\begin{array}{c}\text { Antes de impuestos } \\
\text { y transferencias }\end{array}$ & $\begin{array}{c}\text { Después de impuestos } \\
\text { y transferencias }\end{array}$ \\
\hline OCDE & 0.47 & 0.32 \\
México & 0.48 & 0.46 \\
Canadá & 0.43 & 0.31 \\
Estados Unidos & 0.51 & 0.39 \\
Chile & 0.49 & 0.45 \\
Costa Rica & 0.53 & 0.48 \\
Francia & 0.52 & 0.29 \\
España & 0.52 & 0.34 \\
Italia & 0.52 & 0.33 \\
Alemania & 0.50 & 0.29 \\
Reino Unido & 0.51 & 0.35 \\
Finlandia & 0.51 & 0.26 \\
Polonia & 0.46 & 0.28 \\
Noruega & 0.42 & 0.26 \\
Dinamarca & 0.45 & 0.26 \\
Japón & 0.50 & 0.34 \\
\hline
\end{tabular}

Nota: los datos corresponden a 2017 o al último año disponible para los países. Para México se refieren a después de impuestos y antes de transferencias.

Fuente: OCDE (Income Distribution and Poverty Database). 
Nótese que estos datos del índice de Gini nos dicen que los impuestos y el destino del gasto de gobierno ayudan a mejorar la distribución del ingreso y que esto se da de mejor manera en los países desarrollados que han implementado políticas públicas de Estado de bienestar, como los escandinavos y los de Europa Central, pero no nos dicen nada más, pues este índice no tiene una interpretación directa; tampoco nos dice cómo se da el flujo, en qué proporción ni hacia qué sectores se dirige la redistribución, por lo que es importante considerar una medición que permita capturar esta información de la manera más confiable.

\section{LA POLÍTICA TRIBUTARIA Y EL BIENESTAR}

Aunque no es la única manera de hacerlo, una de las funciones del sistema tributario de un país consiste en redistribuir el ingreso que se genera en la economía para procurar la equidad, además de que al incidir sobre el gasto de los hogares, este tiene un efecto directo sobre el bienestar. De acuerdo con Sen, mejorar las condiciones de los menos favorecidos de manera que tengan la misma posibilidad de desarrollar sus capacidades derivará en un mayor bienestar social. Así, la política tributaria ${ }^{3}$ tiene un efecto redistributivo notable en la economía, por lo que resulta importante la medición del bienestar a partir de su capacidad redistributiva.

Para analizar la forma en que la política tributaria impacta en el bienestar es importante considerar dos sentidos. Por el lado de la recaudación, el pago de impuestos disminuye el ingreso disponible de los hogares, por lo que reduce su capacidad de consumo y, por ende, su bienestar; por tanto, el diseño

${ }^{3}$ Entendida como el conjunto de leyes que establecen las tasas de impuestos para cada nivel de ingresos, así como el conjunto de exenciones y deducciones que dan lugar al pago efectivo de impuestos. 
de esta política afecta la distribución del ingreso al definir la forma y las cantidades que van a pagar los diferentes tipos de contribuyentes. Pero por el lado del gasto, el destino que tengan estos ingresos y la manera en que se gasten son importantes, ya que si este gasto está centrado en otorgar acceso efectivo a la población a servicios básicos, en transferencias focalizadas de recursos o alguna otra forma de política pública que pueda derivar en un mayor bienestar y se realiza de manera eficiente, tendrá un impacto importante en la reducción de la desigualdad y en el bienestar social. Sin embargo, si estos recursos se desvían a otros gastos que no abonan a mejorar el bienestar colectivo o se gastan de manera ineficiente, no tendrán un efecto relevante e incluso pueden ahondar las desigualdades en esa sociedad.

Entre los impuestos con mayor potencial redistributivo, destaca el impuesto sobre la renta (ISR) por su monto de recaudación, que según datos del Servicios de Administración Tributaria (SAT) en 2018 aportó $7.1 \%$ del PIB. Por tipo de contribuyente, las personas morales pagaron un ISR equivalente a $3.4 \%$ del PIB, seguidos por los asalariados con $3.2 \%$, las personas físicas $0.2 \%$ y los residentes en el extranjero $0.2 \%$ (cuadro 2).

Cuadro 2. Monto de recaudación del contribuyente

\begin{tabular}{lcc}
\hline \multicolumn{3}{c}{ Porcentaje } \\
\hline \multicolumn{1}{c}{ Tipo de contribuyente } & PIB & Ingresos públicos \\
Personas morales & 3.4 & 15.8 \\
Personas físicas & 0.20 & 0.88 \\
Asalariados & 3.20 & 15.00 \\
Residentes en el extranjero & 0.20 & 0.88 \\
Total & 7.00 & 32.56 \\
\hline
\end{tabular}

Fuente: elaboración propia con datos de la Secretaría de Hacienda y Crédito Público, 2018. 
Es importante notar que las personas morales y los asalariados contribuyeron con poco más de $30 \%$ de los ingresos públicos totales. Sin embargo, aunque la participación de estos dos tipos de contribuyentes prácticamente es igual, los asalariados solo perciben poco más de la cuarta parte de los ingresos generados (26\%) en el país (medido en valor agregado bruto del PIB), mientras que el pago a excedente bruto de operación representa casi $50 \%$ (gráfica 3 ) en contraste con los países de la OCDE, donde el pago a asalariados es de $49 \%$, lo que refleja la situación de gran desigualdad en México.

\section{Gráfica 3. Composición del valor agregado bruto de México (2017)}
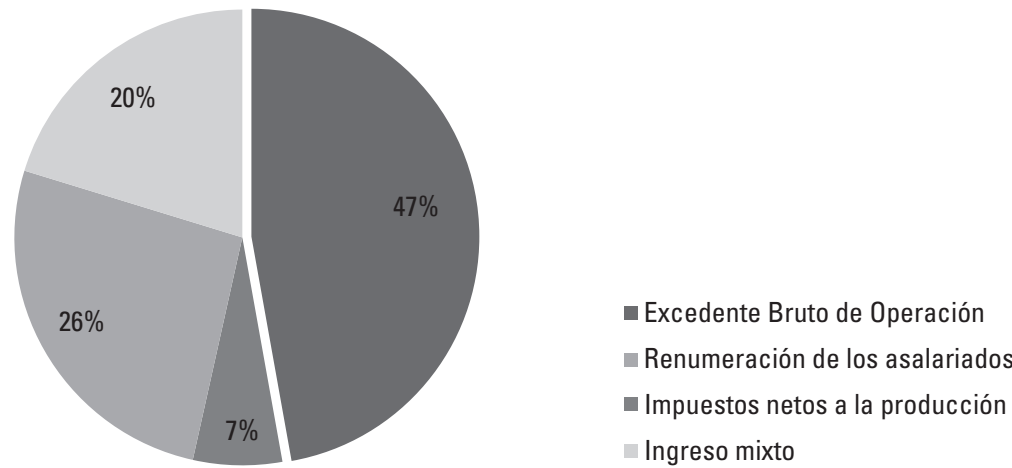

Fuente: Solís y Hernández [2019].

De acuerdo con la Secretaría de Hacienda y Crédito Público, las deducciones para las personas físicas se concentran en los deciles de ingresos más altos, lo que se estimó en $71.1 \%$ del total de deducciones personales en 2018, mientras que en el primer decil solo se ubica $0.1 \%$. Entre las deducciones de las que se benefician los deciles de mayores ingresos están los seguros de gastos médicos y las colegiaturas, dos dimensiones de bienestar en los que hay un claro rezago en México. Otro elemento que debe evaluarse es el acceso diferenciado por tipo de contribuyentes al conjunto de deducciones, exenciones, tasas 
reducidas, diferimientos y acreditamientos, además de los regímenes sectoriales y las facilidades administrativas, lo que también impacta en el poder de redistribución del sistema tributario.

\section{LA MATRIZ DE CONTABILIDAD SOCIAL}

Es claro que hay elementos que permiten advertir la importancia de evaluar el bienestar a partir del poder redistributivo y recaudatorio del sistema fiscal en México, lo que sin duda puede brindar elementos para formular políticas públicas que promuevan el bienestar. Una herramienta que posibilita lo anterior es el análisis de las cuentas nacionales, las cuales consideran la economía como un sistema formado por unidades institucionales capaces de realizar transacciones, por lo que dentro de este sistema existen flujos económicos que pueden agruparse en transacciones de bienes y servicios, transacciones distributivas entre los sectores institucionales, transacciones financieras (ahorro, inversión y otros pagos) y otras partidas de acumulación.

Las cuentas nacionales registran con detalle estas transacciones entre agentes, por lo que pueden incorporarse las cuentas satélites de la economía para añadir información no monetaria y pormenorizar diferentes actividades contabilizadas en este esquema. Entre estas opciones, la matriz de contabilidad social (MCS) se construye a partir de abrir las cuentas por sectores institucionales con base en las cuentas nacionales y se considera como el marco ideal para la generación de modelos de equilibrio general computable. Formalmente, la mcs surge de la matriz de contabilidad nacional (MCN), que es la representación matricial del Sistema de Cuentas Nacionales, incorporando información socioeconómica de los hogares. La elaboración de la MCN pretende captar el comportamiento económico de los agentes de una economía mediante el registro de los flujos organizados de 
mercancías o transacciones (locales y foráneas) en un año (cuadro 3), por lo que puede medir de manera detallada, coherente y bastante completa la actividad económica, al reflejar el proceso de producción y distribución completo de la economía [McDonald, Robinson y Thierfelder, 2007].

Cuadro 3. Esquema de una matriz de contabilidad social

\begin{tabular}{|c|c|c|c|c|c|}
\hline & Producción & $\begin{array}{l}\text { Generación } \\
\text { del ingreso }\end{array}$ & Capital & $\begin{array}{c}\text { Sectores } \\
\text { institucionales }\end{array}$ & $\begin{array}{l}\text { Resto del } \\
\text { mundo }\end{array}$ \\
\hline Producción & $\begin{array}{l}\text { Consumo } \\
\text { intermedio }\end{array}$ & & $\begin{array}{l}\text { Formación } \\
\text { bruta de } \\
\text { capital fijo }\end{array}$ & $\begin{array}{l}\text { Consumo del } \\
\text { sector público } \\
\text { por hogares }\end{array}$ & Exportaciones \\
\hline $\begin{array}{l}\text { Generación } \\
\text { del ingreso }\end{array}$ & $\begin{array}{l}\text { Pago del va- } \\
\text { lor agregado } \\
\text { a factores }\end{array}$ & $\begin{array}{l}\text { Ingreso } \\
\text { generado } \\
\text { bruto }\end{array}$ & & & \\
\hline Capital & & & $\begin{array}{l}\text { Transfe- } \\
\text { rencias de } \\
\text { capital }\end{array}$ & $\begin{array}{l}\text { Ahorro de } \\
\text { sectores insti- } \\
\text { tucionales }\end{array}$ & $\begin{array}{l}\text { Transferen- } \\
\text { cias de capi- } \\
\text { tal recibido }\end{array}$ \\
\hline $\begin{array}{l}\text { Sectores } \\
\text { institucionales }\end{array}$ & $\begin{array}{l}\text { Impuestos } \\
\text { netos a los } \\
\text { productos }\end{array}$ & & $\begin{array}{l}\text { Impuestos } \\
\text { sobre bienes } \\
\text { de capital }\end{array}$ & $\begin{array}{l}\text { Transferencias } \\
\text { corrientes }\end{array}$ & $\begin{array}{l}\text { Transferen- } \\
\text { cias del resto } \\
\text { del mundo }\end{array}$ \\
\hline $\begin{array}{l}\text { Resto del } \\
\text { mundo }\end{array}$ & $\begin{array}{l}\text { Importacio- } \\
\text { nes }\end{array}$ & & $\begin{array}{l}\text { Transfe- } \\
\text { rencias } \\
\text { de capital } \\
\text { pagadas }\end{array}$ & $\begin{array}{l}\text { Transferencias } \\
\text { al resto del } \\
\text { mundo }\end{array}$ & \\
\hline
\end{tabular}

Fuente: elaboración propia.

Típicamente, las MCs contienen las siguientes cuentas [McDonald, Robinson y Thierfelder, 2007]:

- Cuenta de producción (actividad de todos los agentes que producen bienes o servicios)

- Cuenta de generación del ingreso (remuneración al capital y el trabajo)

- Cuentas de capital (ahorros y transferencias de capital combinadas)

- Cuenta de sectores institucionales (hogares, empresas y gobierno) 
- Cuentas del resto del mundo (importaciones y exportaciones, cuentas corrientes o de capital, etcétera)

Todas estas cuentas se pueden desagregar o abrir por los diferentes grupos o sectores que los componen, de acuerdo con alguna propiedad o característica que los defina. Así, dada su naturaleza y composición, permite realizar modelos multisectoriales, localizados regional y temporalmente, y analizar elementos clave, como la generación y distribución del ingreso entre sectores institucionales de la economía (figura 1).

Figura 1. Esquema de la submatriz de distribución del ingreso

\begin{tabular}{|c|c|c|c|c|}
\hline $\begin{array}{c}\text { Asignación } \\
\text { del ingreso } \\
\text { primario }\end{array}$ & $\begin{array}{l}\text { Distribución } \\
\text { secundaria } \\
\text { del ingreso }\end{array}$ & $\begin{array}{l}\text { Generación } \\
\text { del ingreso }\end{array}$ & $\begin{array}{c}\text { Bienes } \\
\text { y servicios }\end{array}$ & $\begin{array}{c}\text { Resto } \\
\text { del mundo, }\end{array}$ \\
\hline $\begin{array}{c}\text { Sectores } \\
\text { institucionales }\end{array}$ & $\begin{array}{l}\text { Sectores } \\
\text { istitucionale }\end{array}$ & $\begin{array}{l}\text { Categorías de } \\
\text { ingreso primario }\end{array}$ & Productos & \\
\hline
\end{tabular}
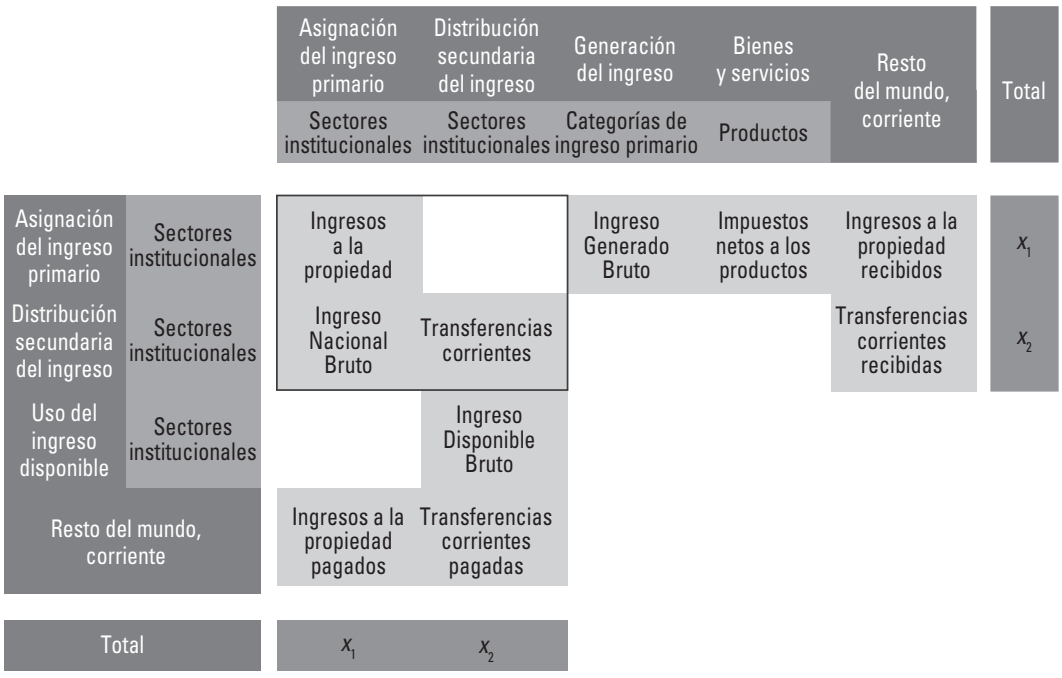

\begin{tabular}{|ccc}
$\begin{array}{c}\text { Ingreso } \\
\text { Generado } \\
\text { Bruto }\end{array}$ & $\begin{array}{c}\text { Impuestos } \\
\text { netos a los } \\
\text { productos }\end{array}$ & $\begin{array}{c}\text { Ingresos a la } \\
\text { propiedad } \\
\text { recibidos }\end{array}$ \\
& & $\begin{array}{c}\text { Transferencias } \\
\text { corrientes } \\
\text { recibidas }\end{array}$
\end{tabular}

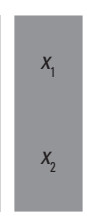

\section{Total}

Fuente: Solís y Hernández [2019].

En nuestro caso, para obtener una matriz enfocada a la parte de política fiscal, incluimos cuentas de asignación de ingreso primario, distribución secundaria del ingreso y uso del ingreso disponible, las cuales fueron desagregadas por los siguientes sectores institucionales: 
- Hogares (desagregados a su vez por deciles)

- Empresas (distinguiendo el excedente bruto de operación y el ingreso mixto)

- Gobierno

Para obtener la Mcs mexicana, es necesario utilizar las cuentas por sectores institucionales, las cuentas de bienes y servicios, y los cuadros de oferta y utilización [Casares, García y Sobarzo, 2017]. Del mismo modo, se incorporan fuentes complementarias como las estadísticas de comercio exterior, la Encuesta Nacional de Ingresos y Gastos de los Hogares y la Encuesta Nacional de Ocupación y Empleo (ENOE).

Además, se consideraron activos y pasivos que son componentes de los balances de la economía total y pueden ser activos financieros (depósitos de valor) y activos no financieros, así como las cuentas de la hacienda pública. Cada proceso económico registrado en las estadísticas mencionadas se describe en una matriz independiente que registra las transacciones económicas, distinguiendo entre usos y recursos, las cuales se insertan en la matriz de contabilidad social.

En la figura 2, se muestran los flujos de transacciones en las diferentes etapas del proceso de redistribución del ingreso por sectores institucionales de la economía (asignación del ingreso primario, distribución del ingreso de la propiedad y redistribución por transferencias corrientes), el cual se obtuvo a partir de la MCs con datos de México de 2016. El ancho de la línea representa el porcentaje del flujo.

En la parte izquierda, se muestra la repartición de los $p a$ gos a factores a partir de la etapa de la generación del ingreso (excedente bruto de operación, remuneraciones de asalariados e impuestos sobre la producción), los cuales se reparten entre los sectores institucionales (sociedades financieras y no financieras, los 10 deciles de la población por ingreso y el gobierno) de acuerdo con su ingreso generado (segunda columna) y su participación en el ingreso nacional, después de los pagos a la 
Figura 2. Proceso de distribución de ingreso para México, 2016

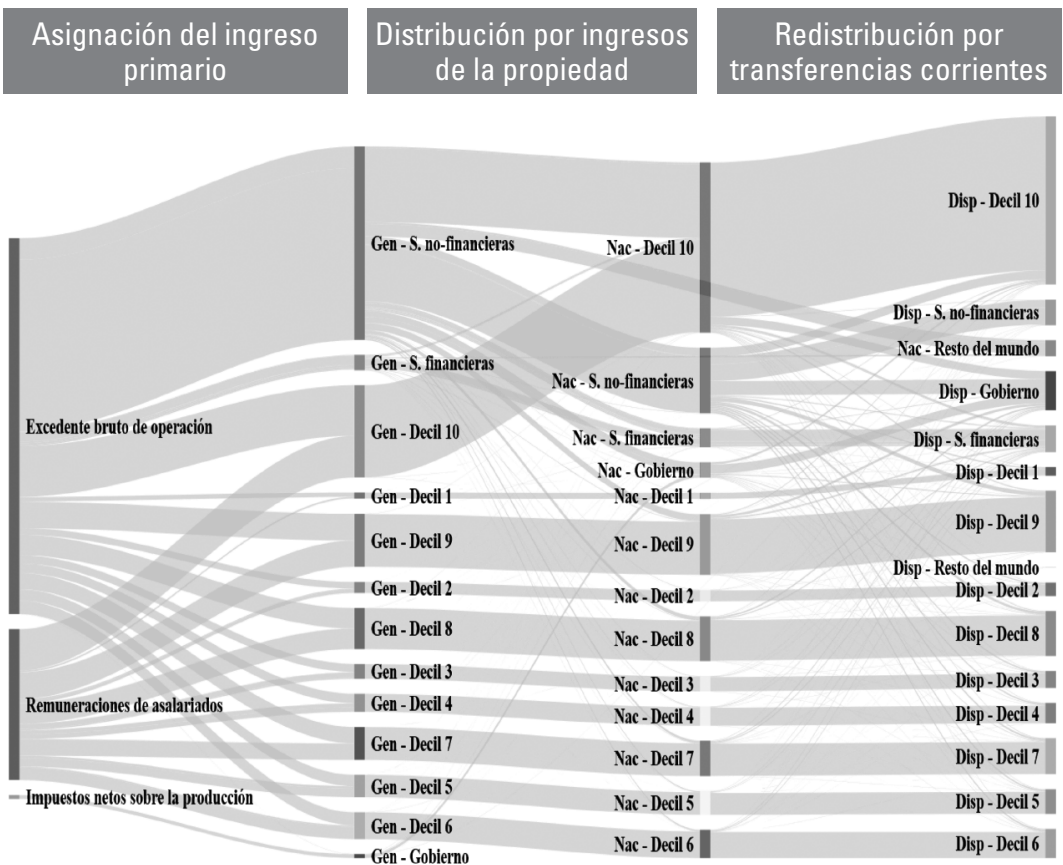

Fuente: Solís y Hernández [2019] con datos de la MSc de México, Inegi.

propiedad. Por último se tiene la columna del ingreso disponible después del pago de impuestos y transferencias, que es lo que realmente pueden gastar los hogares.

En la etapa de asignación del ingreso primario, la alcanzada por los hogares representa $60.5 \%$ del total, mientras que los sectores institucionales restantes (sociedades financieras y no financieras, fondos de mercado y de inversión, instituciones financieras, seguros y pensiones, así como el gobierno) generan una remuneración de 49.5 por ciento.

El decil 10, que es el de menor población en nuestro país, es el que tiene mayor remuneración de ingreso primario, 
obteniendo casi $29 \%$ del total, cifra casi similar a la suma de la participación de los primeros seis deciles. Además, este decil más rico aumenta sus ingresos de manera significativa (42\%) después del pago por ingresos de la propiedad, es decir, no solo se adueña de buena parte del excedente de operación y tiene la mejor remuneración por el pago a factores, sino además se lleva $41 \%$ del pago por ingresos de la propiedad.

Los demás deciles se mantienen casi iguales por el pago a la propiedad, nada más los deciles 8 y 9 (los segundos más altos) alcanzan un porcentaje mayor de $10 \%$. Además, tomando en cuenta el ingreso disponible, después de la redistribución del ingreso, los tres deciles más bajos mejoran en 34.1, 18.9 y $14.1 \%$, respectivamente, desde la asignación del ingreso primario hasta la obtención del ingreso disponible, mientras que el decil más alto mejoró en $82.1 \%$ su ya de por sí alto ingreso. Los deciles que menos mejoran son el 6 y 7 , con 8.6 y 8.8 por ciento.

Cuadro 4. Cambio total del ingreso primario-ingreso disponible (en porcentaje) por deciles de la población, México (2016)

\begin{tabular}{cc}
\hline Decil de la población & Cambio total porcentual \\
\hline 1 & 34.1 \\
2 & 18.9 \\
3 & 14.1 \\
4 & 10.8 \\
5 & 10.3 \\
6 & 8.6 \\
7 & 8.8 \\
8 & 10.2 \\
9 & 15.4 \\
10 & 82.1 \\
\hline
\end{tabular}

Fuente: Solís y Hernández [2019], con datos del Inegi.

Así, la concentración de la riqueza contribuye aún más a la profundización de la desigualdad del ingreso entre la población; es decir, no solamente el pago a factores está muy sesgado hacia los deciles de más ingresos, sino que, además, los 
ingresos a la propiedad que están incluso más sesgados hacia el primer decil hacen que la brecha de ingresos entre los deciles más altos y los más bajos se amplíe casi en 50 por ciento.

Asimismo, con base en lo anterior, recordando que el índice de Gini antes y después de impuestos y transferencias para México es básicamente el mismo y considerando este índice para la remuneración a asalariados y los ingresos mixtos (el grueso de la población en el país) que se mantiene casi idéntico, podemos afirmar que los impuestos no funcionan como un mecanismo efectivo de redistribución de la riqueza en México.

Cuadro 5. Índice de Gini antes y después de pago a la propiedad, impuestos y transferencias, México (2016)

\begin{tabular}{lcc}
\hline & $\begin{array}{c}\text { Generación del } \\
\text { ingreso }\end{array}$ & Ingreso disponible \\
\hline Remuneración a asalariados & 0.4031 & 0.3938 \\
Ingresos mixtos & 0.3814 & 0.3713 \\
\hline
\end{tabular}

Fuente: Solís y Hernández [2019] con datos de la mcs de México, Inegi.

\section{Conclusiones}

La matriz de contabilidad social es un instrumento muy útil que nos permite conocer de manera amplia la estructura de la economía y la distribución de los flujos de mercancías y servicios en la economía, así como la distribución del ingreso para los diferentes sectores institucionales. Esta metodología, a diferencia de los índices y las medidas macroeconómicas, hace posible cuantificar y seguir con detalle los flujos de ingresos y transferencias entre los sectores institucionales de la economía, lo que permite cuantificar e interpretar los efectos de los distintos procesos de la remuneración y redistribución del ingreso. Además, con esta herramienta podemos hacer proyecciones y cuantificar posibles consecuencias de medidas fiscales y redistributivas en la distribución del ingreso. 
Asimismo, mientras que los impuestos, transferencias, deducciones y exenciones tienen una función redistributiva importante en la economía de la mayoría de los países de la OCDE, para el caso de México esta redistribución es muy reducida, ya que la distribución del excedente bruto de operación y los ingresos a la propiedad están muy sesgados hacia los deciles de mayores ingresos, que representan a la minoría de la población.

Por lo anterior, puede recomendarse revisar la Ley de Ingresos para eliminar los vacíos legales que permiten a las grandes empresas eludir impuestos, así como realizar una reforma fiscal progresiva de acuerdo con el nivel de ingresos de las personas (que pague más quien más gana) que incluya gravar los ingresos a la propiedad; del mismo modo, buscar mecanismos para enfocar estratégicamente las deducciones, exenciones y transferencias, así como el destino de lo recaudado a través de los impuestos, de tal forma que contribuya a una redistribución más efectiva del ingreso e impulse el crecimiento del sector productivo, es decir, que se hagan deducciones y exenciones a pequeñas y medianas empresas productivas; transferencias directas a personas y hogares que enfrentan mayores restricciones para acceder a servicios básicos y oportunidades; y un gasto en infraestructura y servicios básicos de calidad, todo ello con el fin de cerrar las brechas en el bienestar de la población, y que los impuestos sean verdaderos promotores del bienestar económico.

\section{REFERENCIAS}

CÁmara Sánchez, Ángeles, Manuel Alejandro Cardenete Flores y José Ramón Monrobel Alcántara [2014], "Matrices de Contabilidad Social y Modelos de Equilibrio General Aplicado elaborados en España a nivel regional", Estudios de Economía Aplicada, 32(1): 427-454. 
Casares, Enrique R., María G. García y Horacio Sobarzo [2017], "Las Matrices de Contabilidad Social como base de datos y soporte de modelos multisectoriales", EconoQuantum, Revista de Economía y Negocios, Universidad de Guadalajara, 14(1): 119-142, enero-junio.

Coneval [2018], Anexo único de los "Lineamientos y criterios generales para la definición, identificación y medición de la pobreza", México, Coneval, <https://n9.cl/t2he>.

DEATON, Angus [2015], El gran escape: salud, riqueza y los origenes de la desigualdad, México, Fondo de Cultura Económica, $404 \mathrm{pp}$.

García, José [2011], "Hacia un nuevo sistema de indicadores de bienestar", Realidad, datos y espacio revista internacional de estadística y geografía, 2(1): 78-95, enero-abril.

Gobierno DE MÉxico [2019], Plan Nacional de Desarrollo 2019$2024,<$ https://n9.cl/db0t>, 14 enero de 2020.

Inegi [2013], Encuesta Nacional de Gastos de los Hogares 2012, México, Inegi.

[2000], "Cuentas por sectores institucionales", $E l A B C$ de las cuentas nacionales, México, Inegi.

KeELey, B. [2018], Desigualdad de ingresos. La brecha entre ricos y pobres, París, OECD Publishing.

Mainar-Causapé, A. J., E. Ferrari y S. McDonald [2018], Social accounting matrices: basic aspects and main steps for estimation, EUR 29297 EN, JRC Technical Reports, Publications Office of the European Union, Luxembourg.

McDonald, Scott, Sherman Robinson y Karen Thierfelder [2007], Globe: A SAM Based Global CGE Model using GTAP Data, Departmental Working Papers, United States Naval Academy Department of Economics.

Miquel, Ana [2015], "La medición del bienestar económico a través de las macromagnitudes de la contabilidad nacional", CIRIEC-España, Revista de economía pública, social y cooperativa, 85:245-286. 
Molpeceres, María de las Mercedes [2008], Métodos de aproximación a la medición del bienestar: una panorámica, $<$ https://cutt.ly/5hvxWny>, 10 de enero de 2020.

oCDE [2017], ¿Cómo va la vida en México? <https://n9.cl/sbjz>.

[2016], Panorama de las Administraciones Públicas: América Latina y el Caribe 2017, París, Éditions ocDE, $<$ https://cutt.ly/XhvxYLE $>, 30$ de enero de 2020.

[2015], ¿Cómo va la vida? 2015: medición del bienestar, París, oECD Publishing, <https://n9.cl/g5wvy>.

OrTiz, Isabel y Matthew Cummins [2019], Austerity: The New Normal A Renewed Washington Consensus 2010-24, Working Paper, Nueva York, Initiative for Policy Dialogue.

Pauw, Kalie [2003], Social Accounting Matrices and Economic Modelling, Background Paper Series 15610, PROVIDE Project.

PNUD (Programa de las Naciones Unidas para el Desarrollo) [2019], Panorama general: Informe sobre Desarrollo Humano 2019. Más allá del ingreso, más allá de los promedios, más allá del presente: Desigualdades del desarrollo humano en el siglo XXI, Nueva York, PNUD.

SHCP (Secretaría de Hacienda y Crédito Público) [2018], Informe sobre la situación económica, las finanzas públicas y la deuda pública, cuarto trimestre, <https://cutt. ly/6hvxS3S $>$.

Sen, A. [1980], "Equality of what?", en Sterling McMurrin (ed.), Lectures on Human Values, vol. 1, Cambridge, Cambridge University Press.

Solís, V., y V. Hernández [2019], Macro-cuentas, distribución del ingreso y redistribución entre hogares y sectores institucionales, Documento de trabajo, México, Inegi.

Stiglitz, J. E., A. Sen y J. P. Fitoussi [2009], Report by the commission on the measurement of economic performance and social progress, París, <https://cutt.ly/2hvxX3w>. 


MERCAdo De TRABAJO, MigRACIÓN Y BIENESTAR 



\section{ABANDONO DE LA POLÍTICA NEOLIBERAL Y MARCO NORMATIVO DELTRABAJO}

José Alfonso Bouzas Ortiz*

El cambio político en México del año 2018 ha llenado de expectativas a diversos sectores de la sociedad que habían sido abandonados y poco escuchados; el retorno de una política social en México que transforme de raíz a la sociedad mexicana cada vez más degradada se presenta como una necesidad de urgencia creciente.

En lo laboral, desde el nacimiento de la clase obrera en México a principios del siglo xx, los trabajadores históricamente fueron desposeídos de sus derechos de asociación sindical y negociación colectiva de sus legítimos intereses. El esquema normativo que materializa los derechos de asociación sindical y negociación colectiva de las relaciones de trabajo permitió que todas las determinaciones de las organizaciones sindicales quedaran en manos de los líderes sindicales, sin que los trabajadores como colectivo pudieran ser un contrapeso para el capital y las políticas gubernamentales contrarias a sus derechos.

Por otra parte, en las últimas décadas de lo que va de la implementación del modelo económico neoliberal, los trabajadores han experimentado una disminución de sus derechos, la pérdida del poder adquisitivo de los salarios, la aparición de formas atípicas de trabajo y el aumento del sector informal de trabajo, todo lo anterior en detrimento de las condiciones dignas de trabajo.

En el contexto de un nuevo gobierno que se autocaracteriza como reivindicador de las políticas sociales es que se

* Investigador del Instituto de Investigaciones Económicas, UNAM. Correo electrónico: <bouzas@unam.mx>. 
presenta la posibilidad de dar marcha atrás en los fenómenos que transgreden las relaciones laborales, tanto de las flexibilidades impuestas por las realidades del mercado de trabajo, como las que son consecuencia del histórico diseño normativo de control de las organizaciones sindicales, donde la participación de los trabajadores al interior de sus organizaciones sindicales sea el medio que posibilite que las mismas representen verdaderamente un factor de equilibrio de los factores de la producción capital y trabajo, y una voz organizada de la sociedad que guíe al Estado en el establecimiento de sus políticas públicas y económicas.

\section{LAS RELACiONES LaboRALES Y El Estado de BIENESTAR}

Comúnmente se toma la finalización de la Segunda Guerra mundial como el punto de arranque de un nuevo modelo de desarrollo distinto al que predominó en las primeras décadas del siglo xx. El crack de 1929 provocó una crisis sin precedentes que agravó (aún más) la gran desigualdad en los países occidentales; esta etapa de desolación (inestabilidad económica) provocó el surgimiento de ideologías nacionalistas, xenófobas y supremacistas cuyos proyectos encarnaban alternativas para solucionar el estancamiento económico mediante la centralización y la militarización. Estas ideologías se erigían en un régimen autoritario que silenciaba a la disidencia, exterminaba a la oposición y a la pluralidad, y buscaba expandir sus fronteras (inestabilidad política internacional).

En 1938 se reunieron en París un grupo de intelectuales con el propósito de discutir el futuro de las ideas liberales en lo que se denominó "Coloquio Walter Lippmann", justamente en un contexto de restricción de las libertades políticas y económicas en Alemania e Italia. Se trataba de la refundación del proyecto liberal que estaba siendo restringido. No obstante, una vez derrotado el nacionalsocialismo y el fascismo 
italiano por Estados Unidos y primigeniamente por la Unión de Repúblicas Socialistas Soviéticas (URSS), el proyecto liberal no encontró mejor suerte. El final de la guerra y la división del territorio alemán por parte de los vencedores dio comienzo a 45 años de tensión internacional que se conoció como la Guerra Fría; el mundo polarizado fue una de las causas de la adopción de un nuevo modelo de desarrollo por parte de los países occidentales.

De este modo, no hubo alternativa sino darle la espalda al laissez faire, laissez passer más puro, predominante hasta antes de la crisis, que se enfrentó a una coyuntura desfavorable: "todos pensaban que era necesario un Estado mucho más activo que defendiese el mercado, que procurase activamente la ampliación del mercado" [Escalante, 2017: 28]. Entonces, el proyecto que prevaleció fue el de las políticas anticíclicas de John Maynard Keynes que apuntalaba al Estado como la institución máxima que liderara y financiara la reconstrucción en los países europeos y que reintegrara a los combatientes a la economía. Ese proyecto se materializó en el Estado de bienestar, que, como señala Claus Offe, "ha sido celebrado a lo largo del periodo de postguerra como solución política a contradicciones sociales" [Offe, 1991: 136]. Y no era para menos, todo el mundo occidental comenzó a gozar de asistencia médica, acceso a la educación sin precedentes, retiros por vejez, seguros contra accidentes de trabajo, etcétera.

Algunos países como los nórdicos europeos tenían un camino recorrido en cuanto a protección social, pero fue hasta terminada la posguerra que se extendió a toda Europa e incluso a un país de tradición liberal como Estados Unidos. Por supuesto que el contexto político fue determinante por dos razones. La primera es de carácter internacional pues del otro lado del mundo había una alternativa al capitalismo que parecía progresar a un ritmo más acelerado. El socialismo real de la URSS se plantó como una amenaza a las pretensiones expansionistas del capital y, sin duda, no podía ser atractiva para las 
poblaciones de Occidente; la forma de hacer frente a su imagen fue con la generalizada política social que implementaron los Estados.

La segunda razón, estrechamente vinculada con la primera, fue la función de los sindicatos. Estas instituciones son fundamentalmente parte de los países capitalistas y en el siglo xx fueron esenciales para la repartición más equitativa de la riqueza; si las clases sociales estaban diferenciadas y las industrias fuertemente arraigadas en un territorio, se gestaban las condiciones para la organización y la negociación colectiva. Amparados por un Estado fuerte, los sindicatos tuvieron prominencia en el siglo pasado gracias a que los trabajadores eran el grupo social mayoritario y más organizado; de ahí que constituyeran el centro de las políticas sociales.

En México, en los años que correspondieron a la institucionalización y el funcionamiento del gobierno emanado de la Revolución de 1910 a 1917, se dio mayor control del Estado sobre la economía, hasta la década de 1970, por las características industriales del siglo pasado y la corriente económica que se expandió por todos los países occidentales que sostenía la importancia del papel que el Estado debería tener en la economía.

La relevancia del Estado benefactor fue precisamente que, basado en políticas keynesianas, reactivó la economía, produjo empleos y otorgó seguridad social sobre todo a los grupos mejor organizados, que en el siglo xx fueron los trabajadores industriales. Para este segmento de la sociedad, los Estados tenían reservadas políticas sociales para mitigar la brecha de desigualdad con el capital, políticas que resultaron imposibles de instrumentar en la etapa neoliberal.

En el anterior escenario, el sindicalismo en México fue sometido a la obligada anuencia del aparato de gobierno dentro de un permanente control y calificación de la conducta de las organizaciones sindicales. La formación, la actuación, la lucha e incluso la disolución de las organizaciones sindicales 
se desarrollaron de manera permanente con la injerencia del gobierno. El Estado surgido de la Revolución de 1910 a 1917 se levantó y consolidó teniendo como uno de sus pilares al movimiento obrero organizado, articulando la legislación laboral de tal manera que le posibilitara estas condiciones de injerencia.

Como lo señala Graciela Bensusán: "Los rasgos dominantes de la ley [Federal del Trabajo] fueron el marcado intervencionismo estatal, que posibilitaba supeditar los intereses obreros a los criterios de oportunidad del Ejecutivo, y el control de la autoridad en el proceso organizativo y reivindicativo" [Bensusán, 2000: 206], un fenómeno que la teoría política denomina corporativismo en las relaciones laborales.

De la Garza señala que el corporativismo mexicano se caracterizó por la ausencia de democracia en los sindicatos y la representación de los intereses de los trabajadores subordinada a los intereses políticos estatales. Lo anterior se llevó hasta el extremo de considerarse un rasgo cultural de las organizaciones sindicales mexicanas, caracterizadas por atender los problemas solo dentro del Estado, delegar las decisiones en los líderes sindicales (el fenómeno de ver los dirigentes sindicales como patrones de los sindicatos) y aplicar la normatividad laboral que no se hace efectiva sin la intervención del "favor" del poder público y con la expectativa del "compromiso" por parte de quien lo recibe [Garza, 2006: 179].

En México, el terreno de las injerencias finalmente se construyó desde el Estado y en el contexto de la "legalidad", de modo que al establecer que las autoridades registran, autorizan, impiden, reconocen y realizan un sinnúmero de conductas y señalan diversas condiciones para la acción de los trabajadores, convirtieron la participación de las distintas instancias de autoridad en enclaves básicos para el ejercicio de los derechos laborales e incluso para la existencia de las organizaciones sindicales. Además, las autoridades encargadas del registro de los sindicatos hicieron de la dirección sindical una 
institución más importante que el sindicato mismo y por supuesto dejaron a un lado a los trabajadores y sus auténticas organizaciones.

Las consecuencias de este modelo de relaciones laborales pueden sintetizarse de la siguiente manera: la mayoría de los ejercicios de organización sindical y de representación de trabajadores es simulada, en tanto que la voluntad de los trabajadores y el peso político y social que representan se encuentran ausentes.

Los actores de gobierno y empresarios encontraron como mecanismo para manejar la conflictividad laboral el centrar todo el poder (político y económico) que los trabajadores podían representar en las manos del dirigente sindical. Esto convirtió al dirigente sindical en una persona poderosa y tejió diversos compromisos e intereses con los gobiernos en turno.

Así, se observa que los sindicatos combativos con los trabajadores más aguerridos, creados a principios y hasta mediados del siglo xx, llegaran a una conclusión poco afortunada: su dirección sindical, inserta en el aparato de poder, les brindaba buenos resultados o eran preferibles los saldos que por esta vía se alcanzaban frente a la incertidumbre de una confrontación derivada de definir su interés en el proceso productivo (nacimiento del sindicalismo corporativo).

Los últimos 40 años constituyen un periodo de cambios profundos en el modo de vida de las personas alrededor del mundo. Múltiples procesos sociopolíticos y económicos, la globalización de la economía y las empresas, nuevas formas de organizar la empresa, la producción y el trabajo, y los avances tecnológicos han conducido a la metamorfosis de aspectos cruciales del paradigma capitalista, entre otros, el trabajo.

Esta cuestión cambió dadas las crisis financieras y tecnológicas que tuvieron lugar en la década de 1970 y las siguientes, década que se distingue por ser una etapa cualitativa y cuantitativamente diferente a las anteriores. 


\section{LAS RELACIONES LABORALES Y LAS POLÍTICAS NEOLIBERALES}

Varios factores hicieron posible que el siglo pasado se constituyera como un siglo de cambios significativos, una época de extremos opuestos, de violencia y otros problemas, pero que también trajo oportunidades para las poblaciones de Occidente. Las ventajas que los trabajadores consiguieron décadas atrás sobre la construcción de un marco normativo proteccionista y tutelar de su condición de sujeto vulnerable en las relaciones de producción capitalistas han ido desvaneciéndose en los últimos años. Hoy es tema habitual en la comunidad académica tratar de analizar cuáles fueron los detonantes del cambio que hicieron posible que las condiciones se transformaran de modo tajante, así como las formas de convivencia en ese entonces aceptadas.

Las opiniones respecto del porqué el trabajo precario se ha ido convirtiendo en una regla alrededor de todo el mundo plantean complicaciones importantes y el choque de varias visiones. Existe, sin embargo, una idea rectora que coadyuva a proponer una exégesis de cómo los cambios en la concepción clásica de la relación de trabajo se hicieron realidad y con ello la proliferación de trabajos atípicos y en condiciones de desprotección social. Ese argumento se avoca a las transformaciones tecnológicas que tuvieron lugar en los últimos 40 años. El ingreso de microchips y software sofisticados planteó la pauta de lo que vendría después. Ese cambio tuvo dos consecuencias determinantes. Una de carácter organizativo, que provino del Japón de la posguerra e hizo posible que las viejas estructuras rígidas del capitalismo del siglo pasado se derribaran, cambiando con eso el perfil de los trabajadores. La segunda fue de carácter económico y estaba dirigida a dejar de lado la producción de bienes para avocarse al comercio y las finanzas.

Por cuanto a la transformación de las formas organizativas del trabajo, el fordismo-taylorismo fue una forma de organización típica de las sociedades industriales. Se caracterizaba por 
mantener una jerarquía fuertemente marcada, donde cada individuo tenía una función específica y un lugar ganado dentro de la estructura organizativa. El éxito lo encontró debido a que en el contexto estadounidense de inicios del siglo xx se arremetió contra los monopolios; ahí Henry Ford encontró un nicho que potenció la producción. A partir de ese momento, adoptó la cadena de montaje que rápidamente se popularizó al permitir que la producción aumentara en un tiempo menor; su éxito fue tal que llegó a ser la forma productiva más importante del siglo xx.

Bajo los principios rectores de la administración científica de Frederick Winslow Taylor, el fordismo encontró un aliado en la búsqueda de productividad pues se basaba en la disciplina laboral y en estudiar a profundidad cada parte del proceso para encontrar formas mejores de hacerlo eficiente; ensayo y error propios de la experimentación se convirtieron en la máxima de Taylor. Este fue un actor imprescindible de las nuevas tendencias organizativas debido a que perfeccionó las técnicas de la gestión mediante patrones más efectivos para cada proceso. Como apunta George Claude: "deseaba saber cuánto tiempo tomaría y debería tomar a una máquina o a un trabajador efectuar un proceso dado, o fabricar una parte, utilizando métodos y materiales específicos bajo condiciones controladas" [Claude, 2005: 80], es decir, logró basar su teoría en los procesos estandarizados para así generar productividad y evitar la mayor incertidumbre posible.

No obstante, no fue sino hasta bien asentada la posguerra que los japoneses comenzaron a adoptar un modelo distinto al que hasta entonces era hegemónico. Forjado por las condiciones económicas y políticas de un país destruido por la guerra y golpeado económicamente por las sanciones que sobre él cayeron, se presentaron problemáticas urgentes que debían resolverse.

Como en el caso de Europa Occidental, Japón fue una de las naciones que recibieron inversión estadounidense para la 
reconstrucción, misma que se tradujo en la llegada de industrias y capitales provenientes del máximo ganador de Occidente que buscaba encontrar en los habitantes nipones un nicho abundante de mano de obra. Los capitales entrantes permitieron a Japón recomponerse y comenzar a desarrollarse; como apunta Immanuel Wallerstein, después de dos décadas, los países que gozaban del favor de la potencia hegemónica occidental ya no eran tan vulnerables [Wallerstein, 2015: 34].

Japón tenía que aprovechar la abundante mano de obra poco calificada con la que contaba así como la tecnología trasplantada en su territorio. En ese sentido, Taiichi Ohno, uno de los directivos de la empresa de automóviles Toyota, revolucionó la forma de organización, pues invirtió el proceso productivo propio del fordismo en lo que se denominó toyotismo u ohnismo. Para Enrique de la Garza, el toyotismo como nueva forma de gestión organizativa convergió con la nueva fase neoliberal que tenía como base "la flexibilidad al interior de las empresas [que] se mueven entre los ámbitos de la organización del trabajo y los de las relaciones laborales" [Garza, 2012: 5].

El toyotismo es un modelo de producción que se caracteriza principalmente por dar prominencia a la descentralización. Su origen se remonta a la posguerra cuando Japón tenía mano de obra excedente, poco calificada y además escasos lugares en los cuales emplear a dichos trabajadores. No fue sino hasta cuando la tecnología y las corporaciones norteamericanas se instalaron en el país asiático que comenzó a dar frutos. La idea era disminuir los costos de producción a toda costa y la manera idónea de hacerlo fue contratando empresas externas. Si el outsourcing o la tercerización ya constituía una actividad recurrente de los capitalistas, se potenció en la década de 1980; tanto que llegó a desplazar al fordismo-taylorismo como el hito organizativo y se convirtió en el estandarte del capitalismo.

Si la cadena de montaje se distinguió por estandarizar los procesos y delegar una actividad específica a cada trabajador, 
el toyotismo predominante de la década de los años 80 se preocupó por encontrar una nueva forma de eficientar la producción en el seno de la fábrica. Ya no se trataba de una corporación robusta, sino que comenzó a delegar tareas a empresas externas que se caracterizaban por contar con la capacidad tecnológica y material y los recursos humanos para atender las nuevas necesidades de reproducción del capital. Las empresas no solo comenzaron a externalizar actividades con otras empresas instaladas en el mismo territorio, sino que lo hicieron a través de las fronteras.

Otro acierto del nuevo modelo de Ohno fue que dejó de pensar en la producción masiva y el resguardo de esta en espera de su consumo; la descentralización le permitió implantar un modelo en el cual las empresas externas proveían el material necesario en el momento en que la empresa principal lo necesitara. Es decir, la empresa japonesa supo resolver el problema de los ciclos económicos cuando el consumo de cierto producto comienza a disminuir; las bodegas ya no se llenarían con miles de unidades en espera de ser compradas, sino que se produciría de acuerdo con la demanda y para eso era importante externalizar el riesgo. La provisión justo en el momento preciso, de ahí su nombre Just in Time.

Así, las nuevas tecnologías de la información permitieron a las grandes corporaciones desconcentrar su producción; grandes procesos se trasladaron a los países del tercer mundo con el único propósito de abaratar los costos. La tecnología, por tanto, fue un detonante del nuevo escenario mundial en el cual los sindicatos ya no contaban con la misma capacidad política para influir en las reglas internas de la empresa. Las corporaciones tenían ahora el poder para sacar la inversión de un país y trasladarlo a otro, concentrando en una matriz las tareas de gestión y organización de la producción.

Según Óscar Ermida, el proceso globalizador trajo tres procesos importantes para el trabajo que no se conocían hasta hace tres décadas: un desinterés generalizado por fortalecer 
el mercado interno; el abandono estatal de las variables macroeconómicas que hicieron posible mantener estabilidad tanto productiva como salarial; e ideologías que no privilegian el factor trabajo como determinante en la estructura productiva [Ermida, 1999: 3]. Esos tres pilares fungieron como los ejes transversales de la política económica de los países en el siglo xx; una vez deteriorados, hicieron posible que la estabilidad en el trabajo comenzara a flaquear. Las economías comenzaron a virar hacia el mercado externo; en prácticamente todos los países de Occidente, el Estado comenzó a adoptar políticas poco proteccionistas que favorecían al mercado internacional (so pena de sufrir sanciones por parte de organismos trasnacionales) y en ese contexto de descentralización mundial se hizo plausible trasladar partes fundamentales del proceso productivo a zonas con poca o nula protección e inspección laboral. He aquí el porqué, a partir de las década de 1980, en países en desarrollo las variantes de la relación laboral: jornada, salario y estabilidad en el empleo comienzan a verse duramente vulneradas.

Ante el planteamiento de producción de característica maleable que se postuló como el paradigma empresarial después de la década de 1980, las tutelas de los derechos de los trabajadores se presentaron como una "rigidez" que afectaba el proceso de producción mismo y comenzaron a verse como un obstáculo para el desarrollo capitalista. Es entonces cuando inicia un proceso de desregulación de las normas jurídicas laborales, entre ellas las que conciernen a duración de la relación de trabajo (contratos ya no por tiempo indeterminado), la aparición de formas atípicas de trabajo (por hora, a prueba, por capacitación, subcontratación), las flexibilidades para el despido (en algunos casos, incluso sin indemnizaciones), la ausencia de seguridad social, la caída de poder adquisitivo de los salarios, etc., sin que en México las organizaciones sindicales pudieran hacer frente a la desregulación en los hechos, en tanto que, como se explicó con anterioridad, estas se encontraron cooptadas por el esquema corporativo. 
A principios de la década de 1980, comienza una etapa nueva del capitalismo, denominada de diferentes formas: globalización, neoliberalismo, modernidad, dependiendo el énfasis del tema que se quiere resaltar. A partir de estos años, se dio un proceso de polarización social, concentración de capital y precarización de la mayoría de la población; así, los Estados experimentaron una paulatina delegación de gran parte de las facultades, tareas y empresas que con anterioridad tenían.

Es el caso de México, donde sucedieron transformaciones importantes en la composición del mercado de trabajo sin distinción entre el sector formal y el informal, transformaciones que desembocaron en distintos indicadores de precarización mientras que la legislación laboral, en términos generales, se mantuvo estática. Llegó con su carácter tutelar y benefactor hasta donde el Estado proteccionista e interventor le permitió avanzar para después, en los años de crisis, convertirse en letra muerta.

Desde la década de 1980, con la incursión paulatina del proceso de globalización, han surgido nuevas formas de trabajo, entre otras razones, porque la economía se ha desplazado hacia los servicios y el sector financiero, nichos que generalmente echan mano de los avances tecnológicos. El sector industrial ha sufrido una caída constante reduciéndose a maquila de valor secundario, el campo ha sido abandonado ante la imposibilidad de vivir de él y el sector público, como se señalará más adelante, dejó de ser el motor de crecimiento que fue en los años del Estado benefactor.

El nuevo diseño se plasmó en una serie de medidas impulsadas en instituciones que John Williamson denominó como el Consenso de Washington; tales medidas implicaron: iniciar un proceso de privatización de actividades que tradicionalmente había realizado el Estado y de las que podía prescindir; la desregulación ante la excesiva reglamentación, que se sostenía, hacía perder interés en la inversión; y la apertura a la 
inversión extranjera directa en un proceso globalizador. Esos fueron los factores que hicieron que el Estado perdiera su función central en la economía y se subordinara a los vaivenes del mercado y los intereses de una clase capitalista trasnacional que tomó gran fuerza en los años 90, logrando acumular una cantidad enorme de capital. Lo anterior, entre otras consecuencias, ha incrementado la desigualdad que fue designada como el desafío más serio del mundo por el Foro Económico Mundial en Davos [González, 2014: 24].

Es el paso de un modelo de organización de la producción tradicional de corte fordista hacia otros modelos que reducen los costos para los productores, como el toyotismo, cimentado en la flexibilidad tanto de la organización como del trabajo, impactando sobre la relación existente entre el empleador y el empleado, y de este con la forma de experimentar el desempeño de la actividad que realiza para poder vivir y de las oportunidades que se le brindan.

En México, el abandono de la política del "Estado proteccionista" comienza en 1982. Con el paso del tiempo fueron definiéndose las características de una nueva etapa, cuyo objeto fue sentar las bases para la entrada de lo que se conoce como "neoliberalismo", enfocado en montar la infraestructura necesaria para su implementación, con lo que empezó un nuevo modelo. Con ello se rompió “el pacto social”, que si bien había evolucionado hacia formas cada vez más heterodoxas, encontraba su sustento en los principios surgidos de la Revolución mexicana.

Las medidas tomadas en esta etapa consistieron básicamente en una desaceleración de los procesos económicos a través de la disminución del presupuesto para el gasto público y el casi abandono de lo social (hecho hasta entonces sin precedente en la historia moderna del país); la privatización de las empresas paraestatales y de participación estatal, que a mediados de los 70 ascendían a más de 800 entidades paraestatales [Villarreal y Villarreal, 1977: 233] y se habían 
multiplicado incluso de manera irracional durante el sexenio de Luis Echeverría; y una política destinada a asegurar una mayor tasa de ganancia del sector empresarial a costa fundamentalmente de un descenso del precio de la fuerza de trabajo y el desempleo. Los efectos inmediatos de este programa estribaron en una caída vertiginosa de los ingresos de la mayoría de la población, que impactó sobre todo a la clase trabajadora [Calva, 2000: 7].

Así, a partir de 1983 las políticas estatales, principalmente la económica, sufrieron una metamorfosis. En una primera etapa, se sientan las bases para acceder a la modernidad, aunque ello no haya significado un crecimiento económico significativo y, en una segunda fase, se puso en marcha plenamente el nuevo modelo. La primera etapa corresponde al periodo de Miguel de la Madrid y la segunda al de Carlos Salinas de Gortari y, en lo correspondiente, al sexenio de Ernesto Zedillo.

Si bien la "reforma del Estado" empieza en 1982, es en el sexenio de Salinas de Gortari cuando se acerca a su clímax; las modificaciones a los Artículos $3^{\circ}$ y 27 , y el intento de reforma al 123 constitucional así lo demuestran; tales preceptos fueron los pilares de la legitimidad en que se asentó el Estado surgido de la Revolución, cuya ideología se apoyaba en el nacionalismo revolucionario.

Frente a las críticas de los empresarios en relación con el excesivo proteccionismo y la rigidez del marco jurídico, la acción de las autoridades se orientó a dejar claro que las instituciones laborales, incluidos los sindicatos, los contratos colectivos, el derecho de huelga, las juntas de conciliación y arbitraje y, en general, el conjunto de los mecanismos protectores contenidos en la legislación laboral, no constituirían un obstáculo infranqueable para avanzar en la modernización económica [Lóyzaga et al., 1996: 136-137].

Los rasgos autoritarios y corporativos de las instituciones laborales sirvieron para poder transitar el proyecto hacia la apertura comercial y la reestructuración industrial. 
La "flexibilización" y la desregulación de las relaciones laborales fue uno de los pilares más significativos de esta transición; la introducción de figuras como la subcontratación, identificada con el anglicismo outsourcing, ${ }^{1}$ también fue un rasgo importante de este proceso de adaptación a la economía global.

\section{EL MARCO NORMATIVO DEL TRABAJO EN SU CONTEXTO}

La Ley Federal del Trabajo (LFT) de 1931 estableció las bases necesarias para que la tutela del trabajo dependiera de la voluntad del gobierno ${ }^{2}$ con reglas que limitaron la actuación de los sindicatos y que establecieron las condiciones necesarias para que sea el propio gobierno el que tutele y reivindique el trabajo en los términos que su entender lo determine. Con ello se inicia un proceso en el que la conducta que se tenga frente al trabajo dependerá de la interpretación del gobierno en turno y de su proyecto económico. El papel de los sindicatos y de las propias empresas quedó subordinado y dependiente de la capacidad de negociar con las autoridades constituidas, debido a que una de las características más notables del esquema de relaciones laborales mexicano es la relación corporativa entre los actores. Ello hizo que la figura del Secretario General fuera importante para la obtención de beneficios a cambio de la subordinación.

1 "El concepto fue acuñado en 1980 para describir la creciente tendencia de las grandes compañías que estaban transfiriendo parte de sus procesos productivos a proveedores, como una estrategia de negocio, cuando la realidad era que querían desentenderse de los compromisos laborales que implica la operación de estas empresas, haciéndolas, en consecuencia, más rentables" [Lañas y Bouzas, 2010: 256.

${ }^{2}$ No contempla la libertad sindical, excluye a los trabajadores del sector público (Art. 2), impone la tipología sindical (Art. 233), establece el registro sindical (Art. 242) y regula el derecho de huelga (Art. 259 y siguientes). 
La LFT de 1970 y sus reformas de $1980^{3}$ ratificaron y ampliaron el margen de control por parte del gobierno. ${ }^{4}$ Resulta complejo establecer si se dio primero el cambio de rumbo de la economía del intervencionismo al liberalismo o fueron anteriores las expresiones de falta de cumplimiento del marco normativo del trabajo (reivindicativo y tutelar), tendencia que se acentúa a partir de la década de 1980 y que en la actualidad nos permite hablar de una dicotomía entre la norma del trabajo y la realidad laboral puesto que transitan por senderos diferentes.

A partir de los años 80, se inició en México el debate respecto de la reforma laboral. Las razones estuvieron ligadas al agotamiento del modelo de sustitución de importaciones y al cambio de política económica y, con ello, de política laboral, lo que motivó el rompimiento del equilibrio entre las funciones de protección y control de los trabajadores y sus demandas, que antes se observaba en el comportamiento entre las autoridades laborales, el sector patronal y las dirigencias sindicales.

Después de algunos debates respecto de la necesidad de reformar la legislación laboral, mismos que implicaron foros y publicaciones diversas, el 12 de julio de 1995, los senadores a la LVI Legislatura del H. Congreso de la Unión integrantes del Grupo Parlamentario del Partido Acción Nacional presentaron un proyecto de reforma al ordenamiento jurídico laboral que incluso planteó reformar la Constitución, ${ }^{5}$ documento elaborado por Néstor y Carlos de Buen.

Poco tiempo después se hizo público otro proyecto de reformas laborales, ahora planteado por el diputado Víctor Manuel

${ }^{3}$ Diario Oficial de la Federación, 1 de mayo de 1980.

${ }^{4}$ Se pone énfasis en los temas referidos a la reforma de 1931 y particularmente en el Artículo 923, en el que se faculta al gobierno para no dar trámite a una demanda por firma o revisión de contrato colectivo cuando estime que no se cumplen con los requisitos de ley.

${ }^{5}$ Proyecto de reforma al ordenamiento jurídico laboral presentado por el Grupo Parlamentario del PAN, 12 de julio de 1995., p. 169. 
Ochoa Camposeco, del Grupo Parlamentario del Partido de la Revolución Democrática (PRD). Esta nueva propuesta implicaba reformas constitucionales; en particular, planteaba suprimir el apartado B del Artículo 123 constitucional, la creación de un Instituto Nacional de Salarios Mínimos, Productividad y Reparto de Utilidades, y un Registro Público de Organizaciones Sindicales y Contratos Colectivos. ${ }^{6}$

Debe tenerse en cuenta que paralelamente, desde 1996, la representación empresarial de la Coparmex en la persona de Carlos Abascal y la representación del sindicalismo corporativo, durante la presidencia de Ernesto Zedillo, llevaron a cabo un nuevo intento de reforma laboral, ahora al amparo de lo que se denominaba "nueva cultura laboral", que, como menciona Néstor de Buen, se basa en el rechazo a la lucha de clases y funda sus razones en el mutuo amor entre trabajadores (explotados) y empresarios (explotadores) [de Buen, 2001: 16].

Es entonces que por iniciativa de Carlos Abascal se instala una mesa central de decisiones integrada por 22 representantes, mismos que la Secretaría del Trabajo y Previsión Social (STPS) determinó que lo eran: 11 representantes empresariales de Canacintra y 11 representantes, supuestamente, de los trabajadores, otorgándole dos asientos a la Unión Nacional de Trabajadores (UNT). Los trabajos se iniciaron y desde la primera resolución hubo disentimiento por parte de la representación de la UNT y la representación del sindicalismo corporativo. La UNT pugnaba por una reforma integral, es decir, al marco normativo constitucional y al reglamentario, mientras que el sindicalismo corporativo planteaba solo una reforma a la ley reglamentaria del apartado A del Artículo 123 constitucional. Ante esta situación, la UNT decidió retirarse para continuar trabajando en su propia iniciativa.

\footnotetext{
${ }^{6}$ Gaceta Parlamentaria de la Cámara de Diputados, 1 de noviembre de 2002.
} 
En el anterior escenario político y el desarrollo de los hechos antes citados, el sindicalismo corporativo y la Canacintra se mantuvieron en la Mesa Central de Decisión de la Secretaría del Trabajo y concluyeron con un proyecto de LFT; la UNT se alió con el PRD e hizo lo propio. El caso es que el proyecto de Abascal finalmente fue presentado por PRI, PAN y Partido Verde, y publicado el 20 de enero de $2003,{ }^{7} \mathrm{y}$ el proyecto UNT-PRD entró al Congreso de la Unión en marzo de 2003 bajo la denominación "Una reforma democrática para el mundo del trabajo" [Grupo Parlamentario del PRD, 2003: 12].

Como se refirió con anterioridad, una vez separada de la mencionada mesa de concertación, la UNT tomó la determinación de elaborar y presentar su iniciativa de reforma laboral. Tal iniciativa retomó lo mejor de los proyectos antecesores -el elaborado por los De Buen y el del PRD- logrando que este partido la hiciera suya. El documento fue elaborado, entre otros, por los notables laboralistas Graciela Bensusán Aerous, Arturo Alcalde Justiniani y Héctor Barba.

El día 21 de noviembre de 2007, el subsecretario del Trabajo y Previsión Social, el doctor Álvaro Castro Estrada, durante el Seminario "Panorama Laboral 2007-2008", presentó las principales acciones a realizar para la reformar del marco normativo del trabajo. ${ }^{8}$ Se plantea reformar las relaciones laborales para hacerlas más productivas y benéficas tanto para los trabajadores como para los productores, teniendo como finalidades: conservar la paz laboral; promover el equilibrio entre los sectores laboral y empresarial; fortalecer la coalición; tramitar demandas laborales con procedimientos más ágiles, transparentes y expeditos; y fortalecer el diálogo en las revisiones contractuales, salariales y conflictos laborales. Se sostenía que la bandera de esta reforma era lograr una "economía competitiva y generadora de empleo".

\footnotetext{
${ }^{7}$ Gaceta Parlamentaria de la Cámara de Diputados, 20 de enero de 2003, p. 106.

${ }^{8}$ Secretaría del Trabajo y Previsión Social, 2012, <https://n9.cl/r4xc9>.
} 
Desde mediados de 2008 y oficialmente el 2 de octubre de 2009, ${ }^{9}$ Javier Lozano presentó desde la propia Secretaría del Trabajo un documento público que retoma la iniciativa de Abascal y la de Álvaro Castro. En marzo de 2010, durante el gobierno del presidente Felipe Calderón Hinojosa, se presentó la versión del proyecto de reforma conocido como el "Proyecto Lozano", en alusión al Secretario del Trabajo. Tal proyecto, como era de esperar al ser el proyecto oficial del gobierno federal, fue presentado por el grupo parlamentario del $\operatorname{PAN}^{10} \mathrm{y}$ se caracterizó por ser más represor y limitador de los derechos laborales de lo que sus antecesores lo fueron. Para entonces y por la conducta posterior del PRI, estimamos que la alianza PRIPAN era una forma de enfrentar a la oposición haciendo unidad con la iniciativa privada y con los sindicatos corporativos.

El grupo parlamentario del PRD presentó una nueva propuesta en abril de $2010^{11}$ y el grupo parlamentario del PRI propuso cuatro iniciativas con algunos cambios entre ellas. ${ }^{12} \mathrm{La}$ Comisión de Trabajo de la Cámara de Diputados publica sus conclusiones, según sostiene, tomando en cuenta las diversas propuestas de reforma presentadas ${ }^{13}$ y el 6 de abril de 2011 la fracción del PRI pide que antes de resolverse, se consulte a la sociedad sobre la reforma. ${ }^{14}$

Pero los temas estaban ya en la mesa y la combinación de fuerzas y poderes permitió que pasara la iniciativa de

9 Hacia una reforma laboral para la productividad y la previsión social, p. 114.

${ }^{10}$ En versiones fechadas el 18 y 20 de marzo de 2010 y suscritas por la fracción del PAN.

${ }^{11}$ Iniciativa presentada el 14 de abril de 2010 con la particularidad de que se trata de tres iniciativas: una de reforma constitucional, otra de reforma a la Ley Federal del Trabajo y una tercera en materia de seguro de desempleo.

${ }^{12}$ Iniciativa del PRI, 29 de octubre de 2010; Iniciativa del PRI, 21 de diciembre de 2010; Iniciativa del PRI, 6 de enero de 2011; y Gaceta parlamentaria de la Cámara de Diputados, 10 de marzo de 2011.

${ }^{13}$ Gaceta parlamentaria de la Cámara de Diputados, 28 de marzo de 2011.

${ }^{14}$ Gaceta parlamentaria de la Cámara de Diputados, 5 de abril 2011. 
Felipe Calderón. ${ }^{15}$ Como antecedentes, el 9 de agosto de 2012 [Burgoa, 2012] se publicó el decreto de reforma constitucional en materia política que incorporó la iniciativa preferente a cargo del presidente de México prevista en el Artículo 71 constitucional.

La iniciativa laboral, que pretendió consumar la reforma que durante lustros se había buscado, presentó un sinnúmero de deficiencias y finalmente dejó insatisfechos a todos los involucrados.

Como se apreciará, en paralelo al proceso de desregulación de la normatividad laboral de las relaciones laborales en México que se presentó en los hechos a partir de la década de los 80, comenzó la discusión acerca de la necesidad de reformar la normatividad laboral. Básicamente se expusieron dos posturas: una que sostenía flexibilizar las relaciones laborales y otra tendiente a salvaguardar el derecho de asociación y democratizar las organizaciones sindicales. Esta discusión se materializó en una primera reforma a la Ley Federal del Trabajo del año $2012,{ }^{16}$ en concordancia con la primera de las posturas, en la que introdujeron los contratos a prueba y por capacitación inicial, el régimen de subcontratación (outsourcing) y la limitación del pago de los salarios vencidos de los trabajadores en los procesos jurisdiccionales, entre otros cambios.

Acorde con la segunda de las posturas de la discusión de la reforma laboral, se llevó a cabo la reforma constitucional más trascendente en materia de trabajo de los últimos años, ${ }^{17}$ la reforma constitucional al Artículo 123 que eleva por vez primera la negociación colectiva, establece garantías en materia de libertad y democracia sindical, poniendo en el centro de las decisiones sobre la vida sindical a la persona trabajadora, e incorpora un nuevo paradigma para la impartición de justicia laboral.

\footnotetext{
${ }^{15}$ Diario Oficial de la Federación, 30 de noviembre de 2012.

${ }^{16}$ Publicada en el Diario Oficial de la Federación el 29 de noviembre de 2012.

${ }^{17}$ Publicada en el Diario Oficial de la Federación el 24 de febrero de 2017.
} 
La necesidad de que el derecho de asociación sindical se convirtiera en la columna vertebral de las reformas al marco normativo laboral, después de décadas de que en lo nacional el sector obrero independiente y la comunidad académica lucharon, no fue una realidad sino hasta que las presiones y los compromisos adquiridos por el gobierno mexicano a nivel internacional le exigieron que terminara con la simulación alrededor de las organizaciones sindicales, demandas que en contexto de la política económica neoliberal son urgentes y un tema que debía atender el Estado en el ánimo de recobrar el sentido social del trabajo.

CONTEXTO INTERNACIONAL DE LA REFORMA LABORAL Resolución del Comité de Libertad Sindical

La Organización Internacional del Trabajo (OIT) tiene un papel de presión internacional para que los países atiendan problemáticas como el trabajo forzado, el empleo informal y el derecho a la negociación colectiva por parte de los sindicatos. Esto lo hace buscando leyes nacionales eficaces y mecanismos de aplicación más estrictos, como sanciones legales y enjuiciamiento enérgico. Al sensibilizar a la opinión pública, la OIT pretende destacar las violaciones de los derechos humanos laborales.

El 5 de febrero de 2009, el Comité de Libertad Sindical de la OIT adoptó en sus debates el tema de la democracia y la libertad sindical en México, bajo el número de caso 2694 como consecuencia de una queja que presentara la Federación Internacional de Trabajadores de las Industrias Metalúrgicas (FITIM), apoyada por la Confederación Sindical Internacional (CSI), en contra del gobierno de México [Consejo de Administración, 2011]. Dicho comité recibió el informe del gobierno mexicano el 1 de marzo de 2010 y realizó sus primeras recomendaciones en marzo de 2011. 
De esta forma, el Comité de Derechos Económicos, Sociales y Culturales examina que se cumplan las disposiciones contempladas en el Pacto Internacional. La última vez que el Estado mexicano compareció ante este comité fue en 2016 [Consejo Económico y Social, 2016] y el comité manifestó preocupaciones acerca de la situación laboral igual que lo hizo años antes como respuesta al informe generado por México. En él ya se expresaban problemas que la OIT vio y puntos que habría que mejorar dadas las condiciones que vive el país y para que esté en concordancia con las disposiciones y las preocupaciones en materia de derechos humanos laborales [Consejo Económico y Social, 2009]:

- Aproximadamente $40 \%$ de la población económicamente activa (PEA) trabaja en el sector "no estructurado".

- Los salarios mínimos son bajos, sobre todo los de las mujeres y los indígenas.

- Las condiciones laborales de los trabajadores indígenas son malas. Se encuentran mal remunerados (si es que lo están), no cuentan con seguridad social ni vacaciones y muchos trabajan con contratos de jornaleros o sin ellos.

- Se exige a las trabajadoras certificados de no gravidez para que sean contratadas o evitar ser despedidas (principalmente en la industria maquiladora textil).

- Hay restricciones severas en la Ley Federal del Trabajo y en la Ley Federal de los Trabajadores al Servicio del Estado respecto de su derecho a constituir sindicatos y/o adherirse a uno (como los monopolios sindicales), así como la inhabilitación de sindicatos en el sector público y las limitaciones que tienen estos al constituirse en federaciones o confederaciones, restringiendo con ello también su derecho de huelga.

Estas preocupaciones por parte del Comité del Consejo de Derechos Económicos, Sociales y Culturales son solo algunos de los puntos ya expuestos en entregas anteriores a 
pesar de que México es un país conocido por ratificar protocolos y acuerdos internacionales, pues de los 18 instrumentos de protección a los derechos humanos de la onU ha ratificado 16 de ellos. Aún están pendientes algunos convenios importantes como el Protocolo Facultativo del Pacto Internacional de Derechos Económicos, Sociales y Culturales que, entre otras cosas, da competencia al Comité de Derechos Económicos, Sociales y Culturales para recibir y examinar comunicaciones referentes a estos derechos. Sin embargo, el apartado segundo del Artículo $1^{\circ}$ apunta que "El Comité no recibirá ninguna comunicación que concierna a un Estado Parte en el Pacto que no sea parte en el presente Protocolo" [ONU, s/f] México aún no ratifica este protocolo, con lo cual deja sin competencia a dicho comité.

El 4 de octubre de 2016 [Confederación Sindical Internacional, 2016], la representación sindical internacional nuevamente hace valer su reclamo mediante una solicitud de audiencia temática sobre violaciones del derecho a la libertad sindical y el derecho de negociación colectiva en México, presentada ahora ante la Comisión Interamericana de Derechos Humanos de la Organización de los Estados Americanos por la Confederación Sindical Internacional, la Confederación Sindical de Trabajadores y Trabajadoras de las Américas y la Unión Nacional de Trabajadores, teniendo como particularidad del momento que el poder ejecutivo del gobierno mexicano había presentado al Senado de la República una iniciativa de reforma constitucional y a la LFT que atendía el tema de la libertad y la democracia sindical en México y daba pasos para terminar con los contratos colectivos de protección patronal.

La inquietud se centraba en que no obstante se estaba procesando ya la reforma constitucional, existían evidencias de que la reforma a la LFT vendría a dar marcha en el tratamiento de este sentido problema. 
Acuerdo de Cooperación Laboral de América del Norte (ACLAN)

Una segunda incidencia se dio fue como consecuencia de las negociaciones del tratado comercial Tratado de Libre Comercio de América del Norte (TLCAN), de las que surgió la necesidad de celebrar acuerdos paralelos en materias de medio ambiente y laboral. El 14 de septiembre de 1993 se realizó la firma oficial de los acuerdos paralelos en los terrenos laboral y del medio ambiente en las capitales de los tres países. Los tres acuerdos entraron en vigor el 1 de enero de 1994: el acuerdo comercial (TLCAN) y los acuerdos de cooperación laboral (ACLAN) y de medio ambiente (ACAAN).

\section{El Tratado entre México, Estados Unidos $y$ Canadá (T-MEC)}

Tras 14 años de vigencia del TLCAN, los tres países de América del Norte vieron la necesidad de actualizar dicho tratado; el resultado fue que el 30 de noviembre de 2018 México, Estados Unidos y Canadá firmaron un nuevo acuerdo de libre comercio llamado T-MEC (por sus siglas), que sustituiría a su predecesor. En el capítulo 23 del nuevo acuerdo se incluyen los aspectos laborales y el compromiso de los tres países de promover la aplicación de los derechos laborales fundamentales en sus respectivas legislaciones nacionales.

Respecto del capítulo 23 del T-MEC

En el escenario global, es indudable el énfasis que los dos países socios del nuestro pusieron en que México garantice condiciones de trabajo mínimas del mundo moderno como consecuencia de que los trabajadores que laboran en los indicados 
países obligaron a sus gobiernos a que en el tratado se garantizaran condiciones laborales semejantes en los tres países, bajo la hipótesis de que México ofrecía a los inversionistas condiciones laborales que afectaban no solo a los trabajadores mexicanos, sino que repercutían en su perjuicio por la competencia desleal que les hacían, dejando claro que estas conductas afectan el comercio y la inversión.

Como un precedente de particular importancia, el capítulo que comentamos refiere como compromiso de los firmantes cumplir las obligaciones que adquirieron al ser parte de la OIT y en particular su declaración sobre la justicia social para una globalización equitativa, reconociendo la importancia de la organización de los trabajadores y empleadores, y condicionar el acuerdo comercial al cumplimiento de los anteriores compromisos.

El tratado, además de reiterar los diversos tratados en los que México es parte en materia de trabajo forzoso, trabajo infantil y eliminación de la discriminación, hace énfasis en la aplicación efectiva de los derechos laborales fundamentales en la legislación nacional y pormenoriza como disposiciones específicas el derecho a la contratación colectiva y el derecho de asociación sindical, e insiste en la necesidad de establecer órganos registrales autónomos y que atiendan las disputas por la contratación colectiva.

Aborda de forma discreta el tema de la estabilidad en el empleo, que el gobierno mexicano había abandonado a cambio de fomentar la inversión extranjera, política establecida en los últimos 30 años de desarrollo liberal (paraíso laboral).

Trata el importante tema de la conciliación de las diferencias, el arbitraje y el respeto a los derechos procesales de las partes y los importantes trabajos de los tribunales laborales.

Como obligación particular de México ${ }^{18}$ y condicionante de la puesta en marcha del T-MEC se establecen las siguientes

${ }^{18}$ Es por demás interesante que en un tratado internacional se convengan obligaciones particulares para uno de los firmantes en contraposición a la soberanía de los Estados, lo que cuestiona la libertad con la que celebran el tratado. 
cuestiones que podemos interpretar de dos formas. Primera, las fronteras han caído no solo en lo comercial sino en todo, incluso lo laboral, lo que ahora nos coloca en que el debate del trabajo es internacional; y segunda, se está violentando la autonomía de los Estados. Nos quedamos en la primera por múltiples razones para el bien del trabajo:

- Establecer en sus normas laborales el derecho a la contratación colectiva y libre sindicalización.

- Establecer en sus normas laborales la creación de instancias autónomas que registren contratos colectivos y organizaciones de trabajadores, y realicen los procedimientos de conciliación.

- Establecer en sus normas garantías de que los conflictos intersindicales serán resueltos mediante voto universal directo y secreto de los trabajadores.

- Garantizar en su legislación la participación mayoritaria de los trabajadores para la aprobación de los contratos colectivos y la revisión obligatoria de los contratos cuando menos cada cuatro años.

- Por último, un compromiso del gobierno mexicano de realizar lo anterior antes de que termine el año 2019.

Finalmente, los cambios que se están dando a nivel normativo y en el proceso de las relaciones sociales de producción son radicales y son un saldo positivo de los tratados comerciales que México ha celebrado; dinamizan la acción de los trabajadores como no se había logrado en décadas y abren expectativas de que se inicie un proceso de recuperación de las condiciones de trabajo, particularmente del salario.

Es complejo decir hasta dónde las realidades laborales de nuestro país se transformarán, pero se piensa que será para bien en tanto que los trabajadores recuperen su representación colectiva, el sindicato que ahora se encuentra secuestrado por direcciones corporativas que privilegian los intereses de los líderes sindicales sobre los de los trabajadores y el proceso 
productivo que está en manos de los empresarios que no tienen disposición de negociar y menos de hacerlo respecto de la rentabilidad de las empresas. El 15 de enero de 2019 se hace público el texto final del capítulo 23 del Tratado de Libre Comercio entre México, Estados Unidos y Canadá. ${ }^{19}$

LA REFORMA LABORAL 2017 A 2019: REIVINDICACIÓN

DEL CARÁCTER TUTELAR DE LA NORMA DE TRABAJO

Por último, el proceso de cambio se gestó de 2017 a 2019, años de una inédita reforma constitucional que tenía como propósito romper el viejo esquema corporativo arraigado en el Estado mexicano, teniendo en cuenta que en 2019, con un gobierno de izquierda, se aprobaron las reformas a la Ley Federal del Trabajo impulsadas por el partido Movimiento de Regeneración Nacional (Morena).

La reforma constitucional, incluida su aprobación por las legislaturas locales, fue publicada el 24 de febrero de 2017 en el Diario Oficial de la Federación.

El 5 de abril de 2019, la Comisión de Trabajo y Previsión Social de la Cámara de Diputados somete a dictamen la iniciativa que presentara Morena, retomando puntos de las otras iniciativas, y finalmente, con algunas adiciones que se plantean en el pleno tanto de la Cámara de Diputados como de la de Senadores, el 1 de mayo de 2019 se aprueba la iniciativa de reforma a la LFT de Morena. ${ }^{20}$

Las instituciones de la reforma que se modificaron nos permiten afirmar que lo que se realizó es una reforma que recupera el carácter tutelar del derecho laboral y adapta la reglamentación a los requerimientos del mundo global.

Además, que es una reforma que tiene la firme intención de poner fin a los lastres de simulación que tanto perjuicio

${ }^{19}$ Capítulo 23 Laboral en Español (T-MEC), <https://n9.cl/srgh4>.

${ }^{20}$ Diario Oficial de la Federación, 1 de mayo de 2019. 
ha causado a los trabajadores y al proceso productivo mismo, y que es el primer paso después del cual será necesario dar otros más para completar la modernización del marco normativo del trabajo.

Las reformas al texto constitucional publicadas el 24 de febrero de 2017 y a la LFT publicada el 1 de mayo de 2019 son las más importantes que se han realizado en materia laboral desde 1917. Afirmamos lo anterior porque implicaron establecer en el texto constitucional el derecho a la contratación colectiva y porque tomaron el tema de la libertad y la democracia de los trabajadores como eje fundamental para hacerlos efectivos.

Se quiere dejar claramente establecido que antes de las indicadas reformas, el sujeto implícito y en muchos casos explícitamente establecido era el sindicato, diluyéndose así los trabajadores y sus voluntades.

Con la reforma, desde el texto constitucional se establece que el Centro de Conciliación y Registro laboral:

- Debe garantizar certeza en sus resoluciones tanto conciliatorias como registrales, es decir, otorgar certidumbre a los interesados respecto del contenido y alcance de sus resoluciones.

- Que al realizar sus funciones conciliatorias y registrales, el Centro no se someterá a la voluntad de las partes o de cualquier tercero, incluso autoridad.

- Que al realizar sus funciones, el Centro lo hará en los términos que las leyes aplicables se lo ordenen, principalmente la LFT.

- Que el Centro será imparcial.

- Que el Centro, principalmente en la función conciliadora que se le encomienda, cuidará de que no se pierda la confianza como instancia que resolverá las diferencias entre las partes.

- Que el Centro demostrará ser eficaz en la solución de los conflictos de trabajo, principio que ha perdido legitimidad en las autoridades actuales. 
- Que las actuaciones del Centro, tanto conciliatorias como registrales, no dejarán duda en relación con la realidad a la que están destinadas.

- Que el trabajo que realice el personal del Centro, estará a cargo de profesionales que pongan por delante la valía de su formación.

- Que el Centro, dentro de las primeras tareas que atenderá, garantizará que a sus acciones, archivos y registros pueda acceder la persona que lo desee, sin más limitaciones que las que la información privada tiene establecidas para bien del particular.

- Que dentro de los primeros retos que el Centro atenderá estará el que todas sus acciones y resoluciones sean del conocimiento público y por las vías de acceso más eficientes.

- Adicionalmente, en la fracción XXII bis (texto nuevo en el Artículo 123 constitucional) se garantiza la libertad de negociación colectiva y los legítimos intereses de trabajadores y patrones, remitiendo a que la LFT establezca procedimientos y requisitos para garantizar, entre otros, los siguientes principios:

A. Representatividad de las organizaciones sindicales, es decir, que los trabajadores sean verdaderamente representados por los sindicatos terminando con el sindicalismo fraudulento que a la fecha existe.

B. Certeza en la firma, registro y depósito de los contratos colectivos de trabajo. Terminando así con los contratos colectivos de protección patronal y su contraparte, las "huelgas locas".

- Asimismo, establece que el voto de los trabajadores deberá ser personal, libre y secreto para resolver conflictos entre sindicatos, para la solicitud de celebración de un contrato colectivo de trabajo y para la elección de sus dirigentes.

En congruencia con lo anterior y dejando precisado que el voto para la elección de las representaciones sindicales debe 
ser personal, libre y secreto, la Constitución consigna que los estatutos sindicales podrán, de conformidad con lo dispuesto en la ley, fijar modalidades aplicables a los respectivos procesos de elección de sus direcciones.

Así, acatando el mandato constitucional se reformó la $\mathrm{LFT}^{21}$ para establecer:

a) Registro sindical (Art. 364 bis). Que en el registro de los sindicatos y actualización de sus directivas se deberán observar los principios de legalidad, transparencia, certeza, gratuidad, inmediatez, imparcialidad y respeto a la libertad sindical y sus garantías.

b) Verificación por parte del Centro Federal de Conciliación y Registro Laboral del cumplimiento de las disposiciones estatutarias en materia de elección de la directiva sindical y del cumplimiento de los principios de libertad y democracia sindical (Art. 371 bis).

c) Constancia de representatividad para dar cumplimiento a los principios de representatividad y de certeza a la firma de un contrato colectivo nuevo (Art. 387).

d) Procedimiento para obtener la Constancia de Representatividad para la firma de un contrato colectivo inicial a fin de garantizar los principios de representatividad en las organizaciones sindicales y certeza en la firma, registro y depósito de los contratos colectivos de trabajo (Art. 390 bis).

e) Naturaleza, competencia, lineamientos y principios para los Centros de Conciliación de las Entidades Federativas. Observándose los principios de certeza, independencia, legalidad, imparcialidad, igualdad, confiabilidad, eficacia, objetividad, profesionalismo, transparencia y publicidad (Art. 590 F).

f) Competencia (integración) del Poder Judicial de la Federación y de los Tribunales de las Entidades Federativas, y los principios que deben observar de legalidad, imparcialidad, transparencia, autonomía e independencia (Art. 604).

${ }^{21}$ Diario Oficial de la Federación, 1 de mayo de 2019. 
g) Obligaciones especiales y principios que deben acatar los conciliadores: los principios de conciliación, imparcialidad, neutralidad, flexibilidad, legalidad, equidad, buena fe, información, honestidad y confidencialidad (Art. $684 \mathrm{H}$ ).

h) Selección de conciliadores y garantía de cumplimiento de los principios de conciliación (Art. $684 \mathrm{~L}$ ).

i) Garantía del cumplimiento de los principios de legalidad, imparcialidad, calidad, objetividad, certeza, equidad, competencia por mérito, publicidad y transparencia en la selección de conciliadores (Art. $684 \mathrm{R}$ ).

j) El procedimiento laboral (los juicios), se regirá bajo los principios de inmediación, inmediatez, continuidad, celeridad, veracidad, concentración, economía y sencillez procesal. Será público, gratuito, predominantemente oral y conciliatorio (Art. 685).

k) El juez deberá atender al principio de realidad sobre los elementos formales que lo contradigan. Asimismo, se privilegiará la solución del conflicto sobre los formalismos procedimentales, sin afectar el debido proceso y los fines del derecho del trabajo (Art. 685).

1) En el desahogo de la testimonial, el tribunal implementará los sistemas que considere necesarios para dejar constancia del desarrollo de la audiencia, privilegiando los principios de inmediatez, concentración y celeridad procesal (Art. 815 VII).

m) Hay presunción legal cuando la Ley la establece expresamente o cuando se deriven de la aplicación de alguno de los principios que rigen el derecho del trabajo (Art. 831).

\section{A MANERA DE CONCLUSIÓN}

Es cierto que se dio un paso importante con la reforma constitucional de 2017 y la reglamentaria de 2019, pero tomará bastante tiempo para que sea efectiva una vez que la adopten los 
trabajadores; tal y como se mencionaba al inicio de este texto, las características de las relaciones obrero-patronales incluso ya son consideradas un rasgo cultural y, por tanto, de difícil transformación.

Como se pudo observar, los cambios en la normatividad laboral se dieron en gran medida como consecuencia de la presión internacional. Las estructuras normativas que van contra grupos cuyos intereses están enquistados en la estructura del sistema político y solo se han logrado abrir cuando México tiene interés en formar parte de un acuerdo supranacional de carácter económico. Pareciera ser que la medida más efectiva para hacer valer la legislación laboral será, al menos en el corto plazo, la presión a través de mecanismos internacionales de vigilancia y si queremos ver el fenómeno de manera positiva, en la etapa que actualmente vive el capitalismo, el mercado de trabajo se internacionaliza, pero también vemos esa posibilidad de proceso de los derechos de los trabajadores y las organizaciones sindicales.

Una de las preguntas que surgen al analizar la dramática estabilidad de la normatividad laboral, a pesar del creciente debate académico y público respecto de la pobreza y la desigualdad, es por qué México sigue siendo un país que no apuesta por la inspección laboral como un mecanismo para hacer efectiva la normatividad laboral. Los siguientes pasos de un gobierno que pretenda ser reivindicador de los derechos de los trabajadores deberán responder a esta pregunta.

\section{REFERENCIAS}

Bensusán, Graciela [2000], El modelo mexicano de regulación laboral, México, Universidad Autónoma Metropolitana, Fundación Friedrich Ebert, Flacso, Plaza y Valdez.

DE Buen Lozano, Néstor [2001], "Prólogo a cambio de una aportación no hecha”, Democracia Sindical, México, Instituto de Investigaciones Económicas, UNAM. 
BuRgOA, Francisco [2012], "La iniciativa preferente, ¿oxígeno ante la falta de acuerdos?", Expansión, México.

Calva, José Luis [2000], México más allá del neoliberalismo. Opciones dentro del cambio global, México, Plaza \& Janés. Claude, George [2005], Historia del pensamiento administrativo, México, Pearson Prentice Hall.

Confederación Sindical Internacional et al. [2016], La violación del derecho de la libertad sindical y la negociación colectiva en México, <https://n9.cl/qldr>.

Consejo de Administración [2011], Actas de la $310^{a}$ reunión del Consejo de Administración de la Oficina Internacional del Trabajo, Suiza, Organización Internacional del Trabajo, $<$ https://n9.cl/gp2no>.

Consejo Económico y Social [2016], Examen de los informes presentados por los Estados partes en virtud de los artículos 16 y 17 del Pacto Internacional de Derechos Económicos, Sociales y Culturales, Organización de las Naciones Unidas, <https://n9.cl/6uzgb>.

[2009], Examen de los informes presentados por los Estados partes de conformidad con los artículos 16 y $17 \mathrm{del}$ pacto. Observaciones finales del Comité de Derechos Económicos, Sociales y Culturales, Organización de las Naciones Unidas, <https://n9.cl/oa5if>.

ERMidA, Óscar [1999], "Globalización y relaciones laborales", Las relaciones de trabajo en el Siglo XXI, III Congreso Regional de las Américas, Lima.

Escalante, Fernando [2017], Senderos que se bifurcan. Reflexiones sobre neoliberalismo y democracia, México, Instituto Nacional Electoral, Conferencias Magistrales, núm. 28.

Garza Toledo, Enrique de la [2012], "La subcontratación y la crisis capitalista", Revista Trabajo, México, Organización Internacional del Trabajo, núm. 9.

[2006], "Corporativismo sindical y modelo neoliberal en México", México en transición: globalismo neoliberal, 
Estado y sociedad civil, México, Cámara de Diputados, LIX Legislatura.

GonZÁlez, Susana [2014], "Millonarios responsables de la crisis de 2008-09 incrementaron más su riqueza", La Jorna$d a$, México, 6 de abril, <https://n9.cl/h0kx>.

GRUPO PARLAMENTARIO DEL PRD [2003], Una reforma democrática para el mundo del trabajo, México, Cámara de Diputados del Congreso de la Unión-LVIII Legislatura, <https:// n9.cl/ts8e>.

LaÑas, Sergio y José Alfonso Bouzas [2010], "El trabajo desde el punto de vista de la organización", en José Alfonso Bouzas (coord.), Perspectivas del Trabajo en México, México, Instituto de Investigaciones Económicas, UNAM, <https:// n9.cl/qwjz2>

LÓYZAGA, Octavio et al. [1996], Legislación laboral: El debate sobre una propuesta, México, Universidad Autónoma Metropolitana, Fundación Friederich Ebert.

OfFe, Claus [1991], Contradicciones en el Estado del Bienestar, México, Alianza.

onU [s/f], Protocolo Facultativo del Pacto Internacional de Derechos Económicos, Sociales y Culturales, Oficina del Alto Comisionado de Naciones Unidas, <https://n9.cl/xg5nd>.

VILLARREAL, René y Rocío de Villarreal [1977], La apertura de México y la paradoja de la competitividad: hacia un modelo de competitividad sistémica, México, Océano.

WALLERSTEIN, Immanuel [2015], ¿Tiene futuro el capitalismo?, México, Siglo xxi Editores. 


\title{
EMPLEO BECENTE DIGNOY SALARIO JUSTO EN EL CRECIMIENTO DE LA PRODUCTIVIDAD LABORAL EN MÉXICO
}

\author{
Andrés Blancas* \\ Rodrigo Aliphat **
}

Es axiomático que los pueblos no prosperan sino cuando la generalidad de los ciudadanos disfruta de siquiera relativa prosperidad.

Ricardo Flores Magón, 1906

\section{INTRODUCCIÓN}

Después de 36 años de un régimen neoliberal, México se enfrenta a fuertes problemas económicos y sociales que el nuevo gobierno de la Cuarta Transformación (4T) está tratando de resolver a partir de una estrategia diferente de combate a la corrupción y un Estado promotor del desarrollo cuyo objetivo es la transformación del país hacia una economía moral orientada al bienestar.

Ante la necesidad de una nueva política productiva encaminada a apoyar la economía popular, aumentar la competitividad con el exterior y fortalecer tanto las actividades productivas como al mercado interno [López-Obrador, 2019], resulta necesario establecer políticas públicas e instituciones dirigidas a promover el desarrollo del bienestar entre toda la población. Este documento relaciona la importancia de promover el bienestar en lo laboral con el crecimiento de la productividad por trabajador.

* Investigador del Instituto de Investigaciones Económicas, UNAM. Correo electrónico: <neria@unam.mx>.

** Doctorante del Instituto de Investigaciones Económicas, UNAM. Correo electrónico:<raliphat@hotmail.com>. 
Se toma como premisa que una de las causas que han limitado el crecimiento de la productividad laboral es precisamente la precarización del empleo en México [Levine, 1995; Casanueva y Rodríguez, 2009; Blinder, 2011]; en sexenios anteriores, se consideró a la base trabajadora como un factor productivo más y no como el agente económico detonador del crecimiento de la productividad y la innovación [Espinosa, 2012; Brown, Domínguez y Mertens, 2007; Salazar y Azamar, 2014; Orozco y Magallón, 2013; Samaniego, 2010]. La precarización del empleo es un reflejo de la injusticia social y al revertir esta condición en el trabajo se contribuye al mejoramiento del bienestar laboral [Sen, 2009]; conviene señalar que la atención a la precarización del empleo corresponde simultáneamente tanto a las políticas públicas como al desarrollo y la democratización de las instituciones vinculadas con el empleo, como los sindicatos, los cuales históricamente han luchado por el mejoramiento de las condiciones laborales y salariales de los trabajadores en México.

El presente documento se divide en cuatro secciones adicionales a la introducción y las conclusiones. En la primera, se define el concepto de bienestar laboral y su relación con el crecimiento de la productividad laboral; la segunda sección presenta los hechos estilizados sobre la situación del empleo y el bienestar laboral en México; en la tercera, la productividad laboral se descompone a partir del planteamiento de Reati [2001] entre la atribuida a la eficiencia en el uso del capital y la propiciada por el simple incremento de la relación capital-trabajo. Por último, en la cuarta sección se presenta un planteamiento de lo que podría ser una propuesta de política pública encaminada a generar una sinergia positiva entre bienestar y productividad laboral.

Entre las principales conclusiones se demuestra que el crecimiento de la productividad laboral se encuentra por debajo de su potencial debido a la falta de condiciones de bienestar laboral y es posible alinear con el Plan Nacional de Desarrollo 2019 a 2024 [Gobierno de México, 2019] una estrategia de política pública encaminada a promover el bienestar laboral de 
los trabajadores mexicanos con efectos positivos sobre la productividad laboral. Cabe señalar que los objetivos de una propuesta encaminada a mejorar el bienestar laboral coinciden con el Objetivo del Desarrollo Sostenible 8, Trabajo Decente y Crecimiento Económico [NU, 2019].

\section{BIENESTAR Y PRODUCTIVIDAD LABORAL}

Para entender la relación entre bienestar y productividad laboral es necesario definir ambos conceptos. Ryff [1989] describe el bienestar como un ideal que da sentido y dirección a la vida de un individuo. Además, el bienestar subjetivo se conforma esencialmente de tres aspectos: 1) el afecto positivo; 2) la ausencia de afecto negativo; y 3) la satisfacción de vida [Diener, Suh, Lucas y Smith, 1999]. Combinando esta definición con el concepto de bienestar laboral, que para Baptiste [2009] se entiende en términos de condiciones materiales y experiencias en el trabajo, puede concluirse que el bienestar laboral se compone de cuatro condiciones que deben preexistir en el trabajo: superación personal, experiencias positivas, ausencia de experiencias negativas y un salario justo (figura 1).

Figura 1. Bienestar laboral y sus componentes

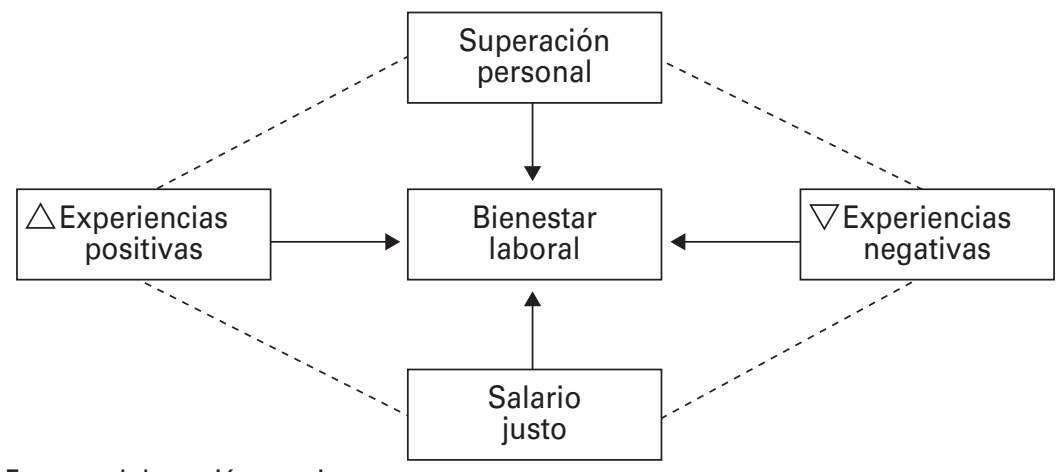

Fuente: elaboración propia. 
El concepto de superación personal se relaciona con el desarrollo por parte del trabajador de habilidades y capacidades técnicas que se encuentren estrechamente ligadas con sus actividades laborales. En la medida que el trabajador mejora su desempeño, el proceso de producción avanza en su curva de aprendizaje y se vuelve más eficiente. Lo anterior se traduce en una mayor productividad laboral para la empresa y en un sentimiento de superación en el empleado [Siliceo, 2006].

Las experiencias positivas en el trabajo están conformadas por diversos aspectos, como un ambiente laboral sano dentro del cual se desarrollen valores de respeto, empatía y tolerancia [Blanc, Boada, Garrosa y Moreno, 2010]. Además, es imprescindible garantizar el desarrollo profesional a lo largo del periodo de vida de los trabajadores; esencialmente, cuando se cumple la relación capacitación-eficiencia-crecimiento, el empleado tiene incentivos para mejorar su desempeño y la cantidad de experiencias positivas en el trabajo aumenta [Hernández, Galvis y Narváez, 2003]. De acuerdo con Salazar, Guerrero, Machado y Cañedo [2009], un buen clima y cultura organizacional tiene efectos positivos en la productividad laboral. Valencia, Broncano y Andres [2013] añaden que los espacios laborales óptimos contribuyen a la formación de capital humano.

Las experiencias negativas se refieren a aquellas que generan algún tipo de frustración en y entre los empleados; en este sentido, la ausencia de incentivos para el personal calificado y la falta de desarrollo entre los trabajadores más eficientes fomenta escenarios de frustración que con el tiempo propician la renuncia del personal capacitado, trabajadores poco eficientes o con rendimiento por debajo de su potencial e incluso situaciones en que los empleados no comparten opiniones que podrían mejorar los procesos productivos [Ccollana, 2015]. Por otra parte, al igual que un ambiente laboral sano genera experiencias positivas, también inhibe las conductas que causan malestar o molestias entre los trabajadores. 
Sobre salario justo conviene establecer una diferenciación respecto del salario mínimo: un salario justo permite al trabajador cubrir las necesidades económicas del hogar (Objetivo de Desarrollo Sostenible [oDs] 1), ${ }^{1}$ de tal forma que sus gastos no representen necesariamente un problema de fondo en su día a día. Por otra parte, si los ingresos del trabajador están asociados con su desempeño laboral, entonces la relación entre superación personal-eficiencia laboral-experiencias positivas tendrá un efecto en el ingreso de los trabajadores, construyéndose un círculo virtuoso que da lugar a las características descritas como bienestar laboral. En México, aunque existe una relación de largo plazo entre salarios y productividad, los hechos también demuestran que en el corto plazo esta relación es poco significativa [Rodríguez y Castillo, 2009].

En la medida que se van consolidando los aspectos nodales del bienestar laboral se logra una sinergia positiva llamada bienestar productivo sostenible [Peiró et al., 2014]. Esta sinergia consiste en generar espacios laborales donde los trabajadores felices tienen altos niveles de desempeño laboral y hacen a las organizaciones más competitivas. Además, tiene efectos positivos en la innovación y mejora de los procesos productivos.

En la relación entre bienestar-desempeño laboral pueden darse cuatro relaciones: alto bienestar laboral con alto (B) o bajo (A) desempeño laboral, o bajo bienestar laboral con alto (D) o bajo (C) desempeño laboral (figura 2).

Figura 2. Interacciones básicas entre bienestar y desempeño laboral

\begin{tabular}{llll}
\hline \multirow{2}{*}{ Bienestar laboral } & + & A & B \\
\cline { 2 - 4 } & - & C & D \\
\hline & & - & + \\
\cline { 2 - 3 } & & Desempeño laboral \\
\hline
\end{tabular}

Fuente: recuperado de Peiró et al. [2014: 11].

${ }^{1}$ oDs Erradicar la pobreza, meta: garantizar que todos los hombres y mujeres, en particular los pobres y los vulnerables, tengan los mismos derechos a los recursos económicos [NU, 2019]. 
La combinación ideal para una economía se encuentra en el recuadro B (alto niveles de bienestar y desempeño laboral); de acuerdo con trabajos de Salazar, Guerrero, Machado y Cañedo [2009] en esta interacción se da una relación de largo plazo enmarcada en la idea de las sinergias del bienestar productivo sostenible y representa el objetivo de política pública en materia de bienestar laboral integral. Alcanzar esta interacción representa lograr el Objetivo de Desarrollo Sostenible 8, Trabajo decente y crecimiento económico.

El recuadro C, bajo bienestar y bajo desempeño laboral, representa la combinación que requiere atención inmediata. Conviene señalar que en esta categoría podrían encontrarse los empleos denominados outsourcing, por honorarios y de confianza, que en México representan a $17 \%$ de la población ocupada total; ${ }^{2}$ este tipo de contratación se considera empleo formal con reducidas prestaciones laborales y bajas expectativas de crecimiento [Fuentes, 2015]. Por poner un ejemplo, suelen ser empleos subrogados en los que el trabajador es dependiente de una tercera empresa y es excluido de los beneficios o incentivos que la empresa donde labora otorga a sus empleados directos. El escenario descrito crea experiencias negativas en el trabajador, lo que lo aleja del planteamiento de bienestar laboral; este fenómeno observado para México se replica en toda Latinoamérica [Fernández y Sotelo, 2013].

Las empresas de outsourcing ${ }^{3}$ se caracterizan por una extrema precarización de las condiciones laborales y en muchos casos evaden el pago de las prestaciones sociales ya descontadas a sus trabajadores. Si bien el outsourcing permite aumentar el

${ }^{2}$ Censo Económico 2018 [Inegi, 2019].

${ }^{3} \mathrm{El}$ outsorcing se considera una forma de subcontratación, externalización o terciarización que se entiende como un proceso en el que una empresa, a través de un contrato de prestación de servicios, transfiere a la empresa subcontratante las funciones laborales administrativas y operacionales para que esta las realice [García, Fuentes, Silva y Flores, 2014]. 
empleo e incrementar los rendimientos de las empresas, en el conjunto de la economía causa pérdidas de bienestar social, inhibe el crecimiento de los salarios y fomenta menores niveles de productividad. En términos de bienestar social y salarios, las empresas de outsourcing promueven un tipo de subcontratación abusiva, sin prestaciones sociales, remuneración en términos reales por debajo del salario mínimo y jornadas de trabajo extensas [Vela, Moreno y Aguilar, 2015], y claramente incentivan el empleo informal. Lo anterior lleva a que los trabajadores se encuentren en una situación de injusticia que genera desigualdad económica y malestar social, y atenta de manera evidente contra los derechos laborales.

La interacción bajo bienestar laboral y alto desempleo laboral (D) se considera un escenario temporal, en el que eventualmente el trabajador disminuye su desempeño o busca otras opciones laborales; además, en este escenario se reduce la posibilidad de innovar. Esta interacción también forma parte de la población objetivo de la propuesta de política pública debido a la existencia de un alto potencial para el crecimiento de la producción y la innovación, mismos que podrían detonarse bajo ciertas intervenciones en materia de bienestar laboral.

El bienestar laboral tiene un efecto sobre la productividad que no necesariamente está ligado con la implementación de políticas públicas; los trabajadores tienen la capacidad de influir sobre su productividad a través de su poder de negociación, mediante sus organizaciones sindicales [Salazar y Saldaña, 2018]. En escenarios de bajo bienestar laboral y alta productividad (D) se hace necesaria la democratización o intervención de las instituciones sindicales, toda vez que los trabajadores ven precarizadas sus condiciones laborales al tiempo que su productividad se incrementa. Por otra parte, escenarios de alto bienestar laboral y baja productividad (A) ponen en evidencia un sobreaprovechamiento del poder de negociación de los sindicatos que lleva a las empresas a pérdidas de competitividad. En ambos casos, se requiere la 
intervención de instituciones mediadoras que corrijan ambas situaciones de injusticia social.

\section{EMPleO, SAlARIO y BIENESTAR LABORAL EN MÉXICO}

El empleo digno y el salario justo forman parte de los "derechos humanos laborales" [CNDH, 2016], los cuales se han desarrollado a través de la historia del capitalismo, desde la Revolución Industrial hasta los derechos sociales expuestos en la Constitución Mexicana de 1917. Estos derechos humanos laborales o "justicia del trabajo" se vinculan con un salario justo o bien remunerado, con la seguridad social, con el derecho a la permanencia en un empleo y a ser indemnizado en caso de despido injusto, con una vivienda digna, con la capacitación y el adiestramiento, con una jornada máxima laboral, el reparto de utilidades y el derecho a la asociación profesional [CNDH, 2016]. El Artículo 123 de la Constitución Política de los Estados Unidos Mexicanos (CPEUM) garantiza el derecho al trabajo y en su primer párrafo indica: "Toda persona tiene derecho al trabajo digno y socialmente útil; al efecto se promoverán la creación de empleos y la organización social para el trabajo, conforme a la ley" [CPEUM, 2020]. Sin embargo, como se podrá observar a continuación, las condiciones laborales y salariales en México distan mucho de corresponder a los derechos humanos laborales de los habitantes del país.

A pesar de ser integrante de la ocDE, México aún presenta características de economía emergente al registrar malas condiciones de bienestar laboral que es desigual al promedio de los integrantes de este organismo internacional. El índice para una vida mejor de la OCDE [2017] permite comparar el nivel de bienestar en distintos países con base en 11 temas que ha identificado como esenciales para las condiciones de vida materiales y la calidad de vida; en 2015, la esperanza de vida en México fue menor en cinco años que la del promedio de la 
OCDE, que es de 80 años, mientras que $66 \%$ de la población adulta se consideró con buena o muy buena salud; en cuanto a la vivienda, en sus tres indicadores (habitación por persona, acceso a la vivienda y servicios básicos) se ubica por debajo del promedio de la ocDE.

En México, la productividad y las condiciones sociales de los trabajadores están por debajo del promedio de los países de la OCDE. En términos de ganancias por trabajador, un empleado mexicano genera alrededor de 15000 dólares (purchasing power parity, PPP), mientras que en la OCDE el promedio es de 44000 dólares; esta diferencia coincide con las brechas laborales existentes. Por ejemplo, el ingreso promedio de los hogares es, en promedio, del doble en los países de la OCDE respecto de México; además, en términos de personal calificado solo 37\% de los trabajadores mexicanos tienen educación secundaria superior, porcentaje 30 puntos por debajo de la oCDE. Con respecto al bienestar laboral, los trabajadores en México tienen mayor estrés laboral y cerca de $29 \%$ de ellos trabaja jornadas laborales superiores a las 50 horas semanales; ambos indicadores se encuentran por encima de los promedios de la OCDE. Con los datos mencionados, se comprueba que el bienestar laboral y la productividad de los empleos en México están por debajo de la media de los países de la ocDE (cuadro 1).

\section{Situación del empleo y el salario en México}

$\mathrm{Al}$ analizar los datos más recientes del Censo Económico [Inegi, 2019] puede observarse una alta concentración del empleo en las principales ciudades del país. El personal ocupado en México es de 35 millones de personas, equivalente a $28 \%$ de la población total: $92 \%$ del personal ocupado se encuentra en zonas urbanas y $6.7 \%$ en zonas rurales; $35 \%$ de los trabajadores se localiza en la Ciudad de México (cDmx), Estado de México, Jalisco y Nuevo León, las cuatro entidades económicamente 
Cuadro 1. Índice de bienestar de la OCDE

\begin{tabular}{lrr}
\hline \multicolumn{1}{c}{ Variable } & OCDE & México \\
\hline $\begin{array}{l}\text { Ganancias brutas anuales promedio por empleado a } \\
\text { tiempo completo (USD PPP 2016) }\end{array}$ & 44290 & 15311 \\
Ingreso disponible ajustado neto de los hogares (USD & 30620 & 13891 \\
PPP per cápita 2015) & 80 & 75 \\
Esperanza de vida (2015) & 69 & 66 \\
Salud percibida (2015) & 67 & 61 \\
Tasa de empleo (2016) & 37 & 43 \\
Tensión laboral (2015) & 67 & 37 \\
Porcentaje de personas de 25 a 64 años con al menos & & \\
una educación secundaria superior (2016) & 13 & 30 \\
Porcentaje de empleados que suelen trabajar 50 & 19 & 21 \\
horas o más por semana (2015) & 7 & 8 \\
Acceso a la vivienda (2015) & 5 & 5 \\
Satisfacción ante la vida (2013) & 2 & 4 \\
Inseguridad del mercado laboral (2015) & 2 & 1 \\
Servicios básicos (2015) & 2 & 0.1 \\
\hline Habitaciones por persona (2015) & & \\
Tasa de desempleo a largo plazo (2015) & & \\
\hline
\end{tabular}

Fuente: elaboración propia con datos de OCDE [2017].

más importantes del país y que generan alrededor de $40 \%$ del PIB nacional. Por actividad económica, los servicios y las manufacturas concentran el empleo en México: 36\% de los trabajadores se concentra en servicios, $28 \%$ en comercio, $25 \%$ en actividades manufactureras y $11 \%$ de los trabajadores totales se encuentra en el resto de actividades económicas.

Para centrar el análisis en la situación laboral en México, la gráfica 1 muestra la situación del desempleo y de la población económicamente activa; es decir, los mexicanos que 
tienen o debieran tener derechos humanos laborales han presentado una tendencia creciente de 43 millones en 2005 a casi 57 millones de mexicanos en 2019. En este periodo, la tasa de desempleo ha mostrado una trayectoria cíclica ascendente con el valor más bajo del ciclo en 2005 , de $3.5 \%$, que llega a la parte más alta de su trayectoria en la crisis de 2008 a 2009 con un valor de 5.3\%; a continuación inicia otro ciclo con una tendencia más o menos descendente, hasta llegar a 3.3\% en 2018 e iniciar un ascenso en 2019 a $3.5 \%$, que puede explicarse por la caída de la actividad económica en este año o más específicamente por el decremento de la inversión. Al observar que la población económicamente activa (PEA) ha crecido en los últimos 11 años y que la tasa de desempleo se ha reducido, puede intuirse que en México no necesariamente hay un problema en la demanda de empleo sino en la calidad de los puestos de trabajos ofrecidos por parte de las empresas (cuadro 1).

\section{Gráfica 1. Población económica activa y tasa de desempleo en México}

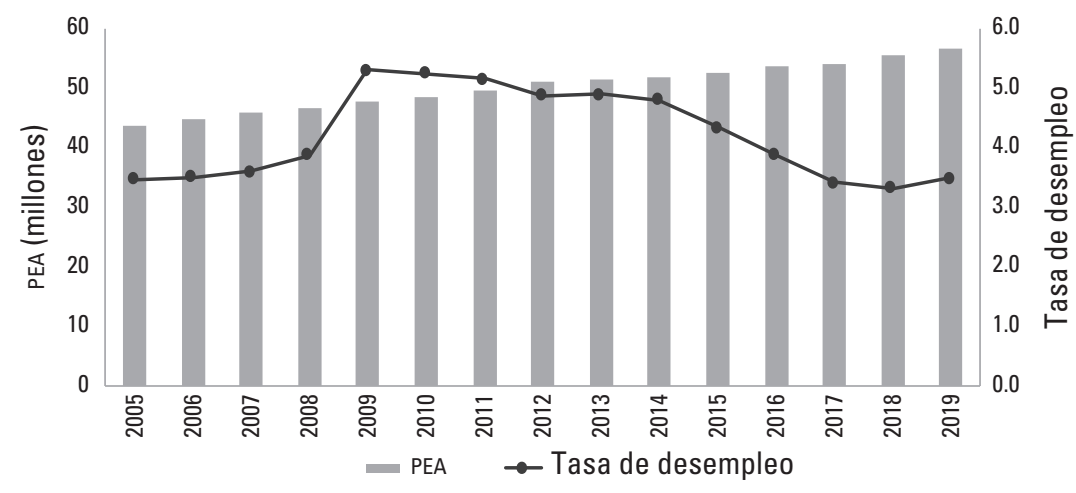

Fuente: elaboración propia con datos de Inegi [2020a].

La tasa de desocupación por entidad federativa (gráfica 2) refleja algún grado de heterogeneidad en el desempleo. Destacan los casos de: 1) Tabasco, que ocupa el $5^{\circ}$ lugar en la 
producción total del país con 5.3\% del PIB nacional y presentó la tasa más alta de desempleo (7.1\%) como porcentaje de la PEA, probablemente asociada con la menor actividad petrolera en esta entidad; 2) y entidades de gran importancia económica como la CDMx, que produce $17.3 \%$ del PIB nacional y presenta la segunda tasa más alta de desempleo (5\%); 3) seguida por el Estado de México, que produce 9.1\% del PIB nacional, con una tasa de desempleo de 4.6\%. Tabasco, cDMx y Estado de México son los estados con mayor tasa de desempleo. Por otra parte, Yucatán, Oaxaca y Guerrero tienen el menor nivel de desempleo, según datos de la Encuestas Nacional de Ocupación y Desempleo [Inegi, 2020a]. Estas cifras contrastan con la percepción común de la situación del empleo en México; bajo las condiciones socioeconómicas del sur del país, se podría suponer que en esta región una mayor cantidad de PEA se encontraría desempleada. Por otra parte, es importante considerar que una baja tasa de desempleo no necesariamente está

\section{Gráfica 2. Tasa de desocupación total por entidad federativa en 2019 (porcentaje con respecto a la PEA)}

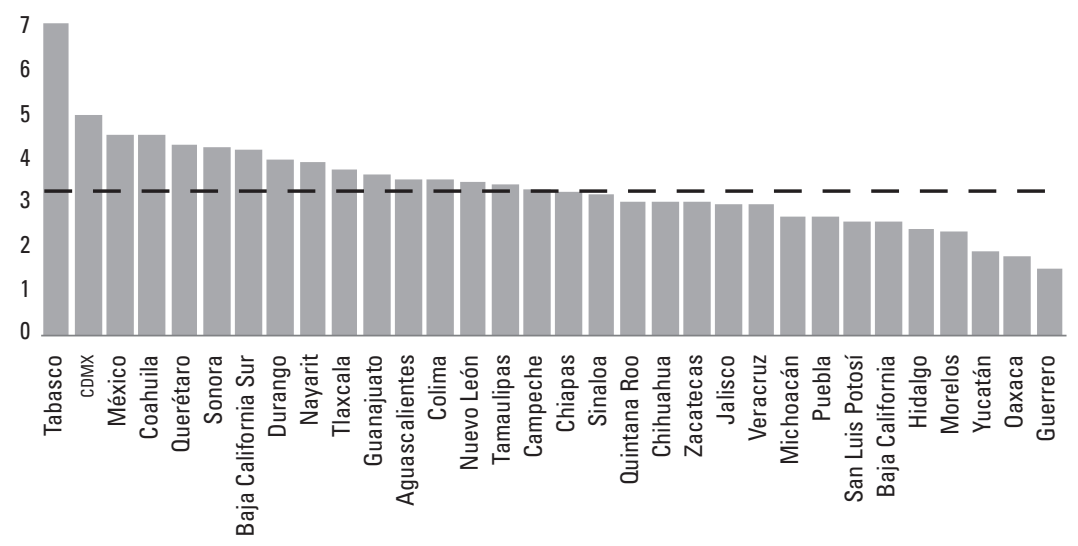

Fuente: elaboración propia con datos de Inegi [2020a]. 
relacionada con mejores salarios; de acuerdo con Lewis [1954], los salarios en economías emergentes solo crecerán cuando sus industrias se especialicen en actividades intensivas en capital y no en mano de obra.

\section{Bienestar laboral}

El patrón de comportamiento del desempleo, el empleo informal y las condiciones críticas de ocupación en el ámbito regional determinan la precariedad y la injusticia en las remuneraciones salariales y de ingresos de los trabajadores. En relación con las condicionales laborales, en México $17 \%$ del personal ocupado total se encuentra bajo el esquema de contratación por outsourcing, lo que representa $25 \%$ más con respecto al dato observado para 2009; la banca múltiple, conformada por 37 unidades económicas, es la actividad económica con mayor porcentaje de personal contratado por outsourcing, ya que $30 \%$ de su personal ocupado total se encuentra bajo ese esquema de contratación [Inegi, 2019].

A nivel nacional, el ingreso laboral se mantiene en niveles similares a los reportados en 2005; a pesar de que la tasa de desempleo se redujo, el salario real no se ha incrementado. El mismo hecho se observa para el indicador de pobreza laboral [Coneval, 2020], el cual, aunque desde 2013 ha ido a la baja, aún no recupera sus niveles de 2005 (gráfica 3). Ambos indicadores son muestra de una tendencia a la precarización del empleo y, como se plantea en la figura 1, tienen un efecto negativo sobre el bienestar laboral. El índice de la tendencia laboral de la pobreza (ITLP) y el ingreso laboral han presentado trayectorias opuestas desde el primer trimestre de 2005 hasta el último de 2019; estas trayectorias opuestas muestran tres puntos donde los dos indicadores se cruzan: uno durante la crisis de 2008 a 2009 y otros dos durante el cambio de gobierno en 2018 a 2019. 
Gráfica 3. Comportamiento de las condiciones laborales en México: índice de la tendencia laboral de la pobreza (ITLP) e ingreso laboral*

2005 a 2019

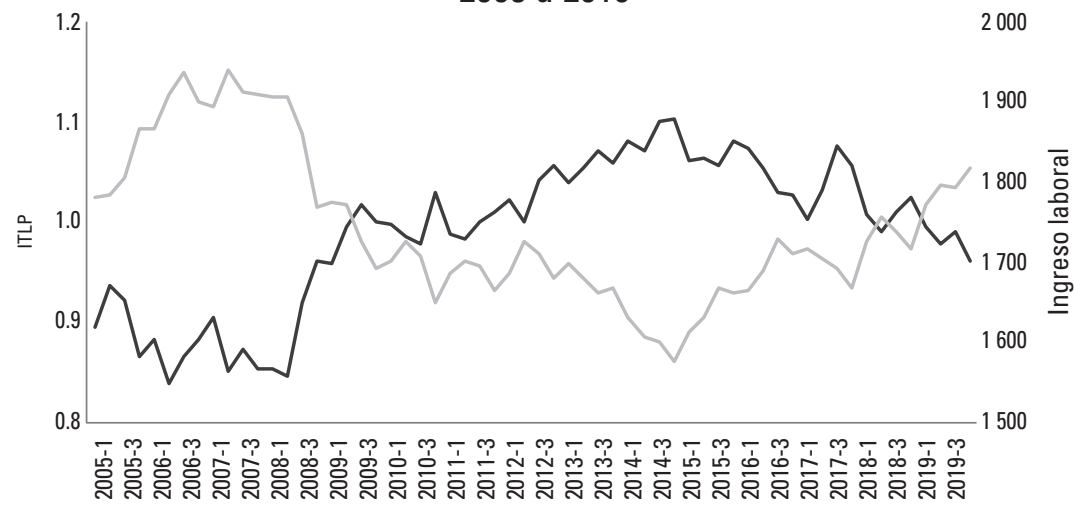

—ITLP_Ingreso laboral

* Ingreso laboral a precios constantes de 2010.

Fuente: elaboración propia con datos de Coneval [2020].

El ITPL inicia una trayectoria creciente en 2005 hasta alcanzar el valor más alto de todo el periodo, de 1.1, en 2014, lo cual puede asociarse con los mayores efectos de precariedad laboral de las políticas neoliberales en materia laboral, como la reforma laboral de noviembre de 2012 [Quiñones y Rodríguez, 2015]. En este año también se presenta el menor nivel del ingreso laboral (1 576 pesos) para el cuarto trimestre de 2014. Asimismo se observa que a partir del nuevo gobierno de la 4T, el ITPL ha mostrado un descenso importante por debajo del valor unitario hasta llegar a 0.96 al último trimestre de 2019; esto se puede relacionarse con las reformas secundarias en materia de justicia laboral y democracia sindical de mayo de 2019, hechas con el objeto de dar cumplimiento al Artículo 123 constitucional.

El ingreso laboral, por otra parte, ha continuado aumentando hasta llegar a 1820 pesos al cuarto trimestre de 2019 . 
Así, de acuerdo con el Coneval [2020], el porcentaje de población con ingreso laboral inferior al costo de la canasta alimentaria (pobreza laboral) disminuyó de $39.8 \%$ a $37.3 \%$ entre el cuarto trimestre de 2018 y el último trimestre de 2019 . El ingreso laboral real presentó un aumento de $5.9 \%$ del último trimestre de 2018 al último trimestre de 2019. Es importante destacar que el aumento del ingreso laboral entre los dos últimos trimestres de 2019 se observó principalmente en $20 \%$ de la población de menor ingreso laboral, asociado con un incremento del salario mínimo.

La gráfica 4 muestra que las condiciones laborales por entidad federativa son heterogéneas. En términos generales, destaca que más de $50 \%$ de la población ocupada se encuentra en condiciones de informalidad laboral, que en algunos estados alcanza tasas cercanas a $80 \%$. Los estados fronterizos como Coahuila, Nuevo León, Baja California (вс), BC Sur y Chihuahua tienen los menores niveles de informalidad de toda la república (gráfica 4.1). Es probable que esta situación se explique porque en los estados de sur las actividades económicas están asociadas sobre todo con el ámbito rural agropecuario y el campo, donde predomina la informalidad en el empleo y condiciones de precariedad tanto en el empleo como en las remuneraciones de los trabajadores

Con respecto a las condiciones críticas de ocupación, la región sur del país tiene los indicadores más altos. En Chiapas cerca de $40 \%$ de los trabajadores está en condiciones críticas, mientras que en Nuevo León menos de $10 \%$ se encuentra en condiciones de bajo bienestar laboral; cabe destacar que la CDMX presenta una tasa de condiciones críticas de ocupación igual a la media, que se explica por su alta tasa de informalidad (gráfica 4.2). La situación de mejor bienestar laboral en los estados fronterizos puede vincularse con el hecho de que son los estados con mayores tasas de productividad [Blancas y Aliphat, 2020]. 
Gráfica 4. Condiciones laborales por entidad federativa en 2018 4.1. Tasa de informalidad laboral*

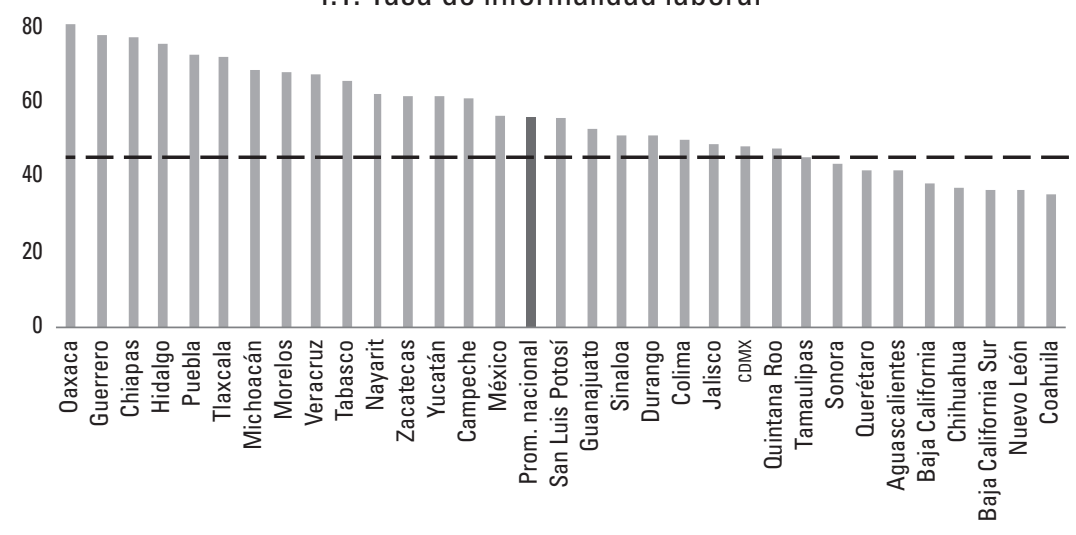

4.2. Tasa de condiciones críticas de ocupación*

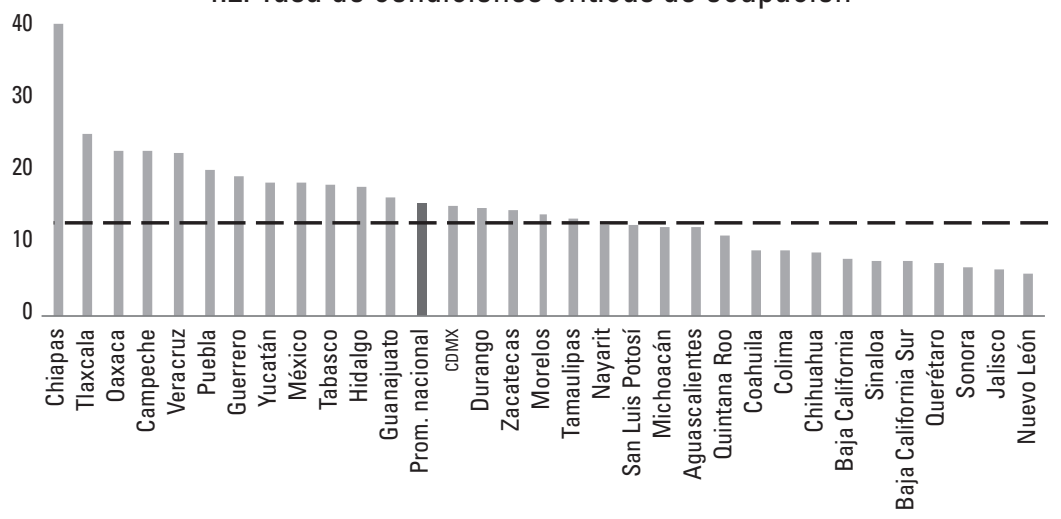

*Respecto del personal ocupado total.

Fuente: elaboración propia con datos de Inegi [2020a].

La situación de Oaxaca sobresale del resto, ya que mientas es la entidad con mayor nivel de informalidad y la tercera con mayor tasa de empleo en condiciones críticas, es también, según lo observado en la gráfica 2, la entidad con menor tasa de desempleo. Esto comprueba que si bien en Oaxaca no hay problemas de desempleo si hay fuertes problemas de bienestar laboral. 
Los datos presentados en el cuadro 1 y las gráficas 1, 2, 3 y 4 evidencian la actual precarización del empleo en México; a nivel nacional, la pobreza laboral se ha incrementado respecto de la observada en 2005. Aunque la tasa de desempleo se redujo, las condiciones del trabajo están por debajo de las condiciones medias de la OCDE. Puede concluirse que en México más de $50 \%$ de la población ocupada se encuentra en la informalidad, con $15 \%$ de los trabajadores en condiciones laborales críticas. Es decir, en México hay problemas de bienestar laboral.

Por entidad federativa, Veracruz, Chiapas y Sinaloa fueron las entidades con mayor reducción trimestral del porcentaje de población con pobreza laboral. En 7 de los 32 estados, la pobreza laboral aumentó en el último trimestre. Hidalgo, Puebla y Nayarit presentaron los mayores incrementos.

El poder adquisitivo del ingreso laboral real per cápita creció 5.9\% entre el último trimestre de 2018 y el último trimestre de 2019, al pasar de 1718 pesos a 1820 pesos. Cabe mencionar que es el máximo valor observado desde el primer trimestre de 2005, cuando inició el mayor crecimiento del periodo, y el tercer trimestre de 2008, cuando el ingreso laboral real comenzó una tendencia a la baja. Sin embargo, el ingreso laboral aún no supera el nivel más alto de todo el periodo, que fue de 1841 pesos para el segundo trimestre de 2007.

EFECTO DE LA PRECARIZACIÓN LABORAL EN LA PRODUCTIVIDAD

De acuerdo con Reati [2001] la productividad laboral puede descomponerse mediante una identidad de la siguiente manera:

$$
\frac{Y}{L}=\frac{Y}{K}{ }^{*} \frac{K}{L}
$$

Donde $K / L$ representa el crecimiento de la productividad laboral atribuido al mayor capital disponible por trabajador 
en la empresa y $Y / K$ representa el crecimiento atribuido a una mejor eficiencia en el uso del capital por parte de los trabajadores; es decir, el crecimiento de la productividad atribuido a las capacidades técnicas y el aprendizaje adquirido de los trabajadores.

En el caso de la economía mexicana, la productividad laboral de los últimos 28 años ha crecido a una tasa promedio anual de $0.94 \%$ (gráfica 5.1), mientas que la relación $Y / K$ lo hizo a una tasa negativa de -0.18 y la relación $\mathrm{K} / \mathrm{L}$ a una tasa positiva de $1.16 \%$ (gráfica 5.2). Se encuentra que el crecimiento de la productividad laboral se asocia con una mayor acumulación de capital con una eficiencia cada vez menor. Es decir, la falta de capacitación y de un espacio laboral adecuado provocó que la productividad laboral creciera por debajo de su potencial.

Los datos mencionados evidencian la necesidad de promover la formación técnica de los trabajadores; sin embargo, resulta necesario definir, al menos en una primera instancia, los sectores y las regiones o estados con mayor rezago en cuanto a la eficiencia de los trabajadores en el uso del capital (Y/K).

$\mathrm{Al}$ analizar el crecimiento acumulado de la eficiencia en el uso del capital por parte de los trabajadores, destaca que los subsectores de servicios educativos, de esparcimiento y profesionales son los que requieren atención con mayor urgencia dado que han tenido tasas de crecimiento anual de la productividad laboral de 0.8, 0.4 y $0.04 \%$, respectivamente, es decir, estos subsectores han tenido un desempeño laboral bajo; sobre manufacturas los datos revelan que la eficiencia en el uso del capital se ha reducido a una tasa anual de $0.83 \%$. Se concluye que en los subsectores mencionados la eficiencia de los trabajadores es menor ahora en comparación con 1990. En todos los casos señalados, la proporción de capital-trabajo se incrementó, por lo que se puede afirmar que la productividad laboral se encuentra por debajo de su potencial ya que la PEA no cuenta con la capacitación técnica suficiente. 
Gráfica 5. La productividad laboral en México

Gráfica 5.1. Evolución de la productividad laboral en México

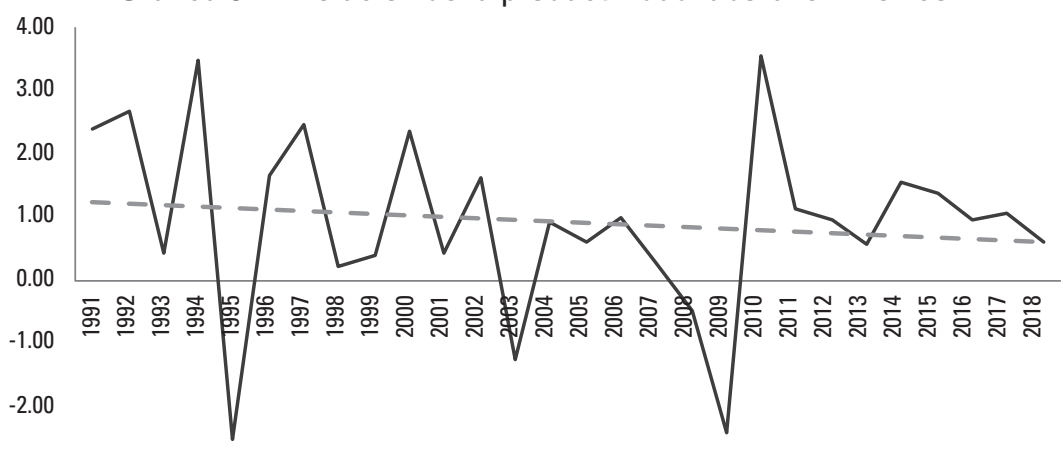

$\longrightarrow$ Y/L $\quad--\operatorname{Linear}(\mathrm{Y} / \mathrm{L})$

Gráfica 5.2. Índice de productividad laboral y su descomposición por eficiencia del capital (K/L) y relación capital trabajo (K/L) Año base $1990=100$

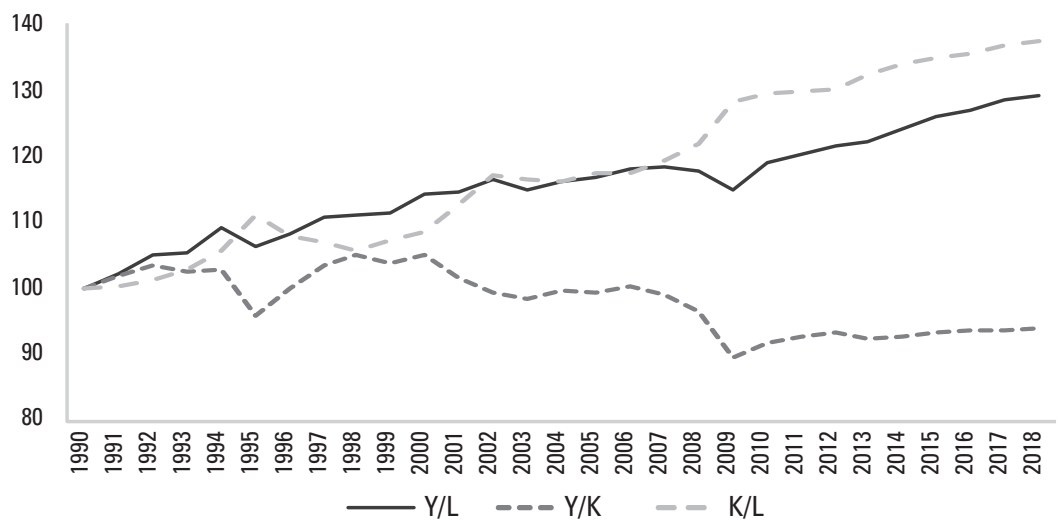

Fuente: elaboración propia con datos del proyecto KLEMS de Inegi [2020b].

Por entidad federativa, el mapa 1 da un panorama de los estados con mayor nivel de producción en las actividades consideradas prioritarias en la formación de capacidades técnicas de los trabajadores. En el caso de servicios de esparcimiento 
culturales y deportivos, y otros servicios recreativos (1a) los estados objetivo (por su nivel de producción) son Nuevo León, Baja California y Estado de México; para los servicios educativos (1b) son Estado de México, Veracruz y Jalisco; respecto de servicios profesionales, científicos y técnicos (1c) se requiere especial atención en Nuevo León, Jalisco y Estado de México. Las entidades relevantes en el sector manufacturero (1d) son el Estado de México, Nuevo León y Coahuila.

\section{Mapa 1. Distribución geográfica de la producción de subsectores de actividad económica seleccionados en 2018}

1a. Servicios de esparcimiento

1b. Servicios educativos culturales y deportivos, y otros servicios recreativos

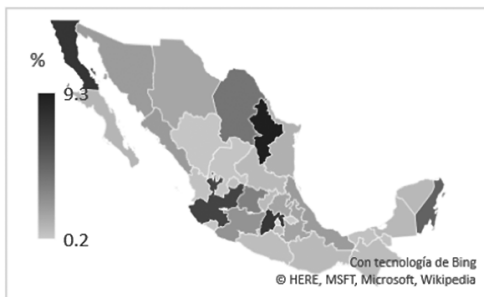

1c. Servicios profesionales, científicos y técnicos

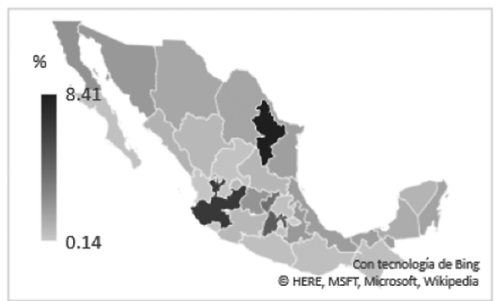

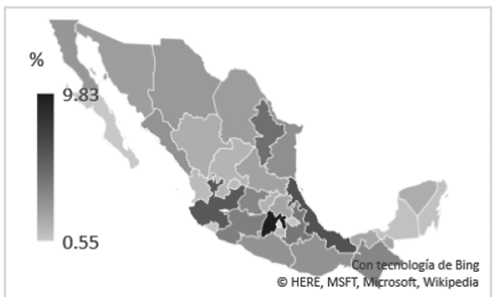

1d. Industrias manufactureras

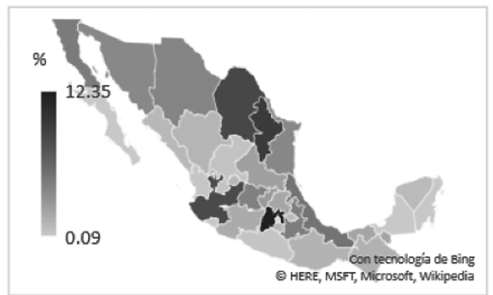

*Nota: se excluye la Ciudad de México porque concentra el mayor nivel de producción en todos los casos.

Fuente: elaboración propia con datos de Inegi [2020c]. 


\section{Propuesta de POLÍtica PÚBlica}

Ante la precarización del empleo, la pérdida de bienestar laboral y el escaso crecimiento de la productividad, es necesaria una estrategia de intervención social encaminada a dos objetivos: mejorar el ambiente laboral y aumentar las capacidades técnicas de los trabajadores, que de manera conjunta contribuyan a lograr la sinergia "bienestar laboral-productividad laboral". El derecho a un trabajo digno o decente, como un derecho humano fundamental, debe ser garantizado por el Estado, en los términos de los Artículos $1^{\circ}$ y 123 constitucionales [Quiñones y Rodríguez, 2015].

Según la definición de bienestar laboral, cuando el clima organizacional de las empresas se encuentra en armonía y hay oportunidades equitativas, se reduce la probabilidad de experiencias negativas con un efecto directo en el estado de ánimo del trabajador y en su relación con el resto de sus compañeros. Por tanto, se identifica que una meta de política pública debería ser la consolidación de un marco institucional que propicie entornos de trabajo decente en las entidades públicas y privadas ya que esto tiene un doble efecto positivo: 1) aumento del bienestar de la población, y 2) creación de las condiciones para incrementar la productividad laboral en la economía.

En una vía paralela, es urgente, de acuerdo con los datos de la gráfica 1, desarrollar las capacidades técnicas de los trabajadores porque esto tiene un efecto positivo en la superación personal de los empleados y mejora su eficiencia laboral, trayendo consigo experiencias positivas e incrementando las expectativas salariales del trabajador, mismo que, al ser un empleado especializado, tiene la capacidad de elevar la eficiencia en el uso del capital.

Al combinar ambos objetivos de política pública, se logra un escenario de bienestar laboral dentro del cual, y con base en los argumentos mencionados, se incrementarán los niveles de productividad; además, desde el punto de vista de las 
industrias y de empresa, surgen escenarios positivos para incrementar la productividad laboral y crear condiciones que propicien la innovación.

A manera de externalidades, una política pública encaminada a promover el bienestar laboral mejora la competitividad de México en la región al respetar los requerimientos y acuerdos del T-MEC, por lo que es compatible con los acuerdos y compromisos comerciales ya firmados; propicia tasas de crecimiento del PIB superiores y acerca la economía al objetivo de $4.5 \%$ anual, lo cual genera un efecto de atracción por el que la población ocupada en el sector informal tendrá incentivos para buscar trabajo en el sector formal.

\section{Conclusiones}

Con base en la evidencia presentada y considerando las condiciones de la PEA, se encuentra que en México no se cumplen los derechos humanos laborales. Asimismo, se observa que la falta de bienestar laboral, como condicionante de demanda agregada, es una de las razones que explican la falta de crecimiento de la productividad laboral mexicana.

Es importante destacar la función de los sindicatos como una institución que debe democratizarse para lograr de manera efectiva y paralela políticas públicas en favor del bienestar laboral y el salario justo. Sin embargo, la historia del sindicalismo en nuestro país se ha visto llena de casos de corrupción en la operación y dirigencia, y aunque este tema requiere una investigación aparte, cabe destacar que la democratización del sindicalismo debería ser un objetivo de política pública; los sindicatos representan la institución natural por medio de la cual los trabajadores podrían lograr el cumplimiento de sus derechos humanos laborales, lo que sin duda se traducirá en un aumento de la productividad laboral. 
Resulta importante atender la relación bienestar-productividad laboral mediante una estrategia de política pública alineada con los objetivos estratégicos de: 1) economía para el bienestar; 2) desarrollo sostenible; 3) impulsar la reactivación económica, el mercado interno y el empleo; y 4) ciencia y tecnología, con la meta de "garantizar empleo, educación, salud y bienestar" y apoyándose en los programas "Jóvenes construyendo el futuro" y "Jóvenes escribiendo el futuro", los cuales están enmarcados en el Plan Nacional de Desarrollo 2019 a 2024.

Una propuesta de política pública en materia de bienestar laboral contribuirá a mitigar la precarización del empleo; tendría la intención de fomentar el desarrollo de habilidades en los trabajadores, lo que con el tiempo se traduciría en mejores salarios. A nivel macroeconómico, tendría efectos positivos en la demanda agregada, además de crear un clima propicio para la innovación dentro de las empresas e industrias. Y aunque una propuesta como la mencionada está lejos de ser vista como la panacea sobre empleo y crecimiento económico, su carácter focalizado permite contribuir al crecimiento de la productividad laboral y competitividad global de las empresas mexicanas con bienestar para los trabajadores.

\section{REFERENCIAS}

BAptiste, N. [2009], "Fun and well-being: insights from senior managers in a local authority", Employee Relations, 31(6): 600-612.

Blanc, L., M. Boada, E. Garrosa y B. Moreno [2010], "Emociones positivas y bienestar laboral", Gestión práctica de riesgos laborales: Integración y desarrollo de la gestión de la prevención, 74(1): 22-27.

Blancas, A., y R. Aliphat [2020], "El crecimiento de la productividad total de los factores del sector manufacturero 
como estrategia de combate a la desigualdad en México", en La cuestión social en el siglo XXI, México, Siglo XXI, en prensa.

Blinder, A. S. (ed.) [2011], Paying for productivity: A look at the evidence, Estados Unidos, Brookings Institution Press, $308 \mathrm{pp}$.

Brown, F., L. Domínguez y L. Mertens [2007], "La importancia del capital social en la mejora de la productividad: el caso de la industria manufacturera mexicana”, Revista Mexicana de Sociología, 69(2): 277-308.

Casanueva, C., y C. Rodríguez [2009], "La productividad en la industria manufacturera mexicana: calidad del trabajo y capital humano", Comercio Exterior, 59(1): 16-33.

Ccollana, Y. [2015], "Rotación del personal, absentismo laboral y productividad de los trabajadores", San Martín Emprendedor, 6(2): 40-49.

CNDH [2016], Derecho humano al trabajo y derechos humanos en el trabajo, México, CNDH, 33 pp.

Coneval [2020], Medición de la pobreza en México, México, Coneval.

Constitución Política de los Estados Unidos Mexicanos (CPEUM) [2020], México, Secretaría de Gobernación.

Diener, E., E. Suh, R. Lucas y H. Smith [1999], "Subjective well-being: Three decades of progress", Psychological Bulletin, 125(2): 276-302.

ENCISO, J., y M. Juárez [2006], "Desverticalización productiva, outsourcing y efectos sobre el empleo en la relación México-Estados Unidos 1987-2003”, Aportes, 11(33): 27-36.

Espinosa, M. [2012], "Límites del Trabajo Decente: la precarización laboral como problema estructural en América Latina", Gaceta Laboral, 18(1): 87-106.

Fernández, D., y A. Sotelo [2013], "Outsourcing and the new labor precariousness in Latin America", Latin American Perspectives, 40(5): 14-26. 
Fuentes, H. [2015], "Análisis del régimen de subcontratación o outsourcing en México", Visioni LatinoAmericane, 12(1): 44-58.

García J., J. Fuentes, A. Silva y M. Flores [2014], "La subcontratación laboral, su abuso y reglamentación en México", IX Congreso Iberoamericano de Derecho del Trabajo y la Seguridad Social de la AIJDTSSGc, Asociación Iberoamericana de Juristas del Derecho del Trabajo y la Seguridad Social.

Gobierno DE MÉxico [2019], Plan Nacional de Desarrollo 20192024, México, Secretaría de Gobernación.

Hernández, G., S. Galvis y K. Narváez [2003], "Cultura organizacional y bienestar laboral”, Cuadernos de Administración, 16(25): 109-137.

INEGi [2020a], Encuesta Nacional de Ocupación y Empleo, México, Inegi.

[2020b], Sistema de Cuentas Nacionales de México. Productividad Total de los Factores Modelo KLEMS, México, Inegi.

[2020c], Sistema de Cuentas Nacionales de México. Producto Interno Bruto por Entidad Federativa, México, Inegi. [2019], Censos económicos 2019: resultados oportunos, México, Inegi.

Levine, D. [1995], Reinventing the workplace: How business and employees can both win, Estados Unidos, Brookings Institution, $242 \mathrm{pp}$.

Lewis, A. [1954], "Economic Development with Unlimited Supplies of Labour", The Manchester School, 22(2): 139-191. López-Obrador, A. [2019], Hacia una economía moral, México, Planeta, $192 \mathrm{pp}$.

Nu (Naciones Unidas) [2019], Informe de los Objetivos de Desarrollo Sostenible 2019, Estados Unidos, Naciones Unidas, $62 \mathrm{pp}$.

ocde [2017], Cómo va la vida en México, París, oecd, 9 pp. 
Orozco, A., y R. Magallón [2013], "Reforma laboral en México: precarización generalizada del trabajo", El Cotidiano, 182(1): 95-104.

PeiRó, J., et al. [2014], "Bienestar sostenible en el trabajo: Revisión y reformulación”, Papeles del psicólogo, 35(1): 5-14.

QuiÑones, C., y S. Rodríguez [2015], "La reforma laboral, la precarización del trabajo y el principio de estabilidad en el empleo", Revista Latinoamericana de Derecho Social, 21(2): 179-201.

Reati, A. [2001], "Total factor productivity-a misleading concept", PSL Quarterly Review, 54(218): 313-332.

Rodríguez, M., y R. Castillo [2009], "Empleo, productividad y salarios en México: Un análisis de corto y de largo plazo para el sector manufacturero", EconoQuantum, 5(2): 7-21. RYFF, C. [1989], "Happiness is everything, or is it? Explorations on the meaning of psychological well-being", en Journal of Personality and Social Psychology, vol. 57, núm. 6, pp. 1069-1081.

Salazar, C., y A. Azamar [2014], "Flexibilidad y precarización del mercado de trabajo en México", Política y cultura, 42(2): 185-207.

Salazar, J., J. Guerrero, Y. Machado y R. Cañedo [2009], “Clima y cultura organizacional: dos componentes esenciales en la productividad laboral", Acimed, 20(4): 67-75.

SalazAR, L., y Saldaña, A. [2018], "Competitividad y Organizaciones Sindicales: Caso Walmart México y Centroamérica", Advocatus, 31(2): 219-233.

Samaniego, N. [2010], "El empleo y la crisis: precarización y nuevas válvulas de escape", Economía UNAM, 7(20): 47-70.

Sen, A. [2009], The idea of justice, Harvard, Harvard University Press, $496 \mathrm{pp}$.

Siliceo, A. [2006], Capacitación y desarrollo de personal, México, Limusa, 280 pp. 
VALencia, J., S. Broncano y M. Andres [2013], "El rol del capital humano en la generación de valor: variables determinantes", Revista Ciencias Estratégicas, 21(29): 31-47.

VeLA, H., V. Moreno y M. Aguilar [2015], "Impacto del 'outsourcing' en la calidad de vida de empleados de vigilancia y limpieza en Durango", Revista Global de Negocios, 3(4): 83-97. 



\title{
¿EL ESTADO DE BIENESTAR PUEDE FRENAR LA MIGRACIÓN?
}

\author{
Ana María Aragonés* \\ Uberto Salgado**
}

\section{INTRODUCCIÓN}

La enorme desigualdad en la distribución del ingreso mundial pone en entredicho el modelo de desarrollo actual y lo ha vuelto insostenible al haber beneficiado a los más ricos e incrementado la pobreza para un conjunto cada vez mayor de personas. Todo ello está causando enormes tensiones en la medida en que la desigualdad es disfuncional al inhibir el crecimiento económico, crear inestabilidad democrática y favorecer la crisis ambiental que está alcanzando enormes proporciones. Esto explicaría por qué los organismos internacionales urgen poner la equidad en el centro de una nueva agenda del desarrollo cuyos términos enfaticen un "equilibrio adecuado entre el crecimiento económico y la redistribución" [United Nations, 2018]. Parece quedar clara la necesidad de transformar un modelo dominante que no solo enfrenta su agotamiento, sino que, como se señala, está poniendo en peligro a las generaciones futuras. Este cambio estructural está señalado en la Agenda 2030 para el Desarrollo Sostenible y en los Objetivos

* Doctora en Derecho Laboral, Investigadora Titular C de Tiempo Completo. Correo electrónico: <amaragones@gmail.com>.

** Maestro en Economía, Investigador Asociado C de Tiempo Completo. Correo electrónico: <ubertosalgado@comunidad.unam.mx>.

Agradecemos el apoyo de la DGAPA por medio del proyecto PAPIIT con clave IN301819 que permitió desarrollar la presente investigación. Agradecemos también al Instituto de Investigaciones Económicas por las facilidades prestadas para la buena realización del proyecto. 
de Desarrollo Sostenible aprobados en septiembre de 2015 por Naciones Unidas, y constituye un avance político y conceptual respecto de la Agenda previa definida en los Objetivos de Desarrollo del Milenio (ODM). Sus ejes principales son la igualdad y el cuidado del ambiente además de incorporar temas como el derecho al empleo productivo, la transparencia y una nueva ecuación entre Estado, mercado y sociedad para superar la marcada concentración del ingreso y la riqueza. En el mundo desarrollado y en varias regiones en desarrollo, la desigualdad se ha situado al nivel más elevado en más de tres décadas [Bárcena, 2016]. El coeficiente de Gini en los países de la Organización para la Cooperación y el Desarrollo Económicos (OCDE) aumentó de 0.29 en los años 80 a 0.32 en 2013, tendencia que se observa tanto en países desarrollados tradicionalmente desiguales como Estados Unidos (0.34 en 1985 a 0.39 en 2013) como en naciones con una fuerte tradición igualitaria como los escandinavos (Finlandia aumentó de 0.21 a 026 , Noruega de 0.22 a 0.25 y Suecia de 0.20 a 0.27) [Bárcena, 2016].

De acuerdo con la Comisión Económica para América Latina y el Caribe (Cepal), la causa estructural que explica el malestar social en la región latinoamericana es precisamente la desigualdad; por ello señala que es urgente avanzar "de la cultura de los privilegios a la cultura de igualdad y la inclusión social" [Notimex, 2020]. El aumento de la desigualdad económica en todo el mundo, el deterioro del empleo y la aparición del cambio climático como condición económica prioritaria condujeron en Davos (enero 2020) a destacadas instituciones económicas internacionales a preguntarse si las sociedades están aplicando las estadísticas adecuadas para medir la riqueza. Ante este cuestionamiento, se planteó la necesidad de preparar un nuevo indicador que mida el bienestar de la población tomando en cuenta otros indicadores, en la medida en que mejorar la situación de los ciudadanos va más allá de aumentar la producción, el consumo o el empleo. 
En el refutado modelo dominante, si bien se incrementaron los niveles de desigualdad en el conjunto de los países, las condiciones para los llamados subdesarrollados llegaron a niveles dramáticos, lo que explicaría el enorme despliegue de flujos migratorios que se dirigieron hacia los polos desarrollados. Tales flujos fueron marcados por una enorme vulnerabilidad debido a que la globalización y su modelo económico neoliberal concitaron el libre movimiento de mercancías y capital, pero no así el de trabajadores, lo que dio lugar a un extraordinario incremento de trabajadores indocumentados cuyas condiciones laborales se enmarcaron en la desprotección laboral. A pesar de encontrarse ocupados con $85 \%$ de participación, como fue en el caso en Estados Unidos, se les impidió regularizar sus condiciones administrativas y por ello enfrentaron las inhumanas deportaciones cuando la crisis hizo su aparición en los años 2007 a 2008.

A partir de esa crisis estructural, el mundo ha sido testigo del enorme deterioro en el que los migrantes actuales buscan desesperadamente asilo y refugio en los países de mayor desarrollo, huyendo de las guerras y los conflictos geopolíticos que han creado una verdadera crisis humana, con violación de sus derechos humanos ante el rechazo para acogerlos. Este es un espectáculo por demás dramático que se ha repetido prácticamente en todas las fronteras del planeta. Sin embargo, los países desarrollados se mantendrán como polos receptores de migrantes llamados "económicos", pues enfrentan conflictos estructurales, demográficos y educativos que no pueden resolver con contingentes internos. ¿Este será el destino de los países: unos receptores y otros expulsores?, ¿qué función desempeñan la equidad y los programas de beneficio social en esta ecuación?

En este trabajo presentamos nuestra propuesta, cuya idea central gira en torno a que "migración no es destino" y los países expulsores pueden revertir la tendencia de lo que se ha denominado migración forzada, por causas relacionadas con la 
necesidad o la sobrevivencia, cuando la migración debe ser por opción. Planteamos que un país deja de ser expulsor de trabajadores cuando ha superado las condiciones económicas del subdesarrollo y transita, de manera deliberada, hacia el desarrollo y el bienestar de sus sociedades. De acuerdo con Sunkel y Paz

el subdesarrollo económico consiste en ese conjunto complejo e interrelacionado de fenómenos que se traducen y expresan en desigualdades flagrantes de riqueza y de pobreza, en estancamiento, en retraso respecto de otros países, en potencialidades productivas desaprovechadas, en dependencia económica, cultural, política y tecnológica [Sunkel y Paz, 1999: 15].

Hemos realizado investigaciones que muestran cómo algunos países -Suecia, Corea del Sur y España, entre otros- pudieron cambiar su tendencia migratoria [Aragonés y Salgado, 2013a]. El análisis de las transformaciones que estos países llevaron a cabo destaca un conjunto de políticas sociales enmarcadas en lo que se ha denominado Estado de bienestar, Estado social o Estado providencial y cuyo efecto fue la absorción de su población, lo que revirtió la tendencia de expulsión, pero, curiosamente, a la larga se convirtieron en receptores de migrantes. Buscamos explicaciones de esta nueva tendencia, es decir, qué tipo de factores promueven la llegada de migrantes a esas naciones. Encontramos que esos países presentan conflictos estructurales que se resuelven a partir de trabajadores migrantes [Aragonés y Salgado, 2013b, 2014, 2018].

Nuestra hipótesis es que la política que permite revertir la tendencia migratoria se relaciona directamente con la satisfacción de la población, cuya clave de convivencia es la igualdad y los beneficios sociales universales. Las políticas públicas deben estar en línea directa con el bienestar de la población para que los trabajadores estén en posibilidades de enfrentar las restricciones a las que se ven sometidos ante los determinantes del propio sistema capitalista. 
En este trabajo presentamos, en primer término, nuestra propuesta sobre el fenómeno migratorio. Nuestra visión parte de afirmar la migración como un derecho humano pero que debe responder a una opción, no a una necesidad. En este sentido, hacemos un breve repaso de las teorías más utilizadas y presentamos nuestra propuesta. En segundo término, revisamos lo que en su momento se llamó Estado de bienestar, porque consideramos que esta política tuvo un gran impacto y nos parece pertinente rescatar sus propuestas y comprender la función que el fenómeno migratorio tuvo. En tercer término, buscamos comprobar nuestra hipótesis que relaciona bienestar y migración. Se analizan 26 países desarrollados a los que les aplicamos un indicador alternativo que mide el bienestar de la población de una forma integral. Este nuevo estadístico complementa la medición del producto interno bruto (PIB) al incorporar un análisis multidimensional que no solo toma en cuenta el factor salud y la educación en la medición, sino criterios relacionados con medio ambiente, violencia e inclusión social entre otros indicadores [Porter, Stern y Artavia, 2015].

Finalmente, presentamos algunas reflexiones acerca de las condiciones de México en el marco de la nueva política del presidente Andrés Manuel López Obrador y algunos de los desafíos en su propósito de hacer realidad el "derecho a migrar y a no migrar".

\section{MigRACIÓN: PROPUESTAS TEÓRICAS Y SU DEBATE}

Uno de los modelos más conocidos construido sobre los factores "expulsión/atracción" se denomina neoclásico. El eje explicativo gira en torno a las diferencias de salario entre las regiones receptoras (desarrolladas) y las expulsoras (subdesarrolladas). Otra visión busca la explicación del fenómeno a partir de la relación que se produce entre regiones centrales y periféricas, y plantea la necesidad del estudio histórico, sosteniendo 
que estos flujos se generaron por la particular forma en que los países se han relacionado a partir de los momentos coloniales. Otra propuesta sitúa los supuestos explicativos a niveles individuales y sostiene que el migrante buscará contribuir al beneficio personal y de su familia desplazándose hacia las regiones en que las que pueda hacer efectivos sus deseos personales. Para esta visión, el estudio de las redes sociales es fundamental y afirma que los flujos migratorios persisten aun después de que las causas originales que lo llevaron a migrar desaparezcan.

Por nuestra parte, ponemos el énfasis en los aspectos estructurales, es decir, se estudian las vinculaciones entre el desarrollo de las sociedades capitalistas y los movimientos migratorios tomando en cuenta factores de expulsión y atracción, y la migración como resultado de ambas tensiones, cuyo elemento disparador son las necesidades de la acumulación capitalista. Esto permite entender y dar cuenta de que los cambios en los perfiles y patrones migratorios están vinculados con las necesidades de la valorización del capital. Precisamente la permanencia de la migración y su dificultad para revertirla se explican porque son un componente de la acumulación capitalista que favorece su expansión y reproducción. En este sentido, la migración se activa como producto de las contradicciones y las graves desigualdades que el sistema genera y los desplazamientos se contraen o dilatan en relación con la necesidad de los mercados laborales internacionales de obtener la mayor tasa de ganancia posible.

Hay cierta tendencia hacia cuestionar los factores de expulsión/atracción por considerar que las redes han sustituido estos elementos; sin embargo, si bien las redes han adquirido una enorme importancia, estas deben ser consideradas como una consecuencia de la inercia migratoria, pero no significa que se hayan superado los problemas que mantienen los flujos migratorios. Vale la pena tomar algunas precauciones para no caer en ciertos determinismos. En primer lugar, 
el binomio expulsión-atracción puede sugerir una forma de complementariedad entre los factores de la producción y desconocer el conflicto que se genera entre las regiones, cuando en realidad lo que indica es que los factores no son estáticos, van cambiando en relación con las necesidades de la acumulación y se encuentran en la base de los diferentes patrones migratorios y de las necesidades de los mercados laborales internacionales.

Nuestra propuesta plantea como eje precisamente los llamados factores expulsión-atracción (pull-push) no como proceso que genera equilibrio, todo lo contrario en tanto que el capitalismo es todo menos eso. A lo largo de nuestras investigaciones hemos comprobado que si bien los factores de expulsión tienen como explicación la incapacidad del país origen para otorgar los beneficios que las personas esperan y ameritan, estos migrantes se dirigen hacia aquellos destinos (factor de atracción) que presentan dificultades y conflictos que difícilmente pueden superar de forma endógena; por ello los migrantes resultan una opción funcional y necesaria en el destino. Así, el fenómeno migratorio es de dos vías, articuladas a partir de condiciones estructurales generadas por necesidades y exigencias cambiantes de los mercados laborales a las cuales responden los flujos migratorios.

Desde nuestro punto de vista, los "patrones migratorios" se explican por estar vinculados al patrón de acumulación. En este sentido y retomando los planteamientos de Valenzuela [1990], un patrón de acumulación está determinado históricamente "es decir no se trata de acumulación capitalista a secas, sino de la forma que esta toma en un periodo histórico dado, por tanto, cambian sus especificidades". Nuestra propuesta es que los patrones migratorios modifican sus características porque responden a las necesidades de reproducción del capital en el centro. Por otro lado, en el sistema capitalista hay una relación contradictoria entre centro-periferia, de tal suerte que a la periferia se le van asignando distintas formas 
de "succión y traslado de excedentes a favor del centro" [Valenzuela, 1990]. La migración de trabajadores es una de las formas en las que se concreta el traslado de excedentes a favor del centro. Y en la medida en que los distintos patrones de acumulación sufren su agotamiento y se produce la crisis, cuya causa central es la tendencia decreciente de la tasa de ganancia, se dará paso a un nuevo patrón de acumulación y a nuevas formas de articulación entre centro-periferia. A esta nueva configuración corresponden nuevos patrones migratorios que satisfarán los requerimientos de la acumulación capitalista y las exigencias de sus mercados laborales. De esta manera, podríamos hablar de tres grandes patrones migratorios: a) las migraciones clásicas (siglo xIX-principios del siglo $\mathrm{xx}$; b) migraciones en el fordismo y la sustitución de importaciones (1945 a 1970); y c) las migraciones en la globalización y el neoliberalismo (1980-2009).

Hasta aquí hemos planteado nuestra propuesta en relación con las condiciones bajo las cuales el fenómeno migratorio se despliega a partir de un polo no desarrollado a uno desarrollado. Estos flujos migratorios los consideramos "forzados" entendiendo por ello que esas personas están obligadas a buscar nuevos horizontes de vida, de sobrevivencia, ante la incapacidad de sus países para generar políticas económicas y sociales que permitan la absorción de su población bajo condiciones de vida productiva digna, con lo necesario para responder a sus expectativas de bienestar. Hay que señalar que el término migración "forzada" suele cuestionarse al considerar que solo al concepto de refugiado puede atribuírsele; sin embargo, en este trabajo consideramos que si bien los determinantes por los cuales se suele hablar de refugiados son conflicto armado, violencia generalizada y violaciones de los derechos humanos, los imperativos hambre, inseguridad, desempleo, etc., son otros matices que pueden enmarcarse en el término "forzado" porque todos ponen en peligro la sobrevivencia. 


\section{LA POLÍTICA ECONÓMICA DEL EsTADO DE BIENESTAR} Y EL FENÓMENO MIGRATORIO

Algunos autores denominaron la política económica del Estado de bienestar o Estado benefactor como la "edad de oro" del capitalismo al auspiciar el auge económico por un lapso de casi 25 años, resultado del "incremento del salario real combinado con mayores niveles de productividad" [Lipietz, 1986: 119]. Se produjo una forma de intervencionismo estatal que permitió "un complejo de instituciones sociales promovidas por el pacto social entre capital y trabajo [dentro] de las relaciones capitalistas en la fase de la posguerra" [Farfán, 1988: 15]. El crecimiento espectacular vivido por Europa fue resultado de la interacción de muchas variables relacionadas entre sí, entre las que destacan las transformaciones tecnológicas, el surgimiento de nuevas formas de energía, el desarrollo de la energía nuclear y la instrumentación de nuevos procesos de trabajo. Pero sobre todo fue la política social que permitió a los trabajadores acceder a educación, salud y a una organización laboral que al fortalecer los sindicatos y las contrataciones colectivas permitió establecer un salario mínimo.

La política económica estuvo sustentada en la producción en masa, acompañada por el consumo de masas. De esta forma fue posible que los trabajadores tuvieran acceso a un conjunto de bienes y productos que en otras épocas hubieran sido impensables. Parecía superarse la idea de algunos autores que pensaban que la crisis de 1929 mostraba claramente el agotamiento del sistema capitalista. Aunque no hay que olvidar que también se asignó una parte importante del presupuesto a gastos militares, poderoso generador de empleos y de divisas para la nación hegemónica, Estados Unidos.

En el contexto de auge económico y creciente nivel de vida de los asalariados de los países altamente industrializados se produjo un movimiento migratorio de gran importancia cuyos desplazamientos respondieron a un conjunto de factores de 
atracción y mantuvieron un drenaje continuo de la fuerza de trabajo de los países menos desarrollados hacia los polos dinámicos de desarrollo. La discusión en esos momentos giraba en torno a si era necesario mantener un crecimiento positivo de la población o frenarla, léase fuerza de trabajo migrante. Tal parece que ganó la posición inicial al plantear que estimularía la inversión y el progreso técnico, fomentaría la producción a gran escala y se incrementaría la posibilidad de flexibilizar la economía, todo lo cual explica los números ascendentes de fuerza de trabajo migrante en sus economías.

La Comunidad Económica Europea, creada en 1957, pretendía el establecimiento de un mercado internacional para estimular los movimientos de trabajadores dentro del Mercado Común. Sin embargo, la migración extracomunitaria no pudo impedirse puesto que de los seis países solo uno contaba con un excedente de fuerza de trabajo (Italia). Los cinco países escandinavos: Dinamarca, Finlandia, Noruega, Suecia e Islandia, crearon en 1954 el Mercado de Trabajo Nórdico, que establecía el mutuo derecho de los ciudadanos de cada uno de estos países a entrar, residir y trabajar sin ninguna restricción en cualquiera de ellos.

Los bajos índices de desempleo que los más importantes países receptores de migrantes presentaron en el periodo 1950 a 1970 fueron un poderoso factor de atracción. Habría que recordar que el capitalismo requiere un nivel determinado de desempleo para enfrentar el poder de negociación de los trabajadores, lo contrario puede afectar negativamente la ganancia capitalista, una condición más para que las naciones consideren indispensable la incorporación de trabajadores migratorios en sus economías.

De acuerdo con Panitch, las políticas keynesianas de pleno empleo fueron el fruto directo de la fuerza política de la clase obrera y sus aliados, pero también se debieron al rápido crecimiento económico de la posguerra y, como consecuencia, la reducción del ejército industrial de reserva. El Estado 
de bienestar fue una forma mucho más eficiente al restablecer el equilibrio político para satisfacer las demandas y aspiraciones participativas de liderazgo obrero, "al tiempo que tuvo la capacidad de captar el conflicto y a las luchas obreras les dio forma y las canalizó para salvar al capitalismo avanzado" [Panitch, 1981, citado en Farfán, 1988: 43]. El Estado de Bienestar "universaliza las demandas obreras convertidas en problemas individuales de salud, educación, seguridad social, reagrupadas como problemas globales de gasto público" [Farfán, 1988: 43].

\section{La crisis del fordismo y la nueva estrategia capitalista}

No obstante, la efectividad política y económica del Estado de bienestar comenzó a dar muestras de agotamiento a partir de la segunda mitad de la década de 1970 y estalló abiertamente en la crisis de 1973 a 1975. El sistema puso en marcha un nuevo conjunto de políticas para intentar salir del crecimiento muy débil y de una inflación cada vez más acelerada, lo que se denominó estanflación. Se culpó al Estado de bienestar como el causante de la crisis al señalar que los gastos estatales son improductivos y "provoca una disminución de la masa de plusvalor" [Bullock y Yaffe, 1979]. Si bien la producción siguió en aumento, la ganancia empezó a verse afectada, lo cual se atribuyó a los costos salariales. Se intentaría por todos los medios decrementar los salarios, pero el sustancial poder de negociación de los sindicatos dificultaba esta posibilidad y si el salario repercutía en el precio de las mercancías estas verían afectada su competitividad.

De acuerdo con algunos autores [Bowles, Gordon y Weisskopf , 1989: 128], el control del capital sobre el trabajo había perdido eficacia desde los años sesenta debido a la imposibilidad de la amenaza del desempleo aun cuando se habían incorporado importantes contingentes de fuerza de trabajo extranjera en sus 
economías. Hubo un acuerdo bastante generalizado tanto por visiones de izquierda como de la derecha en el sentido de que la crisis tenía una sola causa: el intervencionismo del Estado de bienestar y la interferencia en el mercado del keynesianismo [Farfán, 1988: 46].

La consecuencia inmediata de la crisis de esos años fue frenar los flujos migratorios poniendo en marcha un conjunto de medidas para detenerlos, estrategia acompañada de una verdadera ofensiva contra los extranjeros, deportaciones, repatriaciones, se puso término a las reunificaciones familiares, etc. Los países industrializados registraron niveles internos de desempleo de tal envergadura que alcanzaron dimensiones lo suficientemente graves como para debilitar la fuerza de trabajo.

La crisis se propagó a todos los países incorporados al sistema capitalista. Una enorme inestabilidad recorrió el mundo y produjo entre otras cosas la caída de los acuerdos de Bretton Woods y la eliminación del dólar como patrón de cambio mundial. Hizo explosión el problema de la deuda del Tercer Mundo y se declararon en bancarrota gran cantidad de países, lo que puso a temblar a los centros financieros internacionales. Estos graves acontecimientos llevaron a una nueva reestructuración productiva: la globalización, cuyos ejes principales fueron un proceso creciente de internacionalización de la economía y la instauración de una nueva división internacional del trabajo que redefiniría no solo las nuevas relaciones entre las grandes potencias, sino la forma de incorporación de los diferentes países al comercio internacional; se liberalizaron los flujos de mercancías y capitales, pero se obstaculizaron los de la fuerza de trabajo. La generalización de estos nuevos procesos de trabajo requirió flexibilizar las relaciones laborales; se eliminaron las formas de contratación y negociación colectiva en favor de una individualizada, al tiempo que se desarrolló una ofensiva frontal contra los sindicatos. Este modelo fue dominante hasta la crisis de 2008, la cual produjo la mayor 
desigualdad y pobreza para la mayor parte de la población mundial. Los migrantes enfrentados a refuerzos fronterizos y a la práctica militarización de la frontera por parte del más importante receptor mundial de migrantes (Estados Unidos) provocaron enormes tragedias humanas. El modelo está mostrando su agotamiento, como se señaló antes, y parece consensarse la idea de que se requiere uno nuevo que ponga en el eje de sus políticas el bienestar de la población para evitar que "las generaciones futuras se vean amenazadas".

En la siguiente sección, se trata de probar la relación entre bienestar y migración, para lo cual se realiza, en primer lugar, una discusión acerca de los indicadores de bienestar ampliamente utilizados por organismos internacionales; en segundo término se presenta una nueva propuesta de indicadores alternativos que miden el bienestar de la población de forma integral: el índice de progreso social.

\section{DisCUSIÓN SOBRE LOS INDICADORES \\ DE BIENESTAR Y LA MIGRACIÓN}

En la actualidad, existen diversos indicadores que buscan reflejar el nivel de calidad de vida de la población; sin embargo, algunos de ellos, como el PIB per cápita o el índice de desarrollo humano (IDH), que son muy usados por organismos multinacionales y gobiernos para medir la eficiencia de las políticas pública en materia de desarrollo, no reflejan la realidad en la que vive buena parte de la población.

El IDH se considera un estadístico muy completo al medir el desarrollo económico tomando en cuenta tres dimensiones: ingreso, salud y educación de la población. De acuerdo con la Cepal [2014], el IDH puede estimarse a partir de variables como la esperanza de vida, la tasa de alfabetización de la población, la tasa de matriculación bruta y el PIB per cápita; los países que tienen valores de PIB elevados dan un valor alto en 
su IDH. No obstante, esta medida basada en los ingresos puede ser engañosa debido a la posibilidad de una elevada concentración de los mismos: por más altos que sean esos ingresos en sus medidas per cápita, no reflejarán las condiciones de vida de su población en general.

El cuadro 1 muestra los países que durante 2017 mostraron los mayores niveles de IDH. En los primeros cinco lugares destacan Noruega, Suiza, Australia, Irlanda y Alemania; Estados Unidos se ubica en la posición 16 y Finlandia en la posición 12 .

Cuadro 1. Países con valores de índice de desarrollo humano muy altos de acuerdo con la clasificación de Naciones Unidas para el Desarrollo (UNDP)

\begin{tabular}{rcc}
\hline Posición & País & Valor del IDH \\
\hline 1 & Noruega & 0.954 \\
2 & Suiza & 0.946 \\
3 & Irlanda & 0.942 \\
4 & Alemania & 0.939 \\
5 & Hong Kong (China) & 0.939 \\
6 & Australia & 0.938 \\
7 & Islandia & 0.938 \\
8 & Suecia & 0.937 \\
9 & Singapur & 0.935 \\
10 & Países Bajos & 0.933 \\
11 & Dinamarca & 0.930 \\
12 & Finlandia & 0.925 \\
13 & Canadá & 0.922 \\
14 & Nueva Zelanda & 0.921 \\
15 & Reino Unido & 0.920 \\
16 & Estados Unidos & 0.920 \\
\hline
\end{tabular}

Fuente: Programa de las Naciones Unidas para el Desarrollo (PNUD) [2018]. 
Si bien todos estos países son considerados desarrollados o de reciente desarrollo, este ordenamiento no refleja el verdadero nivel de vida de sus poblaciones pues no muestra la distribución de los ingresos, cuando una distribución equitativa es la única que garantiza mayor bienestar entre la población. $\mathrm{Al}$ respecto es posible resaltar el caso de los Estados Unidos, que ocupa la séptima posición a nivel mundial con uno de los más altos valores de PIB per cápita de acuerdo con cifras del Fondo Monetario Internacional [2019], y, sin embargo, la desigualdad del ingreso se ha ido incrementando en ese país. Según la OCDE, desde 2010 los estadounidenses ya habían entrado al top cinco de los países con los mayores niveles de desigualdad [Mackintosh, 2013] y así se mantuvieron hasta 2018 ya que el Census Bureau de ese país señala que el valor del coeficiente de Gini ha alcanzado el valor más elevado jamás registrado: paso de 0.397 puntos en 1967 a 0.485 puntos para el 2018 [Telford, 2019].

Si bien es cierto que el coeficiente de Gini es útil para estudiar la inequidad en la distribución de los ingresos, este estadístico es limitado y poco transparente, ya que va del valor cero al uno, donde cero implica la igualdad absoluta y el uno, que un solo miembro de esa sociedad se lleva todo el ingreso. Entre esos extremos, se coloca a todos los países y si se compara un país con un índice de 0.3 con respecto a otro con un índice de 0.4 , implicaría que el primero es menos desigual. Sin embargo, esa cifra no es clara para conocer cuál de los sectores es el más afectado por la desigualdad; específicamente, ¿esta diferencia se debe a un menor ingreso entre los más pobres?, ¿al aumento de la riqueza entre el sector de los más acaudalados? o ¿es la clase media la que está sufriendo el impacto? [Justo, 2016].

Una medición alternativa al índice de Gini es el índice de Palma, desarrollado por el economista chileno José Gabriel Palma para medir la desigualdad; incluso organismos como la ONU, OCDE entre otros, han comenzado a incorporar 
esta métrica de desigualdad en sus reportes. El índice de Palma realiza una comparación entre el 10\% más rico de una población y el $40 \%$ más pobre debido a que cuando se compara la desigualdad entre países, esta nunca se debe a lo que sucede en el medio de la población, es decir, en lo que se lleva la población que se ubica en los deciles 5 al 9 del ingreso, que por lo general se llevan la mitad del ingreso. Según Palma, la diversidad distributiva en todo el mundo se debe a lo que pasa en la otra mitad de los ingresos, en especial lo que se lleva el $10 \%$ más rico. Por ejemplo, en América Latina la desigualdad es mayor que en la región nórdica, pero esto no se explica por lo que ocurre en los sectores medios de la distribución que, a decir de Palma, en ambos casos se llevan casi lo mismo, algo cercano a la mitad; la diferencia radica en cómo los ricos y los pobres se distribuyen la otra mitad, pues mientras que en América Latina el 10\% más rico se lleva el doble de la proporción del ingreso de su contraparte nórdica, el $40 \%$ más pobre se lleva una parte muy pequeña [Justo, 2016].

Retomando la clasificación de los países con los mayores niveles de IDH de 2019 se construyó el cuadro 2, que reporta el índice de Palma y en la que se observa que los países nórdicos son los que muestran una distribución más equitativa del ingreso al presentar los valores más bajos del estadístico del índice de Palma, es decir, que la diferencia entre los más ricos y los más pobres no es tan amplia, en tanto que en Estados Unidos la diferencia entre la pobreza y riqueza extrema es el doble de la reportada por Noruega, Suecia, Finlandia, Islandia y Dinamarca. Esta situación permite cuestionar si el IDH refleja la calidad de vida de sus poblaciones, pues los países nórdicos no se ubican en las primeras posiciones de ese indicador y Estados Unidos se encuentra dentro de los primeros 15 a nivel mundial a pesar de ser uno de los países con los más altos niveles de desigualdad en el planeta. 
Cuadro 2. Índice de Palma en países seleccionados, 2010 a 2015

\begin{tabular}{cc}
\hline \multirow{2}{*}{ País } & Índice de Palma \\
\cline { 2 - 2 } Noruega & 0.88 \\
Suecia & 0.93 \\
Islandia & 0.95 \\
Finlandia & 0.95 \\
Países Bajos & 0.99 \\
Dinamarca & 1.04 \\
Alemania & 1.10 \\
Suiza & 1.22 \\
Irlanda & 1.25 \\
Reino Unido & 1.25 \\
Canadá & 1.32 \\
Australia & 1.40 \\
Estados Unidos & 2.00 \\
\hline
\end{tabular}

Nota: no se encontraron datos para Hong Kong y Singapur.

Fuente: elaboración propia con base en datos de Naciones Unidas para el Desarrollo.

Como respuesta a esto se han desarrollado algunos indicadores alternativos que miden el bienestar de la población de una forma integral. Un ejemplo de ellos es el índice de progreso social (IPS), propuesta de medición que fue desarrollada por Michael E. Porter y Michael Green de la Escuela de Negocios de Harvard [Porter, Stern y Artavia, 2015]. Este estadístico busca complementar la medición del PIB incorporando a la medición del bienestar tres grandes dimensiones [Incae Business School, 2019], las cuales son:

1. Las necesidades humanas: sobre este rubro se toman en cuenta variables para identificar si la población consigue suficiente alimento, acceso a cuidados médicos, agua y 
saneamiento y vivienda digna, y agrega indicadores que muestren el nivel y la percepción del crimen.

2. Los fundamentos del bienestar: se consideran los factores relacionados con la matriculación en educación básica, equidad de género en el acceso a la educación, acceso a la información y las comunicaciones, esperanza de vida media y calidad medioambiental.

3. Oportunidades: se evalúa la participación ciudadana y el respeto a los derechos humanos, a la libertad, la libre elección, la no discriminación y el acceso a la educación superior.

Debido a esto, el IPS va ganando cada vez más popularidad entre los líderes gubernamentales, la academia y la sociedad civil, pues la población demanda mejores condiciones de vida y para esto es necesario un estadístico que mida de forma más adecuada el bienestar y cuyos indicadores no enmascaren las diferencias estructurales que existen entre los países.

El reporte de este indicador para el año de 2019 señala que las economías de la región nórdica se posicionan en los primeros seis lugares con los más altos índices de bienestar para sus poblaciones, medida que tiene una metodología multidimensional mejor consolidada que la empleada por el IDH. Al respecto es posible señalar que países de economías emergentes, como Singapur o Hong Kong (China), no se posicionan entre los primeros lugares del ranking del IPs (a diferencia del IDH), pues si bien estas economías han crecido de forma acelerada con altos valores de su PIB per cápita, sus poblaciones no cuentan con un acceso más equitativo a mejores condiciones de bienestar. Otro caso particular es Estados Unidos, que si bien es la economía líder a nivel mundial tampoco se posicionó entre los primeros lugares del IPs (cuadro 3), lo que muestra el importante nivel de desigualdad que prevalece entre su población. 
Cuadro 3. Los 26 países con el mayor nivel de IPS para 2019

\begin{tabular}{clcclc}
\hline Posición & \multicolumn{1}{c}{ País } & IPS & Posición & \multicolumn{1}{c}{ País } & IPS \\
\hline 1 & Noruega & 90.95 & 14 & Irlanda & 87.97 \\
2 & Dinamarca & 90.09 & 15 & Francia & 87.79 \\
3 & Suiza & 89.89 & 16 & Luxemburgo & 87.66 \\
4 & Finlandia & 89.56 & 17 & España & 87.47 \\
5 & Suecia & 89.45 & 18 & Portugal & 87.12 \\
6 & Islandia & 89.29 & 19 & Bélgica & 86.77 \\
7 & Nueva Zelanda & 88.93 & 20 & Austria & 86.4 \\
8 & Alemania & 88.84 & 21 & Eslovenia & 85.8 \\
9 & Canadá & 88.81 & 22 & Italia & 85.69 \\
10 & Japón & 88.34 & 23 & Corea del Sur & 85.61 \\
11 & Países Bajos & 88.31 & 24 & República Checa & 84.36 \\
12 & Australia & 88.02 & 25 & Estonia & 83.98 \\
13 & Reino Unido & 87.98 & 26 & Estados Unidos & 83.62 \\
\hline
\end{tabular}

Fuente: The Social Progress Imperative [2019].

Es importante hacer énfasis en que todas las economías referidas en los primeros 26 lugares del IPs son países con altos y muy altos estándares de calidad de vida de su población; sin embargo, la diferencia entre las posiciones que ocupa cada país respecto del IDH muestra distintos matices en relación con el acceso equitativo al bienestar entre sus poblaciones. ${ }^{1}$

Para buscar la asociación que puede haber entre los altos niveles de bienestar y la migración, se elaboró el cuadro 4 considerando los países con los mayores niveles del IPs y sus respectivos valores de migración neta; ${ }^{2}$ se observa que prácticamente todas estas economías reportaron un signo positivo, lo cual implica que los mayores niveles de bienestar evitan que la población salga del país y que en realidad se mantengan ganando población (excepto Portugal y Estonia)

\footnotetext{
${ }^{1} \mathrm{Si}$ estas diferencias en los indicadores se encuentran a nivel de los países desarrollados, quizás las discrepancias de estas métricas para las naciones en vías de desarrollo son aún mayores.

${ }^{2}$ La migración neta se calcula como la diferencia entre la población que ingresa y sale del país, por lo que un signo positivo indica ganancia y uno negativo refleja pérdida.
} 
Cuadro 4. Migración neta de países seleccionados, 2019

\begin{tabular}{lclc}
\hline \multicolumn{1}{c}{ País } & $\begin{array}{c}\text { Migración neta } \\
\text { (miles } \\
\text { de personas) }\end{array}$ & \multicolumn{1}{c}{ País } & $\begin{array}{c}\text { Migración neta } \\
\text { (miles } \\
\text { de personas) }\end{array}$ \\
\hline Noruega & 665 & Reino Unido & 5277 \\
Dinamarca & 467 & Irlanda & 17 \\
Suiza & 1892 & Francia & 6038 \\
Finlandia & 93 & Luxemburgo & 216 \\
Suecia & 1651 & España & 4659 \\
Islandia & 10 & Portugal & -1743 \\
Nueva Zelanda & 291 & Bélgica & 1400 \\
Alemania & 9118 & Austria & 1204 \\
Canadá & 6638 & Eslovenia & 106 \\
Japón & 1660 & Italia & 3196 \\
Países Bajos & 1302 & Estonia & -18 \\
Australia & 6972 & Estados Unidos & 47500 \\
\hline
\end{tabular}

Fuente: elaboración propia con base en datos de un Population Division y The Social Progress Imperative [2019].

Debido a que los migrantes se dirigen principalmente hacia países con altos niveles de bienestar, algunas investigaciones sugieren que esos programas sociales se han convertido en un imán que atrae los flujos migratorios [Agersnap, Jensen y Kleven, 2019; Borjas, 1999; Razin y Wahba, 2015]. Otro conjunto de autores señala que los migrantes tienden a deteriorar la calidad y la cobertura de los servicios sociales afectando el nivel de bienestar de la población nativa [Hansen, Schultz-Nielsen y Tranæs, 2017; Razin, 2004], planteamientos con los que no estamos de acuerdo y que no solo son muy peligrosos pues generan una conducta racista y xenófoba contra los migrantes, sino que dejan de lado lo más importante: los factores estructurales de atracción que muestran las exigencias y necesidades de esos mercados laborales que los migrantes satisfacen y que esos países no pueden resolver a partir de contingentes internos, entre los cuales encontramos los demográficos y los educativos. 
Es importante resaltar que la mayoría de las economías desarrolladas con altos niveles de bienestar presenta un envejecimiento poblacional con tasas de fecundidad que se ubican por debajo del nivel de reemplazo (2.1 hijos nacidos vivos durante la edad reproductiva de las mujeres), situación que genera problemas importantes. Por un lado, la población económicamente activa (individuos de 15 a 64 años) crece a una tasa inferior a la de la población de la tercera edad, que crece al doble, lo que da lugar al nocivo incremento de la dependencia laboral en prácticamente todos los países analizados [Aragonés y Salgado, 2014], como muestra el cuadro 5. No hay que olvidar que la población migrante en edad productiva apoya fiscalmente mediante sus impuestos los costos de los programas sociales y sobre todo lo relacionado con las jubilaciones.

Cuadro 5. Tasas de fecundidad y relación de dependencia de la población de edad avanzada en los países con un alto valor del IPS

\begin{tabular}{|c|c|c|c|c|c|c|c|c|c|}
\hline \multirow{2}{*}{ País } & \multicolumn{2}{|c|}{$\begin{array}{c}\text { Tasa de } \\
\text { fecundidad }\end{array}$} & \multicolumn{2}{|c|}{$\begin{array}{c}\text { Tasa de } \\
\text { dependencia }\end{array}$} & \multirow{2}{*}{ País } & \multicolumn{2}{|c|}{$\begin{array}{c}\text { Tasa de } \\
\text { fecundidad }\end{array}$} & \multicolumn{2}{|c|}{$\begin{array}{c}\text { Tasa de } \\
\text { dependencia }\end{array}$} \\
\hline & $\begin{array}{l}1950 \text { व } \\
1955\end{array}$ & $\begin{array}{c}2010 \text { a } \\
2015\end{array}$ & 1950 & 2015 & & $\begin{array}{c}1950 \text { a } \\
1955\end{array}$ & $\begin{array}{c}2010 \mathrm{a} \\
2015\end{array}$ & 1950 & 2015 \\
\hline Noruega & 2.6 & 1.82 & 14.5 & 24.8 & Reino Unido & 2.18 & 1.87 & 16.2 & 27.9 \\
\hline Dinamarca & 2.55 & 1.73 & 14 & 29.7 & Irlanda & 42 & 1.97 & 18.1 & 19.6 \\
\hline Suiza & 2.31 & 1.53 & 14.1 & 26.8 & Francia & 2.76 & 1.98 & 17.3 & 30.1 \\
\hline Finlandia & 3 & 1.77 & 10.4 & 32 & Luxemburgo & 1.98 & 1.55 & 13.9 & 20.1 \\
\hline Suecia & 2.24 & 1.9 & 15.3 & 31.1 & España & 2.53 & 1.33 & 10.9 & 28.1 \\
\hline Islandia & 3.86 & 1.98 & 12.1 & 20.8 & Portugal & 3.10 & 1.28 & 11.0 & 31.9 \\
\hline Nueva Zelanda & 3.69 & 2.04 & 14.5 & 22.4 & Bélgica & 2.36 & 1.78 & 16.2 & 28.0 \\
\hline Alemania & 2.13 & 1.43 & 14.4 & 32.4 & Austria & 2.10 & 1.45 & 15.6 & 28.1 \\
\hline Canadá & 3.64 & 1.6 & 12.2 & 23.6 & Eslovenia & 2.68 & 1.58 & 10.7 & 26.8 \\
\hline Japón & 2.96 & 1.41 & 8.2 & 42.7 & Italia & 2.36 & 1.42 & 12.4 & 34.1 \\
\hline Países Bajos & 3.05 & 1.73 & 12.2 & 27.4 & Estonia & 2.06 & 1.59 & 16.6 & 28.9 \\
\hline Australia & 3.18 & 1.88 & 12.5 & 22.4 & Estados Unidos & 3.31 & 1.88 & 12.6 & 22.1 \\
\hline
\end{tabular}

Fuente: elaboración propia con datos de un Population Division. 
Es posible afirmar que tras la crisis financiera de 2008, se configuró un nuevo patrón migratorio que podemos llamar "selectivo" pues requiere migrantes calificados y altamente calificados, si bien esta situación empezaba a perfilarse desde finales del siglo pasado. Se explica porque los mercados laborales internacionales demandan trabajadores con mayores niveles de calificación y especialización al profundizar políticas orientadas a la economía del conocimiento, las innovaciones, la inteligencia artificial, la cuarta revolución industrial, etc., y los países se enfrentan a una escasez de jóvenes nativos con la formación requerida en las áreas de conocimiento relacionadas con ciencia, tecnología, ingeniería y matemáticas (STEM, por sus siglas en inglés) necesarias para sostener los niveles de bienestar para sus poblaciones y continuar con sus proyectos de desarrollo científico y tecnológico.

Los países ya probaron distintas estrategias para hacer frente al envejecimiento de la fuerza laboral, como retrasar la edad de retiro, lo que no ha sido fácil de aplicar por la renuencia de los trabajadores. Otra propuesta consiste en incrementar los niveles de productividad laboral con la finalidad de compensar la escasez de trabajadores; no obstante, esta tarea no es tan sencilla pues, según la Ley de KaldorVernoorn, el crecimiento de la productividad es endógeno y, por tanto, existe una fuerte correlación entre el crecimiento de la productividad y la tasa de crecimiento de la actividad económica, la cual responde a los estímulos de la demanda [Camara-Neto y Vernengo, 2010]. Esto implica que la productividad es incentivada primordialmente por las fuerzas de la demanda, es decir, no se incentiva una mayor producción de bienes y servicios si la demanda se contrae, pues provocaría una acumulación en los inventarios de las empresas, que operarían incluso en números rojos si la demanda no crece. Estos argumentos explican por qué la migración internacional se ha convertido en el factor que permite resolver el problema del envejecimiento: no solo ingresa a los países 
fuerza de trabajo joven, sino que desempeñan una importante función como consumidores, representan un impacto positivo para el estímulo de la demanda [Lima, 2014] y son cotizantes fiscales para beneficio de las pensiones.

\section{Conclusiones}

Ha sido posible demostrar que los países que cuentan con un alto nivel de bienestar muestran muy bajos índices de migración y muchos de ellos fueron exportadores de fuerza de trabajo antes de alcanzar esos niveles de bienestar. Nuestra propuesta es que "migración no es destino" y los países pueden revertir la tendencia si mejoran las condiciones de vida de la población, garantizando el acceso a la salud, la educación, la alimentación, el medio ambiente sano y empleos dignos, y cerrando las brechas de desigualdad económica por medio de los programas públicos. Así estarán en el camino de abatir las causas que generan la migración forzada y la población podrá ejercer su derecho a la migración como una opción.

México se ubica dentro del $25 \%$ de los países con mayores niveles de desigualdad en el mundo, a tal grado que uno de los hombres más ricos del mundo coexiste con cerca de 50 millones de pobres [Delgado, Vázquez y Jaramillo, 2018]. Un informe de Oxfam-México señala que para revertir esta situación es necesario implementar políticas como: seguridad social universal, mejorar la infraestructura escolar y de salud, otorgar becas para alumnos de bajos ingresos, enfocar recursos a la matriculación en nivel medio superior, implementar una política industrial que brinde empleos dignos y de calidad, elevar el salario mínimo, instituir mecanismos de transparencia para el combate a la corrupción y establecer un impuesto a la herencia e impuestos a rendimientos de instrumentos de renta fija y variable en mercados de capital [Delgado, Vázquez y Jaramillo, 2018]. 
En este sentido, es posible destacar que bajo la administración de Andrés Manuel López Obrador se está impulsando una serie de programas orientados a reducir las brechas entre la población, entre las se encuentran algunas señaladas por Oxfam. Por ejemplo, se está trabajando en un programa para brindar cobertura de salud universal por medio de la creación del Instituto de Salud para el Bienestar (Insabi) [Instituto de Salud para el Bienestar, 2020] y se instrumentó el programa de becas "Bienestar para la familia" y "Benito Juárez" que apoyan a familias de escasos recursos que tienen algún estudiante: la primera se orienta a estudiantes de nivel básico y la segunda a los de nivel medio superior [Gobierno de México, s/f]. Además, durante su primer año de gestión se aprobó un incremento histórico de $20 \%$ al salario mínimo en términos reales [Comisión Nacional de los Salarios Mínimos, 2019] y se ha puesto un énfasis muy especial en el combate a la corrupción, lo que ha generado hasta ahora un ahorro de 230000 millones de pesos, que serán reorientados hacia proyectos públicos [Notimex, 2019].

Estos programas representan una alternativa al modelo neoliberal y su propuesta central es buscar un México más igualitario y justo, y con ello hacer que la migración sea finalmente una opción, no una necesidad.

\section{REFERENCIAS}

Agersnap, O., A. S. Jensen y H. Kleven [2019], "The Welfare Magnet Hypothesis: Evidence from an Immigrant Welfare Scheme in Denmark", NBER Working Paper Series. 26454, noviembre, <https://n9.cl/7c47>, 3 de enero de 2020.

ARAGonÉs, A. M., y U. Salgado [2018], "Migración calificada en los países nórdicos y la crisis migratoria en Europa", en Ana María Aragonés y Uberto Salgado (eds.), Competencia mundial por los talentos. Retos y perspectivas para 
México y América Latina, México, Instituto de Investigaciones Económicas, UNAM.

[2014], “¿Competencia internacional por la migración altamente calificada?", Comercio Exterior, 64(2): 18-26.

[2013a], "Migración y desarrollo. Un estudio comparativo", en Alicia Girón, Del vivir bien al buen vivir, México, Instituto de Investigaciones Económicas, UNAM.

[2013b], "La crisis y la economía del conocimiento en Estados Unidos. Su impacto en la política migratoria", Norteamérica, 8(2), 34, <https://cutt.ly/yhb7h5L>, 9 de enero de 2020.

Bárcena, A. [2016], Horizontes 2030. La igualdad en el centro del desarrollo sostenible, Santiago Chile, Cepal, 176 pp. BorJAS, G. J. [1999], "Immigration and welfare magnets", Journal of Labor Economics, 17(4): 607-637.

Bowles, S., D. M. Gordon y T. E. Weisskopf [1989], La economía del despilfarro, Madrid, Alianza, 374 pp.

Bullock, P., y D. Yaffe [1979], "Inflation, the crisis and the post-war boom, Revolutionary Communist", Theoretical Journal of the Revolutionary Communist Group, Reprint, núm. 3/4:5-45, noviembre.

Camara-Neto, A. F., y M. Vernengo [2010], "Keynes after Sraffa and Kaldor: Effective demand, accumulation and productivity growth", Working Paper Utah University, Department of Economics, 2010_07, Utah, <https://n9.cl/his2o>, 30 de octubre 2016.

CEPAL (Comisión Económica para América Latina y el Caribe) [2014], Guía para estimar la pobreza infantil. Información para avanzar en el ejercicio de los derechos de los niños, niñas y adolescentes, Santiago de Chile, Cepal, <https://n9.cl/ ehhy1>, 17 de enero de 2020.

Comisión Nacional de los Salarios Mínimos [2019], Histórico aumento del salario mínimo para 2020, México, Gobierno de México, <https://n9.cl/h1xl>, 15 de enero de 2020.

Delgado, M., D. Vázquez y M. Jaramillo [2018], México justo: propuestas de políticas públicas para combatir la 
desigualdad, México, Oxfam, <https://n9.cl/5tac3>, 12 de enero de 2020.

FARfán, G. [1988], "Capital, trabajo y Estado de Bienestar en el capitalismo avanzado", en Gonzálo Farfán, La crisis del Estado de Bienestar, México, Universidad Nacional Autónoma de México.

Fondo Monetario Internacional (FMi) [2019], World Economic Outlook (October 2019) - GDP percapita, International Monetary Fund, <https://n9.cl/w52g>, 17 de febrero de 2020.

Gobierno de México [s/f], Coordinación Nacional de Becas para el Bienestar Benito Juárez, México, Gobierno de México, <https://www.gob.mx/becasbenitojuarez>, 4 de febrero de 2020.

Hansen, M. F., M. L. Schultz-Nielsen y T. Tranæs [2017], "The fiscal impact of immigration to welfare states of the Scandinavian type", Journal of Population Economics, 30(3): 925-952, <https://n9.cl/il7j1>, 18 de enero de 2020.

Incae Business School [2019], Índice de progreso social México 2019. Más allá del PIB. ¿México cómo vamos?, Ciudad de México, 50 pp.

Instituto de Salud para el Bienestar [2020], El Pulso de la Salud, México, Gobierno de México, <https://n9.cl/hxzvw>, 4 de febrero de 2020.

Justo, M. [2016], "Palma, el índice de un economista chileno que revela el lado oculto de la fuerte desigualdad en América Latina", $в$ вС Mundo, 23 de junio, <https://n9.cl/12noy>, 22 de enero de 2020.

Lima, A. [2014], Contributions of Immigrant Labor to the American Economy, Boston, Research Boston Redevelopment Authority, <https://n9.cl/n8iik>, 29 de noviembre de 2016.

LipiETz, A. [1986], "La mundialización de la crisis general del fordismo: 1967-1984", Economía Teoría y Práctica, México, núm. extraordinario 1:115-143. 
MackinTosh, E. [2013], "Report: Income inequality rising in most developed countries", The Washington Post, Washington D. C., <https://n9.cl/qzgp>, 13 de enero de 2020.

Notimex [2020], "Desigualdad, causa del malestar social en AL: Alicia Bárcena", El Economista, 26 de enero, Ciudad de México, https://n9.cl/ujuhg, 26 de enero de 2020.

[2019], "Combate a corrupción genera ahorros por 230,000 millones de pesos: AMLO", El Economista, 27 de diciembre, Ciudad de México, <https://n9.cl/mv93h>, 26 de enero de 2020.

Porter, Michael E., Scott Stern y Roberto Artavia Loria [2015], "Social Progress Index", Choice Reviews Online, 53(03), 53-1089-53-1089.

Programa de las Naciones Unidas para el Desarrollo (PNud) [2018], Índices e indicadores de desarrollo humano, Suiza, Programa de Las Naciones Unidas para el Desarrollo, $123 \mathrm{pp}$.

RAZIN, Assaf [2004], "Welfare Migration: Is the Net Fiscal Burden a Good Measure of its Economic Impact on the Welfare of the Native-Born Population?", CESifo Economic Studies, 50(4): 709-716, <https://n9.cl/ytcrq>, 23 de enero de 2020.

y J. Wahba [2015], "Welfare Magnet Hypothesis, Fiscal Burden, and Immigration Skill Selectivity", The Scandinavian Journal of Economics, 117(2): 369-402. <https:// n9.cl/aiy38>, 13 de enero de 2020.

Sunkel, O., y P. Paz [1999], El subdesarrollo latinoamericano y la teoría del desarrollo, México, Siglo xxi, $395 \mathrm{pp}$.

Telford, T. [2019], "Income inequality in U.S. is at a five-decade high, Census data show", The Washington Post, Washington D. C., <https://n9.cl/rh2bl>, 15 de enero de 2020.

The Social Progress Imperative [2019], 2019 Social Progress Index, The Social Progress Imperative, Boston, <https:// n9.cl/aqknz>, 20 de enero de 2020. 
United Nations [2018], Transforming Our World: The 2030 Agenda for Sustainable Development. United Nations, Washington D. C., United Nations, <https://n9.cl/csu9>, 13 de enero de 2020.

VALENZUela, J. C. [1990], ¿Qué es un patrón de acumulación?, México, Facultad de Economía, unam, 189 pp. 


ECOSISTEMAS Y BIENESTAR 



\title{
MEDIO AMBIENTE: BIENESTAR INDIVIDUALY COLECTIVO
}

\author{
Alonso Aguilar Ibarra*
}

\section{INTRODUCCIÓN}

Cuando se habla de bienestar en una sociedad es importante distinguir lo individual de lo colectivo para evaluar y poner en práctica políticas públicas. En efecto, Sadique [2006], en relación con la epidemiología de enfermedades transmisibles, menciona la importancia de la responsabilidad individual de vacunarse (o usar cubrebocas) para contribuir al bienestar colectivo. Esto es también evidente para las cuestiones ambientales, ya que decisiones que toman individuos pueden afectar el bienestar de otros actores, incluso de toda la sociedad. Ejemplos como la generación de residuos domésticos, la contaminación del agua o el aire y aun la pérdida de ecosistemas y biodiversidad afectan a toda la sociedad a partir de las acciones de unos cuantos.

Entonces, la manera de tomar decisiones individuales debe analizarse como parte de la acción colectiva [Ostrom, 2003]. Así, los recursos de uso común están sujetos a las decisiones individuales que afectan el colectivo de otros usuarios y viceversa. La teoría de la acción colectiva analiza las condiciones de interacción entre los grupos de usuarios frente a los recursos naturales compartidos [Barsimantov y Kendall, 2012]. Esta interacción incluye los costos y beneficios de la cooperación, el

* Investigador del Instituto de Investigaciones Económicas, UNAM. Correo electrónico: <aaguilar@iiec.unam.mx>. 
desarrollo de las instituciones, el monitoreo, las reglas, los factores externos y la naturaleza del recurso natural [Adams et $a l ., 2003]$. Dietz, Ostrom y Stern [2003] se preguntan si es posible gobernar recursos comunes, como los océanos y el clima. Este es un dilema que comprende el bienestar general que es afectado por millones de decisiones individuales que se toman cada día y que Muradian y Cardenas [2015] consideran que puede caracterizarse como un dilema de acción colectiva y no tanto como una falla de mercado, como la economía tradicional neoclásica lo ha concebido tradicionalmente.

El objetivo de este capítulo es demostrar que el bienestar de una sociedad no solo es un aspecto individual sino también colectivo. En la primera parte del capítulo se desarrolla la problemática de la degradación ambiental como un resultado de la falta de claridad en el régimen de propiedad de los recursos naturales y el medio ambiente. La siguiente sección trata sobre la teoría de los bienes públicos y los recursos de uso común, fundamentada con ejemplos reales.

\section{TEORÍA DE LOS BIENES PÚBLICOS Y LOS RECURSOS DE USO COMÚN}

Gran parte de la degradación ambiental es resultado de la falta de claridad en el régimen de propiedad de los recursos naturales y el medio ambiente. Entonces, para relacionar los aspectos ambientales con el bienestar social es necesario definir la escala de análisis y el régimen de propiedad. Ambos conceptos están estrechamente relacionados porque la definición de propiedad y, por tanto, la manera de administrar un territorio o actividad dependen de ello. Por ejemplo, un ejido es al mismo tiempo un régimen de propiedad privado y común [Bray, 2013]. En otras palabras, un grupo de personas, en este caso ejidatarios, poseen un título legal que les acredita un espacio el cual una persona ajena al mismo no tiene el derecho de traspasar. Es un equivalente a propiedad privada. Efectivamente, cuando un 
particular identificable tiene un certificado de propiedad para un bien, este no puede pertenecer a otra persona, a menos que se concierte un intercambio voluntario. Sin embargo, al mismo tiempo la naturaleza misma del ejido implica una propiedad comunal, donde un grupo de personas comparten la administración y decisiones de la misma.

Este efecto de escala también se manifiesta a nivel de países. En el caso de los recursos naturales, estos son propiedad de la nación, de acuerdo con el Artículo 27 constitucional. Es decir, son propiedad exclusiva de México, no de otro país. Dentro de la nación, el gobierno salvaguarda, controla y administra los recursos naturales. Estos son bienes comunes porque hay muchos dueños y todos ellos podrían tener acceso a los recursos naturales: son, de facto, de libre acceso. Por tanto, se necesitará restringir el acceso en aras del bien común y se puede conceder o permitir el uso a un individuo o grupo.

Esta conceptualización entre acceso individual o grupal es la cuestión clave sobre el bienestar social con respecto al medio ambiente. En otras palabras, las decisiones o acciones que tome un individuo o grupo afectarán el bienestar colectivo y viceversa. Efectivamente, acciones de muchos agentes o actores van a influir en cada uno de los individuos involucrados en la actividad. Por ejemplo, en un lago donde se lleva a cabo la actividad pesquera, los peces que son extraídos por un pescador individual dejan de estar disponibles para otros. Si cada uno de estos individuos trata de sacar la mayor cantidad posible de peces, con el tiempo ya no podrá sacar más, porque se habrán agotado y tanto el bienestar común como el colectivo serán afectados negativamente con la desaparición de la actividad pesquera, junto con todos sus beneficios. Este tipo de recursos o bienes se conoce como bienes de uso común. Si hay una percepción de que los recursos son de todos y al mismo tiempo de nadie, entonces el riesgo de colapso aumenta.

Bienes de uso común y bienes públicos son conceptos que se confunden, es decir, erróneamente se los considera sinónimos 
[Brando et al., 2019]. Por un lado, los bienes públicos "puros" tienen dos características fundamentales:

- La no exclusión: se le ofrece a todos los usuarios e incluso los que no pagan por el bien lo pueden disfrutar (el gorrón o free-rider).

- No rivalidad o indivisibilidad en el consumo: el hecho de consumir un bien no reduce su disponibilidad.

Cuando estas características se presentan, no hay mercados dispuestos a proveer el bien o el recurso [Budds y McGranahan, 2003]. Los ejemplos incluyen: un paisaje bonito, aire o agua limpios, biodiversidad, áreas naturales protegidas, faros, banquetas, presas, servicios públicos (drenaje, la defensa nacional y otros servicios gubernamentales).

En contraste, los bienes de uso común constituyen lo que se conoce como la "tragedia de los comunes". El autor de este concepto, Garrett Hardin, publicó en 1968 un artículo muy influyente en el cual se refería a la pérdida de recursos compartidos en el sentido de una tragedia griega. Así, este tipo de recursos tenían un final predeterminado e inevitable: su pérdida eventual. Otra forma de explicarlo es que los usuarios no tienen suficientes incentivos para invertir en la conservación del recurso en el largo plazo [Basurto, 2005]. A pesar de las numerosas críticas que el artículo ha recibido [Dietz, Ostrom y Stern, 2003], su importancia radica en haber detonado el debate sobre el régimen de propiedad y la distinción entre bienestar individual y colectivo. Elinor Ostrom, Premio Nobel de Economía 2009, fue quien redirigió la discusión, no hacia el recurso per se, sino hacia la gobernanza [Berge y van Laerhoven, 2011; Barsimantov y Kendall, 2012], es decir, hacia el comportamiento humano.

Ostrom centró sus análisis en la gobernanza de los recursos de uso común o de libre acceso. En la figura 1, se muestra esta diferencia junto con los recursos o bienes privados y los de tipo "club". 
Figura 1.Gobernanza de los recursos

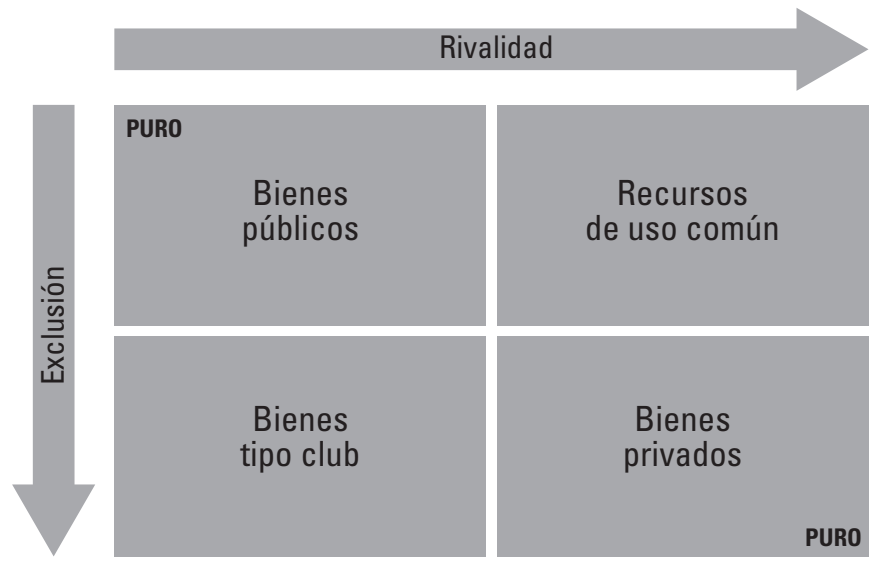

En un extremo superior izquierdo de la figura se encuentra la situación de los bienes públicos puros que, como ya se mencionó, se caracterizan por una baja rivalidad y una baja exclusión. En el otro extremo, los bienes privados "puros" tienen una alta rivalidad y alta exclusión: es la propiedad privada per se. Entonces, el mayor dilema es la gestión de los recursos de uso común, que poseen las características de alta rivalidad, pero baja exclusión. Esto significa que son los recursos que pueden agotarse si no hay una regulación efectiva para su acceso. Este libre acceso es la consecuencia de la baja exclusión del recurso natural y que lleva a la conocida "tragedia de los comunes".

Hay otro régimen en el cual los recursos no pertenecen a persona o país alguno: res nullis (como la Luna, la Antártida o altamar). Este caso es parecido al de recursos de uso común: hay una percepción que nadie es responsable de su mantenimiento o cuidado.

¿Cómo se expresan estos conceptos en la práctica? A continuación se presentan algunos ejemplos. 
EJEMPLOS EN LOS QUE EL BIENESTAR INDIVIDUAL INTERFIERE CON EL BIENESTAR COLECTIVO

Como ya se señaló, los bienes públicos son de baja rivalidad y baja exclusión. En otras palabras, el uso de alguna persona o grupo no afecta a otras personas o grupos. La mayor implicación aquí es una cuestión de equidad en la responsabilidad ya que si solo una parte de la sociedad paga por el bien o servicio, de todos modos el resto se beneficia de ello. Por ejemplo, si los impuestos permiten que el Estado provea de calles limpias y bien pavimentadas, quien no los paga será beneficiado. Esto se conoce como el efecto del polizón (free-rider en inglés). Una posible consecuencia del efecto polizón es que si las personas que cumplen con la regla o el pago se dan cuenta que pueden ser también polizones sociales, entonces pueden dejar de cumplir, en detrimento del bienestar general. Eventualmente, el bien podría convertirse en servicio o bien de club, en caso de que el Estado decida concesionarlo a particulares para que lo provean y quienes puedan pagar lo podrán tener. No es una privatización total, pero sí aumenta la exclusión. Ejemplos serían el aumento de empresas de seguridad privada o de agua embotellada.

Es pertinente introducir aquí el concepto de "mal público". Es análogo al bien público solo que genera malestar en lugar de bienestar. El ejemplo más claro es el de la contaminación atmosférica. El aire contaminado afecta a todos los actores, quienes buscan o desean la exclusión de este. El cambio climático también sería un ejemplo, pero a nivel global. En contraste, el aire limpio se vuelve un bien escaso y está sujeto a la acción colectiva; es decir es un bien común [Everard et al., 2013]. En la figura 1, se le podría representar en la división entre el cuadro superior izquierdo (público) y el derecho (de uso común). Así, esta complejidad por la falta de definición clara en el régimen de propiedad dificulta la gestión ambiental. 
Los efectos en el bienestar colectivo, en comparación con el bienestar privado, son más evidentes cuando se analizan los recursos de uso común. En este caso y, a diferencia de los bienes públicos, sí hay quienes son beneficiados y eso es lo que evita que otros se beneficien, lo que se conoce como una alta rivalidad.

Una situación que evidencia las afectaciones en el medio ambiente (y numerosos actores) es el cambio de uso de suelo. Si no hay títulos de propiedad claros (o no hay aplicación de la ley para hacerlos cumplir), cualquier agente puede utilizar el espacio para su beneficio individual. Por ejemplo, en un territorio con un alto capital natural, los servicios ecosistémicos proveen beneficios indirectos para la sociedad. Algunos de estos pueden ser: captura y almacenamiento de carbono en biomasa y suelos; infiltración de agua para recargar acuíferos; regulación regional del clima; protección para la biodiversidad; valor estético o cultural, entre otros. Aunque nadie paga directamente por ellos, muchas personas se benefician de la disminución de emisiones de gases a efecto invernadero, la disponibilidad de agua, un clima más benigno, menos inundaciones. La tala desregulada o ilegal transforma estos ecosistemas y los beneficios ambientales se pierden para muchas personas y solo benefician a un reducido grupo de usuarios.

Existe evidencia en México que una definición clara de la propiedad e incentivos adecuados para un manejo sostenible de los recursos naturales llevan a un equilibrio entre los beneficios individuales y los colectivos. Así, las investigaciones de Johnson y Nelson [2004] y de Barsimantov y Kendall [2012], entre otros, encontraron que la propiedad común (por ejemplo, ejidos) donde los usuarios cooperan, monitorean y cumplen los acuerdos, está relacionada con la reducción de la deforestación. Entonces, una gobernanza ambiental efectiva trae beneficios generalizados no solo hacia el ecosistema, sino también a la sociedad y la economía local. 
Otro caso es el agua, que es complejo e interesante. Por ello su análisis debe ser detallado y específico. Hay una gran diversidad de usos para el agua: por un lado están la extracción para la producción o el consumo y, por otro, la descarga de desechos a cuerpos de agua. Como se mencionó en la sección anterior, este es un ejemplo muy claro de un recurso de uso común con alta rivalidad. La exclusión está determinada principalmente por el tipo de tecnología necesaria para utilizarla y, como consecuencia, de quien la financia. Efectivamente, mientras que todos los miembros de la sociedad tienen derecho a la misma, no todos tienen el dinero o la tecnología para extraerla, potabilizarla y distribuirla. Para ello el Estado puede invertir o, de otro modo, concesionar estos servicios a particulares. Esto se conoce como privatización, aunque no es estrictamente del agua per se (ya que es un flujo permanente), sino de tales servicios.

Aunque en el tema del agua se utilizan los términos público y privado, aquí insistimos que el agua no es un bien público. Es un bien de uso común y tomar en cuenta esta definición es muy importante para una gestión sostenible y justa. De hecho, el término "privatización del agua" es un término muy general que incluye toda una gama de posibilidades de participación del sector privado. De acuerdo con Budds y McGranahan [2003], esta dicotomía "público-privado" puede distraer del verdadero problema de la justa distribución y el acceso al agua por parte de toda la sociedad. Una alternativa a este debate es el manejo comunitario del agua, que se lleva a cabo en varios países de Latinoamérica y que en México está muy acotado por las restricciones del marco legal actual [Silva et al., 2015].

La pesca también es un ejemplo frecuentemente evocado para mostrar los efectos de la falta de claridad en el régimen de propiedad. Los recursos acuáticos están sujetos a una extracción caracterizada por la falta de exclusión de usuarios compitiendo por un bien de alta rivalidad. En efecto, los peces 
extraídos por un pescador ya no pueden ser aprovechados por otro. Si no hay freno al libre acceso (en otras palabras, si se permite la baja exclusión), es posible que los recursos pesqueros se agoten y las consecuencias pueden ser no solo ecológicas sino también económicas y sociales. Dicho de otro modo: el bienestar social o común disminuye.

Hay ejemplos en la pesca en los cuales bajo límites definidos de cuasipropiedad y sobre todo la organización efectiva de los usuarios concernidos permiten una utilización sostenible del recurso pesquero. Basurto [2005] describe, por ejemplo, el caso del pueblo Seri, que está organizado con reglas de acceso, control, monitoreo y sanciones. Ello permite la continuidad de la actividad pesquera de manera sostenible, con los beneficios económicos que son preservados para las generaciones futuras. Otro caso es el de las cooperativas que aprovechan recursos marinos como el abulón y la langosta en la península del Vizcaíno, entre los estados de Baja California y Baja California Sur. La efectiva organización dentro de las cooperativas ha permitido, incluso, la certificación internacional de productos pesqueros [McCay, 2017].

\section{CONSIDERACIONES FINALES}

Los ejemplos que se mencionaron en la sección anterior dan cuenta de la complejidad de los conceptos de los bienes públicos, privados y comunes. De hecho, es importante reiterar que el esquema de la figura 1 debe interpretarse como un gradiente de posibilidades entre los extremos. Dependiendo de la escala de análisis, el contexto geográfico y otros factores, como el número de usuarios involucrados, un bien puede percibirse en la "frontera" del concepto bien público y de recurso de uso común. Tal es el ejemplo ya mencionado del aire limpio.

Por lo mismo, las cuestiones ambientales y de otros aspectos de política pública no deberían centrarse en el debate 
público-privado [Budds y McGranahan, 2003], sino en una gobernanza que permita conciliar el bienestar común con el individual. Así, en lugar de pensar de forma dicotómica, un nuevo enfoque más integral y que tome en cuenta la diversidad y complejidad de los problemas ambientales es más deseable [Adams et al., 2003; Berge y van Laerhoven, 2011].

Entre los principales dilemas de política bajo este enfoque de bienes comunes se pueden mencionar dos. Uno es la dificultad de conciliar percepciones distintas entre actores o instituciones [Adams et al., 2003]; se requiere una labor de transmisión de información y conocimientos entre distintos participantes, de manera que el riesgo de conflicto disminuya. Y otro es la naturaleza global y compleja de muchos bienes que comparte la humanidad [Dietz et al., 2003; Berge y van Laerhoven, 2011], como el hoyo en la capa de ozono, la acidificación de océanos, las islas de basura, la pérdida de biodiversidad e incluso el genoma humano y el internet. Estos dilemas requieren una estructura multicapa de gobernanza. Es decir, una armonización de objetivos de políticas locales, regionales y mundiales.

Las políticas públicas que distinguen el bienestar común del individual no solo deberían enfocarse en temas ambientales sino también hacia el resto de los sectores. Un caso es el sector salud. El término "público" aquí también tiene significados diferentes. Por un lado, genera la idea de la responsabilidad primaria de un Estado para proveer la infraestructura, el personal y los servicios para prevenir y curar enfermedades. El gobierno, entonces, puede (o no) delegar algunos servicios al sector privado (como la producción de medicinas). El sector privado puede, a su vez, ofrecer los servicios médicos y hospitalarios para la población que esté dispuesta a pagar por ellos y ampliar la oferta de servicios médicos.

Por otro lado, sin embargo, en cuanto a la gestión pública de salud, es importante identificar que aun cuando sea el Estado quien ofrezca los servicios médicos a la población, se debe 
tomar en cuenta que la infraestructura, el personal médico, administrativo, de enfermería o de limpieza son recursos de uso común y no públicos, si aplicamos la terminología que se desarrolló en el presente capítulo. En otras palabras, si bien el acceso a hospitales y citas médicas es abierto para la población que lo necesite (baja exclusión), hay una capacidad limitada física y humana (por tanto, financiera) para atender a todas las personas que lo requieren (alta rivalidad). Entonces, se debe tener claro cómo organizar dichos servicios y además prever la capacidad para ofrecerlos, de modo que la planeación gubernamental para cumplir su cometido sea adecuada y cumpla el objetivo de proveer (en cantidad y calidad) servicios de salud a la población. El sector educativo sería un ejemplo similar.

En resumen, las ideas que Elinor Ostrom dejó como respuesta a la tragedia de los comunes pueden aplicarse para mejorar la gobernanza de cuestiones ambientales, pero también de otros sectores en los cuales debe conciliarse el bienestar individual con el colectivo. Tomarlas en cuenta ayudará, sin duda, a disminuir conflictos y reducir la inequidad en el acceso a bienes y servicios de los recursos naturales.

\section{REFERENCIAS}

Adams, W. M., et al. [2003], "Managing tragedies: understanding conflict over common pool resources", Science, 302(5652): 1915-1916.

Barsimantov, J., y J. Kendall [2012], "Community forestry, common property, and deforestation in eight Mexican states", The Journal of Environment and Development, 21(4): 414-437.

Basurto, X. [2005], "How locally designed access and use controls can prevent the tragedy of the commons in a Mexican small-scale fishing community", Society and Natural Resources, 18(7): 643-659. 
Berge, E., y F. van Laerhoven [2011], "Governing the Commons for two decades: a complex story", International Journal of the Commons, 5(2): 160-187.

BRANDO, N., et al. [2019], "Governing as commons or as global public goods: two tales of power", International Journal of the Commons, 13(1).

BraY, D. B. [2013], "When the state supplies the commons: origins, changes, and design of Mexico's common property regime", Journal of Latin American Geography, 12(1): 33-55. BudDs, J., y G. McGranahan [2003], "Are the debates on water privatization missing the point? Experiences from Africa, Asia and Latin America", Environment and Urbanization, 15(2): 87-114.

Dietz, T., E. Ostrom y P. C. Stern [2003], “The struggle to govern the commons", Science, 302(5652): 1907-1912.

Everard, M., et al. [2013], "Air as a common good", Environmental Science and Policy, 33:354-368.

Johnson, K. A., y K. C. Nelson [2004], "Common property and conservation: the potential for effective communal forest management within a national park in Mexico", Human Ecology, 32(6): 703-733.

McCAY, B. J. [2017], "Territorial use rights in fisheries of the northern Pacific coast of Mexico", Bulletin of Marine Science, 93(1): 69-81.

Muradian, R., y J. C. Cardenas [2015], "From market failures to collective action dilemmas: Reframing environmental governance challenges in Latin America and beyond", Ecological Economics, 120:358-365.

Ostrom, E. [2003], "How types of goods and property rights jointly affect collective action", Journal of Theoretical Politics, 15(3): 239-270.

Sadique, M. Z. [2006], "Individual freedom versus collective responsibility: an economic epidemiology perspective", Emerging Themes in Epidemiology, 3(1): 12. 
SiLvA, J. A., et al. [2015], "Community water management in Latin America and the Caribbean: Challenges for Mexico", Journal of Sustainable Development, 8(3): 102-112. 



\title{
LA RESILIENCIA COMO UNA MEDIDA DE BIENESTAR DE LOS HOGARES
}

\author{
Véronique Sophie Ávila Foucat*
}

\section{INTRODUCCIÓN}

El sector agropecuario tiene cada vez menor posibilidad de revertir la pobreza debido a la desaceleración de la productividad [Dev y Nuthalapati, 2010], lo que a su vez genera una menor capacidad laboral. De 2000 a 2012, el crecimiento del PIB del sector ha sido de $2 \%$ y la productividad laboral está estancada porque no se han podido diversificar los mercados ni han aumentado las inversiones [FAO-Sagarpa, 2013]. Es por ello que los hogares optan por varias estrategias de vida, como la intensificación, la migración o la diversificación de actividades y en particular en el sector terciario. Sin embargo, la inserción laboral a las actividades no agrícolas no es inmediata y requiere estudiar sus determinantes tomando en cuenta la heterogeneidad de los productores en el país. La extensión de tierra, las capacidades productivas, la infraestructura y el acceso a créditos son algunos de los aspectos que muestran las diferencias a lo largo del país [Inegi, 2014]. Cada uno de estos factores, así como el contexto institucional y de política pública, influyen en las decisiones de los hogares y en su bienestar. Aunque las mediciones de pobreza multidimensional y el índice de desarrollo humano de alguna manera capturan parte de estos aspectos, no reflejan el dinamismo de los hogares con

* Investigadora del Instituto de Investigaciones Económicas, UNAM. Correo electrónico: <savila@iiec.unam.mx>. 
respecto al uso de sus activos en tiempo y espacio, ni la diversidad y la conectividad de sus activos. Las estrategias de vida y los activos que las determinan, así como su contexto, les confieren su capacidad de resiliencia. La resiliencia es vista como las capacidades para enfrentar, adaptar y transformase sin perder su identidad como un sistema que se conforma de la relación sociedad-naturaleza. La capacidad tanto de respuesta como la de transformación son aspectos de la dinámica de los hogares que deben ser estudiados. Por ello este capítulo destaca la importancia de considerar los factores que impulsan la resiliencia de los hogares, como la diversificación sustentable mediada por el acceso a los activos de los hogares y contextos ambientales y sociopolíticos.

\section{EsTRATEGIAS DE VIDA DE LOS HOGARES}

Los hogares establecen estrategias para sobrevivir y enfrentar diversos shocks y estresores. Ellis [2000] indica que los individuos de un hogar toman decisiones en conjunto, es decir, generan estrategias para afrontar las adversidades o la vida diaria; por ejemplo, un hogar puede decidir que uno de sus miembros migre con la intención de que esto beneficie a toda la familia. En otras ocasiones, las decisiones son individuales pero reflejan las condiciones de un hogar y generan efectos positivos o negativos al mismo, por lo que son decisiones que afectan al conjunto de los miembros del hogar. Las principales estrategias que se han identificado, aunque no las únicas, son la intensificación de una actividad casi siempre asociada con la actividad agrícola, la migración -que puede ser nacional o internacional-y la diversificación de ingresos y actividades. Las estrategias de los hogares se definen como las actividades, los activos y el acceso a los mismos requeridos para generar medios de vida [Chambers y Conway, 1991]. Por tanto, una estrategia es el conjunto de actividades y activos que permiten 
generar el conjunto de diversas formas de sustento. Por ejemplo, un hogar cuya estrategia es la diversificación puede dedicarse a la agricultura, pero también tener un taxi o una tienda, es decir, que esta estrategia está conformada por varios medios de vida.

El marco teórico de medios de vida tiene sus raíces en el pensamiento de la teoría del desarrollo y bienestar de Amartya Sen, quien postulaba que el bienestar no solo depende de los derechos a la salud, la educación o el medio ambiente, sino de las capacidades que los individuos tienen para acceder a estos derechos y libertades. En su trabajo sobre la hambruna, menciona que el problema no era la falta de alimento, sino la distribución del mismo, esto es, el acceso a los alimentos y las capacidades de la sociedad para poder aprovecharlos.

Por tanto, la teoría de medios de vida indica que las estrategias son posibles gracias a ciertos activos que se han clasificado en humano, social, financiero, físico y natural. Estos se convierten en capitales cuando se utilizan como insumos para generar un ingreso o se acumulan para emplearse en un futuro. El término capitales ha sido criticado porque se asocia con un pensamiento neoliberal y capitalista, en el que los activos generan bienestar solo cuando son acumulados para generar un ingreso. Sin embargo, hoy en día se reconoce que los capitales generan beneficios intangibles y que existe bienestar sin que esté asociado con un ingreso. Por ejemplo, la propuesta de la Plataforma Intergubernamental Científico-Normativa sobre Diversidad Biológica y Servicios de los Ecosistema enfatiza que existen beneficios tangibles que los ecosistemas proveen a la sociedad en términos monetarios, pero también beneficios intangibles como los culturales que tienen el mismo valor para la sociedad. Asimismo, indica que la naturaleza tiene valores intrínsecos [Díaz et al., 2015]. De igual manera, el capital social no solo tiene un valor monetario sino ético y civilizatorio. El cuadro 1 presenta en qué consiste cada uno de los capitales. 


\section{Cuadro 1. Descripción de los capitales asociados con las estrategias de los hogares}

\begin{tabular}{|c|c|c|}
\hline Capitales & Descripción & Ejemplo \\
\hline Humano & $\begin{array}{l}\text { Características sociodemo- } \\
\text { gráficas del hogar y capaci- } \\
\text { tación }\end{array}$ & Edad, educación, cursos \\
\hline Financiero & $\begin{array}{l}\text { Todas la fuentes de ingreso } \\
\text { del hogar }\end{array}$ & $\begin{array}{l}\text { Ingreso agrícola, ahorro, } \\
\text { crédito, remesas }\end{array}$ \\
\hline Social & $\begin{array}{l}\text { Interacciones internas y } \\
\text { externas }\end{array}$ & $\begin{array}{l}\text { Reglas de la comunidad, } \\
\text { apoyos de externos }\end{array}$ \\
\hline Físico & $\begin{array}{l}\text { Infraestructura de producción } \\
\text { y de la vivienda }\end{array}$ & $\begin{array}{l}\text { Tractores o infraestructura } \\
\text { de riego o bien telecomunica- } \\
\text { ciones }\end{array}$ \\
\hline Natural & $\begin{array}{l}\text { Beneficios que proveen los } \\
\text { ecosistemas }\end{array}$ & $\begin{array}{l}\text { Aprovechamiento maderable, } \\
\text { agua, tierra, clima }\end{array}$ \\
\hline
\end{tabular}

En ocasiones, no es tan fácil clasificarlos; por ejemplo, las transferencias de gobierno son parte del ingreso de los hogares por lo que son capital financiero, pero hay quien las considera parte del capital social ya que al tener relación con una institución de gobierno es parte de sus redes.

Aunado a los capitales, Ellis [2000] propuso un marco teórico más integral sobre medios de vida sustentables. Este marco teórico indica que el hogar debe realizar actividades sustentables para tener bienestar y que está inmerso en un contexto institucional y de políticas públicas, así como en un ámbito de vulnerabilidad donde existen efectos externos como el cambio climático o la volatilidad de los precios agrícolas. Sin embargo, poco se ha estudiado acerca del componente de sustentabilidad, a diferencia del estudio de los capitales o de los aspectos de mercado o institucionales en los hogares.

Algunos estudios a escala comunidad han incluido los factores externos dentro de un nuevo capital, el institucional o político [Magis, 2010]. Sin embargo, Ellis [2000] los presenta 
como factores externos al hogar y las relaciones institucionales del hogar con el exterior son parte del capital social.

De una u otra forma, lo que esto indica es que los hogares están integrados por sus capitales, el acceso a los mismos y sus actividades, reciben diversos estresores y shocks e interactúan con fenómenos políticos, sociales, económicos y naturales que se dan a otras escalas. Por ello los hogares hoy día se definen como sistemas y en particular como socioecosistemas [Ávila y Martínez, 2018].

Los socioecosistemas son sistemas donde interactúan aspectos sociales y naturales, son dinámicos y afectados por su interacción con otras escalas, es decir, son sistemas anidados [Vidal et al., 2020]. La interacción con otras escalas es bidireccional, a diferencia de como se plantea en otros marcos teóricos. Es decir, que las comunidades tienen el potencial de generar cambios a una mayor escala cuando se generalizan ciertos patrones a lo largo del territorio y también, por supuesto, reciben el efecto de políticas públicas. Lo anterior proviene de varias corrientes de pensamiento; las relacionadas con los recursos naturales son el comanejo, el manejo comunitario y el manejo adaptativo; y la proveniente de las ciencias sociales es la acción colectiva, donde los procesos de participación comunitaria generan mayor legitimidad y la construcción de una acción colectiva que promueve gobernanza.

En la teoría de los sistemas adaptativos complejos, estos hogares tienen una evolución o trayectoria asociada con sus estrategias y los factores que las determinan, y cuando un hogar es capaz de absorber los estresores con la capacidad de aprender y cambiar puede salir de trampas de pobreza o mejorar su condición. Este fenómeno se denomina resiliencia socioecológica de los hogares. Es decir, que un sistema es resiliente si tiene las capacidades de enfrentar los estresores que lo atañen e incluso, en caso de ser necesario (cuando el estado actual no es deseable), generar un cambio y una transformación. La diferencia con el concepto clásico de pobreza 
multidimensional o de bienestar basado en la utilidad es que se estudian los hogares como sistemas complejos.

A continuación describiremos una de las principales estrategias de vida de los hogares, la diversificación, y después la vincularemos con la resiliencia de los mismos.

\section{LA DIVERSIFICACIÓN, UNA ESTRATEGIA DE VIDA}

Un gran porcentaje de los hogares tiene diversas fuentes de ingreso, así como una diversidad de fuentes de empleo y actividades. Por ejemplo, el sector cafetalero en México, que durante muchos años fue una de las principales actividades en estados como Chiapas, Oaxaca, Puebla, Veracruz, ha evolucionado hacia otras fuentes de ingreso [Rodríguez y Burger, 2015]. Esto se debe al proceso de liberalización de la economía mexicana en los años 80, así como a la reducción del apoyo al sector cafetalero por el gobierno reflejada en la desaparición del Instituto Mexicano de Café, lo que provocó que los productores tuvieran que enfrentar el mercado y en particular la disminución de los precios en los años 1990 y 2003, diversificando sus actividades dentro y fuera del sector cafetalero [Rodríguez y Burger, 2015].

La diversificación es el proceso por el cual los hogares crean una cartera de actividades y capacidades para su sobrevivencia y para mejorar el bienestar [Ellis, 2000]. Este proceso puede medirse de diversas formas: utilizando fuentes de ingreso (agrícola, no agrícola), de empleo (formal, informal, autoempleo, asalariado, en el sector primario, secundario, terciario), por el número de actividades independientemente del sector (más de una ya es diversificado) o por el tipo de actividades (sustentables versus no sustentables, organizadas o independientes) [Ávila y Rodríguez, 2018].

La decisión de cómo medir la diversificación está en función de la pregunta de investigación, aunque la variable más 
utilizada en estudios de economía agrícola o economía de los hogares rurales es la del ingreso debido al desplazamiento de las actividades agrícolas por no agropecuarias. En Latinoamérica, entre $20 \%$ y $30 \%$ de los empleos son no agropecuarios y representan $40 \%$ de los ingresos rurales [Reardon, Berdegue y Escobar, 2001], aunque puede variar en función del contexto y de los activos de los hogares [Mushongah y Scoones, 2012]. En México, se ha demostrado que el ingreso no agropecuario representa 49.2\% [Cerón y Yúnez-Naude, 2015] y las actividades no agrícolas más comunes son la construcción, la manufactura, las remesas y el comercio [De Janvry y Sadoulet, 2001; Yúnez-Naude y Taylor, 2001]. Sin embargo, es interesante notar que $23 \%$ de las actividades no agrícolas es diferente a las mencionadas antes, lo que indica que hay varias actividades productivas en el sector rural que no se han estudiado [De Janvry y Sadoulet, 2001]. En este ámbito, caben las actividades sustentables que pueden pertenecer a diferentes sectores.

Lo interesante de la diversificación es que es un proceso, lo que quiere decir que es un fenómeno que tiene causas y efectos que pueden ser distintos en el tiempo, dependiendo de las características de los hogares y del contexto en que se encuentra. En relación con lo anterior, la bibliografía ha hecho esfuerzos por identificar los determinantes de la diversificación y su impacto en el bienestar. En términos generales, la diversificación se da por necesidad (push factors) o por opción (pull factors). La crisis del sector agropecuario, el alza de los precios agrícolas, la disminución del ingreso, el riesgo por cambio climáticos, los altos costos de transacción o la pobreza extrema son algunas de las razones que obligan a los hogares a buscar nuevas fuentes de ingreso. En cambio, acceder a nuevos mercados o mercados más específicos es una estrategia económica opcional para complementar el ingreso [Barret, Reardon y Webb, 2001; YúnezNaude y Taylor, 2001; Reardon, Berdegue y Escobar, 2001].

En particular, en este apartado queremos enfatizar los determinantes para diversificarse en actividades sustentables, 
como el ecoturismo o el pago por servicios ambientales, debido a que si bien el marco teórico propuesto por Ellis [2000] promueve los medios de vida sustentables, poco se ha estudiado desde el ámbito de los hogares.

En el caso del ecoturismo, Ávila y Rodríguez [2018] han demostrado que los hogares que cuentan con integrantes jóvenes, con un mínimo de tierra de cultivo para autoconsumo, así como con conocimiento o conciencia ambiental, con participación comunitaria y que tienen transferencias de gobierno son aquellos que deciden diversificarse en ecoturismo. Por otro lado, se ha visto que las remesas no determinan la diversificación en ecoturismo [Aragonés, Ávila y Salgado, 2016]. Por lo anterior, parecería más una actividad que se da como una opción alternativa más que como una actividad obligada por factores estructurales.

Por otra parte, el pago por servicios ecosistémicos (PSE) es un esquema de incentivos económicos voluntarios que fue creado para compensar a los hogares o comunidades que conservan el bosque generando así un beneficio para otros pobladores. El PSE es una transacción voluntaria en la que los beneficiarios de los servicios ecosistémicos (usuarios) proveen una compensación a los que generan dichos servicios (comunidades) condicionada al manejo sustentable del ecosistema [Wunder, 2015]. El incentivo económico hará que la conservación sea más atractiva y evitará la deforestación [Wunder, 2006; Engel, Pagiola y Wunder, 2008].

Por ejemplo, el pago por servicios hídricos es un mecanismo creado primeramente por la Comisión Nacional Forestal (Conafor) por el que el gobierno federal provee a los beneficiarios un monto anual en función de que la cobertura forestal se conserve por el tiempo que dura el contrato (cinco años). Después, con la idea de transitar de un esquema federal a un esquema de mercado se crearon los mecanismos locales que son fondos concurrentes entre la Conafor y otro actor local. Existen varios esquemas de este tipo en nuestro país y por lo general están 
involucrados como contrapartes los organismos operadores de la distribución del agua y organizaciones no gubernamentales. Las compensaciones son condicionadas a la conservación del bosque y/o a un manejo adecuado del mismo [Rodríguez, Ávila y Maldonado, 2015; Nava et al., 2018]. Existen muchas publicaciones a nivel mundial que analizan el impacto de dichos pagos, así como los determinantes para participar en estos esquemas. Debido a que las transferencias de gobierno son un componente importante en las economías de los hogares rurales, este tipo de esquemas es de interés para la diversificación sustentable. Jones et al. [2018] demostraron que existen factores tangibles e intangibles que influyen en la participación de los hogares en esta política; que el capital humano, natural, físico y financiero influye en la decisión de participar en estos esquemas, pero también las motivaciones en torno al ambiente. De manera similar, se demostró que la participación en PSE depende de la identidad indígena del hogar y de su gobernanza [Rodríguez, Ávila y Maldonado, 2015].

Otra forma de aprovechamiento sustentable es el aprovechamiento de la vida silvestre bajo protocolos de manejo. En este sentido, está comprobado que el aprovechamiento de recursos silvestres funciona como una forma de seguro para las familias de zonas rurales [Kar y Jacobson, 2012] y tiende a reducir tanto la pobreza como la desigualdad [López, 2014]. En particular, el aprovechamiento de leña [Perevochtchikova et al., 2015], plantas medicinales y no maderables es importante para las comunidades y depende de las condiciones de las mismas. Por tanto, podemos observar que el enfoque de capitales determina las diversas formas de diversificación.

Los factores regionales que determinan la diversificación son la infraestructura carretera [Corral y Radchenko, 2018], el cambio climático [Fierros y Ávila, 2017; Hernández y Ávila, 2019; Corral y Nadchenko, 2017] y factores físicos como la altitud [Rodríguez y Burger, 2015]. Asimismo, las transferencias de gobierno [Liu y Lan, 2015; Saenz y Thompson, 2017] 
son un factor importante aunque en ocasiones se considera dentro del capital financiero como en el caso del ecoturismo. De manera similar, las redes se han considerado parte del capital social o se han analizado de manera específica [Baird y Gray, 2014; Johny, Wichmann y Swallow, 2017]. Finalmente, en economía agrícola existe un interés particular por analizar la diversificación de cultivos debido a su importancia para la seguridad alimentaria [Tesfaye y Tirivayi, 2020; Bellon et al., 2020]. Aunque este es un tipo de diversificación distinta a la que se plantea en este capítulo, es importante para los hogares rurales.

Con respecto a la diversificación sustentable, las unidades de manejo y aprovechamiento de la vida silvestre están asociadas con regiones con menor marginación, pero no dependen de la población económicamente activa ni del tipo de vegetación [Ávila y Pérez, 2015]. Es decir, a pesar de que surgieron como una estrategia de diversificación productiva para los ganaderos del norte de México después del Tratado de Libre Comercio, son un esquema que existe en todo el país, con diferentes formas de uso de los recursos y en distintos ecosistemas. Sin embargo, las condiciones estructurales de mercado e infraestructura son importantes para su desarrollo.

Por otro lado, la bibliografía de socioecosistemas ha propuesto la diversificación como una estrategia para absorber y enfrentar los estresores y shocks [Ávila y Martínez, 2018], pero también lo han hecho organizaciones internacionales vinculadas con el cambio climático. Cabe recalcar que la migración o la intensificación no se reconocen como estrategias que promuevan la resiliencia de los hogares debido a que el abandono del campo sería una transformación del sistema y la intensificación ha generado muchos problemas ambientales que a largo plazo no generan resiliencia.

Aunado a lo anterior, Biggs et al. [2012] propusieron algunos atributos para hacer que los sistemas sean resilientes y en 
particular cuando están asociados con los servicios ecosistémicos. Uno de estos atributos es la diversidad e incluye tanto la diversidad de ingresos como la biológica y la social. Por ello, en el apartado siguiente describiremos el papel de la diversificación en la resiliencia de los hogares rurales.

\section{RESILIENCIA DE LOS HOGARES}

La resiliencia es la capacidad del sistema de absorber shocks y estresores y reorganizarse, manteniendo o mejorando su bienestar. Folke et al. [2010] definen la resiliencia como la capacidad de un sistema de absorber un disturbio y reorganizarse mientras el sistema cambia manteniendo sus funciones, estructura y retroalimentación y, por tanto, su identidad, es decir, la capacidad de cambiar para mantener dicha identidad. González [2020] propone, con base en la bibliografía [Ifejika, Wiesmann y Rist, 2014; Biggs et al., 2012], que la resiliencia de los hogares depende de los recursos que estos tienen (capitales), de su capacidad de flexibilidad (diversidad), su habilidad para dirigir sus propias acciones, es decir, de autoorganizarse, (recursos propios, conectividad interna y externa), y su capacidad de experimentar e innovar (aprendizaje). La resiliencia específica se refiere a la reacción de una parte del sistema hacia un disturbio en particular [Carpenter et al., 2001] y generalmente se mide con respecto a la cercanía del sistema a un umbral, es decir, qué tanto está cambiando el sistema por el disturbio [Walker y Salt, 2012]. En contraste, la resiliencia general es la capacidad del sistema que permite absorber todo tipo de disturbios, incluidos los nuevos e imprevistos [Walker y Salt, 2012] y, como consecuencia, permite la adaptación y transformación de los sistemas [Folke, 2016].

Dentro de la resiliencia socioecológica existe un conjunto de siete principios que construyen y fortalecen la capacidad de los sistemas para enfrentar shocks y estresores, sobre todo 
asociados con los servicios ecosistémicos, es decir, con las funciones de los ecosistemas que proveen beneficios a la sociedad. Estos atributos son: diversidad, redundancia, conectividad, umbrales y retroalimentación, aprendizaje, participación, gobernanza [Biggs et al., 2012]. Cada uno de estos atributos aplica para las variables naturales o sociales. La diversidad indica que existen más opciones para enfrentar el cambio; en particular la diversidad de actividades o ingresos, indica que si un disturbio afectó una de las fuentes de ingreso existe la otra. La redundancia implica que una misma función puede ser reemplazada por otra variable; por ejemplo, la alimentación puede provenir de la compra de los alimentos o del autoconsumo. La conectividad es buena para la resiliencia en el sentido de que mientras más conectados estén los elementos del sistema, este responderá más rápido; sin embargo, también puede potenciar malas prácticas. Los umbrales y la retroalimentación hacen referencia a que no deben sobrepasarse ciertos umbrales y que debe haber ciertas interacciones que permitan la existencia de los servicios ecosistémicos. Aprendizaje, participación y gobernanza se relacionan con tener un manejo adaptativo así como una gobernanza adaptativa.

La diversificación es, por tanto, un elemento importante para que los hogares tengan la posibilidad de seguir cambiando para absorber disturbios o bien para pasar a otros estados a fin de transformarse en un mejor estado. Este concepto tiene entonces mucha relación con el concepto de bienestar debido a que salir de trampas de pobreza implica un mejor bienestar. Lo interesante aquí es que la resiliencia es una medida más dinámica e incluyente de muchos elementos que afectan la trayectoria de los hogares. Por ejemplo, Ávila y Martínez [2018] muestran que la diversificación es un elemento importante para la conectividad de los capitales dentro de los hogares para sobreponerse de un huracán. Asimismo, González [2020] demuestra que la diversidad de organizaciones, actividades, cultivos, ganado y peces, como una unidad que 
representa la diversidad, cambió significativamente de un año a otro en hogares rurales de la costa de Oaxaca. Por tanto, la diversificación es una variable importante para la resiliencia de los hogares.

\section{Políticas públicas para la resiliencia} de los hogares como medida de bienestar

Los principales conceptos que se miden en resiliencia son absorción y adaptabilidad, así como diversidad y conectividad, y cambio climático es el principal estresor analizado [González y Ávila, 2019]. Por otro lado, son pocas las publicaciones que miden interacciones y umbrales de los sistemas, y casi no se establecen las relaciones causa-efecto por medio de modelos; en contraste son mucho más comunes los indicadores e índices [González y Ávila, 2019]. Con base en lo anterior podemos decir que para medir resiliencia específica es posible utilizar modelos y estos son viables a nivel nacional para evaluar el efecto de un estresor o de una política en particular. Sin embargo, para la resiliencia general la construcción de índices parece más viable a nivel nacional. Aunque es posible crear una metodología para medir la resiliencia de los hogares, siempre existe la limitante de perder especificidad de los socioecosistemas al generalizar el comportamiento de estos debido a que son muy dinámicos y dependen tanto de sus componentes e interacciones como de su contexto. Es por ello que existen varios esfuerzos por generar observatorios nacionales, como el Laboratorio Nacional de Resiliencia Costera (www.lanresc.mx), que tienen la finalidad de hacer mediciones en varias regiones para comparar procesos y su resiliencia.

Otro de los grandes retos es la información existente en las estadísticas a nivel hogar, como la Encuesta Nacional de Ingresos y Gastos de los Hogares (ENIGH) y la Encuesta Nacional a Hogares Rurales de México (ENHRUM) elaborada por el 
Colegio de México. En ellas puede medirse la diversificación de ingresos, pero ninguna de las dos fue creada con el enfoque de capitales. De manera similar, otras estadísticas económicas o incluso sectoriales no son representativas a nivel hogar y tampoco contemplan el enfoque de capitales [Ávila, 2019]. Con respecto a la información sobre la diversificación sustentable (aquella que tiene como objetivo un mínimo impacto ambiental y aumentar el bienestar de las comunidades locales), tampoco hay estadísticas nacionales ni periódicas; por ejemplo, no existe un seguimiento sobre el desarrollo ecoturístico, agrosilvopastoril, del aprovechamiento de vida silvestre, del turismo cinegético o del manejo forestal comunitario, más allá de las tasas de aprovechamiento. Por tanto, uno de los principales retos es tener estadísticas nacionales para conocer los activos de los hogares rurales y las actividades sustentables que realizan o que podrían realizar. Esto quiere decir que para medir la resiliencia como una medida de bienestar necesitamos hacer una primera medición con la información existente, identificar los vacíos y crear una estrategia para su obtención, que puede ser en colaboración entre varios sectores gubernamentales y con las organizaciones de la sociedad civil.

En relación con las políticas que incentivan la diversificación, actualmente existe el Programa Sembrando Vida, que fomenta la producción agroforestal apoyando con un monto de 5000 pesos mensuales, de los cuales 500 se destinan al ahorro y el resto se entrega en especie, en capacitación o en dinero. Los beneficiarios deben ser sujetos agrarios mayores de edad, que habiten en localidades rurales, con ingreso inferior a la línea de bienestar rural y propietarios o poseedores de 2.5 hectáreas disponibles para ser trabajadas en un proyecto agroforestal. Opera también el programa de apoyo a la economía social que tiene el objetivo de fortalecer organismos del sector social de la economía con actividades o iniciativas productivas que presentan medios y capacidades limitados. Se orienta principalmente a comunidades donde hay presencia 
indígena. El Programa 3x1 para Migrantes apoya rubros de educación, infraestructura y proyectos productivos. A escala comunidad, el monto máximo de apoyo federal será de 500000 pesos por proyecto, de los cuales $25 \%$ corresponderá al gobierno federal, $25 \%$ a las organizaciones de migrantes y $50 \%$ a los gobiernos de las entidades federativas y los municipios; a nivel del hogar, el monto máximo de apoyo federal será de 300000 pesos de los cuales, $50 \%$ corresponde al gobierno federal y $50 \%$ a las organizaciones de migrantes. Sin embargo, en ninguno de estos programas se explicita la prioridad ambiental y la población objetivo no se relaciona con las capacidades sino solo con una medida de marginación.

En cuanto a la política ambiental, tenemos el pago por servicios ambientales, las áreas naturales protegidas y las unidades de manejo y aprovechamiento de la vida silvestre, entre otros, pero el recorte presupuestario de $60 \%$ de 2015 a 2019 al sector deja mucho que desear.

Aunado a lo anterior, si bien existen algunos esfuerzos de integración de temas ambientales en otros sectores como la biodiversidad en la agricultura y en turismo (estrategias de integración de la biodiversidad), o bien el programa de cambio climático, es menester una mayor coherencia en las políticas públicas y un enfoque más sistémico en su planteamiento y operación.

En conclusión, con la información y las políticas públicas actuales no estamos fortaleciendo los hogares y las comunidades para que sean resilientes y puedan transformarse hacia un mejor estado de bienestar.

REFERENCIAS

Aragonés, Ana M., V. Sophie Ávila Foucat y Uberto Salgado [2016], "Migración rural, remesas y su relación con la diversificación sustentable y los patrones de consumo. Un 
estudio de caso en la zona costera de Oaxaca", Migración y Desarrollo, 14(27): 109-138, julio-diciembre.

Ávila Foucat V. Sophie [2019], "Resiliencia en comunidades rurales", en Rolando Cordera y Enrique Provencio (coords.), A 10 años de la Gran Recesión. Desastres y desarrollo, México, PUED, UNAM.

y F. Martínez [2018], "Household' Resilience to Hurricanes in Coastal Communities of Oaxaca, Mexico", Society \& Natural Resources: An International Journal, 30(29): 807-821.

y Karla Rodríguez [2018], "Determinants of livelihood diversification: the case wildlife tourism in four coastal communities in Oaxaca, Mexico", Tourism Management, 69:223 - 231.

y Enrique Pérez Campuzano [2015], "Municipality socioeconomic characteristics and the probability of occurrence of Wildlife Management Units in Mexico", Environmental Science \& Policy, 45:146-153.

BAIRD, Timothy y Clark Gray [2014], "Livelihood Diversification and Shifting Social Networks of Exchange: A Social Network Transition?", World Development, 60:14-30.

BARRETT, Cristopher, Thomas Reardon y P. Webb [2001], "Nonfarm Income Diversification and Household Livelihood Strategies in Rural Africa: Concepts, Dynamics and Policy Implications", Food Policy, 26(4): 315-333.

BeLlon, Mauricio et al. [2020], "To diversify or not to diversify, that us the question. Pursuing agricultural development for smallholder farmers in marginal areas of Ghana", World Development, 125:1-10.

Biggs, Reinette et al. [2012], "Toward Principles for Enhancing the Resilience of Ecosystem Services", Annual Review of Environment and Resources, 37:421-448, noviembre.

CARPEnTER, Steve et al. [2001], "From Metaphor to Measurement: Resilience of What to What?", Ecosystems, 4:765-781. 
Cerón, Hazael y Antonio Yúnez-Naude [2015], "Diversificación en la economía rural hacia actividades no agropecuarias y sus impactos en pobreza y desigualdad", en Antonio Yúnez-Naude et al. (coords.), La economía del campo mexicano: tendencias y retos para su desarrollo, México, El Colegio de México.

Chambers, Robert y Gordon Conway [1991], "Sustainable rural livelihoods: Practical concepts for the 21st Century", IDS Discussion Paper, núm. 296.

Corral, Paul y Natalia Radchenko [2017], "What's So Spatial about Diversification in Nigeria?", World Development, 95:231-253.

DE JANVRY, Alain y Elisabeth Sadoulet [2001], “Income Strategies Among Rural Households in Mexico: The Role of Offfarm Activities", World Development, 29(39): 467-480.

Dev, Mahendra y Chandra Nuthalapati [2010], "Agricultural price policy, farm profitability and food security", Economic and Political Weekly, 43(26): 174-182, junio 26-julio 9.

DíAz, Sandra et al. [2015], "The IPbES Conceptual Framework - connecting nature and people", Current Opinion in Environmental Sustainability, 14:1-16.

ELLIs, Frank [2000], Rural Livelihoods and Diversity in Developing Countries, Oxford, Oxford University Press.

Engel, Stefanie, Setfano Pagiola y Sven Wunder [2008], "Designing payments for environmental services in theory and practice: An overview of the issues", Ecological Economics, 65(4): 663-674.

faO-SAGarPa [2013], Propuesta de políticas públicas para el desarrollo del sector rural y pesquero (SRP) en México. Informe final, México, FAO.

Fierros, Israel y V. Sophie Ávila Foucat [2017], "Medios de vida sustentables y contexto de vulnerabilidad de los hogares rurales de México", Revista Problemas del Desarrollo, 191(48): 107-131, octubre-diciembre. 
FoLke, Carl [2016], "Resilience" (Republished), Ecology and Society, 21(4): 44.

et al. [2010], "Resilience thinking: Integrating resilience, adaptability and transformability", Ecology and Society, 15(4): 20.

González, Cristina [2020], Operacionalización y medición de resiliencia socioecológica a nivel hogar: análisis empírico en dos comunidades rurales de la costa de Oaxaca, México. Tesis, Universidad Nacional Autónoma de México, 93 pp.

y V. Sophie Ávila Foucat [2019], "Operationalization and Measurement of Social-Ecological Resilience: A Systematic Review", Sustainability, 11(21): 1-18.

Hernández Solano, Alan y V. Sophie Ávila Foucat [2019], "Adaptación al cambio climático y sus efectos en la economía de los hogares rurales mexicanos productores de alimentos", Ensayos, Revista de Economía, 38(1): 61-86, mayo.

IfEJIKA, Chinwe, Urs Wiesmann y Stephan Rist [2014], "An indicator framework for assessing livelihood resilience in the context of social-ecological dynamics", Global Environmental Change, 28:109-119.

INEGI [2014], Encuesta Nacional Agropecuaria 2014, <https:// n9.cl/sa4o1>, 25 de agosto de 2019.

IPCC [2014], AR5 Climate Change 2014: Impacts, Adaptation and Vulnerability, <https://n9.cl/ov4ea $>$.

JoHNY, Judit, Bruno Wichmann y Brent Swallow [2017], "Characterizing social networks and their effects on income diversification in rural Kerala, India”, World Development, 94:375-392.

JoNES, Kelly et al. [2019], "Exploring the connections between participation in and benefits from payments for hydrological services programs in Veracruz State, Mexico", Ecosystem Services, 35:32-42.

KAR, Shiba y Michael Jacobson [2012], "NTFP income contribution to household economy and related socio-economic 
factors: Lessons from Bangladesh", Forest Policy and Economics, 14(1): 136-142.

LiU, Zhen y Jing Lan [2015], "The sloping land conversion program in China: effect on the livelihood diversification of rural households", World Development, 70:147-161.

LóPEZ-FELDMAN, Alejandro [2014], "Shocks, income and wealth:

do they affect the extraction of natural resources by rural households?", World Development, 64:S91-S100.

MaGis, Kristen [2010], "Community resilience: An indicator of social sustainability", Society and Natural Resources: An International Journal, 23(5): 401-416.

Mushongah, Josphat e Ian Scoones [2012], "Livelihood Change in Rural Zimbabwe over 20 Years", The Journal of Development Studies, 48(9): 1241-1257.

Nava, Mariana et al. [2018], Decentralizing Payments for Hydrological Services Programs in Veracruz, Mexico: Challenges and Implications for Long-term Sustainability", Society and Natural Resources: An International Journal, 31(12).

Perevochtchikova, María et al. [2015], "Información hidroclimatológica para la evaluación de los efectos del programa de Pago por Servicios Ambientales Hidrológicos. Caso de estudio de la comunidad de San Miguel y Santo Tomás Ajusco, México", Revista Latinoamericana de Recursos Naturales, 11(1): 37-55.

Pérez Campuzano, Enrique, V. Sophie Ávila Foucat y María Perevochtchikova [2016], "Environmental policies in the peri-urban area of Mexico City: the perceived effects of three environmental programs", Cities, 50:129-136.

REARDOn, Thomas, Julio Berdegue y German Escobar [2001], "Rural Nonfarm Employment and Incomes in Latin America: Overview and Policy Implications", World Development, 29(3): 395-409.

RodríGuez, Benigno y Kees Burger [2015], "Diversification and labor market effect of the Mexican Coffee Crisis", World Development, 68:19-29. 
Rodríguez, Karla, V. Sophie Ávila Foucat y Jorge Maldonado [2015], "Indigenous communities perception regarding payments for environmental services programme in Oaxaca Mexico", Ecosystem Services, 17:163-171.

Saenz, Mariana y Eric Thompson [2017], "Gender and Policy Roles in Farm Households Diversification in Zambia", World Development, 89:152-169.

Sen, Amartya [1987], Commodities and Capabilities, Amsterdam, North Holland, 180 pp.

Tesfaye, Wondinmagegn y Nyasha Tirivayi [2020], "Crop diversity, household welfare and consumption smoothing under risk: Evidence from rural Uganda", World Development, 125:1-18.

VIDAL, Laura et al. [2020], "Construcción de socioecosistemas costeros y retos para medir su resiliencia", en V. Sophie Ávila Foucat e Ileana Espejel (coords.), Resiliencia de socioecosistemas costeros, México, Instituto de Investigaciones Económicas-unam, Facultad de Ciencias, Laboratorio de Resiliencia Costera.

Walker, Brian y David Salt [2012], Resilience Practice: Building Capacity to Absorb Disturbance and Maintain Function, Estados Unidos, Island Press, 226 pp.

Wunder, Sven [2015], "Revisiting the concept of payments for environmental services", Ecological Economics, 117:234-243.

[2006], Pagos por servicios ambientales: Principios básicos esenciales, Yakarta, Cifor, $24 \mathrm{pp}$.

Yúnez-Naude, Antonio y Edward Taylor [2001], "The Determinants of Nonfarm Activities and Incomes of Rural Households in Mexico, with Emphasis on Education", World Development, 29(3): 561-572. 


\title{
ALIMENTACIÓN, BIENESTAR \\ Y SISTEMAS AGROALIMENTARIOS LOCALIZADOS (SIAL)
}

\author{
Jessica M. Tolentino Martínez*
}

\section{INTRODUCCIÓN}

El panorama de la alimentación en México no es nada alentador: de acuerdo con los datos registrados por la última encuesta de salud y nutrición, $75.2 \%$ de la población adulta en México padece sobrepeso u obesidad [Ensanut, 2018]. Una de las principales y más graves consecuencias de esta situación es el desarrollo de diabetes mellitus tipo II, la cual se ha colocado entre las primeras causas de muerte en México en los últimos años.

En términos alimentarios, los efectos de la globalización han posibilitado una distribución de alimentos que no necesariamente está ligada a los alimentos locales o tradicionales consumidos desde la época prehispánica.

Particularmente, en las zonas urbanas es donde el consumo de productos de fácil acceso y alto contenido calórico es sumamente aceptado por la sencillez con la que pueden adquirirse; la vorágine, la rapidez y la inmediatez que enmarcan estos espacios, sin lugar a duda, lo favorece.

Frente a esta situación se presenta la urgencia de rescatar alimentos nutritivos, tradicionales y con identidad territorial

* Investigadora Titular A, Instituto de Investigaciones Económicas, UNAM. Correo electrónico: <jessicatolentino@comunidad.unam.mx>.

Este documento es un producto secundario de la investigación realizada con el apoyo del programa UNAM-PAPIIT IN303320 "Sistema Agroalimentario Localizado (SIAL) de amaranto de Santiago Tulyehualco, Xochimilco: Retos y oportunidades de producción, transformación y comercialización”. 
cuyo consumo genere bienestar individual y colectivo. Es bajo esta premisa que se recupera el enfoque de sistemas agroalimentarios localizados (SIAL) como formas de organización social ligadas al territorio y al alimento que en él se produce. $\mathrm{Su}$ pertinencia para construir políticas públicas de corte ascendente que puedan impactar en el bienestar será una de las aristas que aquí se discutirá.

El trabajo está dividido en tres apartados. En el primero, se abordan los antecedentes que definieron el curso agroalimentario del país; en el segundo, se plantea la importancia de los SIAL y su relación con el concepto de bienestar; y en el tercero, se analiza la pertinencia y la importancia de construir políticas públicas de corte ascendente que consideren los arreglos institucionales en el espacio local que contribuyan al bienestar de la población.

ANTECEDENTES QUE HAN DEFINIDO EL DESARROLLO AGROALIMENTARIO DEL PAÍS

El desarrollo agroalimentario del país puede dividirse en tres grandes etapas. La primera de ellas marcó una tendencia productiva hasta la primera década del siglo xx, basada en una estructura latifundista [FAO, 2009]. La segunda la enmarca la Reforma agraria, que tenía entre sus objetivos la promoción del campo y la organización productiva del campesinado [FAO, 2009; Alegrett, 2003]; esta etapa vivió su esplendor en la década de 1930 con la expropiación de empresas extranjeras y la sustitución de importaciones de bienes de consumo, lo que propició un fuerte dinamismo y crecimiento económico del sector primario que promovía, entre otras cosas, la participación de los ejidos en la producción y distribución de alimentos.

La posterior consolidación de instituciones como la Productora Nacional de Semillas (Pronase), que facilitó el desarrollo de paquetes tecnológicos resultado de la experimentación 
científica en México llamada "Revolución verde", y la Compañía Nacional de Subsistencias Populares (Conasupo), que garantizó al país la producción y abasto de alimentos, hizo posible la autosuficiencia alimentaria durante este periodo [Chonchol, 1994]. Así, de la década de 1930 hasta la crisis del año 1982, el sector agroalimentario creció debido principalmente a la intervención y regulación del Estado.

Para principios de la década de 1990 se vislumbraba un cambio de políticas económicas y públicas que afectó de manera directa al sector. Una nueva institución pública perteneciente a la Secretaría de Agricultura, Ganadería y Desarrollo Rural (Sagarpa) (hoy Secretaría de Agricultura y Desarrollo Rural, Sader): Apoyos y Servicios a la Comercialización Agropecuaria (Aserca) -encargada de promover la comercialización de algunos granos mas no de la compra, el almacenamiento y la distribución como lo hacía Conasupo-, desempeñó una función relevante en la decadencia del sector agroalimentario [Yúnez y Barceinas, 2000].

La falta de apoyo y propuesta de políticas subvencionistas, el rezago de alimentos respecto del crecimiento demográfico y el decrecimiento en la producción de granos básicos propiciaron la pérdida de seguridad alimentaria, ${ }^{1}$ la cual se agudizó por la disminución del financiamiento de las actividades primarias y la eliminación de subsidios agrícolas [Barkin y Suárez, 1985; González y Torres, 1993; Torres y Aguilar, 2003].

Es en este contexto que inicia la tercera etapa del desarrollo agroalimentario del país, de la década de 1990 a la fecha,

${ }^{1}$ Se dice que "Hay seguridad alimentaria cuando todas las personas tienen en todo momento acceso físico social y económico a suficientes alimentos inocuos y nutritivos para satisfacer sus necesidades alimenticias y sus preferencias en cuanto a los alimentos a fin de llevar una vida activa y sana" [Cumbre Mundial de Alimentación, 1996]. De acuerdo con datos de la FAO [2006], para que se diga que un país cuenta con seguridad alimentaria debe producir al menos $70 \%$ de los productos que requieren para satisfacer la demanda de consumo interno; en el caso de México, para el año 2017 la producción de alimentos fue de 58\% (cálculos propios con base en Faostat [2020]). 
la cual está marcada por la transición hacia un sector agroalimentario liberalizado. Las importaciones del sector agroalimentario pasaron de 231812 dólares en enero de 1994 a 1002306 para enero de 2014 [Banco de México, 2020].

Si bien el discurso oficial resalta que el sector agroalimentario es el de mayor dinamismo en México y que es de los sectores que más exporta -tan solo durante el sexenio de Enrique Peña Nieto las exportaciones del sector agroalimentario se fueron incrementando de manera considerable hasta colocar a México, en el año 2017, en el $10^{\circ}$ lugar de exportaciones a escala mundial [SIAP, 2018]-, es importante reconocer que estas cifras han sido prácticamente resultado de la demanda de productos selectos como la cerveza, el aguacate y las berries.

En este sentido, si bien el proceso de reconversión productiva, es decir, el cambio de siembra de cultivos tradicionales a otros de mayor ganancia ha posibilitado el desarrollo económico de ciertas regiones del país, también ha acarreado otros fenómenos de importancia ambiental, social y económica como la contaminación de suelo y agua, el uso intensivo de plaguicidas, el abandono del campo y el cambio climático [Tolentino, 2017]. Por ello, centrar gran parte de la producción en alimentos de exportación para la satisfacción de mercados globales no ha sido una buena decisión. Tampoco lo ha sido la política de apertura comercial indiscriminada que se ha manejado en las últimas cuatro décadas. Comprar los productos básicos a mejores precios que los ofertados en el país parecía una buena idea; sin embargo, esto ha provocado que productos nacionales básicos, como el maíz, el trigo, el arroz y el frijol, hayan incrementado sus importaciones.

El rezago tecnológico y la baja productividad para competir con modelos económicos más eficientes y eficaces que tienen estímulos financieros para el campo han generado un grave problema de inseguridad alimentaria y han comprometido el bienestar de la población. 
Los datos son contundentes cuando comparamos los porcentajes de dependencia alimentaria en los años 1980, 1990, 2000, 2010 y 2017 (últimos datos disponibles de la FAO) [Faostat, 2020] (cuadro 1).

Cuadro 1. México: dependencia de la importación de granos y cereales básicos (1980 a 2017) (toneladas)

\begin{tabular}{|c|c|c|c|c|c|}
\hline Año & Alimento & Producción & Consumo & $\begin{array}{l}\text { Consumo- } \\
\text { producción }\end{array}$ & Dependencia \\
\hline & & $(\mathrm{T})$ & $(\mathrm{T})$ & $(T)^{\prime \prime}$ & $(\%)$ \\
\hline \multirow{4}{*}{1980} & Maíz & 12374400 & 16156381 & 3781981 & 23.4 \\
\hline & Trigo & 2784914 & 3578967 & 794053 & 22.2 \\
\hline & Arroz & 445364 & 578344 & 132980 & 23.0 \\
\hline & Frijol & 935174 & 1377342 & 442168 & 32.1 \\
\hline \multirow{4}{*}{1990} & Maíz & 14635440 & 18701764 & 4066324 & 21.7 \\
\hline & Trigo & 3930934 & 4286324 & 355390 & 8.3 \\
\hline & Arroz & 394388 & 613153 & 218765 & 35.7 \\
\hline & Frijol & 1287364 & 1617625 & 330261 & 20.4 \\
\hline \multirow{4}{*}{2000} & Maíz & 17556900 & 22933921 & 5377021 & 23.4 \\
\hline & Trigo & 3493210 & 5650251 & 2157041 & 38.2 \\
\hline & Arroz & 351447 & 1005785 & 654338 & 65.1 \\
\hline & Frijol & 887868 & 968438 & 80570 & 8.3 \\
\hline \multirow{4}{*}{2010} & Maíz & 23301880 & 30537240 & 7235360 & 23.7 \\
\hline & Trigo & 3676707 & 6329286 & 2652579 & 41.9 \\
\hline & Arroz & 216676 & 998073 & 781397 & 78.3 \\
\hline & Frijol & 1156251 & 1243468 & 87217 & 7.0 \\
\hline \multirow{4}{*}{2017} & Maíz & 27763203 & 41443118 & 13679915 & 33.0 \\
\hline & Trigo & 3503521 & 7914338 & 4410817 & 55.7 \\
\hline & Arroz & 265567 & 1045799 & 780232 & 74.6 \\
\hline & Frijol & 1183868 & 1260740 & 76872 & 6.1 \\
\hline
\end{tabular}

Fuente: Faostat [2020]. 
En el caso del maíz para consumo humano, en una primera impresión su importación no parece ser relevante (33\% para el año 2017) dado que la producción interna es alta, pero su incremento paulatino es una alarma intermitente si consideramos que es la base de la alimentación mexicana. ${ }^{2}$

El trigo es el segundo producto de mayor importación, del cual se ha incrementado paralelamente la demanda, sobre todo de harina de trigo, con la que se elaboran productos de la panificadora.

Respecto del arroz, otro de los productos de gran aceptación en la alimentación del país, se observa que su porcentaje de importación es el más alto; aunque disminuyó en el último año, importar casi $75 \%$ para satisfacer el consumo interno para nada es un buen indicador ${ }^{3}$ [Faostat, 2020].

De manera similar al comportamiento de las importaciones de granos básicos, se ha dado la importación de soja, fructosas, carne de pollo y leche en polvo; por poner un ejemplo, tan solo en el año 2017, el porcentaje de carne de pollo que se importó para satisfacer la demanda interna fue de más de $20 \%$ [Faostat, 2020].

Dejar atrás cultivos tan importantes está costando más de lo deseable en cuanto a desarrollo económico y social

\footnotetext{
${ }^{2}$ Mención aparte merece la importación de maíz amarillo, la cual ha aumentado de manera drástica desde el Tratado de Libre Comercio de América del Norte (TLCAN); se utiliza principalmente como forraje, en la preparación de alimento para ganado, así como para alimentos procesados. El incremento de su importación se ha acompañado de críticas que provienen de la academia y de colectivos de la sociedad por su lugar de procedencia (Estados Unidos) y porque está catalogado como maíz transgénico.

${ }^{3}$ Esta situación es por demás preocupante, ya que en México existe una declaratoria de Denominación de Origen (Do) para el arroz que se produce en el estado de Morelos, cuya calidad agronómica, molinera y culinaria de excelencia lo distingue de las variedades que se producen en el país y fuera de él. El arroz que se produce en la región destaca por su rendimiento -el cual rebasa las 10 toneladas por hectárea- originado en las características de la región y el conocimiento tácito formado históricamente de los productores primarios en el espacio local [Tolentino, 2014]. El apoyo a este tipo de productos, sin lugar a duda, podría contribuir de manera importante a la seguridad alimentaria del país.
} 
porque los alimentos que se importan no siempre son de la mejor calidad, lo que repercute directamente en la salud de la población.

En el caso del maíz son más que evidentes las consecuencias del abandono del cultivo y el proceso de reconversión productiva, ya que si bien miles de familias rurales continúan su siembra, la situación económica, a la que se ha sumado el cambio en los patrones de consumo, está incluso comprometiendo las razas de maíces endémicos, las cuales, de acuerdo con Sánchez, Goodman y Stuber, [2000], son cincuenta y nueve.

Es un hecho que la dieta del mexicano ha transitado de ser una de las más sanas en el mundo, con platillos tradicionales basados en el maíz y otros productos ricos en nutrimentos provenientes de la milpa, a una que consume cada vez mayor cantidad de alimentos ultraprocesados, con grandes cantidades de grasas, azúcares y sal [Fernández, Morales y Gálvez, 2013; Gálvez y Rodríguez, 2012].

Los datos registrados por la última encuesta de salud y nutrición muestran que $39.1 \%$ de la población tiene sobrepeso y $36.1 \%$ obesidad, es decir, $75.2 \%$ de la población adulta en México padece alguna de estas condiciones [Ensanut, 2018]. Como se mencionó en la introducción del trabajo, la diabetes mellitus tipo II es hoy día la principal causa de muerte en México y se correlaciona de manera directa con el sedentarismo, el sobrepeso y la obesidad [Moreno et al., 2014].

En un futuro, la situación al respecto no es nada alentadora si consideramos que $83.3 \%$ de los niños de uno a cuatro años ingiere bebidas no lácteas azucaradas como refrescos, jugos industriales, naturales, etc., y que además $63.3 \%$ de niños en este rango consume botanas, dulces y postres ${ }^{4}$ [Ensanut,

\footnotetext{
${ }^{4}$ Otra situación que ya ha sido registrada por los expertos, sobre todo en niños, es la correlación entre sobrepeso-obesidad y desnutrición; en México, para el año 2012, se hablaba de que existían en el país más de 1.5 millones de niños que sufren desnutrición crónica y tienen una talla baja [Shamah, Amaya y Cuevas, 2015].
} 
2018]. Es importante señalar que el mayor porcentaje de personas que van desde los segmentos de uno a cuatro años hasta los de 20 años y más concentran su consumo de alimentos no recomendables en las bebidas azucaradas y botanas.

En general, existe una deficiencia en el consumo de alimentos recomendables en todos los rangos de edad, sobre todo en el de verduras, frutas y cereales, leguminosas y oleaginosas; la deficiencia del consumo se ha registrado tanto en hogares rurales como urbanos. No obstante, se ha encontrado diferencia en cuanto al acceso y consumo de alimentos saludables en hogares rurales y urbanos ya que si bien la capacidad de compra de las personas en espacios rurales es la mitad de la de personas en espacios urbanos, su gasto en cereales, verduras, leguminosas, huevo y aceite es mayor; por el contrario, su gasto y consumo de carne es menor que el de consumidores urbanos [FAO, 2019].

En este sentido, son varias las ventajas que tienen las personas que viven en espacios rurales y van desde la posibilidad de consumir productos locales, por lo general de gran calidad, hasta la de sembrar casi cualquiera de los granos básicos que se han mencionado.

Es aquí donde hablar de sistemas agroalimentarios localizados (SIAL) toma relevancia al considerar en su estudio aspectos como la alimentación de calidad, el territorio y los conocimientos locales que sirven para la producción, distribución, comercialización y consumo de alimentos.

\section{SisTEMAS AGROALIMENTARIOS LOCALIZADOS} (SIAL) Y BIENESTAR

El enfoque teórico de los SIAL surge en Francia en la década de 1990 como respuesta a las políticas públicas de producción masiva y estandarizada de alimentos, abriendo la posibilidad a la valoración y el retorno a productos específicos con anclaje 
o identidad territorial [Torres, Ramos y Pensado, 2011]. Los alimentos con identidad territorial son aquellos cuya calidad está estrechamente vinculada con el territorio en que se producen.

Las bases en que se sustenta el criterio teórico de los SIAL son el concepto de distrito industrial de Marshall (1890), el concepto de clúster proveniente de la escuela italiana y el de sistema productivo local, que recupera la importancia de la territorialidad basada en el sentido de pertenencia, la transmisión de saberes tácitos y el apego histórico local que permite la articulación en el espacio local de unidades productivas e instituciones [Boucher, 2012: 20].

Es un enfoque teórico novedoso al centrarse en el análisis de

sistemas localizados y especializados en bienes destinados al consumo alimenticio [ y al estudiar] los alimentos como hecho social y cultural mediante el cual los seres humanos se relacionan e intercambian bienes que integran organizaciones sociales, formas específicas de trabajo y símbolos de identidad: se trata de obras de enraizamiento profundo (embeddedness) con el territorio [Torres, 2017: 323].

Los SIAL, por tanto, hacen referencia a formas específicas de organización y producción ligadas al territorio y los mercados locales. En este sentido, permiten identificar recursos inmersos en el territorio que pueden aprovecharse para generar, por medio de la gobernanza de los actores en el espacio local, la construcción de instituciones que les permitan su funcionamiento.

En México, como se sabe, existe una diversidad de alimentos cuyas características: color, olor, sabor, tamaño, etcétera, se deben a las particularidades fisiográficas de la región y al saber hacer que implica su siembra y en algunos casos su transformación; alimentos y bebidas como los que 
ampara la denominación de origen (DO ${ }^{5}$ son ejemplo de ello (cuadro 2).

Cuadro 2. Denominaciones de origen en México (sector agroalimentario)

\begin{tabular}{lc}
\hline \multicolumn{1}{c}{ Producto } & Año que se obtuvo la do \\
\hline Tequila & 1974 \\
Mezcal & 1994 \\
Café de Veracruz & 2000 \\
Bacanora & 2000 \\
Sotol & 2002 \\
Mango Ataulfo & 2003 \\
Charanda & 2003 \\
Café de Chiapas & 2003 \\
Vainilla de Papantla & 2009 \\
Chile Habanero de la peninsula de Yucatán & 2010 \\
Arroz del estado de Morelos & 2012 \\
Cacao de Grijalva & 2016 \\
Chile de árbol de Yahualica, Jalisco & 2018 \\
Raicilla & 2019 \\
Café Pluma & 2020 \\
\hline
\end{tabular}

Fuente: Instituto Méxicano de la Propiedad Industrial [2020].

Sin bien en México las Do han contribuido a generar mayor valor agregado a los productos, también han sido cuestionadas porque la protección jurídica que otorgan a los productos puede ser un factor de exclusión de estos [Renard y Tolentino, 2019]. No obstante, es un hecho que las Do hacen visibles los

${ }^{5}$ Según el Artículo 2 del Acuerdo de Lisboa, las Do identifican y protegen un producto cuya calidad o características se deben al medio geográfico, así como a sus factores naturales y humanos. 
productos en diversas escalas y con una mejor distribución de los beneficios hacia atrás de la cadena agroindustrial.

Aparte de estos productos, hay muchos que pueden ser aprovechados por sus características nutrimentales, agronómicas, molineras, culinarias, etc., para generar dinámicas de desarrollo económico local. Lo que lleva a la siguiente pregunta: ¿cómo contribuyen y pueden contribuir este tipo de alimentos al bienestar de la población?

Para contestarla, primero se debe aclarar qué se entiende por bienestar. El concepto de bienestar no es nuevo; a lo largo de la historia, su significado se ha ido adecuando a las diversas corrientes teóricas y de pensamiento que lo han acogido. Aquí se abordará a partir de la teoría de economía del bienestar y la evolución del concepto.

La economía del bienestar es una subdisciplina de la economía que cuantifica y mide los beneficios y costos de las diversas formas de asignar recursos, y plantea su posición desde el utilitarismo definido en sus inicios por Benthan y Stuart Mill y retomado por Wilfrido Pareto en 1945; entre sus principales postulados se encuentran: “a) que el bienestar social depende ampliamente del bienestar de los individuos de una sociedad; b) el bienestar de los individuos depende de los bienes y servicios que estos consumen; c) los individuos son los mejores jueces de lo que constituye su bienestar y actúan de acuerdo a su propio interés" [Uribe, 2004: 22].

Esta postura aún puede considerarse de corte neoclásico respecto a la concepción de un sujeto con una racionalidad limitada, un sujeto maximizador de beneficios y minimizador de costos. De hecho, se resalta que el bienestar se deriva de acciones y preferencias individuales y que este es directamente proporcional al consumo de las personas; el bienestar se representa en la felicidad que puede alcanzar un individuo.

Este concepto de bienestar, por tanto, no se disocia por completo del concepto de bienestar económico que sustenta a su vez al de desarrollo. Indicadores como desempleo, distribución 
de la renta y producto interno bruto per cápita continúan siendo indicadores de desarrollo [Duarte y Jiménez, 2007].

A escala mundial, el Fondo Monetario Internacional (FMI) y el Banco Mundial son los organismos más importantes de desarrollo; aunque su liderazgo es indiscutible, sus préstamos están ligados a la propuesta de políticas que no siempre son las adecuadas para las particularidades y necesidades de los diversos países que los ocupan, entre ellos México.

Desde la década de 1980, ambos iniciaron préstamos llamados "de ajuste estructural", enmarcados en políticas para reducir el gasto público y en general el gasto social que en poco favorecieron a los países en desarrollo.

Una de las publicaciones más importantes del Banco Mundial es el informe de desarrollo, en el cual se exponen temas de gran envergadura como el empleo, la pobreza, las pensiones, la salud, etc., y se muestran indicadores financieros básicos. El tema del año pasado, por ejemplo, fue Poner fin a la pobre$z a$, invertir y generar oportunidades, en el cual se delinea la importancia del capital humano "como un esfuerzo mundial destinado a acelerar el aumento y la mejora de las inversiones en las personas con el propósito de lograr más equidad y un mayor crecimiento económico" [Banco Mundial, 2019: 1]. Constituye un gran avance encontrar conceptos como el de capital humano como parte importante del desarrollo, pero aún mantiene la idea de que el ingreso está asociado directamente con el bienestar: a mayores ingresos, mayor bienestar.

Exponentes como Amartya Sen [1998, 2000], quien desde su perspectiva ha contribuido notoriamente al desarrollo de la economía del bienestar, plantean que este no debe verse de forma tan simplista; el aprovechamiento de bienes que se consiguen con él debe considerarse valioso en la medida en que se consiguen otros tipos de realizaciones.

Es interesante el concepto de bienestar que plantea Amartya Sen, el cual menciona que existen múltiples racionalidades del actor que conducen el actuar de las personas y que no 
todas las facetas de las personas se dirigen a maximizar el bienestar [Sen, 1985].

Aquí es donde la función que desempeña el Estado resulta relevante al deber ser garante de las oportunidades sociales, los sistemas de alimentación, la salud, la educación, el medio ambiente, etc., que permitan mayor bienestar individual y que, a su vez, se traduzcan en mayor participación en las esferas social, económica y política.

Cabe señalar que las reflexiones de Amartya Sen se han incorporado en instrumentos de medición y análisis novedosos como lo es el índice de desarrollo humano, el cual además toma en cuenta variables como ingreso, educación, salud, derechos humanos e incluso la dignidad. Por tanto, el análisis de la desigualdad, basado en el desarrollo humano, se centra en las personas y sus capacidades para "ejercer su libertad para ser y hacer aquello a lo que aspiran en la vida" [ONU, 2019].

Otro indicador importante sobre las percepciones de bienestar que un sujeto tiene es el de calidad vida, que está directamente relacionado con la calidad de la alimentación, la educación, la salud, la atención médica y el nivel de vida. Como se puede apreciar, la evolución del análisis del bienestar y sus indicadores de medición se vuelven cada vez más complejos.

En la última década, se planteó la importancia de considerar, sobre todo en la planeación y propuesta de políticas públicas, indicadores de bienestar subjetivo. En México, se han tomado en cuenta las recomendaciones de la Organización para la Cooperación y el Desarrollo Económicos (OCDE) de incorporar en el análisis estadístico que realiza el Instituto Nacional de Estadística y Geografía (Inegi), la dimensión de bienestar subjetivo ${ }^{6}$ a partir de modelos BIARE (bienestar autorreportado) para conocer el impacto de la política pública en

${ }^{6}$ El bienestar subjetivo corresponde a una medición de la calidad de vida de una persona incorporando las emociones de los individuos, su manera de sentir, sus metas, logros, fracasos y anhelos. 
la sociedad mexicana, entre otros elementos [Inegi, 2020]. En su medición contempla la satisfacción con la vida social, familiar y afectiva, el nivel de vida, la salud, los logros de vida, las perspectivas a futuro, el esparcimiento, la seguridad ciudadana y la vivienda.

En lo que aquí compete, existe una relación directa entre alimentación, salud, bienestar y calidad de vida, por lo que, respondiendo a la pregunta que se hizo en este apartado, la calidad de la salud y su goce dependen en gran medida de los hábitos alimenticios de los individuos; por ello, no es de extrañar que los discursos que se dan en torno al incremento de la esperanza de vida y la prevención de enfermedades degenerativas, como la diabetes, estén ligados al consumo de alimentos nutritivos y agua, y a la realización de una rutina de ejercicios.

En este sentido, es importante señalar que los alimentos no solo cumplen una función nutritiva que produce bienestar en la población, también poseen un valor simbólico o moral [Rozin, 2005] que lleva a los individuos a organizarse en torno al alimento para su producción, transformación, comercialización y consumo.

Por tanto, en este documento se afirma que recuperar alimentos con identidad territorial puede repercutir de forma directa en la salud y el bienestar individual, social y económico de la población. Es por demás conocido que México tiene una biodiversidad agrícola que puede contribuir a la seguridad alimentaria, la inclusión social y el desarrollo sustentable.

Por ello, es relevante y se considera un gran avance por parte del gobierno federal encabezado por Andrés Manuel López Obrador la identificación e inclusión en la canasta básica alimentaria, a partir de enero de 2019, de alimentos que habían sido segregados y hasta cierto punto excluidos del consumo cotidiano.

Entre estos productos se encuentran dos que, además de ser endémicos, tienen una calidad nutrimental que supera con creces a otros granos y cereales, y que pueden aprovecharse 
para generar o potenciar dinámicas económicas locales exitosas: el amaranto y la chía.

Ambos productos están siendo de interés tanto para la industria agroalimentaria como para la academia por sus propiedades nutrimentales para el organismo del ser humano, al punto de ser conocidos y llamados súper alimentos prehispánicos [Ríos et al., 2017].

Como es posible apreciar en el cuadro 3, tanto la chía como el amaranto tienen mayor cantidad de proteína, hierro, calcio y fibra que incluso el maíz, el trigo o el arroz (cereales de mayor aceptación en la dieta mexicana).

Cuadro 3. Valor nutricional del amaranto y la chía en comparación con otros cereales (límite superior contenido en $100 \mathrm{~g}$ )

\begin{tabular}{lrrrrc}
\hline & Chía & Amaranto & Maíz & Trigo & Arroz \\
\hline Proteína (g) & 19.5 & 18.0 & 11.0 & 15.0 & 8.0 \\
Hierro (mg) & 16.4 & 9.0 & 1.0 & 4.5 & 3.0 \\
Calcio $(\mathrm{mg})$ & 714.0 & 200.0 & 20.0 & 50.0 & 25.0 \\
Fibra (g) & 24.9 & 15.0 & 7.2 & 12.0 & 4.0 \\
Grasas (g) & 27.9 & 9.0 & 4.9 & 2.0 & 2.0 \\
\hline
\end{tabular}

Fuente: Martínez [2016], complementado con datos de Bautista et al., [2007], JaramiIlo [2013] y Jiménez, Masson y Quitral [2013].

Tanto el amaranto como la chía pueden utilizarse en una gran variedad de productos destinados a la alimentación. Además, la chía -cuya producción se concentra en el centro y sur de México- se caracteriza por un alto contenido de ácidos grasos poliinsaturados esenciales para el ser humano como el omega 3 y el omega 6 [Jiménez, Masson y Quitral, 2013]. Su reciente redescubrimiento en la última década como un alimento con grandes propiedades depurativas y antioxidantes representa una ventana de oportunidad para los productores 
primarios y transformadores mexicanos, tal y como lo es actualmente en países como Bolivia y Argentina.

Por su parte, el amaranto es un producto que se cultiva de manera intensa en la región centro del país y representa uno de los principales eslabones de las economías de las regiones; su cultivo y transformación agroindustrial han permitido conservar las tradiciones alimentarias a su alrededor [Velasco y Villela, 2016].

El caso del amaranto es uno de los más interesantes ya que, gracias a la organización de diversos actores (productores, gobierno local e investigadores) de Santiago Tulyehualco, se consiguió la declaratoria de "la alegría de Santiago Tulyehualco como patrimonio inmaterial de la Ciudad de México" en el año 2016 y la declaración del día 15 de octubre como el "Día nacional del amaranto en México".

En el año 2017, además de participar en el Segundo Congreso "Generando Políticas públicas", llevado a cabo en febrero en el Palacio Legislativo de la Cámara de Diputados, estuvieron como promotores del amaranto Grupo Enlace para la Promoción del Amaranto en México, A. C., y el grupo parlamentario de Morena, los que sentaron las bases para que el amaranto se considerara cultivo prioritario y se incluyera en la canasta básica en el año 2019 [Tolentino y Martínez, 2020].

Lo que se observa en Santiago Tulyehualco son dinámicas organizativas que están contribuyendo a la generación de arreglos institucionales con la finalidad de revalorar el amaranto; se han aprovechado las particularidades socioproductivas del sistema agroalimentario, la organización de actores relevantes del espacio local y la calidad alimenticia del producto.

Esto es importante porque la intervención de los actores en el territorio y la complejidad de sus interrelaciones pueden posibilitar acuerdos a escalas mayores de injerencia que contribuyan al desarrollo local.

Por tanto, sería de gran trascendencia sumar a la regionalización y mapeo que existen actualmente de las zonas 
productoras de los diversos alimentos que se producen en el país, un análisis de la potencialidad que tienen los productos locales y con identidad territorial para proponer alternativas alimenticias que contribuyan a la salud y el bienestar de la población.

Todo esto como derecho a una alimentación que se encuentra plasmado en el Artículo 25 de la Declaración Universal de los Derechos Humanos de 1948 a la que se añadiría que sea "suficiente, nutritiva, variada y de calidad".

Con referencia a este punto, el gobierno federal debe garantizar la calidad de los alimentos que se consumen. Hoy más que nunca existe una diversidad de alimentos al alcance de la gente, aunque estos, como ya se indicó, pueden o no ser de la mejor calidad. Por ello, el gobierno debe mantener una política pública que garantice un patrón de alimentación más o menos saludable basado en indicadores e índices de calidad de la dieta en función de los determinantes que pueden ser un factor de riesgo de enfermedades crónico-degenerativas.

Por ello, el Estado debe proponer políticas públicas que respondan a las necesidades y particularidades socioproductivas y organizativas de los diversos espacios productivos rurales o urbanos.

\section{HACIA LA CONSTRUCCIÓN DE POLÍTICAS PÚBLICAS DE CORTE ASCENDENTE}

Desde la década de 1980, las políticas públicas en México se han expresado de dos maneras: verticales, que se identifican con la implementación y la imposición e incluso el autoritarismo por parte del Estado, y otras que surgen como resultado de la organización de los actores, por lo general opuestos al partido gobernante, y sus movilizaciones sociales.

La política de bienestar social en México se ha interpretado como concesiones de corte vertical diseñadas para una población desmovilizada y también como programas resultado 
de las negociaciones corporativas entre la cúpula y la base. Así, los programas sociales originados en esta política de bienestar se han enfocado a un sector de la población representado por la clase obrera con la finalidad de ofrecer servicios básicos como educación, atención médica y vivienda, además de alimentos a costos accesibles, concentrando su atención a zonas urbanas y dejando a la población rural excluida de sus beneficios [Brachet y Sherraden, 1993].

Los programas sociales dirigidos hacia este sector se han caracterizado por ser de carácter asistencialista y paliativo, en general, porque responden como fin último a la búsqueda de desarrollo y este se ha vinculado prácticamente de manera irrestricta con el desarrollo económico, el cual se ha buscado, desde la época del neoliberalismo, por medio de políticas económicas macroeconómicas que no consideran las particularidades sociales, económicas, organizativas y socioproductivas de los diversos espacios.

Por tanto, son políticas públicas que han tenido repercusiones económicas y sociales que no son las óptimas; en el caso de los campesinos y pequeños productores, las demandas al Estado están orientadas hacia la construcción de políticas institucionales que contemplen su importancia como sujetos económicos y valoren la capacidad de impulsar y promover formas de producción alternas dirigidas a producir alimentos nutritivos acordes con técnicas agroecológicas propuestas hoy día. En este sentido, el enfoque de los SIAL es crítico de las políticas públicas desplegadas para el campo, las cuales

han favorecido la competencia desleal por dumping -es el caso de los cultivos de como maíz, trigo, arroz, café, algodón, productos pecuarios como leche, etcétera-, o al avasallamiento por capital trasnacional de la pequeña industria semiartesanal -como el caso del tequila y el mezcal- [...] [los SIAL] han examinado críticamente el desdén del Estado hacia los cultivos tradicionales, genuinos, típicos e identitarios [Larroa, introducción en Larroa y Tolentino et al., 2018]. 
No obstante este desdén del que se habla y que es traslape de políticas públicas de corte vertical, se ha demostrado la importancia del campesino y el pequeño productor en la organización del espacio local y la conservación de prácticas agrícolas y tradicionales que han mantenido la agrobiodiversidad de México y de América Latina.

Es un hecho que las propuestas de políticas públicas de corte ascendente deben considerar como base los arreglos institucionales que marcan la agenda de los diversos espacios locales, pero también el bienestar de la población basado en el derecho a alimentación suficiente, nutritiva y de calidad.

Si bien las políticas públicas se han centrado en apoyar y aprovechar dichos arreglos, no se ha hecho de la manera más cuidadosa porque se equipara el norte del país con el centro y el sur, cuando son bien sabidas las diferencias socioculturales, económicas y políticas que ostentan.

\section{REFLEXIONES FINALES}

Se requiere una política nacional que contemple de manera integral la problemática alimentaria por la que el país está atravesando. En este sentido, es importante promover la creación e implementación de políticas públicas que garanticen una alimentación sana, inocua y saludable; además de la regulación de la agroindustria -sobre todo refresquera- y la de botanas, que son las que están incrementando los índices de obesidad de la población, sobre todo de los niños menores de cinco años.

Por tanto, se necesitan planes de acción que motiven los diversos sistemas agroalimentarios del país reconociendo sus particularidades socioproductivas, económicas y culturales y aprovechando la participación de los pequeños productores que depositan en sus alimentos conocimientos tradicionales.

El cambio de paradigma que se perfila en el concepto de bienestar debe incluir indicadores tanto objetivos como 
subjetivos y ser aprovechado por los tomadores de decisiones para generar políticas públicas que impacten de manera positiva en espacios urbanos y en la economía del espacio rural.

La construcción de políticas públicas de corte ascendente tiene hoy, más que nunca, una posibilidad de reorientar las capacidades productivas de los actores del campo para generar y aumentar la producción y la disponibilidad de alimentos que contribuyan no solo al ingreso de las familias rurales, sino también a mejorar la calidad de vida de quienes lo consumen.

\section{REFERENCIAS}

Alegrett, R. [2003], "Evolución y tendencias de las reformas agrarias en Latinoamerica", Reforma agraria, colonización y cooperativas, 2:112-126.

BANCO DE MÉxico [2020], Balanza de productos agropecuarios, $<$ https://n9.cl/i9i9>.

Banco Mundial [2019], Informe anual 2019. Poner fin a la pobreza, invertir para generar oportunidades, Washington, D.C., Banco Mundial.

BARKin, D. y B. Suárez [1985], El fin de la autosuficiencia alimentaria, México, Océano-Centro de Ecodesarrollo.

Bautista, M. et al. [2007], "Desarrollo de pan integral con soya, chía, linaza y ácido fólico", Archivos Latinoamericanos de Nutrición, 51(7): 78-85.

Boucher, F. [2012], "De los AIR a los SIAL: reflexiones y desafios en America Latina”, F. Boucher, A. Espinoza y M. D. R. Pensado (coords.), Sistemas agroalimentarios localizados en America Latina. Alternativas para el desarrollo territorial, México, Miguel Angel Porrua, pp. 13-33.

BRACHET, V. y M. Sherraden [1993], Austeridad fiscal, el Estado de bienestar y el cambio politico: los casos de la salud y el bienestar en Mexico (1970-1990), Mexico, El Colegio de Mexico. 
Chonchol, J. [1994], Sistemas agrarios en América Latina. De la etapa prehispánica a la modernización conservadora, México, Fondo de Cultura Económica.

Cumbre Mundial sobre la Alimentación [1996], Declaración de Roma sobre la seguridad alimentaria mundial, Roma, FAO. Duarte, T., y R. Jimenez [2007], "Aproximación a la teoría del bienestar", Scientia et Technica, año XIII, núm. 37.

Ensanut [2018], Encuesta Nacional de Salud y Nutrición, Presentación de Resultados, <https://n9.cl/r4oxb>, 17 de febrero de 2020.

FAO [2019], El sistema alimentario en México. Oportunidades para el campo mexicano en la Agenda 2030 de Desarrollo Sostenible, México, FaO.

[2006], "Seguridad alimentaria", Informe de políticas, núm. 2.

[2009], La FAO en México. Más de 60 años de cooperación 1945-2009, México, FAO, 370 pp.

Faostat [2020], Base de datos de la Organización de las Naciones Unidas para la Alimentación, Mexico, <https://n9.cl/ qggpa>.

Fernández, R., L. A. Morales y A. Gálvez [2013], "Importancia de los maíces nativos de México en la dieta nacional. Una revision indispensable", Revista fitotécnica mexicana, 36(supl. 3-a): 275-283.

Gálvez, A., y H. Rodríguez [2012], "La alimentación en la Ciudad de México", Congreso Internacional "Riesgos para la salud en la vida de una megametropoli". Memoria I, México, Facultad de Medicina, unam, pp. 366-403.

González, C., y F. Torres [1993], Los retos de la soberanía alimentaria en México, México, Instituto de Investigaciones Económicas, UNAM-Juan Pablos Editor.

INEGI [2020], Modelo de Bienestar Autorreportado. BIARE, $<$ https://cutt.ly/5hBMP7T >, 15 de marzo de 2020.

Instituto Mexicano de la Propiedad Industrial [2020], Tradición e identidad protegidas: las denominaciones de origen e 
indicaciones geográficas, <https://n9.cl/rjoam>, 19 de marzo de 2020.

JARAMillo, Y. [2013], La chía (Salvia hispanica L.), una fuente de nutrientes para el desarrollo de alimentos, Antioquia, Corporación Universitaria Lasallista, Facultad de Ingenierías.

JiMÉNEz, P., L. Masson y V. Quitral [2013], "Composición química de semillas de chía, linaza y rosa mosqueta y su aporte en ácidos grasos omega-3", Revista Chilena de Nutrición, 40(2): 155-160.

Martínez, L. [2016], "Seguridad alimentaria, autosuficiencia y disponibilidad del amaranto en México", Revista Problemas del Desarrollo, 168(47): 107-132.

Moreno, L., et al. [2014], "Epidemiología y determinantes sociales asociados a la obesidad y la diabetes tipo 2 en México", Revista Médica del Hospital General de México, 77(3): 114-123.

ONU [2019], Informe sobre Desarrollo Humano 2019. Más allá del ingreso, más allá de los promedios, más allá del presente: Desigualdades del desarrollo humano en el siglo XXI, Nueva York, Programa de las Naciones Unidas para el Desarrollo.

Renard, M. C., y J. M. Tolentino [2019], "Procesos de exclusión en las Denominaciones de Origen. Un análisis crítico desde los Sial en México", en M. C. Renard y J. Tolentino, Red SIAL México. Diez años de contribución a los estudios de los Sistemas Agroalimentarios Localizados, México, IICA/Conacyt/REDSIAL, pp. 53-68.

Ríos, A., et al. [2017], "Prehispanic Functional Foods and Nutraceuticals in the Treatment of Dyslipidemia Associated to Cardiovascular Disease: a Mini-Review", International Journal for Vitamin and Nutrition Research, 87(1-2): 58-98. Rozin, P. [2005], "The Meaning of Food in our Lives: A CrossCultural Perspective on Eating and Well-Being", Journal of Nutrition Education and Behavior, 37(supl. 2): S107-S112. 
SÁnchez, J., M. Goodman y C. Stuber [2000], "Izozimatic and Morphological diversity in races of maize of Mexico", Economic Botany, 54(1): 43-59.

SEn, A. [2000], Desarrollo y libertad, Barcelona, Planeta. [1998], Bienestar, justicia y mercado, Barcelona, Paidos. [1985], Commodities and capabilities, India, Oxford.

Shamah, T., M. A. Amaya y L. Cuevas [2015], "Desnutrición y obesidad: Doble carga en México", Revista Digital Universitaria, 16(5): 1-17, <https://n9.cl/ylhuf>.

SIAP (Servicio de Información Agroalimentaria y Pesquera) [2018], Atlas agroalimentario 2018, México, SIAP.

Tolentino J. [2017], "La situación de los granos básicos en México como punto vulnerable de la seguridad alimentaria", en Felipe Torres, Implicaciones regionales de la seguridad alimentaria en la estructura del desarrollo en México, México, Instituto de Investigaciones Económicas, UNAM, pp. 315-343. [2014], El sistema agroalimentario local del arroz del estado de Morelos. Desarrollo y gobernanza territorial, México, Coordinación de Humanidades, UnAM.

et al. [2018], Sistemas Agroalimentarios Localizados y prácticas agrícolas tradicionales. Hacia una propuesta de política pública, México, Red de Sistemas Agroalimentarios Localizados (Red Sial-México).

Tolentino J., y L. Martínez [2020], "Gobernanza y arreglos institucionales para la revalorización de cultivos agroalimentarios: El caso del amaranto en la región centro de México", en Gobernanza y desarrollo territorial, el papel de las políticas públicas un estudio comparativo, México, unAM, Centro de Investigaciones sobre América Latina y el Caribe.

TorRes, Felipe y Teodoro Aguilar [2003], "Aspectos externos de la vulnerabilidad alimentaria en México", en Felipe Torres (coord.), Seguridad alimentaria: seguridad nacional. México, Instituto de Investigaciones Económicas, Universidad Nacional Autónoma de México/Plaza y Valdés, pp. 87-122 
ToRRES, G. [2017], Los sistemas agroalimentarios localizados y el consumo. Los retos de la gobernanza, Mexico, Universidad Nacional Autónoma de México, Instituto de Investigaciones sobre América Latina y el Caribe.

, H. A. Ramos Chávez y M. D. R. Pensado Leglies (coords.) [2011], Los sistemas agroalimentarios localizados en México. Desafíos para el desarrollo rural y la seguridad alimentaria, México, Centro de Investigaciones Interdisciplinarias en Ciencia y Humanidades.

URIBE, C. [2004], "Desarrollo social y bienestar" Universitas Humanistica, 31(58): 11-25.

Velasco, A., y S. Villela [2016], "Amaranto", Arqueología mexicana. Amaranto. Fuente de la "alegría", núm. 138, marzo-abril.

YúNEZ, A., y F. Barceinas [2000], "Efectos de la desaparición de la Conasupo en el comercio y en los precios de los cultivos básicos”, Estudios Económicos, 15(2): 189-227. 


\section{UN CONTRAPUNTO ENTRE EL “DESARROLLO”-“BIENESTAR” Y LOS “BUENOS VIVIRES" - “BUENA VIDA” DESCOLONIALES EN AMÉRICA LATINA}

Hilda Caballero* Boris Marañón **

\section{INTRODUCCIÓN}

Dado el actual contexto histórico de acelerada destrucción de las bases sociales, ambientales y ecológicas de la vida humana y no humana en el planeta, en este capítulo se plantea una reflexión sobre la necesidad de considerar otras miradas sobre el "bienestar" no vinculadas con la teoría "económica" hegemónica y el "desarrollo", pues es imposible alcanzar material y subjetivamente el "bienestar" desarrollista. Se plantea sentipensar el nuevo horizonte de sentido histórico emergente en América Latina, llamado los "buenos vivires", que abarca visiones de "bienestar" basadas en ontologías relacionales, en epistemologías que reconocen la totalidad y la diversidad, y en relaciones de poder que privilegian la convivencia horizontal sin opresiones.

El trabajo tiene seis partes, que presentan: a) una reflexión sobre la crisis irreversible del proyecto del "desarrollo" capitalista bajo la hegemonía del capitalismo financiero; b) una crítica al sujeto "económico": individualista, "racista" y patriarcal, separado de lo comunitario y de la "naturaleza", que sustenta la visión dominante de "economía"; c) una discusión sobre el "bienestar", su auge y crisis como categoría desde el capitalismo colonial-moderno y del "desarrollo"; d) un análisis de los

* Académica del Instituto de Investigaciones Económicas, UNAM. Correo electrónico:<hildac@unam.mx>.

** Investigador del Instituto de Investigaciones Económicas, UNAM. Correo electrónico:<bolin88@unam.mx>. 
buenos vivires, como alternativa al "desarrollo"; e) algunos aspectos conceptuales e indicadores referenciales del "bienestar" en los buenos vivires; y f) algunas reflexiones finales.

\section{LA CRISIS IRREVERSIBLE DEL PROYECTO}

DEL “DESARROLLO” CAPITALISTA BAJO

LA HEGEMONÍA DEL CAPITALISMO FINANCIERO

En este apartado se plantea que el actual patrón de poder moderno-colonial y capitalista se encuentra en una crisis irreversible en términos subjetivos y materiales que hace inviable la posibilidad de alcanzar el "desarrollo" y el "bienestar".

\section{La mutación del capitalismo colonial-moderno en su fase financiera}

Existe una convergencia de diversos e irresolubles problemas (destrucción ecológica, degradación ambiental, desempleo y "pobreza" crecientes, concentración del poder y exacerbación del patriarcado, entre otros) que se describen en su conjunto como "crisis civilizatoria"; no obstante, esta es una crisis de la "civilización occidental" y no de "civilización" en su conjunto, y sería más apropiado referirse a la crisis de un sistema histórico [Wallerstein, 2004] o patrón de poder específico [Quijano, 2000a], estructurado hace más de cinco siglos: el patrón de poder colonial, moderno, capitalista, mundial y eurocentrado, el cual sigue dominando la vida humana y no humana, anclado en la invención de la categoría "raza", en el siglo xvI, para clasificar a la población mundial y estructurar las relaciones sociales de forma jerárquica según el color de la piel, de manera "racial", como base de la colonialidad.

Este patrón de poder se aleja definitivamente de las promesas asociadas con la modernidad (libertad, igualdad, 
solidaridad y democracia), lo que se evidencia en tres tendencias: desempleo estructural (sustitución de trabajo vivo por trabajo muerto, derrota de las resistencias del trabajo e imposición del neoliberalismo, destrucción de conquistas laborales y re-expansión de la plusvalía absoluta), financiarización estructural (predominio del capital financiero sobre el productivo, creciente desinterés en invertir productivamente para generar empleo) y creciente tecnocratización de la racionalidad instrumental (predominio del criterio tecnocientífico por encima de consideraciones ecológicas, ideológicas, éticas y políticas) [Quijano, 2011].

El Estado-Nación ha perdido su soberanía y capacidad de regulación del espacio interno de dominación por la reconcentración del poder en manos de un gobierno mundial imperial, integrado por Estados del centro, instituciones financieras y grandes corporaciones transnacionales, que se reúnen anualmente para tomar decisiones sobre nuestras vidas de manera vertical y sin representatividad. Este nuevo gobierno mundial imperial implica la erosión de la democracia representativa, pues los Estados responden cada vez más a las necesidades de un entramado de intereses internacionales y nacionales que a los del conjunto de la población del país [Quijano, 2011]. Así, el EstadoNación, en este periodo, es incapaz de impulsar el "desarrollo". ${ }^{1}$

Auge y crisis del "progreso"- "desarrollo": hacia la destrucción de la vida ${ }^{2}$

Según Nisbet [1986], la idea de "progreso" referida desde los griegos al avance del conocimiento práctico contenido en las artes y las ciencias pasó a entenderse en el mundo moderno como la esperanza en un futuro caracterizado por la libertad,

\footnotetext{
${ }^{1} \mathrm{Al}$ respecto, ver Marañón y López [2016], Quijano [2000b].

${ }^{2}$ Ver Marañón y López [2016], Quijano [2000b], Acosta [2011], Gudynas [2011].
} 
la igualdad y la justicia individuales, en una línea de crecimiento evolutivo, acumulativo y continuo para desarrollar las potencialidades humanas. No obstante, esta visión moderna del "progreso" es antropocéntrica y está impregnada de la colonialidad. Por un lado, se trata de un ethos que coloca al humano por fuera de la naturaleza, la que debía ser dominada y manipulada a través del conocimiento científico, como afirmaba Bacon [Acosta, 2011]. Según Carr [1985: 30], desde la Revolución francesa el "progreso" fue sinónimo de abundancia material a partir de la explotación de la naturaleza, el concepto de productividad fue colocado en el centro de la economía política y los fisiócratas y Smith establecieron que la producción (de mercancías) era la fuente de toda riqueza. Por otro lado, la visión moderno-colonial del "progreso" tenía como referencia únicamente la "civilización" europea, "blanca", que legitima la dominación mediante la supuesta expansión de sus logros al resto del mundo, "salvaje", a través de prácticas coloniales e imperialistas [Nisbet, 1986].

La idea de "progreso" fue reformulada bajo el concepto de "desarrollo" en el siglo xx y presentado este último en Estados Unidos, en 1949, directamente vinculado con el de "subdesarrollo" según el nivel de ingreso per cápita, por lo que América Latina y otras regiones del sur debían aplicar un conjunto de políticas, instrumentos e indicadores para salir del "subdesarrollo" y llegar a la deseada condición del "desarrollo": prosperidad material, progreso tecnológico, economía de mercado [Escobar, 2007].

Sobre el "desarrollo", Quijano [2000b] sostiene que: a) emergió como consecuencia de una redistribución del poder mundial derivada de las luchas por la liberación; b) se convirtió en una idea-fuerza, en aspiración e impulso de transformaciones mayores en la sociedad; c) en el debate latinoamericano sobre el "desarrollo"-"subdesarrollo", se dejó de lado el patrón de poder mundial como unidad de análisis privilegiándose al 
Estado-Nación, de modo que las interrogantes se orientaron a identificar los "obstáculos al desarrollo" y las formas de enfrentarlos; d) la "teoría de la modernización", desde Estados Unidos, hegemonizó el debate sosteniendo que la cultura (racionalidad e ideología, especialmente religiosa) era la fuente de explicaciones sobre el "desarrollo" y "subdesarrollo"; e) los países "desarrollados" eran "modernos", "racionales" y "protestantes", mientras que los "subdesarrollados" eran "tradicionales", no-protestantes, con racionalidad "primitiva"; y f) el "desarrollo económico" se asociaba con el principio de ganancia, el valor del dinero y del mercado; el trabajo y el consumo como el sentido de la vida, y la religión, protestante. Los rasgos opuestos a ellos eran parte de la "tradición " y eran los "obstáculos" a remover en el camino del "desarrollo". El "desarrollo" era, ante todo, modernización y no modernidad.

Entre las décadas de 1950 y 1960 se ejecutaron políticas para impulsar el "desarrollo" en América Latina y en todo el mundo periférico sometido a la hegemonía de Estados Unidos, con una fuerte intervención del Estado para estimular la industrialización, fomentar el empleo y crear derechos de ciudadanía, obteniéndose resultados desiguales y contradictorios en el crecimiento económico y la redistribución del ingreso. El propio Prebisch [1981], al final de su vida, en los 80, cuando las experiencias de industrialización por sustitución de importaciones entraron en profundos desequilibrios macroeconómicos y sociopolíticos, sostenía que dentro del sistema capitalista no había solución alguna para los problemas del desarrollo latinoamericano.

Desde los 70, a consecuencia de la crisis de rentabilidad del capital, se impulsó el desmantelamiento del Estado de bienestar, la privatización y desregulación de la economía para permitir el libre funcionamiento de las fuerzas del mercado. Esto significó la pérdida de derechos de ciudadanía y la violación de derechos humanos (v. gr., Chile y Argentina), el crecimiento del desempleo y de la "pobreza". 
Con el neoliberalismo, en el que el capital financiero orienta la acumulación de capital, principalmente de carácter especulativo, carece de sentido crear empleo productivo para generar riqueza, lo que ha profundizado el desempleo estructural, el crecimiento del "polo marginal", la desigualdad y la "pobreza", también estructurales, a niveles que no pueden ser revertidos por las políticas de "combate a la pobreza", pues estas se concentran en lo social sin modificar la estructura económica que genera e incrementa la "pobreza" y que concentra la riqueza; tales tendencias se muestran en las estadísticas publicadas anualmente por Oxfam. Dada la estructuración "racial", patriarcal y clasista de la sociedad capitalista mundial, la "pobreza" recae de modo proporcionalmente mayor en los "inferiores" por su color de piel y por pertenecer a sectores considerados culturalmente "atrasados" ("negros" e "indígenas", sobre todo las mujeres).

A partir de los 60 del siglo pasado, igualmente se evidenció la contaminación del agua y el aire debido a la intensificación de la producción industrial en los países capitalistas "avanzados". Esto fue fundamentado en Los límites del crecimiento (1972), Nuestro futuro común (1987) y la propuesta de "Desarrollo sustentable/sostenible" presentada en Río 92. Al mismo tiempo se demostró científicamente la emergencia del calentamiento global por la emisión de gases de efecto invernadero debida a la utilización de combustibles fósiles. A inicios de la tercera década del siglo XxI, los esfuerzos internacionales multilaterales han sido insuficientes para establecer acciones que permitan contrarrestar la contaminación y el calentamiento global, así como la intensa extracción de "recursos" naturales y la pérdida de biodiversidad. Lo anterior no ha sido posible lograr porque el "desarrollo" y el "desarrollo sustentable" priorizan el crecimiento económico y la acumulación de capital sin considerar la finitud de los "recursos" naturales; por el contrario, dichos desequilibrios se han incrementado y son una seria amenaza para la vida. 
La crítica al sujeto "económico": individualista, "racista" y patriarcal, separado de lo comunitario y de la "naturaleza"

El análisis "económico" hegemónico considera la cientificidad de su disciplina desde la acción social medios-fines, desarrollada por un individuo racional y aislado [Coq, 2005], y de la verificación empírica. Desde la segunda mitad del siglo XI, este enfoque, de corte subjetivo (al destacar la utilidad y productividad marginales), desplazó el de la economía política al plantear que el individuo era capaz de actuar racionalmente para tomar decisiones que le permitieran, con información completa y en un contexto de escasez, lograr la máxima utilidad posible en el mercado. ${ }^{3}$ Así, la idea neoclásica de "economía" impuso: a) una naturalización de las relaciones de mercado y se difundió en los centros de enseñanza de Europa y Estados Unidos, pregonando las bondades del mercado auto regulado, y b) que la "economía", puede ser una esfera de actuación y reflexión que no implica un contexto político, social y/o cultural, distanciándose del enfoque clásico, en que la "economía" era una parte del entramado social en el que era evidente que el poder, la política y el bienestar de la población estaban estrechamente relacionados y se afectaban recíprocamente, por tanto eran objeto de la reflexión económica [Corredor, 2013].

Se ha cuestionado la teoría "económica" desde la propia epistemología hegemónica ${ }^{4}$ desde vertientes críticas. La economía política marxista subraya que el análisis debería realizarse: a) no desde el individuo sino desde las relaciones de poder entre las clases (las poseedoras de los medios de producción y las que carecen de ellas), pues aquellas determinan el

\footnotetext{
${ }^{3}$ La elaboración de este "individuo" se remonta hasta el siglo xvI, al plantearse la conversión de las pasiones en los intereses [Hirschman, 2014]. Ver también Dimmelmeier, Pürckhauer y Shah [2016].

${ }^{4}$ Ver la propuesta de racionalidad limitada de Simon [1957].
} 
comportamiento y las decisiones de los individuos, quienes están condicionados por múltiples estructuras propias del modo de producción capitalista; b) considerando que los ingresos de los individuos no dependen de su decisión libre sobre cuánto trabajo suministrar o de su productividad marginal, sino de la relación de fuerzas entre capital y trabajo y, por tanto, del nivel de apropiación de la plusvalía por parte de los capitalistas; y c) cuestionando la concepción neoclásica de capital (dinero, medios de producción, conocimiento), pues esas cosas se perciben como capital solo si se emplean en el proceso de producción usando mano de obra asalariada, para generar ganancias [Dimmelmeier, Pürckhauer y Shah, 2016].

El feminismo critica la teoría "económica" neoclásica porque la noción de "hombre económico" distorsiona la experiencia de las mujeres y omite las relaciones de poder dentro de la familia [Ferber y Nelson, 2004]. El feminismo marxista cuestiona: a) la lógica de la acumulación capitalista, fundada en la explotación del trabajo humano y en la privatización de la riqueza natural y de la riqueza producida, y b) el concepto mismo de economía basado en la escasez, la cual no existe pues es producida por las desigualdades sociales [Federici, 2018]. La teoría de la des/colonialidad del poder critica la racionalidad social instrumental [Germaná, 2002; Quijano, 1999] que sustenta al "hombre económico", al "individuo" asociado con esta visión y con la manera en que este no es una persona común, sino un hombre blanco, europeo ( $y$ estadounidense), propietario, patriarcal, heterosexual [Lander, 2000], el portador de los intereses y las relaciones de poder que impulsan el poder capitalista, mundial, moderno-colonial, eurocentrado y patriarcal. Este "individuo" específico fue construido desde el siglo XVI separado de la vida comunitaria y la "naturaleza" [Giraldo, 2014], a partir del dualismo radical cartesiano, con la relación sujeto-objeto entre razón y cuerpo, visión extendida a las relaciones con la "naturaleza" (antropocentrismo), entre hombres y mujeres 
(patriarcalismo) y entre "blancos" y no "blancos" (la "raza" y la colonialidad del poder a partir de diferencias fenotípicas y culturales), siendo las mujeres, la población indígena y la población afrodescendiente calificados como inferiores y en un estadio civilizatorio "primitivo" [Quijano, 1999].

La producción de este "individuo" es resultado de la constitución del patrón de poder colonial-moderno y capitalista desde el siglo Xvi, pues en la "Edad Media" (según la periodización histórica europea y eurocéntrica), cada persona desde su nacimiento se identificaba con un rol funcional en la sociedad (campesino, artesano, caballero, "señor feudal"), pero nunca como un "individuo; todos eran integrantes de una familia, pueblo o corporación. Esta situación cambió desde el siglo XVI con la constitución por parte de los conquistadores de un sujeto "racialmente" superior y la destrucción de formas de vida ancladas en la solidaridad en los sectores populares en las ciudades "medioevales" europeas. Debido a estos dos factores, el nuevo "individuo" blanco europeo se tornó egoísta, ansioso de tener (poder y riqueza), y no de ser [Giraldo, 2014]. Todo el proceso de construcción de este peculiar "individuo" se caracterizó (y sigue caracterizándose) por la violencia física y subjetiva y el despojo de los dominados y explotados (la acumulación originaria de Marx), ${ }^{5}$ la "caza de brujas" [Federici, 2010] en Europa, con la conquista de América [Quijano, 1999] y la jerarquización racializada de la sociedad (consiguiente servidumbre de los "indios" y esclavización de los "negros).

Desde la crítica descolonial, es necesario sentipensar en nuevas formas de concebir "lo económico", no tomando como punto de partida este tipo particular de "individuo" aislado de los otros y de la "naturaleza", sino de un sujeto/una sujeta que vive en sociedad y en comunidad, un sujeto/una sujeta diverso por su geografía, historia, cultura, color de piel, sexo/

\footnotetext{
${ }^{5}$ Sigue ocurriendo de manera permanente [Harvey, 2004].
} 
género/sexualidad, reconociendo la heterogeneidad histórico-estructural de la sociedad, la diversidad de epistemes y las relaciones de poder existentes en el capitalismo colonialmoderno [Marañón, 2019]. Esta es la invalorable aportación de Corredor [2013] cuando propone la metáfora de Viernes; esto es, que el punto de partida de la "economía" no sea la visión del dominador, de Robinson Crusoe, sino de Viernes, el sujeto dominado, siervo de Crusoe, pues Viernes tiene otra historia, otra racionalidad, otros intereses sociales, todos distintos al del sujeto portador de la modernidad-colonialidad capitalista.

En este sentido, es imprescindible concebir "lo económico" desde diversas epistemes que se resisten a la modernidad-colonialidad capitalista y que apuntan a suprimir todas las formas de dominación, explotación y discriminación existentes. Esto significa, por ejemplo, recuperar los aportes del marxismo respecto de la explotación humana, de la enajenación y de la necesidad de desmercantilizar las relaciones sociales; las aportaciones del pensamiento "indígena" que entiende la "economía" no solo como la administración del Oikos, de la casa, sino de la Casa Común, la Madre Tierra, cuidando los equilibrios entre lo humano y lo no humano, a partir de relaciones de reciprocidad y complementariedad. Tener en cuenta, también, los aportes del feminismo crítico que propone reconocer como trabajo socialmente necesario el trabajo de reproducción [Federici, 2018] y ubica el conflicto capital-vida como el eje de las contradicciones históricas actuales [Pérez, 2014], añadiendo a la explotación del trabajo y a la explotación y dominación de la mujer, el ecologismo, para cuestionar los supuestos sobre la explotación de la "naturaleza", a la que se entiende únicamente como un "recurso" para el crecimiento económico. ${ }^{6}$

\footnotetext{
${ }^{6}$ Una mayor discusión sobre estos tópicos en Marañón [2019].
} 


\section{Auge y crisis del bienestar, una categoría desde el capitalismo colonial-moderno y del "desarrollo"}

El "bienestar" es un concepto que emerge como creación del "desarrollo"; es también un mecanismo de poder instalado en la subjetividad, en el contexto de consolidación y redistribución del patrón de poder moderno-colonial capitalista, en su fase industrial, a mediados del siglo xx. El "bienestar" fue objeto de una estandarización instrumental al asociarlo con el éxito, entendido este principalmente como la posibilidad creciente de consumo y acumulación de bienes materiales, y desdeñando otras maneras de entenderlo relacionadas con la felicidad, la justicia, la armonía y la vida [Villasana, Gómez y De Vos, 2018]. La noción hegemónica de "bienestar" responde a "formas de representación de los hechos que se imponen al pensamiento y la práctica de los individuos" [Villasana, Gómez y De Vos, 2018: 3]. El pensamiento liberal como mecanismo de poder legitima la propiedad privada y el enriquecimiento individual, responsabilizando a cada individuo de su situación. Históricamente, la condición de "pobreza" y la posibilidad de salir de ella fueron asumidas en el discurso oficial como un proceso generado por designio divino o por fuerzas naturales, desvinculándolas de procesos políticos. Con la modernidad y el desarrollo del capitalismo, el enriquecimiento se erige "como una práctica legítima amparada en el derecho natural", ocultando los efectos de la concentración de la riqueza sobre el empobrecimiento de los trabajadores y sus familias; la "pobreza" se relaciona con los vicios, la flojera o la incompetencia del sujeto para aprovechar las oportunidades mercantiles. "Esta concepción ideologizada de la pobreza enmascara el hecho de que toda forma de riqueza es producto [de la explotación] del trabajo, un hecho reconocido también por Adam Smith" [Villasana, Gómez y De Vos, 2018: 4]. ${ }^{7}$

${ }^{7}$ La pobreza es también resultado de la desvalorización del trabajo femenino y de la inferiorización de las poblaciones no blancas a partir de la "raza" (colonialidad). 
Desde finales del siglo xIx, la llamada "economía del bienestar" trasladó la idea del bienestar individual al social vinculándola con la productividad de una sociedad, medida en la producción de mercancías, estableciendo el ingreso nacional como medida de bienestar, derivado "del progreso continuo de la invención y de la acumulación de aplicaciones superiores para la producción"; en este sentido están las discusiones de Marshall, Pareto y Pigou [Villarespe, 2002: 206-207]. No obstante, el crecimiento capitalista conllevó el incremento de la "pobreza", lo cual generó conflictos sociales y gran inestabilidad política; de modo que luego de la Segunda Guerra Mundial se impulsó el Estado keynesiano para regular los mercados, restablecer el orden social, "mejorar el consumo, asegurar la reproducción y disponibilidad de la mano de obra, proteger la propiedad privada"; y para instrumentar sistemas de seguridad social, "subvencionar la producción de ciertos bienes y servicios, y proporcionar directamente a la población valores de uso en la forma de servicios públicos a bajo costo".

De esta forma, el "bienestar" se incorporó al lenguaje oficial de los gobiernos y los organismos internacionales difundido como welfare state, una nueva promesa para superar la guerra y la crisis [Villasana, Gómez y De Vos, 2018]. Asimismo, con el llamado "Estado benefactor" se amplía la idea del "bienestar", vinculada con la concepción de ciudadanía y de derechos civiles y sociales, donde el Estado, en los países europeos, se responsabiliza de atender las necesidades en "sanidad, educación, vivienda, empleo, pensión de vejez y servicios públicos, con el fin de superar la crisis económica" [Gómez, 2018: 105]. Así, el bienestar constituye un componente importante de las políticas públicas, asociado con lograr el pleno empleo como mecanismo para incrementar el consumo y la inversión.

Desde la década de 1980, en el contexto de la crisis de rentabilidad del capital, el paradigma económico relacionado con el Estado de bienestar en las naciones centrales y con la narrativa del "desarrollo" en los países periféricos empieza a ser 
objeto de críticas, pues se presentan problemas de baja rentabilidad, recesión e inflación simultáneas, y emerge el desempleo estructural. Se les acusa de ser "estáticos, paternalistas, ineficaces, ineficientes y burocratizados" [Gómez, 2018: 106], además de la competencia que implicaba su injerencia en la provisión de servicios que podían constituir un mercado rentable para la inversión privada. En Latinoamérica, que registraba diversos problemas macroeconómicos, se aplicaron programas de ajuste estructural de corte neoliberal que impusieron la privatización de los servicios públicos y la seguridad social, dejaron a amplios sectores marginados del "bienestar" y responsabilizaron a cada individuo de su situación, pues era necesario "disminuir el gasto público y fomentar la autonomía personal" [Esping-Andersen y Wolfson, 1996: 550].

Con el neoliberalismo capitalista, el sentido del "bienestar" se va desplazando progresivamente a la posibilidad de consumo individual de bienes, corporales y emocionales, donde las carencias se satisfacen mediante el consumo de mercancías como parte de un proceso más amplio de mercantilización de la subjetividad. "El Bienestar entra al Mercado, ya cosificado, y se hace rentable" [Villasana, Gómez y De Vos, 2018: 13] en una etapa en la que las políticas desarrollistas van siendo erradicadas; el Estado-Nación es privatizado, por lo que se registra una contradicción entre el discurso del "bienestar" y las posibilidades reales de alcanzarlo.

Así, con el fracaso histórico del "desarrollo económico" como referente del "bienestar", principalmente en los países periféricos, empezaron a incluirse las dimensiones sociales y los valores de las sociedades"8 [Alaminos, 2016: 13-14], en un proceso que presenta tres fases [Alaminos, 2016; Herrero, 2016]: a) hasta inicios de 1990, la dimensión prioritaria era la

${ }^{8}$ Se registra una reformulación del economicismo del "desarrollo" para articularlo a lo social, sustentable, endógeno, humano, sin que la concepción epistemológica y ontológica del mismo haya variado [Esteva, 1996; Quijano, 2000b]. 
económica y los indicadores eran el PIB y el ingreso per cápita [Alaminos, 2016: 15]; b) en los 90, el "desarrollo" se vincula con lo humano pero articulado con el crecimiento económico, se incorporan las ideas de Sen sobre las capacidades de los individuos para alcanzar una vida satisfactoria [Herrero, 2016: 175], con lo que surge el índice de desarrollo humano (IDH), que incluye dimensiones como salud y educación; y c) a inicios del siglo xxI, en que se difunde el informe de Stiglitz, Sen $\mathrm{y}$ Fotoussi, Report by the commission on measurement of economic performance and social progress (2009) [Herrero, 2016], que cuestiona las mediciones economicistas, se proponen 30 variables para mejorar las mediciones de desarrollo, bienestar y progreso. En este mismo tenor, la ocDE formula en 2011 la "Iniciativa para una vida mejor" (Better Life Initiative) [Herrero, 2016: 175]; de igual manera, en 2014 se presenta otra iniciativa para medir a escala mundial el índice de progreso social (IPS), el cual abarca 51 variables que incluyen las necesidades humanas básicas, bienestar y oportunidades [Social Progress Imperative, 2019].

En todo este proceso se va configurando una concepción y una medición multidimensional del "bienestar" [Alaminos, 2016: 14-15]. No obstante, en todas estas mediciones del "bienestar" mantienen un peso fundamental el ingreso per cápita, la noción individual del progreso, una visión antropocéntrica y una idea evolutiva de la historia vinculada con la idea de que más es mejor. Es decir, persiste la mirada colonial-moderna desde el "individuo" egoísta, separado de la colectividad y la "naturaleza".

LOS BUENOS VIVIRES COMO ALTERNATIVA

AL “DESARROLLO” Y EL CAPITALISMO COLONIAL-MODERNO

Los buenos vivires reconocen los derechos de la "naturaleza" o Madre Tierra (negando el dualismo cartesiano) y emergen 
como una visión alternativa a la modernidad, al "desarrollo" y el capitalismo al representar tanto una crítica radical de los fundamentos y los efectos del "desarrollo" como una potente propuesta societal alternativa: "El Bien Vivir como expresión de las poblaciones indígenas de América Latina configura una alternativa de vida social que solo puede ser realizada como la des/colonialidad del poder" [Quijano, 2011: 77].

Gudynas [2014] identifica un campo político conformado tanto por componentes indígenas como occidentales que coinciden en el cuestionamiento al "desarrollo" capitalista y en la postulación de alternativas a este, más allá de la modernidad-colonialidad. Se trata de un proyecto liberador alternativo anclado en la idea básica de reestablecer las relaciones de complementariedad y reciprocidad entre las personas y con la "Naturaleza" a fin de proteger la vida en general [López, 2014]. Asimismo, alude a respuestas y estrategias diversas de viejo cuño, principalmente de los pueblos originarios, pero puestas en marcha en la actualidad para enfrentar las presiones que imponen las dinámicas de dominación y explotación de la modernidad-colonialidad y el capitalismo, pues no son resabios de un pasado perfecto e inmutable [Quintero, 2014] ni esencializaciones e idealizaciones.

Uzeda [2009], para el caso específico de Bolivia, señala que el buen vivir tiene tres acepciones: a) como precepto moral: vivir respetando valores tales como la relacionalidad, la correspondencia, la complementariedad y la reciprocidad; b) como conquista social: al incluirlo en la Constitución, considerando la idea de vida digna como superación de la pobreza y exclusión y el derecho a modos de vida propios; y c) como fórmula o consigna política: breve, significativa y movilizadora, la cual puede ser instrumentalizada por gobiernos, partidos políticos y movimientos sociales.

Los buenos vivires plantean que los seres -humanos y no humanos- existen siempre en relación, nunca como objetos o individuos. En ese sentido: 
El vivir bien no puede concebirse sin la comunidad. Irrumpe para contradecir la lógica capitalista, su individualismo inherente. [...] Al hablar de vivir bien se hace referencia a toda la comunidad, no se trata del tradicional bien común reducido o limitado solo a los humanos, abarca todo cuanto existe, preserva el equilibrio y la armonía entre de todo lo que existe [pues está la] conciencia de que todo está conectado, todo está relacionado y todo es interdependiente. En el vivir bien no existen las jerarquías sino las responsabilidades naturales complementarias [...] Nosotros no somos dueños de la tierra, nosotros pertenecemos a ella. Entonces, más que reclamar un derecho de propiedad, lo que pedimos es el "Derecho de Relación" con la Madre Tierra [Huanacuni, 2010: s/p].

En síntesis, con los buenos vivires: a) se abandona la pretensión del "desarrollo" como un proceso lineal, de secuencias históricas que deben repetirse; b) se defiende una relación con la Madre Tierra no objetivada o cosificada; c) las relaciones sociales no se limitan al plano económico mercantil donde todo se reduce a cosas o mercancías; d) se reconceptualiza la calidad de vida o bien-estar en formas que no dependen solamente de la posesión de bienes materiales o los niveles de ingreso; e) se va más allá de una postura materialista, ya que en su seno conviven otras espiritualidades y sensibilidades; f) se lucha por la descolonización de los saberes y la interculturalidad; ${ }^{9}$ y g) por una toma de decisiones democrática, orientada a la socialización del poder, categoría esta que permite cuestionar la naturalización del Estado como única y legítima autoridad pública colectiva en todo tiempo y en todo espacio, proponiendo formas no estatales de su ejercicio [Marañón y López, 2016].

La inclusión de los buenos vivires como principio rector en las constituciones de Bolivia y Ecuador es un hito de

${ }^{9}$ En tanto conjunción del pensamiento y el sentimiento, separados por el eurocentrismo. 
gran relevancia que se ha traducido en los planes nacionales de "desarrollo" de dichos países, con diversas tensiones y contradicciones [Escobar, 2014; Gudynas, 2011]. Tanto en Ecuador como en Bolivia, los gobiernos denominados "progresistas" han seguido una orientación que ha afianzado la dominación capitalista colonial-moderna, fortaleciendo al Estado-Nación monocultural en lugar de avanzar hacia el Estado plurinacional; profundizando el extractivismo capitalista, la reprimarización de la economía y la devastación de la Madre Tierra y el despojo de los territorios "indígenas". Esta realidad adversa a los movimientos de resistencia y que distorsiona la propuesta de los buenos vivires requiere una severa crítica que puede tener un importante sustento desde la teoría de la descolonialidad del poder, pues de lo que se trata es de establecer la existencia de una disputa entre racionalidades, visiones de mundo y relaciones de poder subjetivas y materiales entre dominantes y dominados, entre explotadores y explotados, y que debe seguir haciendo un esfuerzo por desnaturalizar y desobedecer el sentido común hegemónico que se origina en el eurocentrismo, su racionalidad, su modo de producir saberes científicos, su imaginario y su memoria histórica, para legitimar este patrón de poder moderno-colonial, capitalista, mundial, eurocentrado y patriarcal [Quijano Silva, 2015; Acosta y Martínez, 2017; Prada, 2011].

\section{El “Bienestar” en LOS Buenos ViviRes. INDICADORES REFERENCIALES}

Albó [2011] sostiene que no se pueden medir los buenos vivires solo de acuerdo con el acceso a determinados bienes materiales cuantificables; no obstante, se deben tomar como referencia, para asegurar la plena sobrevivencia (jakaña), instrumentos internacionales que cuantifican la superación de la "pobreza" básica, entre ellos el índice de necesidades básicas 
(in)satisfechas; y el "índice de desarrollo humano" (IDH) que sustituyó a la "renta per cápita" como indicador clave de desarrollo, pero que no profundiza en las características propiamente "humanas", en tanto que sus indicadores solo se refieren a individuos, prescindiendo de si saben relacionarse o no entre sí y con los demás. "Apuntan más al vivir y crecer como individuos que al convivir bien, que es un elemento tan fundamental para crecer en humanidad y para hacerlo en sintonía con la Madre Tierra”. Albó [2011: 141] sugiere abarcar estas dos dimensiones a partir de la calidad de las relaciones entre los humanos y con la naturaleza, la Madre Tierra. En la primera veta, podrían incluirse algunos de los criterios de gobernabilidad desarrollados por el Programa de las Naciones Unidas para el Desarrollo (PNUD) (subíndices de Participación y de Estabilidad Política, que pueden aproximarse al concepto de "buen gobierno" [Albó, 2011: 141]. En la segunda podrían entrar algunos indicadores asociados con el desarrollo sostenible y los "Derechos de la Naturaleza", reconocidos por la constitución ecuatoriana de 2008. No obstante, en lo relativo a aspectos afectivos de la convivencia no es posible pensar en indicadores universales y transculturales, pues deben diseñarse indicadores o aproximaciones más cualitativas para cada realidad social y cultural, de cada pueblo, según los valores más apreciados. Uno de los principales obstáculos para lograr que ese convivir bien llegue a todos es la estructura dominante de poder, en su dimensión tanto económica como política [Albó, 2011: 143].

En este sentido, las nuevas métricas sobre el bienestar no solo implican "cambiar el principio de más es mejor por un principio de suficiencia", sino que demandan abrir espacio a los saberes propios y realidades concretas de las poblaciones, ya que es imposible continuar con acciones de intervención para el "desarrollo" de carácter vertical, que perpetúan una relación de exterioridad sujeto-objeto y que muchas veces se contraponen con las racionalidades o cosmovisiones propias 
de diversos pueblos y comunidades. La medición del "bienestar" desde los buenos vivires debe considerar tanto el carácter multidimensional (lo material y lo subjetivo), como la pluralidad de unidades de análisis (la persona, la comunidad, la "naturaleza"), teniendo en mente que no se busca el "bienestar" del individuo, sino el bien común para lograr una vida plena, ya que el sentido de la vida en sociedad se orienta hacia la reproducción ampliada de la vida, articulando "la armonía interna de las personas, la armonía social con la comunidad y entre comunidades, y la armonía con la naturaleza" [León, 2016: 345; Coraggio, 2011; Unceta, 2014 y Falconí, 2012, citados por León, 2015], como ejes de un sistema de indicadores, más que de un indicador compuesto.

La armonía interna requiere un balance entre lo material y lo subjetivo, esto es, fortaleza interior, conducta equilibrada, sabiduría, capacidad de comprensión, visión de futuro y compasión [Hidalgo et al., 2014 citado por León, 2016: 347], que se obtienen de la sabiduría ancestral y la experiencia comunitaria. Estos conceptos pueden asociarse con los conceptos de salud física, salud mental, educación, conocimiento y sentimientos o emociones [León, 2015]. La armonía social se refiere al equilibrio o balance entre las personas y entre las comunidades [Coraggio, 2011]. Implica reconocer a los otros como condición necesaria de nuestra propia vida como individuos, puesto que el buen vivir, como vida en plenitud, comprende una vida de individuos en sociedad [Coraggio, 2011: 125], donde el respeto, la amistad, la convivencia, la participación civil y política, la convivencia con la naturaleza, el tiempo de ocio y recreación forman parte de los bienes relacionales [León, 2015: 55]. La armonía con la naturaleza comprende el equilibrio o balance entre los seres humanos y la naturaleza [Coraggio, 2011], en tanto que los seres humanos forman parte de la Madre Tierra, no son una exterioridad, por lo que deben cuidarla para permitir su reproducción. El cuadro 1 presenta una síntesis de las dimensiones y subdimensiones objetivas y 
Cuadro 1. Aspectos objetivos y subjetivos del buen vivir

\begin{tabular}{|c|c|}
\hline Dimensión & Subdimensión \\
\hline \multicolumn{2}{|l|}{ 1. Aspectos objetivos } \\
\hline \multirow[t]{4}{*}{ 1.1 Salud } & 1.1.1 Salud \\
\hline & 1.1.2 Agua \\
\hline & 1.1.3 Alimentación y nutrición \\
\hline & 1.1.4 Ambiente sano y ecológicamente equilibrado \\
\hline \multirow[t]{5}{*}{ 1.2 Educación } & 1.2.1 Educación \\
\hline & 1.2.2 Ciencias y saberes ancestrales \\
\hline & 1.2.3 Cultura \\
\hline & 1.2.4 Comunicación \\
\hline & 1.2.5 Información \\
\hline \multirow[t]{3}{*}{1.3 Hábitat } & 1.3.1 Hábitat \\
\hline & 1.3.2 Vivienda \\
\hline & 1.3.3 Ciudad y espacio público \\
\hline \multirow[t]{2}{*}{ 1.4 Trabajo } & 1.4.1 Trabajo \\
\hline & 1.4.2 Seguridad social \\
\hline \multirow[t]{3}{*}{ 1.5 Tiempo libre } & 1.5.1 Tiempo libre \\
\hline & 1.5.2 Recreación y esparcimiento \\
\hline & 1.5.3 Práctica del deporte \\
\hline $\begin{array}{l}\text { 1.6 Armonía con la } \\
\text { comunidad }\end{array}$ & $\begin{array}{l}\text { (Solidaridad, reciprocidad, fraternidad, diversidad } \\
\text { cultural, autonomía, interculturalidad, plurinacio- } \\
\text { nalidad) }\end{array}$ \\
\hline $\begin{array}{l}1.7 \text { Armonía con la } \\
\text { naturaleza }\end{array}$ & $\begin{array}{l}\text { (Vida humana y no humana, biodiversidad, princi- } \\
\text { pio de suficiencia, producción y consumo sosteni- } \\
\text { bles, regeneración natural de ecosistemas) }\end{array}$ \\
\hline 1.8 Participación & $\begin{array}{l}\text { (Acceso y participación equitativa del espacio } \\
\text { público, participación y consulta política iguali- } \\
\text { taria, participación en la definición de políticas } \\
\text { públicas) }\end{array}$ \\
\hline 1.9 Libertad & $\begin{array}{l}\text { (Formas de vida, expresión, religiosa, reunión-aso- } \\
\text { ciación, movimiento, trabajo, seguridad) }\end{array}$ \\
\hline 2. Aspectos subjetivos & 2.1 Eudaimonia \\
\hline & 2.2 Espiritualidad \\
\hline & 2.3 Evaluación de vida \\
\hline & 2.4 Emociones positivas \\
\hline & 2.5 Emociones negativas \\
\hline & 2.6 Florecimiento \\
\hline
\end{tabular}

Fuente: tomado, con algunas modificaciones, de León [2015: 57-58]. 
subjetivas para una métrica del buen vivir, de las que deriva una amplia gama de variables e indicadores desarrollada en el Instituto Nacional de Estadística y Censos de Ecuador (al respecto ver León [2015]), en la que se incorporan la armonía individual, la armonía con la comunidad (que abarca relaciones de solidaridad, reciprocidad, fraternidad, diversidad cultural, autonomía, interculturalidad, plurinacionalidad, acceso y participación equitativa del espacio público, consulta previa, libre e informada, y participación en la definición de políticas públicas, entre otras) y la armonía con la naturaleza (que se orienta por el respeto a la vida humana y no humana, la biodiversidad, el principio de suficiencia, la producción y el consumo sostenibles para permitir la regeneración natural de los ecosistemas).

Esta nueva concepción y métrica del "bienestar" demanda una institucionalidad alternativa que promueva la igualdad social y la interculturalidad, garantice el reparto justo de la riqueza y la socialización del poder, y revierta el deterioro ecológicoambiental. Para ello es necesario el reconocimiento y acceso a diversas formas de trabajo, la participación en la toma de decisiones, el impulso de otras formas de relacionalidad (reciprocidad, solidaridad), el respeto, la protección y el cuidado de los ecosistemas y formas propias de vida (diversidad), y el impulso a la vida comunitaria (promover el bien común), la recreación y el esparcimiento (tiempo libre). Esto implica una reflexión más allá de los derechos humanos, considerando los derechos colectivos y los de la "naturaleza".

\section{REFLEXIONES}

En este capítulo, se ha planteado la necesidad urgente de imaginar y construir otras maneras de entender y vivir el "bienestar", más allá de la teoría económica hegemónica y de la narrativa civilizatoria occidental denominada el "desarrollo", para enfrentar 
la crisis del patrón de poder moderno-colonial capitalista que está poniendo en riesgo las posibilidades de reproducción social y ecológica-ambiental en el planeta.

El "desarrollo" es un dispositivo de poder eurocéntrico, instalado en la subjetividad de la mayoría de la población mundial, una idea/fuerza que impulsa la acción social buscando, alcanzar pautas culturales y de vida según el referente histórico euroestadounidense. Es una idea-fuerza que asume la racionalidad, la ideología y los valores hegemónicos de la colonialidad-modernidad como los referentes para llegar a la modernidad capitalista y sus expresiones mayores: la prosperidad material, el progreso tecnológico, la economía de mercado. El "desarrollo" es la continuación del "progreso" y se basa en la visión evolucionista y dualista, de avance material, emanada de la "civilización occidental" capitalista desde el siglo xVI, la misma que desconoció los aportes de culturas no occidentales, las cuales fueron obligadas a rechazar sus propios modos de vida y adoptar los de los dominadores, quienes los clasificaron como "inferiores" por el color de la piel, inventado la "raza" y la colonialidad.

Luego de un periodo de impulso de procesos de industrialización por sustitución de importaciones entre los decenios de 1950 y 1970, se registró un proceso de desarticulación de las experiencias de intervención estatal en la economía y emergió el neoliberalismo como expresión de otra hegemonía dentro del capital y del capitalismo (hegemonía del capital financiero sobre el industrial), y con ello se desestructuraron el Estado-Nación y la propia democracia representativa y creció el desempleo estructural. Fue mermada la capacidad de regulación del Estado-Nación sobre el espacio interno ante los poderes supranacionales convertidos en un gobierno imperial mundial y se debilitó la posibilidad de impulsar el "desarrollo" y el "bienestar".

La epistemología de la teoría "económica" hegemónica no reconoce que la vida humana (y no humana) es eminentemente 
social, por lo que ancla su análisis en el comportamiento de un inexistente y ahistórico "individuo" "racional", egoísta, capaz de tomar las mejores decisiones para lograr su satisfacción personal y con ello favorecer a los demás, como sostiene Smith. Esta epistemología no permite situar al "individuo", cargado a la vez de razones y emociones, dentro de relaciones de poder más amplias que corresponden a la sociedad moderno-colonialcapitalista existente desde hace cinco siglos. Impide, además, percibir que el "individuo" "económico" tiene características sociales muy precisas y que no corresponden a la mayoría de la población mundial pues es blanco, propietario, europeo, patriarcal y heterosexual. No es cualquier "individuo", sino el portador de los intereses de las relaciones de poder que impulsan el poder capitalista, mundial, moderno-colonial, eurocentrado y patriarcal, naturalizando la estructuración jerárquica de la sociedad y legitimando la desigualdad social, de "raza", sexo-género-sexualidad y clase, y la dominación y explotación de la "naturaleza". La teoría "económica" requiere cuestionarse a sí misma y ser cuestionada acerca de qué es "lo económico" para incorporar la pluriversidad de miradas que no están centradas en el "individuo" egoísta, aislado de su colectividad y de la Madre tierra, y en el valor de cambio, sino en la convivencia a partir de la solidaridad y reciprocidad. "Lo económico" requiere, pues, introducir las preocupaciones sobre el valor de uso emanadas de las visiones "indígenas", sobre el respeto a la Madre Tierra, a los territorios y las culturas no occidentales, como punto de partida, por encima del "desarrollo" y el crecimiento económico capitalistas; considerar la capacidad de carga de los ecosistemas de las propuestas ecologistas; recuperar la valoración del trabajo de reproducción, enfatizado por las corrientes feministas; liberar "lo económico" de las opresiones existentes articuladas bajo la colonialidad del poder: "racismo", patriarcalismo, clasismo y antropocentrismo,

El "bienestar" como una construcción social y desde el poder, en el periodo histórico de la modernidad-colonialidad 
capitalista, se instrumentalizó y se orientó a la reproducción y acumulación del capital. Esto configuró una concepción del "bienestar" que coloca el modo europeo de vida material y subjetivo euroestadounidense en una escala superior "civilizatoria" a la que todo el mundo debe aspirar, lo cual es inviable porque profundizaría los desequilibrios ambientales y ecológicos existentes. La forma hegemónica del "bienestar" legitima la reconcentración de riqueza y poder a escala global, y deslegitima otras maneras de entender y vivir el "bienestar" correspondientes a otras formas de existencia social estigmatizadas como "atrasadas" e "irracionales" porque no explotan "los recursos”, no están interesadas en el bienestar material ni buscan maximizar ganancias.

En el contexto histórico actual, existe un desfase histórico de la propuesta "desarrollo"-"bienestar", pues el capitalismo financiero basa su acumulación más en la especulación que en la inversión productiva, más en la concentración de la riqueza que en su redistribución, más en el despojo que en el respeto de derechos territoriales, culturales, laborales. En otros términos, el capitalismo financiero debilita el Estado-Nación, los derechos de ciudadanía, los derechos humanos, laborales y sociales, y los derechos de la Madre Tierra, así como la democracia representativa. En estas condiciones históricas, las posibilidades de disfrute del "bienestar" son más un discurso que un proyecto concretamente alcanzable.

Esto demanda explorar y valorar la emergencia de otro horizonte de sentido histórico centrado en la reproducción ampliada de la vida y no del capital y de su patrón de poder colonial-moderno, articulado con otra forma de entender, medir y vivir el "bienestar". Este horizonte, conocido en América Latina bajo el nombre de "buenos vivires", abarca visiones de "bienestar" basadas en ontologías relacionales, en epistemologías que reconocen la diversidad, en relaciones de poder que privilegian la convivencia horizontal y no la opresión entre los humanos y los no humanos. En estas visiones, el individuo no 
es concebido de manera aislada, sino articulado a la familia y la comunidad, a un entramado comunitario más amplio en el que se establecen relaciones de solidaridad, reciprocidad y horizontalidad. La reproducción social depende del respeto a la vida y a la generadora de vida, la Madre Tierra, mediante relaciones de armonía entre ella y los seres humanos.

Desde los buenos vivires, el "bienestar" y sus indicadores consideran tanto el carácter multidimensional (lo material y lo subjetivo), como la pluralidad de unidades de análisis (la persona, la comunidad, la "naturaleza"), permitiendo superar la dimensión individualista que lo ha separado de la "naturaleza" y reconociendo la diversidad de saberes propios y realidades concretas de cada pueblo, en tanto que el sentido de la organización de la vida en sociedad se orienta a la reproducción ampliada de la vida, articulando la armonía interna de las personas, la armonía social con la comunidad y entre comunidades, y la armonía con la naturaleza.

REFERENCIAS

Acosta, Alberto [2011], "Solo imaginando otros mundos, se cambiará éste. Reflexiones sobre el Buen Vivir”, en Ivonne Farah y Luciano Vasapollo (coords.), Vivir bien: ¿Paradigma no capitalista?, La Paz, CIDES-UMsa/Sapienza/Oxfam.

y Esperanza Martínez [2017], "Los Derechos de la Naturaleza como puerta de entrada a otro mundo posible", $D i$ reito \& Práxis, 8(4).

Alaminos, Antonio [2016], “Antecedentes en la medición del 'Buen Vivir': conceptos, dimensiones, índices e indicadores”, en Francisco J. Francés, Oscar Santacreu y Alejandro Guillén (dirs.), Exploración de indicadores para la medición operativa del concepto del Buen Vivir, Ecuador, Universidad de Cuenca. 
Albó, Xavier [2011], "Suma qamaña = convivir bien. ¿Cómo medirlo?", en Ivonne Farah y Luciano Vasapollo (coords.), Vivir bien: ¿̇aradigma no capitalista?, La Paz, CIDES-UMsA/ Sapienza/Oxfam.

CARR, Edward [1985], 1917. Antes y después (La revolución rusa), Madrid, Sarpe.

Coq, Daniel [2005], "La economía vista desde un ángulo epistemológico. De la economía a la economía política, del estructuralismo a la complejidad", Cinta de Moebio, 22:19-45.

CoragGio, José Luis [2011], Economía social y solidaria: el trabajo antes que el capital, Quito, Abya Yala-Flacso.

CoRREDor, Carlos [2013], Economía sin Robinson Crusoe: Apuntes para superar el autismo, Popayán, Sentipensar Editores.

Dimmelmeier, Andreas, Andrea Pürckhauer y Anil Shah [2016], "Hombre económico (homo occonomicus)", en Diccionario histórico crítico de marxismo (Historisch-kritisches Wörterbuch des Marxismus), Berlín, Instituto para la Teoría Crítica (INKRIT), <https://cutt.ly/NhvGSdH>>, 18 de diciembre de 2016.

Escobar, Arturo [2014], "América Latina en una encrucijada: ¿modernizaciones alternativas, postliberalismo o posdesarrollo?", en Pablo Quintero (comp.), Crisis civilizatoria, desarrollo y buen vivir, Buenos Aires, Del Signo.

[2007], La invención del Tercer Mundo. Construcción y deconstrucción del desarrollo, Caracas, Fundación Editorial El perro y la rana.

Esping-Andersen, Gosta [1993], Los tres mundos del Estado del Bienestar, España, Ediciones Alfons el Magnanim.

y L. Wolfson [1996] "Después de la Edad de Oro: el futuro del Estado benefactor en el nuevo orden mundial", Desarrollo Económico, 36(142).

Esteva, Gustavo [1996], "Desarrollo", en Wolfang Sachs (coord.), Diccionario del desarrollo. Una guía del conocimiento como poder, Perú, Pratec. 
Federici, Silvia [2018], El patriarcado del salario. Críticas feministas al marxismo, Madrid, Traficantes de Sueños.

[2010], Calibán y la bruja. Mujeres, cuerpo y acumulación originaria, Madrid, Traficantes de sueños.

Ferber, Marianne y Julie Nelson [2004], Más allá del hombre económico, Madrid, Ediciones Cátedra.

Germaná, César [2002], La racionalidad en las Ciencias Sociales, Perú, Universidad Nacional Mayor de San Marcos. GIRALDO, Omar [2014], Utopías en la era de la supervivencia. Una interpretación del Buen Vivir, México, Itaca.

Gómez ARIAS, Rubén [2018], "La vida y el sufrimiento más allá del cuerpo", Revista de la Facultad Nacional de Salud Pública, 36(1): 103-129.

GuDYNAS, Eduardo [2014], "El malestar moderno con el buen vivir", en Pablo Quintero (comp.), Crisis civilizatoria, desarrollo y buen vivir, Buenos Aires, Del Signo.

[2011], "Tensiones, contradicciones y oportunidades de la dimensión ambiental del Buen Vivir", en Ivonne Farah y Luciano Vasapollo (coords.), Vivir bien: ¿Paradigma no capitalista, La Paz, CIDEs-umsa/Sapienza/Oxfam.

HaRveY, David [2004], El nuevo imperialismo, Madrid, Akal. HERRERo, Carmen [2016], La medición del Bienestar y el Buen Vivir, Documentos de trabajo sobre Medidas Alternativas del Bienestar, España, Universidad de Alicante.

Hirschman, Albert [2014], Las pasiones y los intereses: argumentos políticos en favor del capitalismo previos a su triunfo, Madrid, Capitán Swing.

Huanacuni, Fernando [2010], Buen Vivir/Vivir Bien. Filosofía, políticas, estrategias y experiencias regionales andinas, Lima, CAOI.

LANDER, Edgardo [2000], "Eurocentrismo, colonialismo y ciencias sociales", en Edgardo Lander (ed.), La colonialidad del saber: eurocentrismo y ciencias sociales, Buenos Aires, Clacso. 
León, Mauricio [2016], "Hacia nuevas métricas del Buen Vivir", Reporte de Pobreza por Consumo. Ecuador 2006-2014, Quito, Instituto Nacional de Estadísticas y Censos (INEC).

[2015], Del discurso a la medición: Propuesta metodológica para medir el Buen Vivir en Ecuador, Quito, Instituto Nacional de Estadística y Censos (INEC).

LóPez, Dania [2014], "La reciprocidad en las prácticas de solidaridad económica en México", en Boris Marañón (coord.). Descolonialidad y cambio societal: experiencias de solidaridad económica en América Latina, México, Clacso/ IIEC-UNAM.

Marañón, Boris [2019], "Solidaridad 'económica': hacia 'economías' y trabajos descoloniales. Un diálogo con las visiones feministas", en Encuentro Internacional para el diálogo de saberes "Alternativas al Desarrollo y Tendencias a la Descolonización de las 'Economías' para la Reproducción de la Vida y los Buenos Vivires", UniCauca-Clacso, Popayán, Colombia, 21-23 de noviembre de 2019.

y Dania López [2016], "Del desarrollo capitalista al buen vivir desde la descolonialidad del poder", Intersticios, $5(10)$.

NisBet, Robert [1986], "La idea de progreso", Revista Libertas, núm. 5.

PÉrez, Amaia [2014], Subversión feminista de la economía. Aportes para un debate sobre el conflicto capital-vida, Madrid, Traficantes de sueños.

PRADA, Raúl [2011], "La revolución mundial del vivir bien", Aportes Andinos, núm. 28, <http://hdl.handle.net/10644/2790>, 2 de febrero de 2020.

Prebish, Raúl [1981], Capitalismo periférico. Crisis y transformación, México, Fondo de Cultura Económica.

QuiJano, Aníbal [2011], “Bien vivir': entre el 'desarrollo' y la des/colonialidad del poder”, Ecuador Debate, núm. 84. [2000a], "Colonialidad de poder, eurocentrismo y América Latina”, en Edgardo Lander (ed.), La colonialidad del 
saber: eurocentrismo y ciencias sociales. Perspectivas latinoamericanas, Buenos Aires, Clacso.

[2000b], "El fantasma del desarrollo en América Latina", Revista Venezolana de Economía y Ciencias Sociales, $6(2)$.

[1999], "Que tal raza”, Ecuador Debate, núm. 48.

QuiJano Silva, Danilo [2015], "Notas sobre Bolivia y el "proceso de cambio", Rebelión, <https://cutt.ly/IhEFO5I>.

Quintero, Pablo [2014], "Introducción", en Pablo Quintero (comp.), Crisis civilizatoria, desarrollo y buen vivir, Buenos Aires, Del Signo.

Romero, José [2018], La invención de la exclusión. Individuo, desarrollo e inclusión, Venezuela, Editorial El perro y la rana.

Simon, Herbert [1957], "A behavioral model of rational choice", en Models of Man, Social and Rational: Mathematical Essays on Rational Human Behavior in a Social Setting, Nueva York, Wiley.

Social Progress Imperative [2019], Social Progress Index, $<$ https://n9.cl/nznho>, 7 de octubre de 2019.

UzEDA, Andrés [2009], "Suma Qamaña, visiones indígenas y desarrollo", Traspatios, núm. 1.

Villarespe, Verónica [2002], Pobreza: teoría e historia, MéxiCO, IIEC-UNAM.

Villasana, Pedro, Rubén Gómez y Pol de Vos [2018], "Aproximación crítico-hermenéutica a la noción de bienestar en el marco del neoliberalismo", Utopía y Praxis Latinoamericana, 23(83).

Wallerstein, Immanuel [2004], Análisis de sistemas-mundo, México, Siglo XxI. 
Bienestar y políticas públicas es una obra del Instituto de Investigaciones Económicas de la Universidad Nacional Autónoma de México. Se terminó de imprimir en diciembre de 2020 en los talleres de Dataprint, S. A. de C. V., colonia Nápoles, Benito Juárez, C. P. 03810, Ciudad de México. El tiraje consta de 200 ejemplares en impresión offset, en papel cultural de $90 \mathrm{~g}$ y los forros en couché de $300 \mathrm{~g}$. La formación estuvo a cargo de Laura Elena Mier Hughes; se utilizaron fuentes Century Schoolbook de 9, 10 y 11 puntos y Univers Condensado 9 y 10 puntos. El cuidado de la edición estuvo a cargo de Hélida De Sales Y. 